UNIVERSIDADE DE SÃO PAULO

FACULDADE DE ECONOMIA, ADMINISTRAÇÃO E CONTABILIDADE DEPARTAMENTO DE CONTABILIDADE E ATUÁRIA PROGRAMA DE PÓS-GRADUAÇÃO EM CONTROLADORIA E CONTABILIDADE

MARIA APARECIDA SOARES LOPES

Eficiência dos gastos públicos: Análise nas Regiões de Saúde do Estado de Minas Gerais 
Prof. Dr. Marco Antônio Zago

Reitor da Universidade de São Paulo

Prof. Dr. Adalberto Américo Fischmann

Diretor da Faculdade de Economia, Administração e Contabilidade

Prof. Dr. Ariovaldo dos Santos

Chefe do Departamento de Contabilidade e Atuária

Prof. Dr. Lucas Ayres Barreira de Campos Barros

Coordenador do Programa de Pós-Graduação em Controladoria e Contabilidade 
MARIA APARECIDA SOARES LOPES

\section{Eficiência dos gastos públicos: Análise nas Regiões de Saúde do Estado de Minas Gerais}

Tese apresentada ao Programa de PósGraduação em Controladoria e Contabilidade da Faculdade de Economia, Administração e Contabilidade da Universidade de São Paulo, como requisito para obtenção do título de Doutora em Ciências.

Área de concentração:

Controladoria e Contabilidade

Orientador: Prof. Dr. Luís Eduardo Afonso

\section{Versão corrigida}

(versão original disponível na Faculdade de Economia, Administração e Contabilidade)

São Paulo 
Autorizo a reprodução total ou parcial deste trabalho, por qualquer meio convencional ou eletrônico, para fins de estudo e pesquisa, desde que citada a fonte.

\section{FICHA CATALOGRÁFICA}

Elaborada pela Seção de Processamento Técnico do SBD/FEA/USP

\section{Lopes, Maria Aparecida Soares}

Eficiência dos gastos públicos: análise nas regiões de saúde do estado de Minas Gerais / Maria Aparecida Soares Lopes. - São Paulo, 2017. $137 \mathrm{p}$.

Tese(Doutorado) - Universidade de São Paulo, 2017.

Orientador: Luís Eduardo Afonso.

1. Contabilidade pública 2. Gastos em saúde - Eficiência 3. Sistema Único de Saúde 4. Regionalização 5. Indicadores de saúde 6. Política de Saúde I. Universidade de São Paulo. Faculdade de Economia, Administração e Contabilidade. II. Título.

CDD - 657.61 
A Deus, pela vida...

A meus pais Elcides e Virtuosa, pelo amor incondicional, incentivo e pelas preces.

Ao meu marido Dolino Lopes, pela paciência, amor e compreensão.

Ao meu orientador, Professor Dr. Luís Eduardo Afonso, que aceitou a minha orientação, incentivando o meu aprendizado, pelas sugestões e principalmente por entender as minhas dificuldades e limitações, nesse percurso.

A todos os professores do Departamento de Contabilidade e Atuária da FEA, pelo conhecimento transmitido nas disciplinas cursadas e monitoria durante o Doutorado.

A UNIMONTES - Universidade Estadual de Montes Claros, pelo apoio, em especial a todos os professores do Departamento de Ciências Contábeis, pelo incentivo e compreensão por minhas ausências.

Aos meus colegas de turma de Doutorado, Mestrado e disciplinas, que se transformaram em amigos, pois nos entendíamos com as nossas angústias.

As professoras Paola Zucchi e Patrícia Siqueira Varela, pelas imensas contribuições na banca de qualificação.

Aos amigos Alcides Bettiol, Cíntia Nascimento, Cândida Docha, Dona Ione, pelos incentivos e principalmente pela ajuda no cotidiano.

Aos meus familiares e amigos que me acompanharam nessa trajetória, buscando sempre me auxiliar no que fosse possível.

Obrigada a todos de coração. 

"Para ser o que sou hoje, fui vários homens e, se volto a encontrar-me com os homens que fui, não me envergonho deles. Foram etapas do que sou. Tudo o que sei custou as dores das experiências.

Tenho respeito pelos que procuram, pelos que tateiam, pelos que erram. E, o que é mais importante, estou persuadido de que minha luz se extinguiria se eu fosse o único a possuí-la."

Goethe

"Hoje me sinto mais forte, mais feliz, quem sabe Só levo a certeza, de que muito pouco sei, Ou nada sei...

Cada um de nós compõe a sua história, Cada ser em si, carrega o dom de ser capaz, De ser feliz..."

Tocando em frente Almir Sater / Renato Teixeira 



\section{RESUMO}

Lopes, M. A. S. (2017). Eficiência dos gastos públicos: Análise nas Regiões de Saúde do Estado de Minas Gerais (Tese de Doutorado). Faculdade de Economia, Administração e Contabilidade, Universidade de São Paulo, São Paulo.

O objetivo geral deste estudo foi analisar a eficiência da execução dos gastos públicos na função saúde em relação aos indicadores de resultados da saúde, nas Regiões de Saúde (RS) mineiras no período de 2010 a 2014. A proposta da análise da evolução dos recursos executados destinados ao financiamento da função saúde, que se transformam em gastos públicos e o que se espera de retorno na forma de resultados finais (outcomes). Verificamos os níveis de eficiência técnica dos gastos públicos na função saúde nas RS de Minas Gerais, em relação ao indicadores de saúde: Taxa de mortalidade infantil e Taxa de mortalidade materna, aplicando a técnica Data Envelopment Analysis (DEA) pelos métodos clássicos de Retornos Constantes de Escala (CCR) e RetornosVariáveis de Escala (BCC), ambos orientado para os outputs, em cada ano do período, de 2010 à 2014. Aplicamos a DEA nas 13 Regiões Ampliadas de Saúde pelo mesmo modelo de BCC com orientação a outputs, e o no modelo CCR para consolidar as DMUs eficientes. As Regiões Ampliadas de Saúde eficientes em todos os anos, foram: Jequitinhonha e Oeste. Enquanto as ineficientes foram as Regiões Nordeste, Noroeste e Norte. Em seguida aplicamos a DEA para as 77 Regiões de Saúde mineiras. Como resultados as fronteiras de eficiência técnica foram compostas por 28 RS no ano de 2010 e por 33 RS em 2011, por 42 RS em 2012. Em 2013, baixou o número para 29 RS eficientes e em 2014, reduziu para 22 RS eficientes. Apresentamos as RS que serviram como referência para o cálculo da eficiência das demais RS. Algumas RS foram eficientes em pelo menos um dos anos, pelo método BCC. As RS com um score de eficiência menor que $100 \%$ foram consideradas ineficientes, pois apresentaram escores abaixo da fronteira de eficiência. Calculamos também a eficiência pelo método CRS/CCR, orientado para os outputs com retornos constantes de escala. O CCR por ter retorno de escala constante, validou as RS eficientes por seu rigor na eficiência total do modelo. O CCR apresentou poucas regiões de saúde como eficientes. Em 2010 as RS de Santos Dumont e Varginha; em 2011 a RS de Santos Dumont; em 2012 as RS de Contagem, Minas Novas e Nanuque; em 2013, as RS de Viçosa e Santos Dumont; e em 2014 foram eficientes as RS de Viçosa, Guaxupé e Ituiutaba. Considerando a estimação do nível de eficiência pelo método BCC, na DEA, optamos por observar no detalhe, analisando os indicadores na área da saúde dos municípios que compõem essas Regiões de Saúde que foram ineficientes em todos os anos do período analisado. Assim, verificamos a evolução de 12 indicadores de saúde dos municípios das Regiões de Saúde de Itaobim, Janaúba, Manga, Montes Claros, Salinas, Uberlândia, Araxá e Uberaba. Analisou-se a evolução dos indicadores municipais apresentados, das RS ineficientes em todos os anos analisados, e constatou-se que a maioria dos municípios dessas RS contribuíram para a ineficiência das mesmas. Com base nos resultados de eficiência verificados para cada RS, e a análise dos indicadores municipais nas RS ineficientes, verificou-se o cumprimento das metas pactuadas pelas RS junto aos seus municípios, como o atendimento aos objetivos pactuados. Considerando que, cada município compromete-se com a sua RS, o que entregará de resultado em termos de eficiência. Quanto ao atendimento aos objetivos firmados junto à RS, constatou-se que a maioria dos municípios, com poucas exceções, das RS de Itaobim, Uberlândia, Araxá, Uberaba, Janaúba, Manga, Montes Claros e Salinas não atenderam as metas pactuadas em sua totalidade. Entendemos que os municípios que deixaram de atender as metas pactuadas, descumprindo o contrato firmado, contribuíram com a ineficiência das suas RS. Quanto a obrigatoriedade da entrega do Relatório Anual de Gestão (RAG), constatou-se que a maioria do municípios de todas as RS, com poucas exceções, entregaram o RAG e cumpriram com a suas metas de gestão.

Palavras-chave: Contabilidade pública. Gastos em saúde - eficiência. Sistema Único de Saúde. Regionalização. Indicadores de saúde. Política de saúde. 


\section{ABSTRACT}

Lopes, M. A. S. (2017). Efficiency of public spending: Analysis in the Health Regions of the State of Minas Gerais (Doctoral thesis). Faculdade de Economia, Administração e Contabilidade, Universidade de São Paulo, São Paulo.

The general objective of this study was to analyze the efficiency of the public expenditure execution in the health function in relation to the health outcomes indicators in the Health Regions (RS) of the state of of Minas Gerais in the period from 2010 to 2014. T The proposal of the analysis of the evolution of the resources executed destined to the financing of the health function, which become public expenditures and what is expected to return in the form of outcomes.. We verified the technical efficiency levels of the public expenditures in the health function in the RS of Minas Gerais, in relation to the health indicators: Infant mortality rate and Maternal mortality rate, applying the Data Envelopment Analysis (DEA) technique by the classical methods of Constant Returns (CCR) and Variable Returns Scale (BCC), both oriented to the outputs, in each year of the period, from 2010 to 2014. We applied the DEA in the 13 Expanded Health Regions by the same BCC model with output orientation, and in the CCR model to consolidate efficient DMUs. The Expanded Regions of Health efficient in all the years, were: Jequitinhonha and the Oeste. While the Noroeste, Nordeste and Norte Regions were inefficient. We then applied the DEA to the 77 Health Regions of Minas Gerais. As a result the frontiers of technical efficiency were composed of $28 \mathrm{RS}$ in the year 2010 and $33 \mathrm{RS}$ in 2011, by 42 RS in 2012. In 2013, reduced the number to 29 RS efficient and in 2014, reduced to 22 efficient RS. We present the RS that served as reference for the calculation of the efficiency of the other RS. Some RSs were efficient in at least one of the years by the BCC method. RSs with an efficiency score lower than 100\% were considered inefficient, since they presented scores below the efficiency frontier. We also calculate the efficiency by the CRS / CCR method, oriented to the outputs with constant returns of scale. The CCR for having a constant return of scale, validated RS efficient for its rigor in the total efficiency of the model. The CCR presented few health regions as efficient. In 2010 the RS of Santos Dumont and Varginha; In 2011 the RS of Santos Dumont; In 2012 the RS of Contagem, Minas Novas and Nanuque; In 2013, RS de Viçosa and Santos Dumont; and in 2014 the RS of Viçosa, Guaxupé and Ituiutaba were efficient. Considering the estimation of the level of efficiency by the BCC method, the DEA, we opted to observe in detail, analyzing the indicators in the health area of the municipalities that compose these Health Regions that were inefficient in all the years of the analyzed period. Thus, we verified the evolution of 12 health indicators of the municipalities of Itaobim, Janaúba, Manga, Montes Claros, Salinas, Uberlândia, Araxá and Uberaba Health Regions. The evolution of the municipal indicators presented, of the inefficient RSs in all the analyzed years, was analyzed, and it was verified that the majority of the municipalities of these RS contributed to their inefficiency. Based on the efficiency results verified for each RS, and the analysis of the municipal indicators in the inefficient RS, it was verified the achievement of the goals agreed by the RSs with their municipalities, such as meeting the agreed objectives. Considering that each municipality commits itself to its RS, which will deliver results in terms of efficiency. The majority of the municipalities, with few exceptions, from Itaobim, Uberlândia, Araxá, Uberaba, Janaúba, Manga, Montes Claros and Salinas, did not meet the goals agreed in their totality. We understand that the municipalities that failed to meet the agreed targets, not complying with the signed contract, contributed to the inefficiency of their RS. As for the mandatory submission of the Annual Management Report (RAG), it was found that the majority of municipalities in all RSs, with few exceptions, delivered the RAG and complied with its management goals.

Keywords: Public accounting. Health expenditures - efficiency. Unified Health System. Regionalization. Health indicators. Health policy. 


\section{LISTA DE FIGURAS}

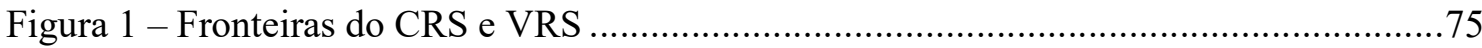

Figura 2 - Representatividade dos potenciais de melhorias dos inputs e outputs em $2010 \ldots 106$

Figura 3 - Representatividade dos potenciais de melhorias dos inputs e outputs em 2011....107

Figura 4 - Representatividade dos potenciais de melhorias dos inputs e outputs em 2012...107

Figura 5 - Representatividade dos potenciais de melhorias dos inputs e outputs em 2013....108

Figura 6 - Representatividade dos potenciais de melhorias dos inputs e outputs em $2014 \ldots .108$ 


\section{LISTA DE TABELAS}

Tabela 1 - Produto Interno Bruto (PIB) da Região Sudeste em relação ao Brasil (\%)...........24

Tabela 2 - Regiões Ampliadas de Saúde e quantitativo de Regiões de Saúde do Estado de

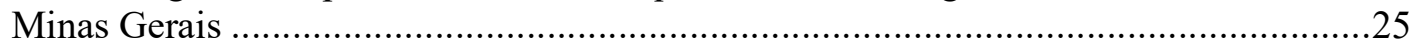

Tabela 3 - Relação das Regiões de Saúde e variação percentual da população de Minas Gerais .71

Tabela 4 - Estatística descritiva das variáveis no período quinquenal de 2010 à $2014 \ldots \ldots \ldots . . .80$

Tabela 5 - Resultados bacon outliers das variáveis de 2010 à 2014 ..................................80

Tabela 6 - Índice Geral de Preços - Disponibilidade Interna (IGP-DI) - 2010 à 2014..........84

Tabela 7 - Despesa Liquidada per capita das Regiões de Saúde de Minas Gerais em valores em R \$ de dezembro de 2014, com uso do IGP-I........................................................... 85

Tabela 8 - Taxa de Mortalidade Infantil (TMI) nas RS de Minas Gerais............................8 88

Tabela 9 - Taxa de Mortalidade Materna (TMM) nas RS de Minas Gerais ..........................91

Tabela 10 - Análise de correlação entre input e outputs do modelo DEA em 2010 ...............96

Tabela 11 - Análise de correlação entre input e outputs do modelo DEA em 2011 ...............96

Tabela 12 - Análise de correlação entre input e outputs do modelo DEA em 2012 ...............96

Tabela 13 - Análise de correlação entre input e outputs do modelo DEA em 2013 ..............97

Tabela 14 - Análise de correlação entre input e outputs do modelo DEA em 2014 ...............97

Tabela 15 - Resultados da DEA pelo método CRS/CCR com orientação aos outputs ............98

Tabela 16 - Resultados da DEA pelo método VRS/BCC com orientação aos outputs ............99

Tabela 17 - Resultados da DEA pelo método CRS/CCR com orientação aos outputs das

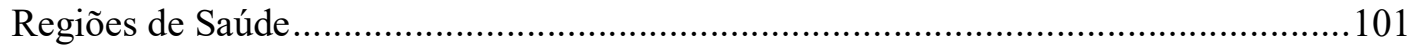

Tabela 18 - Resultados da DEA pelo método VRS/BCC com orientação aos outputs das

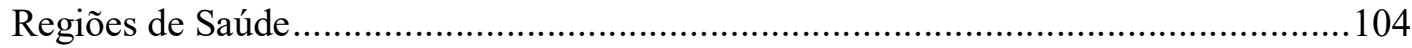

Tabela 19 - Eficiência de escala das Regiões de Saúde....................................................109

Tabela 20 - Variação \% da evolução dos indicadores de saúde dos municípios das Regiões de Saúde: Itaobim, Uberlândia, Araxá e Uberaba, no período de 2010 à 2014..................114

Tabela 21 - Variação \% da evolução dos indicadores de saúde dos municípios das Regiões de Saúde: Itaobim, Uberlândia, Araxá e Uberaba, no período de 2010 à 2014.................116

Tabela 22 - Variação \% da evolução dos indicadores de saúde dos municípios das Regiões de Saúde: Janaúba, Manga, Montes Claros e Salinas - Região Ampliada Norte, no período de 2010 à 2014

Tabela 23 - Variação \% da evolução dos indicadores de saúde dos municípios das Regiões de Saúde: Janaúba, Manga, Montes Claros e Salinas - Região Ampliada Norte, no período de 2010 à 2014 


\section{LISTA DE SIGLAS E ABREVIATURAS}

\begin{tabular}{|c|c|}
\hline ADCT & Ato das Disposições Constitucionais Transitórias \\
\hline $\mathrm{BCC}$ & Banker, Charnes e Cooper (Modelo Clássico do DEA) \\
\hline CEE & Central and Eastern Europe (Europa Oriental Central) \\
\hline $\mathrm{CF}$ & Constituição Federal \\
\hline $\mathrm{CFC}$ & Conselho Federal de Contabilidade \\
\hline CIB & Comissão Intergestores Bipartite \\
\hline CIS & Commonwealth of Independent States (Comunidade dos Estados Independentes) \\
\hline CIT & Comissão de Intergestores Tripartite \\
\hline CNS & Conselho Nacional de Saúde \\
\hline COAP & Contrato Organizativo da Ação Pública de Saúde \\
\hline COSEMS & Conselho Estadual de Secretários Municipais de Saúde \\
\hline CONASEMS & Conselho Nacional de Secretários Municipais de Saúde \\
\hline CONASS & Conselho Nacional de Secretários de Saúde \\
\hline DATASUS & Departamento de Informática do SUS \\
\hline DCASP & Demonstrações Contábeis Aplicadas ao Setor Público \\
\hline DEA & Data Envelopment Analysis (Análise Envoltória de Dados) \\
\hline DMU & Decision Making Unit \\
\hline DRE & Demonstração do Resultado Econômico \\
\hline ESF & Estratégia de Saúde da Família \\
\hline FDH & Free Disposable Hull \\
\hline FIRJAN & Federação das Indústrias do Estado do Rio de Janeiro \\
\hline FJP & Fundação João Pinheiro \\
\hline FMI & Fundo Monetário Internacional \\
\hline FNS & Fundo Nacional de Saúde \\
\hline IBGE & Instituto Brasileiro de Geografia e Estatística \\
\hline IDH & Índice de Desenvolvimento Humano \\
\hline IDHM & Índice de Desenvolvimento Humano Municipal \\
\hline IDS & Índice de Desempenho do Setor \\
\hline IFA & International Federation of Accountants \\
\hline IFDM & Índice FIRJAN de Desenvolvimento Municipal \\
\hline IFRS & International Financial Reporting Standards \\
\hline IPSAS & International Public Sector Accounting Standards \\
\hline IPSASB & International Public Sector Accounting Standards Board \\
\hline LDO & Lei de Diretrizes Orçamentárias \\
\hline LOA & Lei Orçamentária Anual \\
\hline LOS & Lei Orgânica da Saúde \\
\hline LRF & Lei de Responsabilidade Fiscal \\
\hline MCASP & Manual de Contabilidade Aplicada ao Setor Público \\
\hline MQO & Mínimos Quadrados Ordinários \\
\hline MS & Ministério da Saúde \\
\hline NHS & National Health System (Sistema Nacional de Saúde - SNS) \\
\hline NOAS & Norma Operacional de Assistência à Saúde \\
\hline NOB & Norma Operacional Básica \\
\hline OCDE & Organização para Cooperação e Desenvolvimento Econômico \\
\hline OECD & Organisation for Economic Co-operation and Development \\
\hline OMS & Organização Mundial da Saúde (World Health Organization - WHO) \\
\hline ONU & Organização das Nações Unidas \\
\hline PACS & Programa Agentes Comunitários de Saúde \\
\hline
\end{tabular}




$\begin{array}{ll}\text { PAS } & \text { Programação Anual de Saúde } \\ \text { PCASP } & \text { Plano de Contas Aplicado ao Setor Público } \\ \text { PD } & \text { Pacto em Defesa do SUS } \\ \text { PDR } & \text { Plano Diretor de Regionalização } \\ \text { PG } & \text { Pacto de Gestão } \\ \text { PIB } & \text { Produto Interno Bruto } \\ \text { PNAB } & \text { Política Nacional de Atenção Básica } \\ \text { PNPS } & \text { Política Nacional de Promoção da Saúde } \\ \text { PNUD } & \text { Programa das Nações Unidas para o Desenvolvimento } \\ \text { PPA } & \text { Plano Plurianual } \\ \text { PPI } & \text { Programação Pactuada e Integrada } \\ \text { PS } & \text { Plano de Saúde } \\ \text { PSF } & \text { Programa Saúde da Família } \\ \text { PV } & \text { Pacto pela Vida } \\ \text { RAG } & \text { Relatório Anual de Gestão } \\ \text { RAS } & \text { Rede de Atenção à Saúde } \\ \text { RMSP } & \text { Região Metropolitana de São Paulo (RMSP) } \\ \text { RS } & \text { Região de Saúde } \\ \text { SES } & \text { Secretaria Estadual de Saúde } \\ \text { SESMG } & \text { Secretaria de Estado de Saúde de Minas Gerais } \\ \text { SFA } & \text { Stochastic Frontier Analysis } \\ \text { SIOPS } & \text { Sistema de Informações sobre Orçamentos Públicos em Saúde } \\ \text { SNS } & \text { Sistema Nacional de Saúde (National Health System - NHS) } \\ \text { STN } & \text { Secretaria do Tesouro Nacional } \\ \text { SUS } & \text { Sistema Único de Saúde } \\ \text { TMI } & \text { Taxa de Mortalidade Infantil } \\ \text { TMM } & \text { Taxa de Mortalidade Materna } \\ \text { WHO } & \text { World Health Organization (Organização Mundial da Saúde - OMS) } \\ & \end{array}$




\section{SUMÁRIO}

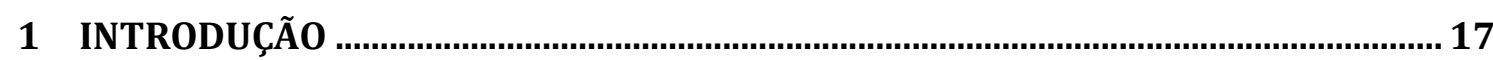

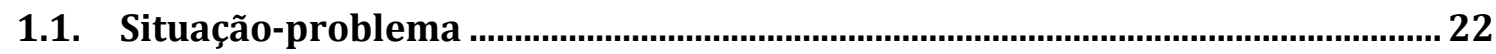

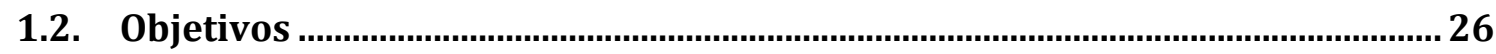

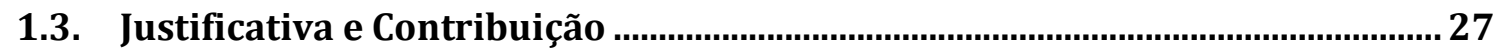

2 FUNDAMENTAÇÃO TEÓRICA E ESTUDOS EMPÍRICOS ............................................. 29

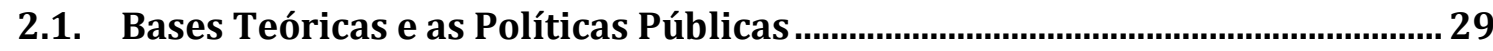

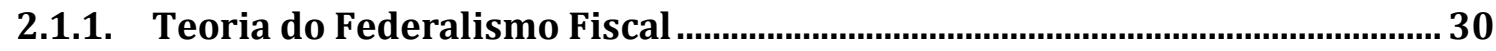

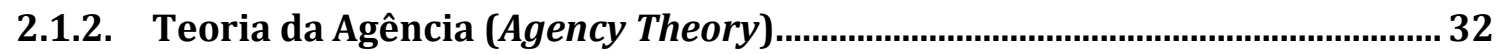

2.2. Sistema Único de Saúde - SUS.............................................................................. 34

2.2.1. Descentralização e Regionalização ................................................................. 42

2.2.2. Estudos Anteriores - Descentralização Fiscal e Administrativa ................... 45

2.3. Controladoria na Gestão Pública ........................................................................ 54

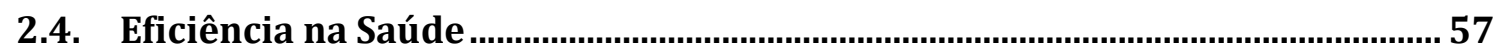

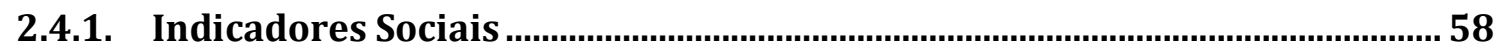

2.4.2. Estudos Anteriores - Eficiência do Gasto em Saúde....................................... 64

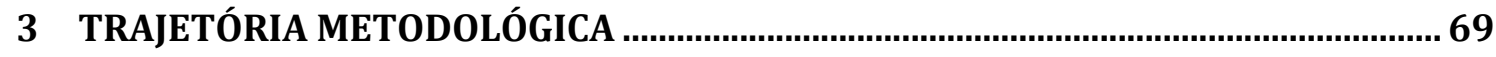

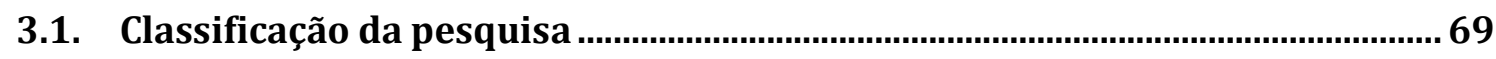

3.2. Definições: objeto, população e período da pesquisa ........................................ 70

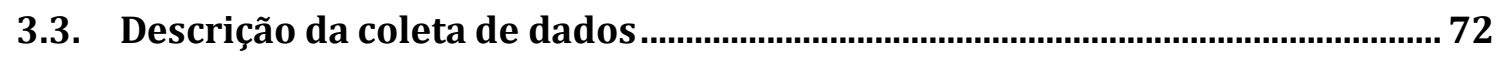

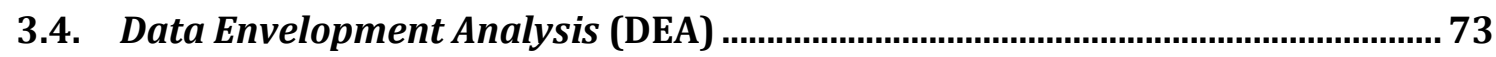

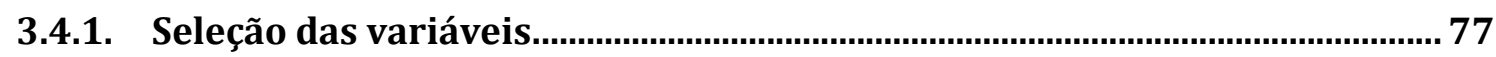

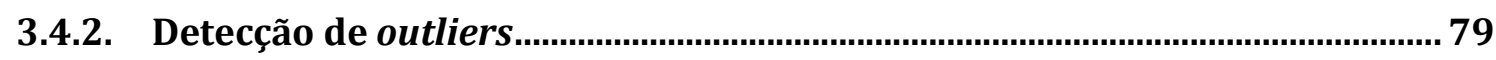

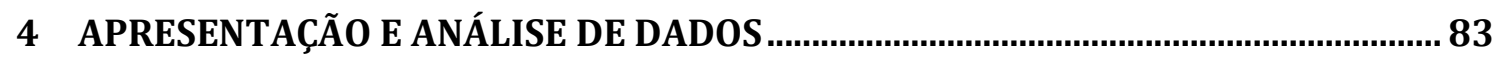

4.1. Análise da variável despesa liquidada na função saúde: input na DEA ......... 83

4.2. Análise das Variáveis TMI e TMM: outputs na DEA ......................................... 86

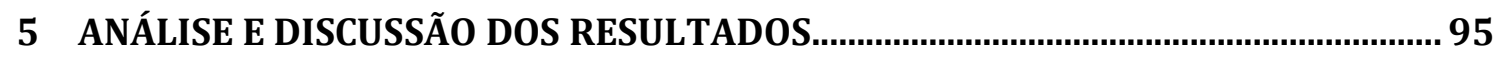

5.1. Análise da eficiência por meio da técnica DEA .................................................... 95

5.2. Eficiência total e técnica por meio da DEA nas Regiões Ampliadas de Saúde 97

5.3. Resultados da eficiência total e técnica por meio DEA nas Regiões de Saúde 100

5.4. Resultados da análise dos indicadores de saúde municipais..........................111

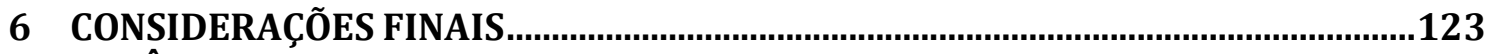

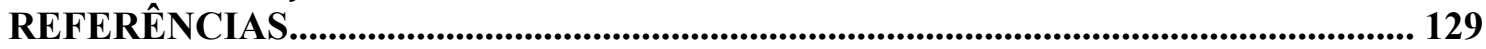





\section{INTRODUÇÃO}

Nas duas últimas décadas cresceu mundialmente a demanda pelos serviços de saúde. Fatores como a longevidade da população, o uso dos cuidados de saúde, as opções de tratamentos e diagnósticos, associados com os avanços da medicina, têm contribuído para este crescimento. Desde a década de 90 , já existia a preocupação da sociedade no sentido de compreender como ocorre a aplicação dos recursos financeiros obtidos, que pressionam os gestores a procurar meios eficientes ao ofertar os serviços de saúde; considerando que o aumento da eficiência no setor da saúde, resulta na economia de recursos ou expansão dos serviços para a comunidade. (Peacock et al., 2001; Zucchi, Del Nero \& Malik, 2000).

Segundo dados da Organização Mundial da Saúde (OMS), o gasto mundial da saúde passou de 7,7\% do Produto Interno Bruto (PIB) em 2000 para 8,6\% em 2012, representando um aumento de $11,69 \%$. No Brasil, no mesmo período, o gasto com saúde passou de 7,2\% para 9,5\% o que representou um aumento de 31,94\%. (World Health Organization, 2015). Neste sentido Marinho, Cardoso e Almeida (2009) avaliaram a eficiência do sistema de saúde no Brasil, comparando-o com os sistemas de saúde dos países da Organização para Cooperação e Desenvolvimento Econômico (OCDE), e constataram que o aumento de 1\% no gasto per capita por ano em saúde implicaria no aumento em torno de cinco anos na expectativa de vida do brasileiro.

O Brasil aumentou sua atenção para as questões sociais a partir da promulgação da CF de 1988 (Brasil, 1988). Houve a necessidade de adequação da estrutura estatal e criação de políticas de proteção social para atender à prestação de serviços públicos. O Estado passa a ter o poder/dever de criar políticas públicas igualitárias e universais que garantam a inclusão social da população. Dentre as muitas inovações trazidas pela CF de 1988, talvez a mais importante tenha sido a garantia de serviços e ações de saúde de forma universal e igualitária (Arretche, 1999).

A saúde pública, enquanto objeto de atenção do Estado, demanda a criação de modelos de gestão, sendo estes utilizados para a gestão, planejamento e assistência por meio das ações e serviços de saúde. Devido à extensão territorial, cada região do país tem necessidades e características específicas, buscou-se um modelo em que fosse possível contemplar estas especificidades. Assim, surge o processo de descentralização da gestão da saúde, já prevista como uma das diretrizes nacionais do SUS, no artigo 198 da CF de 1988. 
Há argumentos que a descentralização da saúde surgiu do uso da autoridade do governo federal para obter adesão dos municípios a um dos objetivos da política de saúde. Condicionar as transferências, à adesão dos governos locais revelou-se uma estratégia com poder de indução sobre os municípios. "Reduzida a incerteza sobre a regularidade na obtenção de recursos, aumentou a disposição para assumir a responsabilidade pela provisão de serviços de saúde." (Arretche, 2004, p. 24). Marques e Mendes (2002) alertam sobre essa prática de incentivos, onde os municípios estão dispostos a assumir responsabilidades devido ao acréscimo de receita financeira.

No Brasil o setor da saúde tem como principal financiador a União, que vincula as transferências de recursos normalmente a programas e ações pré-definidos, sendo o gestor municipal responsável pela administração desses recursos e pela oferta de serviços de saúde para a população. Os municípios brasileiros são os principais responsáveis pela implantação e gestão das políticas públicas, em especial nas áreas da saúde e educação, promovendo o desenvolvimento social como um todo, com base nas características particulares da região e do contexto socioeconômico no qual estão inseridos. Com a descentralização da saúde, o município tornou-se o responsável pelo serviço público de saúde, fortalecendo a estratégia de prevenção e promoção da saúde. (Brasil, 2006).

Transcorridos quase vinte anos da institucionalização do SUS, a portaria $\mathrm{n}^{\circ} .399$ de 22 de Fevereiro divulgou o Pacto pela Saúde 2006 - Consolidação do SUS. O Pacto pela Saúde definiu as diretrizes nacionais para avançar nos processos da descentralização e regionalização das ações e serviços de saúde.

O processo de descentralização ampliou o contato do Sistema com a realidade social, política e administrativa do país e com suas especificidades regionais, tornando-se mais complexo e colocando os gestores a frente de desafios que busquem superar a fragmentação das políticas e programas de saúde através da organização de uma rede regionalizada e hierarquizada de ações e serviços e da qualificação da gestão (Brasil, 2006b).

O Pacto de Gestão (PG), uma das dimensões do Pacto pela Saúde, estabeleceu as diretrizes para a gestão do SUS nos aspectos da Descentralização; Regionalização; Financiamento; Planejamento; Programação Pactuada e Integrada (PPI); Regulação; Participação Social e Gestão do Trabalho e da Educação na Saúde, e definiu as responsabilidades de cada ente federado, tornando claro quem deve fazer o quê, contribuindo, para o fortalecimento da gestão compartilhada e solidária do SUS. O PG constatou que o Brasil é um país com muitas diferenças e iniqüidades regionais, e é necessário uma unidade 
de princípios que respeite as singularidades regionais.

O PG além de promover a descentralização, desburocratizou os processos normativos.

Reforça a territorialização da saúde como base para organização dos sistemas, estruturando as regiões sanitárias e instituindo colegiados de gestão regional. ...

Explicita as diretrizes para o sistema de financiamento público tripartite: busca critérios de alocação eqüitativa dos recursos; reforça os mecanismos de transferência fundo a fundo entre gestores; integra em grandes blocos o financiamento federal e estabelece relações contratuais entre os entes federativos. (Brasil, 2006a, p. 2)

Como premissa da descentralização, com ênfase numa descentralização compartilhada, cabe ao "Ministério da Saúde a proposição de políticas, participação no cofinanciamento, cooperação técnica, avaliação, regulação, controle e fiscalização, além da mediação de conflitos". E às Comissões Intergestores Bipartite (CIB) cabe as "deliberações para a realização dos pactos intraestaduais e a definição de modelos organizacionais, a partir de diretrizes e normas pactuadas na Comissão Intergestores Tripartite” (CIT), (Brasil, 2006a, p. 5); que são as instâncias de pactuação e deliberação, composta por representação de todos os níveis do governo: Ministério da Saúde (MS), Conselho Nacional de Secretários de Saúde (CONASS) e o Conselho Nacional de Secretários Municipais de Saúde (CONASEMS). (Brasil - MS, 2006).

A Regionalização também é uma diretriz do SUS, prevista no artigo 198 da CF de 1988 e um eixo estruturante do Pacto de Gestão, orientando a descentralização das ações e serviços de saúde e também os processos de pactuação entre os gestores. Com os seus instrumentos de planejamento: o Plano Diretor de Regionalização (PDR), o Plano Diretor de Investimento (PDI) e a Programação Pactuada e Integrada da Atenção em Saúde (PPI), a regionalização têm os seguintes objetivos:

- Garantir acesso, resolutividade e qualidade às ações e serviços de saúde cuja complexidade e contingente populacional transcenda a escala local/municipal;

- Garantir o direito à saúde, reduzir desigualdades sociais e territoriais e promover a equidade, ampliando a visão nacional dos problemas, associada à capacidade de diagnóstico e decisão loco-regional, que possibilite os meios adequados para a redução das desigualdades no acesso às ações e serviços de saúde existentes no país;

- Garantir a integralidade na atençãoo a saúde, ampliando o conceito de cuidado à saúde no processo de reordenamento das ações de promoção, prevenção, tratamento e reabilitação com garantia de acesso a todos os níveis de complexidade do sistema;

- Potencializar o processo de descentralização, fortalecendo estados e municípios para exercerem papel de gestores e para que as demandas dos diferentes interesses loco-regionais possam ser organizadas e expressadas na região;

- Racionalizar os gastos e otimizar os recursos, possibilitando ganho em escala nas ações e serviços de saúde de abrangência regional. (Brasil - MS, 2006a, p.06) 
No processo da regionalização estabeleceu-se as Regiões de Saúde (RS) (também conhecidas como microrregiões), que segundo a portaria no .399 de 2006 são "recortes territoriais inseridos em um espaço geográfico contínuo, identificadas pelos gestores municipais e estaduais a partir de identidades culturais, econômicas e sociais, de redes de comunicação e infra-estrutura de transportes compartilhados do território". (Brasil - MS, 2006a, p. 6). As RS são constituídas por um aglomerado de municípios com a finalidade de integrar a organização, o planejamento e a execução das ações e serviços de saúde; contendo ações de atenção básica, atenção psicossocial, urgência-emergência, atenção ambulatorial especializada e hospitalar e de vigilância à saúde.

Considerando o nível de atenção à saúde, a RS é delimitada pelo seu grau de resolutividade do território, como a suficiência em atenção básica e parte da média complexidade. O planejamento regional deve considerar a estratégia para o seu estabelecimento, quando essa suficiência não for atingida, assim como a definição dos investimentos, quando necessário. As RS devem pactuar entre si arranjos inter-regionais para garantir a atencão na alta complexidade e parte da média complexidade, agregando várias Regiões de Saúde em uma Região Ampliada de Saúde (também conhecida como macrorregião). Os níveis de atenção da média e a alta complexidade devem ser pactuados na CIB, e podem estar contemplados na RS ou na Região Ampliada de Saúde.

É de competência da RS organizar a rede de ações e serviços de saúde, definida como Rede de Atenção à Saúde (RAS) e assim assegurar o cumprimento dos princípios constitucionais, de acesso universal, de eqüidade e da integralidade do cuidado; favorecendo a ação cooperativa e solidária entre os gestores, ou seja, é necessário a pactuação entre todos os gestores envolvidos. Neste sentido, cada município com o apoio do estado e da união assume as responsabilidades não compartilhadas da atenção básica e das ações básicas de vigilância à saúde. (Brasil - Ministério da Saúde, 2006b).

A RAS é "definida como arranjos organizativos de ações e serviços de saúde, de diferentes densidades tecnológicas, que integradas por meio de sistemas de apoio técnico, logístico e de gestão, buscam garantir a integralidade do cuidado". Têm o objetivo de promover a "integração sistêmica, de ações e serviços de saúde com provisão de atenção contínua, integral, de qualidade, responsável e humanizada, bem como incrementar o desempenho do Sistema, em termos de acesso, equidade, eficácia clínica e sanitária; e eficiência econômica." (Brasil - Ministério da Saúde, 2010).

As RAS estão contidas no âmbito de uma RS ou em várias RS, sendo que o conjunto 
de ações e serviços de saúde são articulados em níveis de atenção crescentes de complexidade, mediante o referenciamento do usuário na rede regional e interestadual, conforme pactuado nas Comissões Intergestores CIB e CIT. Na RAS ocorre o reagrupamento contínuo de recursos entre e dentro dos serviços de saúde, explorando as melhores soluções e os menores custos, em função das demandas e das necessidades da população e dos recursos disponíveis. São processos importantes para se alcançar os objetivos da RAS, no que se refere "a prestar a atenção certa, no lugar certo, com o custo certo e no tempo certo." (Brasil Ministério da Saúde, 2010).

Os gestores municipais de saúde devem constituir um espaço permanente de pactuação e co-gestão solidária e cooperativa por meio do Colegiado de Gestão Regional, que tomam decisões por consenso, definindo as prioridades e pactuando as soluções para que a estruturação da RAS seja integrada e com resolutividade. Neste contexto, Varela \& Pacheco (2012, p. 117), ressaltam que "a política municipal de saúde deve estar em consonância com a política estadual e esta, por sua vez, com a política nacional”. Portanto, ocorre também a hierarquização da política de saúde, criada ao nível federal com sua aceitação aos níveis estadual e municipal, partindo de uma linha universal ao nível federal ou nacional, para uma expansão em uma perspectiva específica no estado e principalmente nos municípios.

O estudo de Varela \& Pacheco (2012, p. 126) avaliou o desempenho dos gastos públicos no setor saúde e a eficiência técnica dos municípios da Região Metropolitana de São Paulo (RMSP) nas ações de atenção básica à saúde. $O$ artigo discute também a responsabilidade dos gestores públicos municipais quanto às ações desenvolvidas no âmbito da política de saúde. Os resultados da análise da eficiência técnica dos municípios quanto aos gastos com a subfunção atenção básica, sinalizou que existem desempenhos muito diferentes entre os municípios de uma mesma RS e também entre as RS da RMSP. Portanto, os recursos mal empregados em um município ou RS geram prejuízos, já que a falta de cuidados na atenção básica aumentam a pressão por serviços ambulatoriais e hospitalares de média e alta complexidade nos outros níveis de atenção.

Vários estudos como os de Viana et al., (2015); Albuquerque \& Viana, (2015); Mendes et al., (2015); Santos \& Campos, (2015); Lélis, (2012); Varela \& Pacheco, (2012), entre outros, abordam a questão da regionalização da saúde e sua importância, e outros trabalhos como os de Mendes, (2010); Kuschnir \& Chorny, (2010); Puccini et al., (2012); Pinheiro Filho \& Sarti, (2012); entre outros, abordam o processo de Redes de Atenção à Saúde (RAS). 
Segundo Benevides (2011, p. 73), a saúde, enquanto elemento da cidadania é relevante para a sociedade, na medida em que está intimamente relacionada à qualidade de vida. Em seu estudo a autora constatou que com o crescimento na expectativa de vida dos brasileiros, o país deveria se adequar ao aumento da demanda pelos serviços de saúde. Os serviços e ações em saúde dependem de boas estratégias que consideram a realidade peculiar de cada comunidade, sob o risco de, quando não observadas, tornarem-se ineficientes, dispendiosas e onerosas. $\mathrm{Ou}$ seja, passa-se a gastar muito para alcançar resultados mínimos. O sistema de gestão da saúde pública deve-se constituir num fator essencial para a consolidação da eficiência nos gastos públicos e atrair a atenção da coletividade no sentido de participar do processo decisório.

\subsection{Situação-problema}

A Teoria da Agência (Agency Theory), que trata da relação entre o principal e o agente, tem sido uma das principais teorias utilizadas para gerenciar os processos decisórios e as relações contratuais. Os seus pressupostos podem servir como suporte teórico na compreensão das relações contratuais, deixando claro o comportamento das partes relacionadas.

A Teoria da Agência segundo Jensen e Meckling (1976), é definida como um contrato onde uma ou mais pessoas (principal) contrata outra pessoa (agente) que irá desempenhar algum trabalho em nome do principal, o que envolve alguma autonomia ou poder de decisão por parte do agente. De acordo com Sanchez (2005, p. 25) "A Teoria de Agência é um importante instrumento para analisar os conflitos e os processos de tomada de decisão em ambientes hierárquicos, onde existe delegação de poder por meio de um contrato.”

A melhoria dos resultados na saúde advém da interferência e relação de várias ações, não somente ligadas aos investimentos na área da saúde, como as deliberações, programas e políticas de saúde; mas também de investimentos em outras áreas como educação, saneamento, desenvolvimento econômico, etc. A questão saúde pública foi relacionada com a distribuição de renda, no trabalho desenvolvido por Noronha e Andrade (2006), cujos resultados demonstraram que ao mesmo tempo em que o estado de saúde afeta a distribuição de renda, por ela também é afetada, estabelecendo um círculo vicioso.

Teixeira e Gonçalves (2003) argumentam que a necessidade de avaliar os gastos públicos é justificada pela transparência das decisões da ação pública, da avaliação de 
políticas e programas sociais, na mensuração da eficiência, da eficácia e da efetividade do gasto público. Na promoção da eficiência da gestão municipal, é relevante o controle mediante o monitoramento dos resultados e a busca pela melhoria da qualidade dos indicadores sociais que refletem o bem-estar da sociedade. Por meio do embasamento gerencial, a análise dos indicadores de saúde auxilia o gestor a verificar se o modelo de gestão está produzindo os efeitos pretendidos e se pode manter a aplicação dos recursos nas mesmas bases.

Neste contexto, a contabilidade pública pode ser um instrumento para subsidiar as ações governamentais, auxiliando na análise dos gastos nas funções ou subfunções de despesas, como a função saúde, monitorando quais são os resultados obtidos e como podem ser mensurados. O objetivo é que os bens públicos sejam produzidos com o menor gasto possível. No ambiente instaurado após o processo de descentralização e municipalização, a contabilidade é uma ferramenta que auxilia a gestão da saúde pública, a gerenciar os gastos de forma mais eficiente. Por meio do aperfeiçoamento da gestão pública, pode-se dar suporte tempestivo e relevante para a tomada de decisão, ou seja, a essência que garante o alcance da eficiência, eficácia e efetividade das políticas públicas.

O processo de descentralização acompanha paulatinamente as normas operacionais que regem o SUS, como uma diretriz da política pública da saúde. Na NOAS nº 01/02 (Brasil, 2002), há a exigência de avaliação, assim como em qualquer política pública. A análise da eficiência, observando a relação entre os recursos aplicados e os resultados obtidos, evidenciam o cumprimento das metas dos programas de saúde. O valor do gasto público, neste estudo entendido como os recursos aplicados ou consumidos é uma informação obtida por meio da contabilidade em uma rubrica denominada "despesa liquidada" na função saúde. O resultado da aplicação desse recurso pode ser mensurado por meio de indicadores finais, demonstrando o retorno gerado ou a melhoria do bem-estar da população.

Assim, há relevância na análise da execução dos gastos públicos na função saúde, para avaliar se os recursos que foram aplicados estão promovendo a melhoria das condições de saúde, e consequentemente, aumentando o bem-estar da população.

Em um contexto econômico, segundo dados do Instituto Brasileiro de Geografia e Estatística (IBGE), referentes a 2010, a região sudeste representa $42 \%$ da população do país. Minas Gerais é o estado com o maior número de municípios (853 municípios) dentre os estados brasileiros e o quarto estado em extensão territorial (IBGE, 2010). É a terceira economia nacional em termos de produção, com cerca de $9,1 \%$ do Produto Interno Bruto 
(PIB) de 2014. Considerando os dados do PIB, a região sudeste em relação ao Brasil é a que mais contribui em termos de produção do valor adicionado bruto, uma média de 54,86\% no quinquênio de 2010/2014, conforme demonstrado na Tabela 1 (IBGE, 2016).

Tabela 1 - Produto Interno Bruto (PIB) da Região Sudeste em relação ao Brasil (\%)

\begin{tabular}{crrrrr}
\hline \multirow{2}{*}{ Estados } & \multicolumn{5}{c}{ Produto Interno Bruto (PIB) \% } \\
\cline { 2 - 6 } & $\mathbf{2 0 1 0}$ & $\mathbf{2 0 1 1}$ & $\mathbf{2 0 1 2}$ & $\mathbf{2 0 1 3}$ & \multicolumn{2}{c}{$\mathbf{2 0 1 4}$} \\
\hline Brasil & $\mathbf{1 0 0 , 0}$ & $\mathbf{1 0 0 , 0}$ & $\mathbf{1 0 0 , 0}$ & $\mathbf{1 0 0 , 0}$ & $\mathbf{1 0 0 , 0}$ \\
MG & 9,2 & 9,4 & 9,5 & 9,4 & 9,1 \\
ES & 2,1 & 2,3 & 2,3 & 2,1 & 2,2 \\
RJ & 11,5 & 11,7 & 12,0 & 11,7 & 11,7 \\
SP & 32,5 & 31,8 & 31,4 & 31,2 & 31,2 \\
\hline Total Região Sudeste & $\mathbf{5 5 , 3}$ & $\mathbf{5 5 , 2}$ & $\mathbf{5 5 , 2}$ & $\mathbf{5 4 , 4}$ & $\mathbf{5 4 , 2}$ \\
\hline Fonte: IBGE (2016) & & & &
\end{tabular}

Fonte: IBGE (2016).

Nesta pesquisa, o interesse é trabalhar com os dados de Minas Gerais, que assim como em outros estados também possui indicadores com características socioeconômicas heterogêneas. De acordo com Oliveira (2007) "Minas Gerais caracteriza-se por uma ampla diversidade de condições sócio-econômicas e demográficas ... que se traduz na idéia de várias Minas.” (p. 12).

Em Minas Gerais, a extensão geográfica do Estado e as desigualdades regionais reforçam a necessidade de se fazer valer a iniciativa de descentralização/municipalização como instrumento de gestão para a garantia de equidade, integralidade e acessibilidade, conforme preceitua a política do SUS. As diferenças, no entanto, não se limitam à distribuição da segunda maior população do país. As desigualdades sociais podem ser percebidas, conforme indicadores como o Índice de Desenvolvimento Humano (IDH) do estado de Minas Gerais em 2010, obtido no sítio da Atlas Brasil, com uma variabilidade de 0,529 (para o município de São João das Missões) para 0,813 (para o município de Nova Lima). Considerando a média do IDH estadual de 0,731 , somente 82 dos 853 munícipos do estado, conseguiram atingir a média. Isso denota a discrepância do IDH entre os munícipios de Minas Gerais, onde menos de $10 \%$ (dez por cento) dos municípios atingiram a média estadual (Atlas Brasil, 2013).

Considerando dados mais atuais da Federação das Indústrias do Estado do Rio de Janeiro (FIRJAN), obtidos no sítio do Sistema FIRJAN; temos o Índice Firjan de Desenvolvimento Municipal (IFDM), um estudo do Sistema FIRJAN que acompanha o desenvolvimento socioeconômico anualmente de todos os mais de 5 mil municípios 
brasileiros em três áreas de atuação: Emprego \& renda, Educação e Saúde. O IFDM publicado na dimensão Saúde relativo ao ano de 2013, apresentou a média nacional de 0,7684, a mediana estadual de 0,7560, e o IFDM-Saúde municipal com uma variabilidade de 0,2838 (para o município de Juvenília) para 0,9834 (para o município de Natércia). (FIRJAN, 2016)

Segundo a Secretaria de Estado de Saúde de Minas Gerais (SES-MG) o estado dividese em 13 Regiões Ampliadas de Saúde ou macrorregiões, agrupadas em 77 Regiões de Saúde ou microrregiões, que são os conjuntos de municípios com características semelhantes, conforme apresentado na Tabela 2 (SES-MG, 2014).

Tabela 2 - Regiões Ampliadas de Saúde e quantitativo de Regiões de Saúde do Estado de Minas Gerais

\begin{tabular}{|c|c|c|c|}
\hline $\begin{array}{c}\text { Regiões Ampliadas } \\
\text { de Saúde }\end{array}$ & Cidades Sedes & $\begin{array}{c}\text { Quantidade de } \\
\text { Regiões de Saúde }\end{array}$ & $\begin{array}{c}\text { População estimada } \\
\text { pelo IBGE }\end{array}$ \\
\hline Centro & Belo Horizonte / Sete Lagoas & 10 & 6.480 .169 \\
\hline Centro Sul & Barbacena & 03 & 780.011 \\
\hline Jequitinhonha & Diamantina & 02 & 296.870 \\
\hline Leste & Governador Valadares / Ipatinga & 07 & 1.532 .984 \\
\hline Leste do Sul & Ponte Nova & 03 & 694.964 \\
\hline Nordeste & Teófilo Otoni & 08 & 931.946 \\
\hline Noroeste & Patos de Minas & 03 & 691.080 \\
\hline Norte & Montes Claros & 09 & 1.661 .130 \\
\hline Oeste & Divinópolis & 06 & 1.254 .944 \\
\hline Sudeste & Juiz de Fora & 08 & 1.651 .433 \\
\hline Sul & $\begin{array}{l}\text { Alfenas / Pouso Alegre / Poços de } \\
\text { Caldas / Passos / Varginha }\end{array}$ & 12 & 2.745 .220 \\
\hline Triângulo do Norte & Uberlândia & 03 & 1.260 .398 \\
\hline Triângulo do Sul & Uberaba & 03 & 752.948 \\
\hline Total & - & 77 & 20.734.097 \\
\hline
\end{tabular}

Fonte: SES-MG (2014).

Assim como no Brasil, no estado de Minas Gerais, a descentralização trouxe automonia financeira e administrativa aos municípios colocando sob a sua responsabilidade o cuidado, principalmente ao nível da atenção básica da saúde; que depedem das Regiões de Saúde, que devem pactuar entre si arranjos inter-regionais para garantir também ao nível de atencão na média e alta complexidade aos seus municípios, por meio das Redes de Atenção à Saúde, onde se definem a estruturação das ações e serviços de saúde, que buscam garantir a integralidade do cuidado como um todo.

A relação entre as Redes de Atenção à Saúde, as Regiões de Saúde e os municípios, permeadas pelos objetivos do Estado e também da União devem ser integradas, com ações e serviços de saúde com provisão contínua, integral, de qualidade, responsável, promovendo o desempenho do sistema, em termos de acesso, equidade, eficácia clínica e eficiência 
econômica. Tanto as RS quanto os municípios responsáveis pela prestação dos serviços de saúde, necessitam de gerir e monitorar o cumprimento do processo, assegurando que as pactuações alcançem os resultados (outcomes) ou impactos desejados.

Muitos estudos abordam a eficiência dos gastos públicos em Minas Gerais, e os estudos que abordam a área da saúde contemplam uma Região de Saúde, munícipios de uma RS, utilizam somente indicadores de produção. (Fonseca \& Ferreira, 2009; Cabral \& Ferreira, 2014; Ázara, 2016), dentre outros. Assim observou-se uma lacuna que leve em conta a gestão dos gastos, considerando a relação existente entre as RS e os seus municípios, ou a hierarquização da saúde, entre as suas Regiões Ampliadas de Saúde, as Regiões de Saúde e os munícipios que as compõem. Assim os resultados obtidos em um município, reflete nos resultados da RS e em cadeia na Região Ampliada de Saúde.

Assim, considerando a relação entre a RS e os seus municípios, sendo que um dos objetivos da regionalização é racionalizar os gastos e otimizar os recursos, a proposta deste estudo buscará responder à seguinte questão: Qual a eficiência dos gastos públicos aplicados na função saúde, em relação aos indicadores de resultados, nas regiões de saúde mineiras?

\subsection{Objetivos}

O objetivo geral é analisar a eficiência da execução dos gastos públicos na função saúde em relação aos indicadores de resultados da saúde, nas Regiões de Saúde mineiras no período de 2010 a 2014.

A proposta é a análise da evolução dos recursos financeiros executados destinados ao financiamento da função saúde, que se transformam em gastos públicos e o que se espera de retorno na forma de resultados finais (outcomes). Considerando a melhoria dos indicadores de resultados na área da saúde, que também refletem as condições de saúde da população, e seus efeitos na eficiência técnica das regiões de saúde mineiras. Tanto a evolução do gasto público na saúde quanto o desempenho da gestão regional mensurado por meio da eficiência, são fatores que impactam na formulação ou adequação de diretrizes nas políticas públicas na área da saúde, como por exemplo o Pacto pela Saúde.

Como objetivos específicos, pretende-se: 
- Verificar os scores de eficiência total dos gastos públicos na função saúde nas regiões de saúde de Minas Gerais, em relação aos indicadores de saúde;

- Analisar nos municípios mineiros a evolução dos indicadores de saúde pactuados junto às regiões de saúde, consideradas ineficientes;

- Identificar a relação entre a eficiência das regiões de saúde e o cumprimento das metas pactuadas pelos municípios das regiões ineficientes, por meio da evolução dos indicadores de saúde.

Com base nos resultados de eficiência verificados para cada RS, pretende-se verificar o cumprimento das metas pactuadas junto aos seus municípios, como o atendimento aos objetivos pactuados. O resultado da eficiência de uma RS depende de que cada município cumpra a sua parte nas metas estabelecidas e pactuadas, e pode-se observar se os municípios que a compõem, analisando qual deles não atendeu aos objetivos da pactuação junto à RS.

Considerando que cada município compromete-se com a sua RS, o que entregará de resultado em termos de eficiência, por meio das metas pactuadas a cumprir, o gestor municipal é o responsável por esse resultado. Portanto, os resultados de saúde de uma RS irão depender do que o gestor está prometendo entregar à população, assim, pode-se analisar o comportamento interno da RS, considerando que comparativamente os desempenhos são diferentes.

Pretende-se estudar as diretrizes do SUS e as diretrizes específicas de Minas Gerais, considerando também a estratégia administrativa que pode impactar os resultados de uma RS ou município. Uma mudança da política de saúde no SUS ou no estado afeta o setor de saúde nos subníveis e se operacionaliza em cada estado, em cada RS e município.

\subsection{Justificativa e Contribuição}

Depreende-se que é pacífico o entendimento na literatura e entre os pesquisadores da área, de que a saúde é fator determinante para o desenvolvimento. Desta forma, os investimentos na área são necessários quando se trabalha com as políticas de crescimento econômico-social, com foco na redução da pobreza e emancipação social. Este estudo mostrase relevante por tratar de tema de interesse social que é amplamente discutido, mas cuja complexidade e as múltiplas realidades sociais com as quais se relaciona o tornam atual e passível de diferentes discussões e perspectivas. 
O que justificou a escolha do estudo foi o interesse em analisar a gestão pública, com base nos resultados de saúde. Poucos trabalhos se debruçaram no estudo das condições da gestão da saúde nas RS de Minas Gerais foram encontrados, sendo que as pesquisas desenvolvidas nos artigos, dissertações e teses, aos quais se teve acesso, as análises ora englobam todo o país, ou o Estado de Minas Gerais, mas em microrregiões específicas, ou analisam a subfuncão da atenção básica, utilizam indicadores de produção, um procedimento ou mesmo um serviço específico ou voltam-se para determinado município, isoladamente.

As boas condições de saúde e de vida não são demonstradas simplesmente pela eficiência da gestão, ou seja, as análises empregadas no estudo servirão para demonstrar as distorções existentes no interior da RS, entre os municípios que a compõem, e para apontar as ações com maior potencial de converter a atual situação da microrregião e ou município quanto à fronteira de eficiência. Neste caso a utilidade será o auxílio aos gestores de saúde regionais, que também poderão observar as outras regiões de saúde para fins de comparabilidade.

Espera-se que o estudo das despesas e dos indicadores de saúde selecionados apontem algumas dificuldades das das RS e municípios em cumprirem suas metas pactuadas. Outro aspecto que merece destaque é que para fazer qualquer avaliação, exige-se também que os dados sejam de qualidade, além de confiáveis, aspectos que, se não observados, geram limitações na construção da pesquisa e repercutem em seus resultados. Sistemas informacionais nacionais mais perspicazes, objetivos e preenchidos constantemente pelos responsáveis pela sua alimentação, favorecem o desenvolvimento de pesquisas e estudos que devolvem para toda a sociedade retornos relevantes.

O conhecimento das questões que envolvem as ações governamentais é relevante para contribuir com o progresso e aperfeiçoamento dos setores na sociedade. Assim, este trabalho será uma contribuição para a área da saúde pública, considerando a baixa pesquisa empírica na área. 


\section{FUNDAMENTAÇÃO TEÓRICA E ESTUDOS EMPÍRICOS}

Este capítulo está estruturado em quatro seções, elaboradas para que sejam abordados a fundamentação teórica, os conceitos e definições da pesquisa e o suporte de estudos empíricos. O objetivo é que os conceitos e definições apresentados possam contribuir para o futuro desenvolvimento da pesquisa, com o apoio de pesquisas empíricas. Na primeira seção bases teóricas e as políticas públicas são apresentados os conceitos e definições relacionados a uma breve descrição das teorias: das despesas públicas, federalismo fiscal, escolha pública e dos contratos; a segunda seção aborda o SUS e o processo de descentralização e regionalização quanto à literatura e legislação; a terceira seção aborda a controladoria na gestão pública; a quarta seção aborda a avaliação da eficiência na saúde.

\subsection{Bases Teóricas e as Políticas Públicas}

A análise da eficiência dos gastos do setor público envolve conhecer as características do setor. Neste trabalho, o objetivo está em analisar a eficiência dos gastos públicos no setor saúde ao nível regional, e esta linha de pesquisa abrange vários temas para suporte teórico. Portanto nesta seção serão abordadas as teorias e conceitos que podem contribuir e justificar o desenvolvimento da pesquisa.

Política pública é considerada um fluxo de decisões públicas, com o objetivo de sustentar o equilíbrio social ou alterar essa realidade, segundo a visão de Saravia (2006). De acordo com a argumentação de Souza (2006), as políticas públicas auxiliam as inter-relações entre a economia, a sociedade, a política e o Estado. No campo da administração, uma política pública tem beneficiários diretos, objetivos definidos e recursos limitados.

A política pública se utiliza do suporte de teorias, como a Teoria das Despesas Públicas de Samuelson (1954) que presumiu duas categorias de bens: bens de consumo coletivo, que são aqueles em que todos os indivíduos usufruem em comum, ou seja, o consumo por um indivíduo não impede o consumo por outro, e os bens de consumo privado, que são aqueles que não podem ser compartilhados por todos, e o direito de propriedade não permite que todos tenham acesso ao bem, ou seja, o consumo por um indivíduo exclui o consumo por outro indivíduo. Assim há concorrência pelo consumo entre os indivíduos e é 
excludente.

O consumo de bens públicos não é rival e também não é excludente, pois o consumo de certa quantidade de bens públicos por um indivíduo, não reduz a quantidade consumida por outro e também esse mesmo consumo por um indivíduo não exclui (limita) o consumo por outros indivíduos. Nas argumentações de Musgrave (1939) e Samuelson (1954) há a suposição de que as despesas são realizadas ao nível do governo central. No entanto, os serviços são ofertados pelos governos locais. Assim, Tiebout (1956) com base nos conceitos desenvolvidos por estes dois autores, desenvolveu a Teoria das Despesas Locais. Neste modelo, há uma competição entre os governos locais que possibilita que os consumidores de serviços revelem as suas preferências por um determinado pacote de ofertas. Neste sentido, a teoria de Tiebout trata de um modelo de descentralização fiscal, o que contribuiu e nos remete à Teoria do Federalismo Fiscal.

\subsubsection{Teoria do Federalismo Fiscal}

A Teoria do Federalismo Fiscal (Oates, 1972) aborda a eficiência da centralização ou descentralização do setor público, que iniciou a partir da definição de Musgrave (1959), sobre as três funções básicas do governo: alocativa, distributiva e estabilizadora. $\mathrm{Na}$ função alocativa o Estado oferece à sociedade bens e serviços que o mercado não é capaz de oferecer de forma eficiente, considerando que a natureza da atividade requer a universalização, uma vez que seus benefícios repercutem tanto para o indivíduo quanto para a sociedade. Neste sentido, Musgrave e Musgrave (1980) argumentam que para realizar seus compromissos e atender aos anseios da sociedade, o Estado necessita captar recursos e aplicá-los de modo eficiente, racionalizando os gastos e otimizando os resultados.

De acordo com Mendes (2004), o federalismo fiscal pode ser definido "como a divisão de tarefas entre os diferentes níveis de governo: quem (que níveis de governo) deve arrecadar cada um dos tributos do país e quem deve ofertar cada um dos serviços públicos (saúde, saneamento, educação, limpeza, iluminação, segurança pública, estabilidade macroeconômica, assistência aos pobres, etc.)." (p. 422). A dimensão econômica do federalismo trata dos direitos de arrecadação tributária de cada ente, das transferências intergovernamentais e das responsabilidades na prestação dos serviços públicos, ou seja, as fontes de financiamento para os governos exercerem suas funções. 
As principais abordagens do federalismo passíveis de aplicação no Brasil, segundo (Souza, 2008), são quatro: 1) Federalismo como descentralização das instituições políticas e das atividades econômicas; 2) Federalismo e democracia; 3) Federações e federalismos; 4) Federalismo como pacto.

$\mathrm{Na}$ primeira abordagem o federalismo é considerado um sistema e as atividades políticas e econômicas são regionalmente descentralizadas, no mesmo território nacional. As questões relevantes são as divisões políticas, os conflitos e as barganhas. A segunda abordagem destaca a importância da Constituição para a existência, exercício e a manutenção da soberania das federações e funcionamento dos sistemas políticos federativos. (Souza, 2008).

A terceira abordagem separa o conceito de federação, como estrutura institucional composta de um governo central e governos subnacionais dentro de um mesmo Estado; do conceito de federalismo, visto como um fato empírico em reconhecimento à diversidade em seus contextos social, econômico, cultural e político, independentemente de arranjos institucionais. "A relação entre federalismo e federação se dá de uma forma que o primeiro é condição para a existência do segundo". (Franzese, 2010, p. 32).

A última abordagem, do federalismo como pacto, ocorre uma espécie de acordo de confiança estabelecido entre os entes federativos, baseado no mútuo reconhecimento, tolerância e respeito entre as partes e o principal autor dessa abordagem é Daniel Elazar. Segundo Elazar (1987), o pacto dá origem a uma relação pactuada entre os indivíduos, levando a criação da coexistência de diferentes centros de poder, sem relação hierárquica entre eles.

De acordo com (Franzese, 2010):

\footnotetext{
Ancorado na idéia de pacto, o fundamento da criação deste polity não é a violência ou a conquista, mas a escolha. Os protagonistas dessa escolha são os membros constituintes da federação, que constituem a principal unidade de análise dessa abordagem. Nesse sentido, a teoria do federalismo como pacto serve de base para estudos cujo foco esteja na interação entre os entes federativos, ou seja, nas relações intergovernamentais.
}

Como desdobramento da teoria do federalismo como pacto surgiu a teoria do federalismo cooperativo. A existência de interação entre as esferas governamentais decorre da teoria do federalismo como pacto e da relação de não-centralização entre as diferentes esferas, representada por uma matriz. Devido a interação nas federações o sistema recebe o nome de 
federalismo cooperativo. (Elazar, 1994).

Oates (2005) apresenta duas categorias do federalismo fiscal. Na primeira, considera os processos políticos e seus impactos sobre os resultados do sistema e o foco foi a atribuição de funções para os diferentes níveis de governo com características de cooperação e o bem comum. A segunda geração considera a escolha pública, e os participantes do processo tem as suas próprias funções objetivo e procuram otimizar num ambiente que fornece restrições sobre o seu comportamento. As inter-relações entre os agentes envolvidos no financiamento e produção de bens públicos ampara-se na relação agente-principal da teoria da firma e teoria dos contratos.

De acordo com Oates (2005), a Teoria da Escolha Pública tem ampliado as perspectivas do federalismo fiscal. Na Teoria da Escolha Pública, os atores políticos são considerados maximizadores de utilidade, sendo que as decisões são por incentivos, ou seja, mesmo que tomem decisões coletivas, o que prevalece são os interesses individuais. (Buchanan, 1960). O indivíduo tem um comportamento racional e individualista e mesmo que possa ter algum interesse coletivo, a sua principal motivação é o interesse próprio e individual.

\subsubsection{Teoria da Agência (Agency Theory)}

A teoria da agência busca analisar as relações entre os participantes de um sistema, onde a propriedade e o controle são designados a pessoas distintas, o que pode resultar em conflitos de interesse entre os indivíduos. Jensen e Meckling em 1976 apresentaram estudos sobre a Teoria de Agência, ao argumentarem que os problemas de agência decorrem de conflitos de interesses existentes entre os indivíduos, quer ocorra ou não em situações de hierarquia entre o principal e o agente. (Jensen \& Meckling, 1976) Reeditado e traduzido em 2008 (Jensen \& Meckling, 2008).

Para regular a relação entre o principal (proprietário) que objetiva maximizar seus lucros, delegando ao agente (gestor) a gestão da organizacão, a Teoria de Agência, estabelece mecanismos eficientes (sistemas de monitoramento e incentivos) para garantir que o comportamento dos executivos esteja alinhado com o interesse dos acionistas. (Eisenhardt, 1988). 
A Teoria de Agência têm o foco nas transações inter-organizacionais, ou nos contratos, entre o principal e o agente, assumindo a existência de racionalidade limitada e o oportunismo dos indivíduos. A problemática principal-agente é determinada em um contrato entre os dois atores, considerando o comportamento dos indivíduos e os resultados. Dessa relação espera-se conflito de objetivos e mensuração de resultados, e sob ótica da aversão ao risco, o agente seria mais propenso à aversão aos riscos, devido ao seu emprego, enquanto o principal seria capaz de diversificar os seus investimentos, ousando mais e assumindo riscos.

Jensen e Meckling (1976) definem a relação como sendo um contrato onde uma ou mais pessoas (principal) contrata outra pessoa (o agente) para realizar algum serviço ou trabalho, que envolve a delegação de alguma decisão ao agente.

\begin{abstract}
Definimos uma relação de agência como um contrato sob o qual uma ou mais pessoas (o(s) principal(is)) emprega uma outra pessoa (agente) para executar em seu nome um serviço que implique a delegação de algum poder de decisão ao agente. Se ambas as partes da relação forem maximizadoras de utilidade, há boas razões para acreditar que o agente nem sempre agirá de acordo com os interesses do principal. O principal pode limitar as divergências referentes aos seus interesses por meio da aplicação de incentivos adequados para o agente e incorrendo em custos de monitoramento visando a limitar as atividades irregulares do agente. (Jensen \& Meckling, 2008, p. 89)
\end{abstract}

Sob o olhar da Teoria dos Contratos, a empresa aparece como um conjunto de contratos entre os diversos participantes e o funcionamento adequado depende do equilíbrio contratual estabelecido. Se uma das partes não estiver satisfeita com os termos do contrato ou com sua execução, as atividades podem ser prejudicadas. De acordo com Marinho e Façanha (2001), os programas de governo enfrentam dificuldades que podem-se identificar como inerentes aos contratos e aos mecanismos contratuais, o que implica em reconhecer as relações estratégicas entre as características dos programas. Os contratos tratam de objetivos relacionais e podem ser objeto de manipulação estratégica. Como trata da "abordagem que explora fundamentos e regras robustas e resistentes a alterações de contextos, renegociações e quebras de contratos, nesse caso, tendem a provocar perdas de eficiência, entre outras razões, porque seriam o oposto de compromissos (commitments) estratégicos...” (p. 9-10).

Segundo (Williamson, 2002) todos os contratos complexos são inevitavelmente incompletos e por esta razão, as partes serão confrontadas com a necessidade de se adaptar a distúrbios e imprevistos que surjam em razão de lacunas, erros e omissões no contrato original. Os atores são confrontados com necessidades de adaptação aos imprevistos (por razões de racionalidade limitada), ao comportamento estratégico (por causa do oportunismo), e as dispendiosas rupturas contratuais (recusas de cooperação, inadaptação, exigências de 
renegociação). Outros estudos abordam a relação contratual considerando os contratos incompletos (Baker, Gibbons, \& Murphy, 2002; Besley \& Coate, 2003).

Considerando a área da saúde pública, a mesma ampara-se no Welfare State, que objetiva a promoção de políticas públicas na área social e garante o atendimento das necessidades básicas da população. Pode-se considerar o Welfare State um sistema em que o governo se compromete a proteger a saúde e o bem-estar dos seus cidadãos, especialmente aqueles com necessidades financeiras ou sociais, por meio de subvenções, pensões e outros benefícios. Porém, de acordo com o estudo de Eikemo e Bambra (2008), ainda não há uma definição padrão aceita do conceito de maneira ampla.

$\mathrm{Na}$ linha da administração, existe o modelo burocrático Weberiano, relativo ao funcionamento interno do Estado, no qual os atributos são a impessoalidade, a neutralidade e a racionalidade. (Abrucio, 1997). Segundo Weber (2009), a administração burocrática é a forma mais racional do exercício de dominação, "porque nela se alcança tecnicamente o máximo de rendimento em virtude de precisão, continuidade, disciplina, rigor e confiabilidade..., intensidade e extensibilidade dos serviços, e aplicabilidade formalmente universal a todas as espécies de tarefas" (p.145).

O foco deste estudo está na função alocativa do Estado, mais estritamente no provimento dos serviços de saúde pelo poder público municipal. Assim, considera-se que a Teoria do federalismo como pacto juntamente com a Teoria dos contratos incompletos, possam contribuir para responder aos questionamentos sobre o desempenho das regiões e municípios em conformidade com as atitudes dos gestores públicos, referente ao cumprimento das metas estabelecidas. O comportamento dos gestores que se aproximam de uma linha de cooperação ou de competição pode influenciar o desempenho no setor saúde da região ou município.

\subsection{Sistema Único de Saúde - SUS}

O Sistema Único de Saúde (SUS), considerado um dos maiores sistemas públicos de saúde do mundo, segundo informações do Conselho Nacional de Saúde (CNS), é descrito pelo Ministério da Saúde (MS) na sua cartilha Ententendo o SUS como "um sistema ímpar no mundo, que garante acesso integral, universal e igualitário à população brasileira,". Foi instituído na Constituição da República Federativa do Brasil de 1988, com o objetivo de 
promover a justiça social e reduzir as desigualdades na assistência à saúde. Para efetivar o mandamento constitucional do direito à saúde, consta no artigo 196 como um "direito de todos" e "dever do Estado" (Brasil - CN, 1988; Portal da Saúde - SUS, 2016).

O SUS oferece a todo cidadão brasileiro o acesso gratuito aos serviços de saúde, desde os mais simples procedimentos ambulatoriais, como consultas médicas, aos de alta complexidade, como um transplante de órgãos (Brasil - CN, 1988; Portal da Saúde - SUS, 2016). Além da assistência médico-hospitalar, também promove e desenvolve ações como a prevenção, a vacinação, o controle de doenças, a vigilância sanitária permanente, regula o registro de medicamentos e o controle e fiscalização dos alimentos. Após a criação do SUS a saúde passou a ser promovida e sua prevenção começou a integrar o planejamento das políticas públicas da saúde (Pense SUS - Fiocruz, 2016).

Sobre a organização dos serviços de saúde que integram uma rede regionalizada e hierarquizada, o artigo 198 da CF de 1988 detalhou as diretrizes nacionais:

Art. 198. As ações e serviços públicos de saúde integram uma rede regionalizada e hierarquizada e constituem um sistema único, organizado de acordo com as seguintes diretrizes:

I - descentralização, com direção única em cada esfera de governo;

II - atendimento integral, com prioridade para as atividades preventivas, sem prejuízos dos serviços assistenciais;

III - participação da comunidade. (Brasil - CN, 1988)

Além da democratização da saúde (antes acessível apenas para alguns grupos da sociedade), a implantação do SUS representou uma mudança do conceito sobre o qual a saúde era entendida no país. Antes, a saúde representava apenas um quadro de "não-doença", e as políticas implementadas se limitavam ao tratamento de ocorrências de enfermidades. Com o SUS, amparado por um conceito ampliado de saúde, esta passou a ser promovida e a fazer parte do planejamento das políticas públicas da saúde.

Após a criação do SUS, muitas foram as legislações para a sua consolidação. Para promover o seu funcionamento, em conformidade com as três (3) diretrizes definidas no artigo 198 da CF de 1988, a sua regulamentação ocorreu com a aprovação da Lei Orgânica da Saúde (LOS), formada pelo conjunto das Leis $n^{\circ}$ s. 8.080 e 8.142 sancionadas em 1990. A Lei 8.080 dispôs sobre as condições que asseguram o acesso universal e igualitário às ações e aos serviços de saúde no que concerne: aos objetivos e atribuições; aos princípios; à organização, direção e gestão; à competência e atribuições; etc.; enquanto a Lei 8.142 dispôs quanto a 
participação da sociedade na gestão do SUS e as transferências intergovernamentais de recursos financeiros (Brasil - CN, 1990a; Brasil - CN, 1990b).

Roncalli (2003) ressalta que o SUS, garantido pela CF e regulado pela LOS, supõe um sistema com dois tipos de princípios: doutrinários e organizativos:

Os princípios doutrinários dizem respeito às idéias filosóficas que permeiam a implementação do sistema e personificam o conceito ampliado de saúde e o princípio do direito à saúde. Os princípios organizativos orientam a forma como o sistema deve funcionar, tendo, como eixo norteador, os princípios doutrinários. (p. 34)

A normatização dos princípios e diretrizes do SUS, ocorreu por meio da publicação das Normas Operacionais Básicas (NOB). A partir da avaliação dos estágios já alcançados de implantação e desempenho do SUS, as NOBs buscaram a definição de estratégias que orientassem a operacionalidade do sistema, na construção de uma gestão plena. Com a edição das NOBs, Scatena e Tanaka (2001) argumentam sobre o processo de descentralização, como uma relevante diretriz:

\footnotetext{
Regulamenta-se o SUS no final de 1990, mas o processo de descentralização da saúde se inicia, de forma mais concreta, a partir de 1991, com a edição da Resolução n ${ }^{\circ} 273$ do INAMPS - a Norma Operacional Básica 1/91 (BRASIL, 1991) - à qual se seguiram a NOB 1/92, da Secretaria Nacional de Assistência à Saúde/MS (BRASIL, 1992), a NOB 1/93 (BRASIL, 1993) e a NOB 1/96 (BRASIL, 1996), estas últimas emitidas pelo próprio Ministro da Saúde. (p. 49)
}

Nos seus estudos Scatena e Tanaka (2001, p. 68), concluíram que a CF de 1988 definiu os princípios básicos do SUS, que a LOS estruturou o seu arcabouço, mas, foram as NOBs que concretizaram a sua real implantação, a partir de 1991. A descentralização dos serviços e ações de saúde, como uma diretriz, somente "ganha impulso com a edição das NOB 01/91 e 01/92, mas seu enfoque ainda se concentra no financiamento, principalmente da assistência médica, individual e curativa". A NOB 01/93 foi o instrumento "que permitiu o verdadeiro impulso rumo à descentralização". E a NOB 01/96 deu continuidade ao processo de construção do SUS incorporando os princípios da descentralização. Ela tratou do processo de municipalização, principalmente no que se refere à atenção básica, e veio com o intuito de restabelecer o equilíbrio e redefinir as responsabilidades dos estados e da União.

A NOB 01/96 dentre o objetivo de estimular o processo de descentralização e municipalização, enfatizou a implantação do Programa Saúde da Família (PSF), por ser ele parte do conjunto de medidas que visavam o fortalecimento da atenção básica (Marques \& Mendes, 2002, p. 166). O PSF foi implantado quando os municípios que são os responsáveis 
pela execução das ações e serviços de saúde, aderiram ao conjunto de responsabilidades, requisitos e prerrogativas, sob uma das condições de gestão: Gestão Plena da Atenção Básica, para os próprios serviços da atenção básica; ou Gestão Plena do Sistema Municipal, para todos os serviços de saúde inclusive os níveis de atenção à saúde na média e alta complexidade (Brasil - MS, 1996, pp. 24-27).

Neste aspecto a gestão "é a atividade e a responsabilidade de dirigir um sistema de saúde (municipal, estadual ou nacional), mediante o exercício de funções de coordenação, articulação, negociação, planejamento, acompanhamento, controle, avaliação e auditoria." (Brasil - MS, 1996, p. 8). Um dos papeis do gestor estadual era promover as condições e incentivar os gestores municipais a assumirem a gestão da atenção à saúde de sua população, em uma perspectiva de atenção integral; além de assumir de maneira provisória, a gestão da atenção à saúde das populações pertencentes aos municípios que não assumiam esta responsabilidade. Portanto, são gestores do SUS, os Secretários Municipais e Estaduais de Saúde e o Ministro da Saúde, que respectivamente, representam os governos municipais, estaduais e federal. O gestor estadual assume as responsabilidades de mediar as relações entre municípios e União, ou a gestão municipal de forma provisória, até que o município obtenha a sua automonia de gestão (Brasil - MS, 1996, p. 10).

Em 2000 para assegurar os valores mínimos aplicados pela União, pelos estados e pelos municípios, para o financiamento das açoes e serviços públicos da saúde, foi editada a Emenda Constitucional $n^{\circ} .29$ de 13 de setembro que alterou alguns artigos da CF de 1988, e dentre eles o 198, na área da saúde, e acrescentou um artigo ao Ato das Disposições Constitucionais Transitórias (ADCT), que trata dos recursos mínimos para o financiamento da saúde, ou seja, o percentual mínimo sobre o produto da arrecadação de impostos de $12 \%$ (doze por cento) para os estados e de $15 \%$ (quinze por cento) para os municípios, para financiar as ações e serviços na área da saúde (Brasil - CONASS, 2011).

Esses percentuais foram mantidos com a foi a Lei Complementar $\mathrm{n}^{\circ}$. 141, de 13 de janeiro de 2012, que regulamentou o parágrafo $3^{\circ}$. do artigo $198 \mathrm{da} \mathrm{CF}$, para dispor sobre os valores mínimos a serem aplicados anualmente pela União, Estados, Distrito Federal e Municípios nas ações e serviços públicos de saúde; estabelecendo os critérios de rateio dos recursos das transferências para a saúde e as normas de fiscalização, avaliação e controle das despesas com saúde nas três esferas de governo. (Brasil - MS, 2012a). 
A Norma Operacional de Assistência a Saúde (NOAS) nº 01 em 2001, consolidada pela NOAS nº. 01 de 2002, ampliou as responsabilidades dos municípios na Atenção Básica, os gestores municipais devem ser capazes de ofertar além dos serviços da atenção básica, o acesso aos serviços de maior complexidade, estruturando e organizando a demanda regional com o processo de regionalização da assistência. O reconhecimento da regionalização da atenção à saúde como estratégia para consolidar os princípios de universalidade, equidade e integralidade, constituindo-se em direção à descentralização. A definição das reponsabilidades do gestor municipal, os requisitos relativos às modalidades de gestão, as prerrogativas estaduais e municipais, viabilizam por meio do financiamento a política pública (Brasil - MS, 2001; Brasil - MS, 2002).

Marques e Mendes (2002, p. 169) argumentam que o processo de responsabilização dos gestores estaduais e municipais na perspectiva da atenção integral, pressupõe que o funcionamento do SUS depende da conciliação de três diretrizes: a descentralização, ampliando a responsabilidade de gestão dos muncípios; a regionalização, enfatizando o planejamento territorial e a hierarquização, por meio da organização de redes assistenciais na perspectiva da resolutividade. Os autores alegam que o financiamento continua como principal instrumento da política de saúde, onde os recursos federais destinados ao custeio da assistência à saúde são transferidos a estados e municípios, incentivando a ampliação da atenção básica, incentivando a qualificação e responsabilidade das regiões, inerentes a assistência à saúde e a organização dos serviços de média e alta complexidade. Assim, a população tem a garantia do acesso a todos os níveis de atenção à saúde.

Nas considerações finais os autores alertam sobre os incentivos das políticas de saúde, esclarecendo que quando o Ministério da Saúde (MS) "escolheu o PSF como porta de entrada no sistema, entendeu ser essa a melhor estratégia para garantir a universalização de, pelo menos, a Atenção Básica", mas que o princípio da integralidade, que garante o acesso a todos os níveis de atenção à saúde, não pode ser esquecido. Chamam a atenção para o fato de que a ênfase na Atenção Básica acabe por descuidar dos outros níveis de atenção à saúde, podendo causar o "desfinanciamento" da média e alta complexidade, por meio do sucateamento da rede existente ou impedindo a sua ampliação.

\footnotetext{
Por outro lado, não é menos preocupante o fato de os incentivos terem se tornado uma prática constante do MS a partir de 1998 - com a instituição do PAB - e dos municípios serem estimulados a incorporar os programas que lhes acrescentam receita financeira. Na medida em que esses recursos são vinculados aos programas incentivados pelo MS, como é o caso do PSF, não podendo ser redirecionados para outros fins na área da saúde, muitas vezes os municípios enfrentam situações onde falta o necessário até mesmo para manter sua rede de unidades básicas, quanto mais para os
} 
demais serviços de atenção à saúde. Isso é o reflexo da política tutelada da descentralização, que ao incentivar a despesa em determinados programas, impede que os municípios definam livremente sua política de saúde, introduzindo o paradoxo da existência da "pobreza" em um quadro de recursos "abundantes" e garantidos pelos incentivos. ${ }^{1}$ (Marques \& Mendes, 2002, p. 171)

A Portaria n n $^{\circ} 399$ de 2006 estabeleceu o "Pacto pela Saúde" entre as três esferas de governo (federal, estadual e municipal), sustentado em três pilares básicos: Pacto pela Vida (PV), Pacto em Defesa do SUS (PD) e Pacto de Gestão do SUS (PG). "Estas prioridades são expressas em objetivos e metas no Termo de Compromisso de Gestão e estão detalhadas no documento Diretrizes Operacionais do Pacto pela Saúde 2006.” (Brasil, 2006).

A partir desse pacto, conforme análise de Schneider et al. (2007, p. 26) "a intenção é avançar no processo de descentralização dos recursos para que os estados e municípios tenham maior autonomia.”. Dessa maneira, os repasses são transferidos em blocos para o financiamento do custeio da saúde: a) atenção básica; b) atenção de média e alta complexidade; vigilância em saúde; assistência farmacêutica; e gestão do SUS.

Esse pacto tornou-se um marco por ter consolidado o SUS, avançado no aperfeiçoamento das diretrizes operacionais, em prol das iniciativas que levam à otimização dos serviços e ao acesso a todos os níveis de atenção. Foi aprovado pelos gestores do SUS em reunião da Comissão Intergestores Tripartite (CIT), que são as instâncias de pactuação e deliberação, composta por representação de todos os níveis do governo: Ministério da Saúde (MS), Conselho Nacional de Secretários de Saúde (CONASS) e o Conselho Nacional de Secretários Municipais de Saúde (CONASEMS). É um espaço tripartite para a elaboração de propostas para a implantação e operacionalização do SUS (Brasil - MS, 2006).

A sua implantação possibilitou a efetivação de acordos entre os três níveis de gestão do SUS, na adequação de aspectos institucionais e inovações nos processos de gestão que visam alcançar maior efetividade, eficiência e qualidade dos resultados de saúde, redefinindo responsabilidades coletivas em função das necessidades de saúde da população, buscando a equidade social. Composto por 3 (três) dimensões, cada uma, com finalidade específica na composição dos objetivos do pacto.

\footnotetext{
${ }^{1}$ A referência ao Piso da Atenção Básica (PAB), corresponde a modalidade de transferência per capita de recursos federais para os municípios. Segundo os autores, esse incentivo foi determinante para o crescimento do número de equipes de saúde da família na atenção básica. As transferências para Atenção Básica eram realizadas por meio de repasse automático com base em um valor per capita de R\$ 10,00/ano (denominado PAB fixo) ou por transferências que visam incentivar determinados programas, como o PSF e agentes comunitários, integrantes do que se denominou como PAB variável.
} 
A dimensão PV buscou o compromisso entre os gestores do SUS em torno de prioridades que apresentem impacto sobre a situação de saúde da população. A dimensão PD do SUS desenvolveu e articulou as ações, no âmbito de sua competência e em conjunto com os demais gestores, visando qualificar e assegurar o SUS como política pública; e a dimensão PG estabeleceu as diretrizes para a gestão nos aspectos da Descentralização, Regionalização, Financiamento, Planejamento, Programação Pactuada e Integrada (PPI), Regulação, Participação Social e Gestão do Trabalho e da Educação na Saúde (Brasil - MS, 2006).

A criação do pacto pela saúde foi possível devido às reuniões das Comissões Intergestores Tripartite (CIT) e também Bipartite (CIB), que são reconhecidas como foros de negociação e pactuação entre os gestores, quanto aos aspectos operacionais do SUS. As comissões quando criadas têm por objetivos: decidir sobre os aspectos operacionais, financeiros e administrativos da gestão compartilhada do SUS, definir diretrizes, de âmbito nacional, regional e intermunicipal, a respeito da organização e integração das redes de ações e serviços de saúde e fixar diretrizes sobre as regiões de saúde, integração de territórios, referência e contra referência e demais aspectos vinculados à integração das ações e serviços de saúde entre os entes federados (Brasil, 1990).

As Comissões Intergestores Bipartite (CIB) integrada por representação da Secretaria Estadual de Saúde (SES) e do Conselho Estadual de Secretários Municipais de Saúde (COSEMS) são instâncias de negociação e deliberação para a realização dos pactos intraestaduais, quanto aos aspectos operacionais do SUS a partir de diretrizes e normas pactuadas na CIT.

O Pacto pela Saúde criou o Sistema de Planejamento do SUS - PlanejaSUS, que foi regulamentado inicialmente pela Portaria 3.085 de 2006, que definiu como pressupostos para sua concretização, os instrumentos básicos resultantes do planejamento, ou seja, um forma de controle para a gestão: o Plano de Saúde (PS), suas respectivas Programações Anuais de Saúde (PAS) e os Relatórios Anuais de Gestão (RAG), os quais devem ser objeto de formulação e revisão periódicas pelas três esferas de governo. Aborda em seu Art. $4^{\circ}$.:

$\S 1^{\circ}$. São instrumentos básicos do Sistema de Planejamento do SUS:

I - o Plano de Saúde e a respectiva Programação Anual em Saúde; e

II - o Relatório de Gestão.

$\S 2^{\circ}$. Estes instrumentos, em cada esfera de gestão do SUS, deverão ser compatíveis com os Planos Plurianuais (PPA), a Lei de Diretrizes Orçamentária (LDO) e a Lei Orçamentária Anual (LOA), conforme dispositivos constitucionais e legais acerca destes instrumentos.

$\S 3^{\circ}$. O Plano de Saúde é o instrumento básico que, em cada esfera, norteia a definição da Programação Anual das ações e serviços de saúde prestados, assim como da gestão do SUS. 
$\S 4^{\circ}$. O Relatório Anual de Gestão é o instrumento que apresenta os resultados alcançados e orienta eventuais redirecionamentos que se fizerem necessários. (Brasil - MS, 2006a)

Nas literaturas consultadas percebeu-se que o Pacto pela Saúde foi importante na consolidação do SUS. O pacto tornou-se um "divisor de águas" do Sistema de Saúde Brasileiro, pois a partir dele (quase vinte anos depois da criação do SUS), que foram estabelecidos os procedimentos e rotinas padrões na operacionalização dos princípios e diretrizes, e também dos indicadores para monitoramento e avaliação da saúde, com adequações, buscando uma estabilidade e continuidade dos mesmos (Guimarães \& Ribeiro, 2009; Machado, Costa, Erdmann, Albuquerque, \& Ortiga, 2009; Leles, Nicolato \& Tavares Júnior, 2010; Cabral \& Ferreira, 2014; Weiller, 2014 e Martinelli, Viana, \& Scatena, 2015).

Após o Pacto pela Saúde, algumas legislações foram relevantes na mudança da política de saúde, por meio das alterações na forma de Notas Técnicas, Portarias e Resoluções. O Pacto pela Saúde passou por alterações acerca das orientações sobre os Indicadores de Monitoramento e Avaliação do Pacto pela Saúde em 2010/2011, conforme Portarias $n^{\circ} . s 2.669$ de 2009 e 3.840 de 2010 do MS. Em 2012 ocorreu a mudança dos indicadores de transição do Pacto pela Saúde e o Contrato Organizativo da Ação Pública de Saúde (COAP), conforme Resolução CIT n no 04 de 2012. A partir de 2013 os ajustes ocorrem sobre os Indicadores Municipais do rol de Diretrizes, Objetivos, Metas e Indicadores 20132015, conforme proposto na Resolução CIT nº 05 de 2013, com reedições até 2015, vigente atualmente (Brasil - MS, 2012; Brasil -MS, 2013).

As novas publicações de legislações acerca do SUS, trouxeram alterações na condução e prestação dos serviços de saúde. O Decreto ${ }^{\circ}$. 7.508 de 28 de junho de 2011, têm o objetivo de regular a estrutura organizativa do SUS, o planejamento, a assistência e a articulação interfederativa, necessários na consolidação e melhoria permanente. $O$ decreto traz a instituição das Regiões de Saúde (RS) fortalecendo a regionalização, e em seu artigo $5^{\circ}$. diz que a RS deve conter, no mínimo, ações e serviços de saúde da atenção primária; urgência e emergência; atenção psicossocial; atenção ambulatorial especializada e hospitalar; e vigilância em saúde; abrigando as Redes de Atenção à Saúde (RAS) (Brasil - MS, 2011).

A RAS é composta por um conjunto de ações e serviços de saúde articulados em níveis de complexidade de forma crescente, para garantir a integralidade da assistência à saúde. O decreto dispõe sobre o planejamento da saúde de forma ascendente e integrada, considerando os níveis de atenção e os Conselhos de Saúde, equalizando a necessidade das 
ações e serviços em saúde, e os recursos disponíveis. A pactuação das responsabilidades dos municípios quanto às ações e serviços de saúde nas RAS, deve ser realizada nas Comissões de Intergestores (CIB e CIT) e deve estar em consonância com o Planejamento da Saúde (PS) estadual e municipal.

Outra estratégia que dá continuidade ao Pacto pela Saúde é o Contrato Organizativo da Ação Pública da Saúde (COAP), instituído também de acordo com o artigo $5^{\circ}$. do Decreto $n^{\circ}$. 7.508, de 28 de junho de 2011, e o disposto na Resolução CIT n ${ }^{\circ} .01$ de 2011, cabendo à Secretaria Estadual de Saúde (SES) de cada estado, coordenar a sua implementação. Com o objetivo de regular a estrutura organizativa do SUS, o planejamento, a assistência e a articulação interfederativa, necessários na consolidação e melhoria permanente, o decreto trouxe a instituição das Regiões de Saúde (RS). Outro objetivo do COAP é a organização e a integração das ações e serviços de saúde dos entes federativos de uma Região de Saúde (RS) em Redes de Atenção à Saúde (RAS), estabelecendo, para cada uma as responsabilidades organizativas, executivas, orçamentário-financeiras e de monitoramento, avaliação de desempenho e auditoria (Brasil - MS, 2011).

Considerando a trajetória do SUS desde a sua criação, nesses quase 30 anos, muitos foram os esforços a fim de promover a sua implantação e funcionamento. A CF de 1988 já admitia ser a saúde em uma perspectiva ampliada, um direito da população; e a universalidade, a equidade no acesso aos serviços de saúde, a integralidade das ações, o controle social e a descentralização político-administrativa; os princípios norteadores do sistema de saúde vigente no Brasil.

\subsubsection{Descentralização e Regionalização}

Segundo Falleti (2006), “A descentralização é um processo de reforma do Estado composta por um conjunto de políticas públicas que transfere responsabilidades, recursos ou autoridades de níveis mais elevados do governo para níveis inferiores, no contexto de um tipo específico de Estado.” (p. 33) O processo de descentralização se inicia com a transição de um tipo de Estado “desenvolvimentista” para um Estado do tipo "bem público".

O processo de descentralização agrega 3 categorias: a descentralização administrativa,

fiscal e política. A descentralização administrativa engloba o conjunto de políticas que transferem a administração e a provisão de serviços sociais como educação, saúde, assistência 
social e moradia aos governos subnacionais. Pode acarretar transferência da autoridade na tomada de decisões sobre essas políticas, mas não é uma condição necessária.

A descentralização fiscal se refere ao conjunto de políticas desenhadas para aumentar as receitas ou a autonomia fiscal dos governos subnacionais. Podem assumir diferentes formas institucionais, como o aumento de transferências do governo central, a criação de novos impostos subnacionais ou a delegação da autoridade para cobrar impostos. E a descentralização política é o conjunto de emendas constitucionais e de reformas eleitorais desenhadas para abrir novos espaços para a representação das sociedades subnacionais. Transfere autoridade política ou capacidades eleitorais para atores subnacionais.

No Brasil, a sequência de implantação começou com a descentralização política, na década de 1980, seguida pela descentralização fiscal em torno de 1993 e, por último, foi implantada a descentralização administrativa. A descentralização administrativa do financiamento dos serviços de saúde pública ocorreu na década de 1990 (Falleti, 2006).

Um processo descentralizador, que começa com a política, continua com a fiscal e termina com a administrativa, dá poderes aos governos subnacionais. "Isso ocorre independente do tipo de governo, das condições iniciais das estruturas institucionais... isto é, que interesses territoriais dominam em cada instância de negociação das políticas...”. (Falleti, 2006, p.51).

A atenção básica é a porta de entrada dos usuários aos serviços e ações de saúde, sendo o principal ponto de contato com o usuário e a atuação deste nível deve ter como premissa a promoção da saúde e a prevenção / manutenção do estado de saúde. É o nível de atenção com maior capacidade de influir nos indicadores de saúde e de garantir o acesso universal aos serviços que efetivamente geram benefícios para a saúde da população. É fundamental que também seja orientada "pelos princípios da universalidade, da acessibilidade, do vínculo, da continuidade do cuidado, da integralidade da atenção, da responsabilização, da humanização, da equidade e da participação social” (Brasil, 2012).

A primazia pela atenção básica é percebida em políticas do governo federal, tais como: a Política Nacional de Atenção Básica (PNAB) normatizada pela Portaria nº. 648/2006, que determinou a revisão de diretrizes e normas para a organização da Atenção Básica para o Programa Saúde da Família (PSF) e para o Programa Agentes Comunitários de Saúde (PACS) e a Política Nacional de Promoção da Saúde (PNPS), que vislumbra a implantação de diretrizes e ações para promoção da saúde alinhada aos princípios do SUS (Brasil, 2006b). 
Uma forma de verificar o impacto na saúde é por meio de indicadores sociais, que conforme Jannuzzi (2005) representam uma avaliação diagnóstica ganhando cada vez mais relevância nas políticas públicas.

A hierarquização ocorre no âmbito dos procedimentos e dos prestadores. O Decreto Federal no. 7508, de 2011, em seu artigo $8^{\circ}$. dispõe que o "acesso universal ... se inicia pelas Portas de Entrada do SUS e se completa na rede regionalizada e hierarquizada, de acordo com a complexidade do serviço" ( Brasil, 2012). Neste sentido, os procedimentos são organizados em níveis de atenção (ou de complexidade tecnológica) nas categorias: atenção primária, média e alta complexidade; e os prestadores de serviços podem ser hierarquizados em unidades primárias (postos de saúde, ambulatórios), secundárias (hospitais simples) e terciárias (hospitais especializados).

A regulamentação adotada pela Portaria $n^{0}$. 399/2006 representou um avanço, porque fortaleceu a estratégia de regionalização e definiu o papel dos estados, aumentando suas responsabilidades em um sistema regional em desenvolvimento. A Regionalização é uma diretriz do SUS e um eixo estruturante do Pacto de Gestão e deve orientar a descentralização das ações e serviços de saúde e os processos de negociação e pactuação entre os gestores.

No Plano Diretor de Regionalização (PDR) introduzido pela mesma portaria, tem-se que uma região de saúde é um conjunto de municípios periféricos a um polo. A regionalização da assistência no âmbito do SUS é hierarquizada da seguinte forma: os municípios são agrupados em regiões de saúde (microrregiões) que compõem as regiões ampliadas (macrorregiões) de saúde. O PDR em vigência em Minas Gerais divide o estado em 77 regiões de saúde distribuídas em 13 regiões ampliadas de saúde.

Também consta no PDR que cada nível de atenção deve corresponder a um nível de regionalização. O conjunto de procedimentos da atenção básica é ofertado a nível municipal. A atenção secundária é ofertada em hospitais e ambulatórios que prestam assistência nas especialidades básicas, serviços de urgência e emergência; que são as áreas de saúde responsáveis pela oferta desses serviços, organizados no âmbito das RS. A atenção terciária integrada pelos serviços especializados, ofertada em hospitais mais complexos, normalmente sediados em municípios-polo das Regiões Ampliadas de Saúde ou macrorregiões; que normalmente englobam os procedimentos de maior custo, com alta tecnologia e recursos humanos especializados.

$\mathrm{Na}$ organização de serviços, as regiões-polo devem responder por referência e 
cobertura intermunicipal ou inter-regional. A distribuição espacial dos serviços é dimensionada de acordo com as necessidades de cada nível: regional, municipal, micro ou macrorregional, tendo a economia de escala como princípio norteador.

Neste sentido a regionalização deve ser entendida como uma articulação que leve em consideração as características geográficas, fluxo de demanda, perfil epidemiológico, oferta de serviços e, a vontade política expressa pelos diversos municípios da região de se consorciar ou estabelecer relação de caráter cooperativo. A regionalização têm os objetivos de garantir acesso, resolutividade e qualidade às ações e serviços de saúde; reduzir desigualdades sociais e territoriais e promover a eqüidade; garantir a integralidade na atenção a saúde, potencializar o processo de descentralização, fortalecendo estados e municípios para exercerem papel de gestores e racionalizar os gastos e otimizar os recursos, possibilitando ganho em escala nas ações e serviços de saúde de abrangência regional (Brasil - Conselho Nacional de Secretários de Saúde - CONASS, 2011).

A região de saúde pode ser entendida como:

\footnotetext{
"a base territorial de planejamento da atenção à saúde, não necessariamente coincidente com a divisão administrativa do estado, a ser definida pela Secretaria de Estado da Saúde, de acordo com as especificidades e estratégias de regionalização da saúde em cada estado, considerando as características demográficas, sócio-econômicas, geográficas, sanitárias, epidemiológicas, oferta de serviços, relações entre municípios, entre outras. Dependendo do modelo de regionalização adotado, um estado pode se dividir em regiões e/ou microrregiões de saúde. Por sua vez, a menor base territorial de planejamento regionalizado, seja uma região ou uma microrregião de saúde, pode compreender um ou mais módulos assistenciais" (Brasil - Conselho Nacional de Secretários de Saúde - CONASS, 2011).
}

Em seu estudo sobre a atenção básica na saúde brasileira, Bodstein (2002, p.7) explicita que a descentralização dos serviços de saúde foi acelerada a partir da NOB 01/96, que determinou medidas de municipalização, com efetiva vigência a partir de 1998.

\subsubsection{Estudos Anteriores - Descentralização Fiscal e Administrativa}

Pode-se considerar que o processo de descentralização no setor saúde é o item que impulsionou o questionamento deste estudo. Nesta seção, são apresentados, em ordem cronológica, os estudos empíricos, que abordam a descentralização nos serviços públicos, no setor saúde que evidenciam a importância da política pública no mundo e no Brasil, na última década. 
Habibi et al. (2003) analisaram o impacto da descentralização fiscal na saúde e educação e a relação entre a descentralização fiscal e o desenvolvimento humano. Utilizaram dados em painel de 23 províncias, por um período de 25 anos (1970-1994), e uma transição de governo. Utilizaram como indicadores de desenvolvimento humano a TMI e a retenção do ensino primário para o ensino secundário. Os resultados indicam que os recursos e a participação das províncias foram restringidos no governo militar, tendência que se inverteu com o retorno ao regime democrático. Houve redução na TMI e aumento na educação após a transição democrática. A autonomia das províncias reduziu as disparidades regionais e aumentou significativamente os níveis de desenvolvimento humano em todas as regiões de baixa e alta renda.

Os autores argumentam que os resultados indicam os efeitos positivos da gestão sobre o desenvolvimento humano e a importância da responsabilidade democrática para o sucesso da descentralização. Os efeitos da descentralização administrativa sobre o desenvolvimento humano tende a ser mais forte com os recursos locais, pois as receitas fiscais recolhidas nas províncias induzem a uma maior responsabilidade local.

O estudo de Akin, Hutchinson e Strumpf (2005) analisou se a descentralização realmente leva a uma maior eficiência alocativa do setor da saúde. Os autores utilizaram dados dos distritos de Uganda, no período entre 1995-1998. Os dados são os gastos médios por função que constam nos orçamentos dos governos locais para o setor saúde. Os resultados evidenciam proporções menores dos orçamentos locais para as atividades de bens públicos, favorecendo a hipótese de que há um impacto negativo da descentralização na provisão de bens públicos. Os distritos descentralizados há mais tempo, indicam uma maior autonomia.

Segundo os autores, a tendência para maior democratização em muitas regiões do mundo, significa maior descentralização das responsabilidades na alocação de recursos para a saúde nos níveis inferiores de governo, cujas motivações e capacidades podem diferir daquelas dos governos centrais. Observam sobre a necessidade de maior controle das despesas e orçamentos nos níveis subnacionais do governo, relacionados com perfis epidemiológicos e os custos da prestação de serviços.

A pesquisa de Qi (2007) investigou os efeitos da descentralização fiscal nos resultados de saúde, analisados em duas dimensões: estado de saúde, composto pelas taxas: número de médicos e número de leitos por 1000 habitantes urbanos e taxa de mortalidade (TM); e a igualdade de saúde (equidade), composta pela razão das taxas (médicos e leitos), da população urbana sobre a população rural, calculadas nas mesmas bases. O autor utilizou 
dados em painel de 31 províncias chinesas no período de 2002-2006 e encontrou que a descentralização fiscal afetou os resultados de saúde: aumento da renda individual e menor produtividade do setor da saúde. O resultado mostrou que a descentralização fiscal é prejudicial ao estado de saúde, mas ajuda a reduzir as desigualdades na saúde (equidade). O desenvolvimento econômico, a urbanização e o nível de educação superior podem melhorar o estado de saúde.

Cantarero e Pascual (2008) investigaram o impacto da descentralização nos resultados de saúde, com a hipótese de que uma maior descentralização na saúde seria acompanhada por melhorias na saúde da população da Espanha. Utilizaram dados em painel no período entre 1992 e 2003, utilizando a mortalidade infantil e a expectativa de vida como variáveis dependentes. A análise empírica sugere que a mortalidade infantil está negativamente relacionada à renda per capita, à descentralização da saúde e ao número de médicos de clínica geral. Descentralização nestas regiões está associada com a efetividade da política pública em melhorar a saúde da população (redução dos índices de mortalidade infantil). Por outro lado, os resultados mostram que a renda per capita, a descentralização da saúde, o número de leitos e o número de clínicos gerais, estão positivamente relacionados à expectativa de vida. Neste caso, a descentralização está associada a uma maior expectativa de vida.

Em seu trabalho, Uchimura e Jütting (2009) analisaram o efeito da descentralização fiscal em resultados de saúde de 26 províncias da China, no período de 1995-2001, utilizando a TMI, e os resultados de saúde em um painel de dados de efeitos fixos. As províncias mais descentralizadas têm taxas de mortalidade infantil mais baixas do que as províncias que são a principal autoridade nos gastos. As transferências intergovernamentais para as províncias e sua autonomia fiscal são primordiais para alcançar os resultados de saúde desejados. Os autores defendem a descentralização como um meio para melhorar a eficiência e a equidade na prestação de serviços públicos, como a saúde. Em geral, os resultados confirmam os achados de outros países de que a descentralização fiscal pode de fato ajudar a reduzir as taxas de mortalidade infantil.

Com foco nos gastos públicos, o artigo de Alegre (2010) analisa os efeitos da descentralização fiscal sobre a distribuição econômica dos gastos públicos, usando dados em painel de 17 regiões espanholas entre 1984-2003. A hipótese testada é que as regiões com um maior nível de autonomia gastam uma parcela maior do seu orçamento em despesas correntes. A variável dependente é a relação entre as despesas de capital para o total das despesas públicas dos governos regionais. O nível de descentralização é construído como a relação da 
despesa regional per capita para as despesas da administração central per capita. Os resultados são robustos para as análises de sensibilidade que foram executadas: a descentralização é um fator crucial para explicar a proporção das despesas públicas a nível regional. Regiões descentralizadas dedicam uma parcela menor de seu orçamento ao capital público, em contraste com a despesa corrente pública.

Jiménez-Rubio (2011a) analisou o impacto da descentralização fiscal em serviços de saúde em relação ao bem estar e as melhorias na saúde da população, por meio de dados em painel em 10 províncias canadenses durante o período de 1979 a 1995. A TMI é a variável dependente, sendo as variáveis explicativas: renda per capita da província; subsídios em saúde per capita do governo; gastos per capita em saúde a nível federal e municipal; gastos privados em saúde per capita; nível educacional; quantidade de mulheres fumantes; proporção de crianças recém-nascidas com baixo peso; e criou um indicador de descentralização fisscal em saúde. Os resultados obtidos no painel indicam que o aumento em torno de $1 \%$ na descentralização fiscal está associado a uma redução em torno de $10 \%$ na taxa de mortalidade infantil. Assim, há uma relação positiva e significante entre descentralização fiscal em saúde com a melhoria da qualidade de saúde da população. Os resultados sugerem que a descentralização no Canadá teve uma influência positiva e significativa sobre a eficácia das políticas públicas para melhorar a saúde da população. Outros fatores que influenciaram o estado de saúde foram os gastos com saúde e educação do governo federal. O impacto econômico das despesas de saúde e educação é, no entanto, muito menor do que a encontrada para a descentralização.

A pesquisa de Jiménez-Rubio, Cantarero-Prieto e Pascual-Sáez (2011) utilizou um indicador de descentralização fiscal melhorado, construído por Stegarescu em 2005, em dados em painel de 19 países da Organisation for Economic Co-operation and Development (OECD) para testar a hipótese de que maior descentralização leva a melhores resultados de saúde. O Indicador de descentralização de Stegarescu mede a parcela de impostos do governo local sobre o governo geral, mas considera apenas os impostos que o governo local controla. Os resultados sugerem que a descentralização teve uma influência positiva e significativa sobre a eficácia das políticas públicas, melhorando a saúde da população (redução das taxas de mortalidade infantil). Este trabalho analisa somente a descentralização fiscal, e até o momento não há nenhuma medida única que capta todas as múltiplas dimensões do processo de descentralização. Embora a TMI seja superior a indicadores alternativos, como expectativa de vida; não reflete plenamente o nível subjacente da saúde em uma sociedade. 
Ferrario e Zanardi, (2011) exploram como as pressões para uma maior descentralização das competências fiscais para os governos subnacionais podem afetar o grau de redistribuição de renda entre os territórios regionais realizados pelo Sistema Nacional de Saúde (SNS) italiano. Na Itália, as responsabilidades políticas de cuidados de saúde são descentralizadas para os governos regionais, mas o governo central mantém um papel fundamental para garantir a todos os cidadãos o acesso uniforme aos serviços de saúde. Usando dados em painel para o período de1999-2006 descobriu-se que as receitas e despesas do SNS reduzem as diferenças regionais em termos de PIB per capita em cerca de 7\%. A reforma dos SNS em termos de redução dos padrões de despesa enfraquece a redistribuição entre jurisdições e depende crucialmente das modalidades de financiamento dos cuidados de saúde adotados. Os autores concluíram que a descentralização do SNS daria origem a questões políticas relevantes, as diferentes possibilidades de gastos de saúde entre as regiões e o impacto sobre a mobilidade inter-regional dos pacientes.

A redução de despesas dá origem a uma diferenciação das possibilidades de cuidados de saúde e gastos em todas as regiões: regiões mais pobres teriam recursos nada mais do que para os padrões de despesas, enquanto os mais ricos seriam capazes de gastar acima dos níveis atuais. Como os padrões de gastos são reduzidos e as regiões mais pobres não podem pagar mais, um aumento da procura e a mobilidade inter-regional dos pacientes é provável. Neste caso, as regiões fora de fluxo podem coletar recursos para financiar as compensações para as regiões de fluxo, para dificultar a mobilidade inter-regional, ou entrar em déficit esperando um socorro do governo central.

Outro estudo Jiménez-Rubio (2011b) reexamina a hipótese de que uma maior descentralização seria acompanhada por melhorias na saúde da população em um painel de 20 países da OECD durante um período de 30 anos (1970-2001). Os resultados mostram um efeito considerável e positivo da descentralização fiscal sobre a mortalidade infantil, somente se um elevado grau de autonomia nas fontes de receita seja transferida para os governos locais. A proporção de despesas de saúde no PIB e em particular, a educação, foram encontrados por ter uma maior contribuição para a redução da mortalidade infantil na amostra de países da OECD analisados ao longo do período de estudo. O artigo assemelha-se ao estudo de Jiménez-Rubio (2011a).

O artigo de Fritscher e Zamora (2012) estuda o impacto da descentralização da saúde, do financiamento e responsabilidades que teve lugar no México, em 1997, sobre os resultados do nível de saúde estaduais. Os resultados empíricos dos dados em painel sugerem que a 
descentralização de saúde no México não teve os efeitos desejados sobre a saúde a nível de estado. Não encontraram fortes evidências de que as despesas após a reforma possam explicar a melhoria nos indicadores de saúde, como a mortalidade infantil ou as taxas de mortalidade fetal. A descentralização não impulsionou os avanços nos resultados da saúde já alcançados no âmbito do regime centralizado do setor da saúde. Uma explicação está relacionada com controles que os estados têm ao gastar recursos públicos, a capacidade dos contribuintes de saber quão eficiente seu dinheiro está sendo gasto e da disponibilidade de mecanismos de prestação de contas.

O estudo de Soto e Lorant (2012) analisa a distribuição espacial e temporal das taxas de mortalidade infantil na Colômbia antes e depois da concessão de maiores responsabilidades aos municípios para a gestão dos seus sistemas de saúde locais. Usaram dados em painel para 1080 municípios no período de 1998-2007. Os resultados indicam que há uma concentração espacial da TMI que persiste ao longo do tempo e define dois grupos de municípios com níveis de mortalidade que se opõem. Os municípios do centro do país mostram taxas baixas, enquanto aqueles na periferia têm taxas elevadas. $\mathrm{O}$ bairro contribui sensivelmente para distribuição espacial da TMI, e a concentração é explicada pelo acesso das famílias aos serviços básicos e pelas condições socioeconômicas do município e sua área vizinha. Quanto à TMI que não reduziu, os autores justificam que o contexto local adverso pode limitar a capacidade das autoridades para agir. Esforços devem ser feitos a fim de reduzir as desigualdades socioeconômicas entre os municípios antes de conceder-lhes responsabilidades administrativas. Políticas de descentralização de saúde devem ter em conta o contexto local, a fim de melhorar os resultados que poderiam ser alcançados por meio da aplicação deste tipo de estratégia de gestão.

Na pesquisa de Samadi et al. (2013), a descentralização fiscal é considerada um meio de melhorar a eficiência e a equidade na prestação de bens públicos, tais como serviços de saúde. Neste estudo, examinou-se o efeito da descentralização fiscal em Universidades Médicas e descentralização fiscal das províncias sobre a taxa de mortalidade de menores de cinco anos do Irã no período entre 2007 e 2010. Os resultados dos dados em painel mostram que a descentralização fiscal no setor da saúde teve um impacto negativo sobre a taxa de mortalidade de menores de cinco anos. Por outro lado, a descentralização fiscal das províncias tiveram um impacto positivo sobre taxa de mortalidade de menores de cinco anos. Além disso, a taxa de mortalidade de menores de cinco anos teve uma associação negativa com a 
densidade de médicos, leitos hospitalares e o PIB per capita da província, mas uma relação positiva com o coeficiente de Gini e do desemprego.

O estudo de Javed e Qaden (2013) explora a associação entre a descentralização fiscal e a expectativa de vida no Paquistão. A abordagem de dados em painel detectou a relação entre a expectativa de vida e a descentralização fiscal durante o período de 1990-2010. Os resultados sugerem que há associação positiva entre a descentralização fiscal e a expectativa de vida. A expectativa de vida está positivamente relacionada com a renda per capita, o número de médicos, o número de hospitais e parteiras. Se o governo gasta mais em percentagem do PIB no setor da saúde, ocorre também a melhoria da saúde.

No Brasil, Cerchiari (2011) analisou o processo de descentralização da gestão do SUS, sobre o desempenho da saúde. Foram utilizados os indicadores de saúde como a taxa de acesso da população ao SUS, a taxa de internação por doenças infecciosas e parasitárias, a TMI de até um ano de idade e também até cinco anos de idade, e um índice de desempenho do setor (IDS) que é um indicador único de saúde, representado por meio da média ponderada dos quatro indicadores citados. Os resultados estimados por painel de efeitos fixos, com dados anuais de 2000 a 2009 dos municípios brasileiros, obtidos no site do DATASUS indicam que a descentralização fiscal têm uma tendência de impacto positivo sobre o desempenho do setor saúde.

Gadelha (2011) também analisou o impacto da descentralização fiscal nos resultados da saúde pública no Brasil. Verificou a relação entre descentralização fiscal e a taxa de mortalidade infantil nos municípios brasileiros, utilizando dados em painel estático para o período 2000-2009. Há relação entre as variáveis analisadas com a premissa de que o resultado da saúde pública local depende do nível de desempenho econômico, como a renda per capita e a implantação eficaz da descentralização fiscal na comunidade local. A hipótese é que a descentralização fiscal pode melhorar os resultados da saúde pública, uma vez que as autoridades locais conhecem bem os problemas locais e, consequentemente, podem alocar os recursos de maneira eficiente do que as autoridades públicas em um nível regional ou central. Os resultados obtidos do painel estático com modelo de efeitos fixos sugerem que a TMI é negativamente relacionada à renda per capita, à descentralização fiscal, aos gastos em saúde e em educação e ao número de doses de vacinas aplicadas.

O quadro 1 resume os objetivos, indicadores, técnicas e principais conclusões das pesquisas descritas, abordando o contexto da descentralização fiscal e da saúde, desenvolvidas no exterior e no Brasil. 


\begin{tabular}{|c|c|c|c|c|}
\hline $\begin{array}{l}\text { Autoria/Ano } \\
\text { País/Período }\end{array}$ & Objetivos & Indicadores & Técnicas & Resultados \\
\hline $\begin{array}{l}\text { Habibi et al. } \\
(2003)\end{array}$ & $\begin{array}{l}\text { Verificar o impacto } \\
\text { da descentralização } \\
\text { sobre o } \\
\text { desenvolvimento } \\
\text { humano em } \\
\text { províncias } \\
\text { argentinas. }\end{array}$ & $\begin{array}{l}\text { TMI, } \\
\text { Proporção de } \\
\text { matrículas, } \\
\text { PIB per capita, } \\
\text { Despesas per capita. }\end{array}$ & $\begin{array}{l}\text { Dados em } \\
\text { painel. }\end{array}$ & $\begin{array}{l}\text { Restrição da participação das províncias no } \\
\text { governo militar; } \\
\text { Redução da TMI na democracia; } \\
\text { Aumento na educação na democracia; } \\
\text { Autonomia das províncias reduziu } \\
\text { disparidades regionais e aumentou o nível } \\
\text { de desenvolvimento humano. }\end{array}$ \\
\hline $\begin{array}{l}\text { Akin, } \\
\text { Hutchinson } \\
\text { and Strumpf } \\
(2005)\end{array}$ & $\begin{array}{l}\text { Analisar se a } \\
\text { descentralização } \\
\text { leva a uma maior } \\
\text { eficiência alocativa } \\
\text { do setor da saúde, } \\
\text { nos distritos de } \\
\text { Uganda. } \\
\end{array}$ & $\begin{array}{l}\text { Gastos médios na } \\
\text { saúde nos } \\
\text { orçamentos dos } \\
\text { governos locais. }\end{array}$ & $\begin{array}{l}\text { Regressão } \\
\text { Mínimos } \\
\text { Quadrado } \\
\text { s } \\
\text { Ordinários } \\
\text { (MQO). }\end{array}$ & $\begin{array}{l}\text { Proporções menores dos orçamentos locais } \\
\text { para as atividades de bens públicos, } \\
\text { favorecendo a hipótese de impacto negativo } \\
\text { de descentralização na provisão de bens } \\
\text { públicos; } \\
\text { Maior autonomia dos distritos } \\
\text { descentralizados há mais tempo. }\end{array}$ \\
\hline Qi (2007) & $\begin{array}{l}\text { Investigar os efeitos } \\
\text { da descentralização } \\
\text { fiscal em resultados } \\
\text { de saúde em } \\
\text { províncias da China. }\end{array}$ & $\begin{array}{l}\mathrm{N}^{\circ} \text {. de médicos e } \mathrm{n}^{\circ} \text {. } \\
\text { de leitos - urbanos e } \\
\text { rurais, Taxa de } \\
\text { mortalidade, Taxa } \\
\text { de analfabetismo, } \\
\text { PIB per capita. }\end{array}$ & $\begin{array}{l}\text { Dados em } \\
\text { painel: } \\
\text { efeitos } \\
\text { fixos e } \\
\text { aleatórios. }\end{array}$ & $\begin{array}{l}\text { Descentralização fiscal aumentou a renda } \\
\text { individual e reduziu a produtividade do } \\
\text { setor saúde; } \\
\text { Descentralização da saúde trouxe melhorias } \\
\text { para a saúde, mas pode ser prejudicial à } \\
\text { equidade. }\end{array}$ \\
\hline $\begin{array}{l}\text { Cantarero and } \\
\text { Pascual } \\
(2008)\end{array}$ & $\begin{array}{l}\text { Investigar o impacto } \\
\text { da descentralização } \\
\text { sobre resultados da } \\
\text { saúde na Espanha. }\end{array}$ & $\begin{array}{l}\text { TMI, Expectativa de } \\
\text { vida, Renda per } \\
\text { capita, } \mathrm{N}^{\circ} \text {. de leitos, } \\
\mathrm{N}^{\circ} \text {. clínicos geral. }\end{array}$ & $\begin{array}{l}\text { Dados em } \\
\text { painel: } \\
\text { efeitos } \\
\text { fixos e } \\
\text { aleatórios. }\end{array}$ & $\begin{array}{l}\text { A renda per capita, a descentralização e os } \\
\text { cuidados de saúde ( } \mathrm{n}^{\circ} \text {. de médicos), tiveram } \\
\text { uma influência relevante sobre a TMI e a } \\
\text { expectativa de vida. }\end{array}$ \\
\hline $\begin{array}{l}\text { Uchimura } \\
\text { and } \\
\text { Jütting (2009) }\end{array}$ & $\begin{array}{l}\text { Analisar a relação } \\
\text { entre uma maior } \\
\text { descentralização e } \\
\text { os indicadores de } \\
\text { saúde em províncias } \\
\text { da China. }\end{array}$ & $\begin{array}{l}\text { TMI, PIB per } \\
\text { capita, Despesa total } \\
\text { país para despesa } \\
\text { total província, } \\
\text { Taxa analfabetismo, } \\
\text { Taxa de fertilidade. }\end{array}$ & $\begin{array}{l}\text { Dados em } \\
\text { painel. }\end{array}$ & $\begin{array}{l}\text { As províncias mais descentralizadas } \\
\text { reduziram as TMI, } \\
\text { As transferências intergovernamentais para } \\
\text { as províncias e sua autonomia são } \\
\text { primordiais para alcançar os resultados na } \\
\text { saúde. }\end{array}$ \\
\hline $\begin{array}{l}\text { Alegre } \\
(2010)\end{array}$ & $\begin{array}{l}\text { Analisar os efeitos } \\
\text { da descentralização } \\
\text { fiscal sobre os } \\
\text { gastos públicos em } \\
\text { regiões da Espanha. }\end{array}$ & $\begin{array}{l}\text { Razão entre } \\
\text { despesas de capital } \\
\text { para o total de } \\
\text { despesas públicas } \\
\text { regionais. }\end{array}$ & $\begin{array}{l}\text { Dados em } \\
\text { painel. }\end{array}$ & $\begin{array}{l}\text { A descentralização é um fator relevante } \\
\text { para explicar a proporção das despesas } \\
\text { públicas a nível regional, } \\
\text { Regiões descentralizadas tem uma parcela } \\
\text { menor de seu orçamento em contraste com } \\
\text { a despesa corrente pública. }\end{array}$ \\
\hline $\begin{array}{l}\text { Jimenz-Rubio } \\
\text { (2011) }\end{array}$ & $\begin{array}{l}\text { Analisar o impacto } \\
\text { da descentralização } \\
\text { fiscal em relação às } \\
\text { melhorias da saúde } \\
\text { da população em } \\
\text { províncias do } \\
\text { Canadá. }\end{array}$ & $\begin{array}{l}\text { TMI, Renda per } \\
\text { capita, Gastos per } \\
\text { capita em saúde, } \\
\text { Nível educacional, } \\
\text { Mulheres fumantes, } \\
\text { Indicador de } \\
\text { descentralização } \\
\text { fiscal em saúde. }\end{array}$ & $\begin{array}{l}\text { Dados em } \\
\text { painel. }\end{array}$ & $\begin{array}{l}\text { O aumento em torno de } 1 \% \text { na } \\
\text { descentralização fiscal está associado a uma } \\
\text { redução em torno de } 10 \% \text { na TMI. } \\
\text { Relação positiva entre descentralização } \\
\text { fiscal em saúde com a melhoria da } \\
\text { qualidade de saúde da população. } \\
\text { Outros fatores que influenciaram o estado } \\
\text { de saúde foram os gastos com saúde e } \\
\text { educação do governo federal. }\end{array}$ \\
\hline $\begin{array}{l}\text { Jimenz-Rubio, } \\
\text { Cantarero- } \\
\text { Prieto e } \\
\text { Pascual-Saez } \\
\text { (2011) }\end{array}$ & $\begin{array}{l}\text { Analisar se maior } \\
\text { descentralização } \\
\text { leva a melhores } \\
\text { resultados de saúde } \\
\text { em } 19 \text { países da } \\
\text { OECD. }\end{array}$ & $\begin{array}{l}\text { TMI, PIB per } \\
\text { capita, Consumo de } \\
\text { álcool e fumo, nível } \\
\text { educacional e } \\
\text { Indicador de } \\
\text { descentralização. }\end{array}$ & $\begin{array}{l}\text { Dados em } \\
\text { painel. }\end{array}$ & $\begin{array}{l}\text { Os resultados sugerem que a } \\
\text { descentralização teve uma influência } \\
\text { positiva e significativa sobre a eficácia das } \\
\text { políticas públicas, melhorando a saúde da } \\
\text { população (redução das taxas de } \\
\text { mortalidade infantil). }\end{array}$ \\
\hline $\begin{array}{l}\text { Ferrario e } \\
\text { Zanardi } \\
(2011)\end{array}$ & $\begin{array}{l}\text { Analisar se maior } \\
\text { descentralização } \\
\text { afeta o grau de } \\
\text { redistribuição de } \\
\text { renda realizado pelo } \\
\text { Sistema Nacional de } \\
\text { Saúde italiano. }\end{array}$ & $\begin{array}{l}\text { Receitas e despesas } \\
\text { do sistema de saúde } \\
\text { nacional (SNS), } \\
\text { PIB per capita. }\end{array}$ & $\begin{array}{l}\text { Dados em } \\
\text { painel. }\end{array}$ & $\begin{array}{l}\text { As receitas e despesas do SSN reduzem as } \\
\text { diferenças regionais em termos de PIB per } \\
\text { capita em cerca de } 7 \% \text {. } \\
\text { A descentralização do SNS dá origem a } \\
\text { questões políticas relevantes, as diferentes } \\
\text { possibilidades de gastos de saúde entre as } \\
\text { regiões e o impacto sobre a mobilidade } \\
\text { inter-regional dos pacientes. }\end{array}$ \\
\hline $\begin{array}{l}\text { Jimenz-Rubio } \\
\text { (2011b) }\end{array}$ & $\begin{array}{l}\text { Reexaminar se } \\
\text { maior } \\
\text { descentralização }\end{array}$ & $\begin{array}{l}\text { TMI, } \\
\text { Renda per capita, } \\
\text { Despesas de saúde, }\end{array}$ & $\begin{array}{l}\text { Dados em } \\
\text { painel. }\end{array}$ & $\begin{array}{l}\text { Efeito positivo da descentralização fiscal } \\
\text { sobre a mortalidade infantil, com a } \\
\text { autonomia para os governos locais. }\end{array}$ \\
\hline
\end{tabular}




\begin{tabular}{|c|c|c|c|c|}
\hline & $\begin{array}{l}\text { seria acompanhada } \\
\text { por melhorias na } \\
\text { saúde da população } \\
\text { de } 20 \text { países da } \\
\text { OECD. } \\
\end{array}$ & $\begin{array}{l}\text { Consumo álcool e } \\
\text { fumo, } \\
\text { Nível educacional. }\end{array}$ & & $\begin{array}{l}\text { A proporção de despesas de saúde no PIB e } \\
\text { em particular, a educação, contribuíram } \\
\text { para a redução da mortalidade infantil na } \\
\text { amostra de países da OECD analisados ao } \\
\text { longo do período de estudo. }\end{array}$ \\
\hline $\begin{array}{l}\text { Fritscher e } \\
\text { Zamora } \\
(2012)\end{array}$ & $\begin{array}{l}\text { Analisar o impacto } \\
\text { da descentralização } \\
\text { da saúde sobre os } \\
\text { resultados do nível } \\
\text { de saúde estaduais } \\
\text { do México. }\end{array}$ & $\begin{array}{l}\text { TMI, } \\
\text { Taxa de mortalidade } \\
\text { fetal. }\end{array}$ & $\begin{array}{l}\text { Dados em } \\
\text { painel. }\end{array}$ & $\begin{array}{l}\text { A descentralização não teve os efeitos } \\
\text { desejados sobre a saúde nos estados, } \\
\text { As despesas não explicam a melhoria nos } \\
\text { indicadores de saúde, como a mortalidade } \\
\text { infantil ou mortalidade fetal. } \\
\text { A descentralização não impulsionou os } \\
\text { avanços nos resultados da saúde já } \\
\text { alcançados no âmbito do regime } \\
\text { centralizado do setor da saúde. }\end{array}$ \\
\hline $\begin{array}{l}\text { Soto e Lorant } \\
(2012)\end{array}$ & $\begin{array}{l}\text { Analisar as TMI } \\
\text { antes e depois da } \\
\text { concessão de } \\
\text { responsabilidades } \\
\text { aos municípios } \\
\text { colombianos para a } \\
\text { gestão dos seus } \\
\text { sistemas de saúde } \\
\text { locais. }\end{array}$ & $\begin{array}{l}\text { TMI, } \\
\text { Fatores } \\
\text { demográficos e } \\
\text { socioeconômicos }\end{array}$ & $\begin{array}{l}\text { Regressão } \\
\text { MQO }\end{array}$ & $\begin{array}{l}\text { Há uma concentração espacial da TMI que } \\
\text { define dois grupos de municípios com } \\
\text { níveis de mortalidade que se opõem. Os } \\
\text { municípios do centro do país mostram taxas } \\
\text { baixas, enquanto aqueles na periferia têm } \\
\text { taxas elevadas. } \\
\text { O bairro contribui para distribuição espacial } \\
\text { da TMI, e é explicada pelo acesso das } \\
\text { famílias aos serviços básicos e pelas } \\
\text { condições socioeconômicas. }\end{array}$ \\
\hline $\begin{array}{l}\text { Samadi et al. } \\
\text { (2013) }\end{array}$ & $\begin{array}{l}\text { Analisar a relação } \\
\text { entre } \\
\text { descentralização } \\
\text { fiscal e a eficiência } \\
\text { e equidade nos } \\
\text { serviços de saúde do } \\
\text { Irã. }\end{array}$ & $\begin{array}{l}\text { TMI, } \\
\text { TMI }<5 \text { anos, } \\
\text { Gini, } \\
\text { PIB per capita. }\end{array}$ & $\begin{array}{l}\text { Dados em } \\
\text { painel. }\end{array}$ & $\begin{array}{l}\text { Descentralização fiscal no setor da saúde } \\
\text { teve um impacto negativo sobre a taxa de } \\
\text { mortalidade de menores de cinco anos, } \\
\text { A taxa de mortalidade de menores de cinco } \\
\text { anos teve uma associação positiva com o } \\
\text { coeficiente de Gini e do desemprego. }\end{array}$ \\
\hline $\begin{array}{l}\text { Javed e Qaden } \\
\text { (2013) }\end{array}$ & $\begin{array}{l}\text { Explorar a } \\
\text { associação entre a } \\
\text { descentralização } \\
\text { fiscal e a } \\
\text { expectativa de vida } \\
\text { no Paquistão. }\end{array}$ & $\begin{array}{l}\text { Expectativa de vida, } \\
\text { Renda per capita, } \\
\mathrm{N}^{\circ} \text {. de médicos, } \\
\mathrm{N}^{\circ} \text { de hospitais; } \\
\mathrm{N}^{\circ} \text { de parteiras. }\end{array}$ & $\begin{array}{l}\text { Dados em } \\
\text { painel. }\end{array}$ & $\begin{array}{l}\text { Há associação entre a descentralização } \\
\text { fiscal e a expectativa de vida (positiva). } \\
\text { A expectativa de vida está positivamente } \\
\text { relacionada com a renda per capita, o } \\
\text { número de médicos, de hospitais e } \\
\text { parteiras. Se o governo gasta mais \% do } \\
\text { PIB no setor saúde, ocorre também a } \\
\text { melhoria da saúde. }\end{array}$ \\
\hline $\begin{array}{l}\text { Cerchiari } \\
(2011)\end{array}$ & $\begin{array}{l}\text { Analisar o processo } \\
\text { descentralização do } \\
\text { SUS sobre o } \\
\text { desempenho da } \\
\text { saúde nos } \\
\text { municípios } \\
\text { brasileiros. }\end{array}$ & $\begin{array}{l}\text { Taxas de acesso e } \\
\text { de internação por } \\
\text { doenças infecciosas, } \\
\text { TMI e um índice de } \\
\text { desempenho setor. }\end{array}$ & $\begin{array}{l}\text { Dados em } \\
\text { painel. }\end{array}$ & $\begin{array}{l}\text { Os resultados estimados indicam que a } \\
\text { descentralização fiscal têm uma tendência } \\
\text { de impacto positivo sobre o desempenho do } \\
\text { setor saúde. }\end{array}$ \\
\hline $\begin{array}{l}\text { Gadelha } \\
\text { (2011) }\end{array}$ & $\begin{array}{l}\text { Analisar o impacto } \\
\text { da descentralização } \\
\text { fiscal nos resultados } \\
\text { de saúde pública } \\
\text { nos municípios } \\
\text { brasileiros. }\end{array}$ & $\begin{array}{l}\text { TMI, PIB per } \\
\text { capita, Gasto } \\
\text { municipal em saúde, } \\
\text { Gasto municipal em } \\
\text { educação, } \mathrm{N}^{\circ} \text {. de } \\
\text { doses de vacina, } \\
\text { Índice de } \\
\text { descentralização } \\
\text { fiscal. }\end{array}$ & $\begin{array}{l}\text { Dados em } \\
\text { painel. }\end{array}$ & $\begin{array}{l}\text { Há relação entre as variáveis e o resultado } \\
\text { da saúde pública local depende do nível de } \\
\text { desempenho econômico, como renda per } \\
\text { capita e implantação eficaz da } \\
\text { descentralização fiscal local. } \\
\text { Os resultados sugerem que a TMI é } \\
\text { negativamente relacionada à renda per } \\
\text { capita, à descentralização fiscal, aos gastos } \\
\text { em saúde e em educação e ao número de } \\
\text { doses de vacinas aplicadas. }\end{array}$ \\
\hline
\end{tabular}

Quadro 1 - Síntese dos estudos que abordam descentralização no exterior e no Brasil

Considerando as contribuições trazidas pelos trabalhos citados, depreende-se que o processo de descentralização fiscal e da saúde é um tema recorrente, no qual há preocupação constante acerca dos impactos gerados sobre os resultados da saúde, com abrangência em 
todos os níveis de governo. Portanto existem muitos estudos explorando a linha da descentralização de forma ampla. Segundo os resultados das pesquisas descritas, verificou-se que:

- A maioria dos trabalhos analisam o impacto da descentralização sobre os resultados de saúde de forma agregada ou ampla, utilizando dados em painel como técnica estatística;

- Utilizam indicadores de saúde, educação e socioeconômicos, com primazia da TMI, e outros como expectativa de vida, nível educacional e PIB per capita;

- Os resultados indicam normalmente relação positiva com a melhoria dos indicadores de saúde, principalmente a mortalidade infantil, mas há exceções; e também na expectativa de vida;

- Autonomia dos governos subnacionais por meio da descentralização reduz disparidades regionais;

- Descentralização fiscal impactou o aumento da renda individual e melhorias das condições de vida da população;

- A maior parte dos estudos são conduzidos a partir de conceitos relativos ao processo de descentralização fiscal e da saúde.

As conclusões dos estudos apresentados contribuem para identificar o impacto da descentralização da saúde de forma ampla numa visão macro comparativa, sobre os indicadores da saúde de países ou de estados e províncias. Percebe-se a existência de lacuna de uma abordagem mais profunda que objetive o detalhe, como uma pesquisa em microrregiões, municípios ou de gestão local.

\subsection{Controladoria na Gestão Pública}

A Contabilidade Aplicada ao Setor Público vem de um processo de mudanças que visam maior controle e transparência por meio de normas e técnicas. Acompanhando o contexto mundial, no Brasil, a Contabilidade Aplicada ao Setor Público também passou por adequações, desde a sua regulamentação por meio da sanção da Lei $n^{\circ}$. 4.320/64. Ocorreram

reformas, passando de uma administração pública burocrática, concentrada no processo, para uma nova administração pública. Denominada de administração pública gerencial, é orientada 
para o cidadão e para a obtenção de resultados e nos controles preventivos (Bresser-Pereira, 2001) e (Giambiagi \& Além, 2011).

As mudanças têm o intuito de tornar o serviço público mais flexível, descentralizado, eficiente, visando à satisfação do interesse público, com controles preventivos, orientado para os cidadãos e para a obtenção de resultados; para a avaliação do desempenho e a prestação de contas. Em 2000, foi implantada a Lei de Responsabilidade Fiscal (LRF) ou Lei Complementar $\mathrm{n}^{\mathrm{o}}$. 101, decorrente dessa mudança na administração pública, usando os conceitos da contabilidade gerencial, e dentre esses conceitos a eficiência. (Giambiagi \& Além, 2011).

A LRF, conforme Silva (2009, p.31), estabeleceu as bases para a instituição desse novo ambiente de controle fiscal das contas públicas, consubstanciado num rígido controle da conduta dos administradores públicos. A LRF tem por pressupostos básicos o planejamento, o equilíbrio fiscal e a transparência da gestão, desta forma cria a obrigatoriedade da elaboração e divulgação de relatórios que informe o andamento e resultados dos programas e projetos desenvolvidos pela gestão. É também objetivo da LRF assegurar a transparência com maior participação popular nos processos de elaboração e discussão dos planos, diretrizes orçamentárias e orçamentos.

A evolução na contabilidade gerencial pública, em termos administrativos e políticos, visa restringir os gastos públicos e otimizar a aplicação dos recursos, implementando a gestão pública, dentro do estado. A eficiência na gestão pública visa o bem estar da população. Se sobra recursos a tendência é a sua aplicação em outras áreas. (Giambiagi \& Além, 2011).

O objetivo é que os bens públicos sejam produzidos com o menor custo e maior eficiência. A gestão dos custos incentiva o exercício da accountability e o controle é um dos componentes básicos proporcionando condições de maior confiança nos governantes, tendo mais transparência nas ações.

A contabilidade do setor público utiliza o sistema orçamentário para exposição das receitas e despesas, que evidenciam o montante dos créditos orçamentários, a despesa empenhada, a despesa realizada, a despesa liquidada, apresentando ao final do período os resultados comparativos entre a previsão e a execução orçamentária. No contexto da adoção do princípio de competência, que é um regime no qual a atribuição do fato gerador do direito ou obrigação ocorre no período de competência, as receitas e as despesas são atribuídas aos 
exercícios segundo a ocorrência, e não quando há o desembolso ou o recebimento financeiro, assim como ocorre no regime de caixa; a utilização do regime de competência é obrigatória.

Atribuem-se ao Estado três funções básicas: promover a estabilidade e crescimento da economia, alocar de forma eficiente os recursos e propiciar a equidade na distribuição e no acesso a bens e serviços fornecidos pelo setor público. No Brasil, os gastos públicos são executados por meio dos orçamentos, necessários para a realização dos serviços públicos, sendo que as funções orçamentárias passam pelas etapas de elaboração da proposta orçamentária, discussão e aprovação, execução do orçamento e o controle e avaliação de tais rotinas. Neste contexto, encontram-se integrados o Plano Plurianual (PPA), a Lei de Diretrizes Orçamentárias (LDO) e a Lei Orçamentária Anual (LOA). O PPA é a definição táticooperacional das ações governamentais e a LDO, deve respeitar suas definições ao traçar as diretrizes para a elaboração da LOA (Giacomoni, 2002).

Em Minas Gerais, a Secretaria de Estado de Saúde de Minas Gerais (SES-MG) dispõe material didático para auxiliar os gestores municipais de saúde, no processo de elaboração dos instrumentos de planejamento do SUS: do Plano Municipal de Saúde (PMS), da Programação Anual de Saúde (PAS) e do Relatório Anual de Gestão (RAG). O apoio técnico aos gestores contribui para o aumento de municípios adimplentes com os instrumentos de planejamento, como também para a melhoria da qualidade desses documentos, representando, melhoria da qualidade do planejamento na gestão municipal e dos serviços ofertados à população. $\mathrm{O}$ objetivo é fornecer aos gestores municipais de saúde, conhecimento acerca desses instrumentos de planejamento do SUS.

Regulamentado pela Lei $n^{\circ}$. 8.142/90 (Brasil - Congresso Nacional, 1990b) e pela Lei Complementar no. 141/2012 (Brasil - Ministério da Saúde, 2012a), o Relatório Anual de Gestão é a principal ferramenta de acompanhamento da gestão da saúde nos Municípios, Estados, Distrito Federal e União. Os Relatórios de Gestão apresentam os resultados alcançados com a execução da Programação Anual de Saúde, comprovando a aplicação de recursos do SUS, orientando ainda a elaboração de nova programação anual e eventuais adequacões que se façam necessárias.

O controle e a execução do planejamento de uma estratégia, por meio de parâmetros estabelecidos, como: resultados e causas, é uma das premissas da avaliação de desempenho. Implantar uma estratégia em determinado setor é um dos principais objetivos do sistema de avaliação de desempenho (formular estratégias, definição de objetivos e controle gerencial). (Anthony \& Govindarajan, 2008). 
O desempenho operacional são as atividades relacionadas ao processamento de recursos para a geração de produtos e serviços. Considera o atingimento de determinados níveis (padrões) de eficiência, de utilização de recursos e equipamentos, de qualidade dos produtos, etc. A eficiência refere-se à relação recursos consumidos por produtos gerados.

\subsection{Eficiência na Saúde}

As ações e serviços em saúde sempre direcionam ao mesmo ponto, a questão do financiamento. A avaliação, como ensinam Tanaka e Tamaki (2012) deve ser objetiva ao ponto de permitir a realização de determinado processo no espaço de tempo e recursos disponíveis. Nesse mesmo sentido, Arretche (2001) afirma que a avaliação da eficiência com a possibilidade de dar aos recursos públicos, melhor alocação e racionalizar seu uso, é um importante determinante do planejamento e gestão de políticas.

No setor público a medida de eficiência demonstra até que ponto o governo está produzindo o máximo possível com os recursos disponíveis. A eficiência representa uma relação entre custos e os benefícios. Para promover a eficiência e efetividade na gestão municipal dos recursos públicos é fundamental o controle mediante o monitoramento dos resultados e, principalmente, mediante avaliação da execução orçamentária das políticas públicas e da melhoria dos indicadores sociais que refletem o bem-estar da sociedade, principalmente na área da saúde.

Segundo Couttolenc (2002), a eficiência no setor da saúde pode ser verificada sobre dois aspectos: a eficiência alocativa, que refere-se à opção dentre as alternativas disponíveis, para distribuição de recursos, as mais aptas a proporcionar os melhores resultados; e a eficiência técnica, que refere-se a capacidade de geração de resultados em relação a uma estrutura, em decorrência da redução das ineficiências do processo. $\mathrm{O}$ autor revela que "a otimização dos recursos existentes implica, portanto, a alocação e utilização eficiente desses recursos, priorizando-se as intervenções mais custo-efetivas e eliminando-se desperdícios e ociosidade" (p. 296). A eficácia representa uma medida do alcance de resultados, objetivos, ou seja, a capacidade de satisfazer uma necessidade de uma sociedade por meio do suprimento de seus produtos (bens ou serviços).

A eficiência técnica reflete a capacidade de se obter o máximo de produtos (outputs) com os menores custos (inputs); a eficiência relativa entre as unidades; a relação dos gastos 
com a função atenção à saúde e os indicadores de saúde ou estrutura no período analisado. A eficiência (resultado) passa pelo planejamento, execução e controle, ou seja, pelo processo de gestão e sistema de informações. A responsabilidade do gestor municipal é voltada para a identificação de ações e serviços de saúde, priorizando nestas a alocação dos recursos disponíveis, para devolver a população as melhores condições de vida possível.

\subsubsection{Indicadores Sociais}

Nas últimas décadas cresceu no Brasil o interesse do uso de indicadores na administração pública e isso está relacionado à melhoria do controle social por parte do Estado brasileiro. Aplicado na avaliação de políticas públicas, o indicadores sociais "são medidas usadas para permitir a operacionalização de um conceito abstrato ou de uma demanda de interesse programático" (Jannuzzi, 2005, p. 137-138).

De acordo com as definições de Miles, e Nações Unidas, respectivamente (1985 e 1988, citados por Jannuzzi, 2005):

\footnotetext{
Os indicadores apontam, indicam, aproximam, traduzem em termos operacionais as dimensões sociais de interesse definidas a partir de escolhas teóricas ou políticas realizadas anteriormente. Prestam-se a subsidiar as atividades de planejamento público e a formulação de políticas sociais nas diferentes esferas de governo, possibilitam o monitoramento das condições de vida e bem-estar da população por parte do poder público e da sociedade civil e permitem o aprofundamento da investigação acadêmica sobre a mudança social e sobre os determinantes dos diferentes fenômenos sociais. (p. 138)
}

Para Jannuzzi (2005, p. 139), os indicadores como a Taxa de Mortalidade Infantil (TMI), o percentual de crianças com baixo peso ao nascer e o percentual de domicílios com saneamento adequado, são exemplos relevantes e pertinentes para o acompanhamento de programas na área da saúde pública, considerando que podem responder à demanda de avaliação e controle governamental das prioridades definidas para a área.

A escolha de indicadores está pautada em critérios fundamentais, como defendem os pesquisadores, tais como:

A validade é um critério importante, pois o que se deseja é a disponibilidade de medidas tão próximas quanto possível do conceito ou demanda política de origem, ou a capacidade de refletir a realidade. A confiabilidade é outro critério relevante para legitimar o uso do indicador. Está relacionado estritamente à qualidade da informação ou do 
levantamento dos dados. Outros critérios citados como importantes são a relevância social e a cobertura para representar uma realidade em análise. (Jannuzzi, 2005, p. 139-140).

Os indicadores contemplam diversas taxionomias. A classificação mais comum é dos indicadores de acordo com a área temática da realidade social a que se referem; como os indicadores de saúde, de educação, demográficos, etc. Outra classificação é a divisão entre indicadores objetivos, que referem-se às situações concretas ou realidade empíricas, como a taxa de mortalidade materna e os indicadores subjetivos que correspondem a indicadores construídos, levantados com base em pesquisas de opinião pública, como o nível de confiança em instituiçoes públicas (Jannuzzi, 2005, p.143).

$\mathrm{Na}$ análise de políticas públicas, é interessante a diferenciação entre os indicadores de insumo, processo, resultado e impacto:

\footnotetext{
Os indicadores-insumo correspondem às medidas associadas à disponibilidade de recursos humanos, financeiros ou de equipamentos alocados para um processo ou programa ... . Os indicadoresresultado são aqueles ... vinculados aos objetivos finais dos programas públicos, que permitem avaliar a eficácia do cumprimento das metas especificadas, ... . Os indicadores-impacto referem-se aos efeitos e desdobramentos mais gerais, antecipados ou não, positivos ou não, que decorrem da implantação dos programas, ... . Os indicadores-processo ou fluxo são indicadores intermediaries, que traduzem, em medidas quantitativas, o esforço operacional de alocação de recursos humanos, físicos ou financeiros ... para obtenção de melhorias ... . (Jannuzzi, 2005, 144)
}

No campo das políticas públicas, os indicadores podem ser classificados quanto à eficiência, eficácia ou efetividade. Os indicadores de eficiência mensuram o nível do uso racional ou o desperdício dos recursos aplicados na execução dos serviçoes, enquanto que os indicadores de eficácia mensuram a distância ou proximadade em relação às metas estabelecidas previamente. Os indicadores de efetividade mensuram os efeitos dos programas em termos de bem estar social, impactos, etc. (Jannuzzi, 2005).

$\mathrm{Na}$ area da saúde ainda existem as classificações de indicadores de mortalidade, morbidade, letalidade, etc. Os indicadores de mortalidade tradicionalmente são utilizados para mensurar a saúde, considerando o tempo de monitoramento e registros dos mesmos, com relativa precisão pelos sistemas de saúde. Os principais indicadores de mortalidade são: taxa de mortalidade geral, taxa de mortalidade infantil, taxa de mortalidade neonatal, taxa de mortalidade materna, etc. O "uso em Saúde Pública ainda é considerado o mais importante ou, pelo menos, o mais difundido"; e também estes indicadores cumprem "uma das funções essenciais da Saúde Pública: análise e avaliação da saúde da população”. (Laurenti, Jorge, \& Gotlieb, 2008) 
Portanto, uma maneira de se ter conhecimento sobre as condições de saúde de uma população, é avaliá-la por meio de indicadores, e a saúde sempre foi acompanhada por diferentes indicadores, cobrindo os seus múltiplos aspectos, desde antes da obrigatoriedade de indicadores, para cumprir o Pacto pela Saúde em 2006. O Pacto pela Vida foi constituído por um conjunto de compromissos, expressos em objetivos e metas, derivados da análise da situação de saúde do País e das propriedades definidas pelos governos federal, estaduais e municipais.

Neste estudo destaca-se que a TMI é um dos indicadores mais utilizados em estudos empíricos, como abordado nos estudos sobre descentralização e eficiência dos serviços de saúde. Portanto, a principal razão da escolha desse indicador para representar a saúde, foi a sua validade na literatura, em razão do uso constante em estudos empíricos.

A Taxa de Mortalidade Infantil (TMI) também chamada de Coeficiente de Mortalidade Infantil, é conceituada como o Número de óbitos de menores de um ano de idade, por mil nascidos vivos, na população residente em determinado espaço geográfico, no ano considerado. Segundo a REDE, interpreta-se o indicador para:

- Estima o risco de morte dos nascidos vivos durante o seu primeiro ano de vida.

- Reflete, de maneira geral, as condições de desenvolvimento socioeconômico e infra-estrutura ambiental, bem como o acesso e a qualidade dos recursos disponíveis para atenção à saúde materna e da populace infantil.

- Expressa um conjunto de causas de morte cuja composição é diferenciada entre os subgrupos de idade (ver componentes de mortalidade infantil, no item categorias de análise).

- Costuma-se classificar o valor da taxa como alto (50 por mil ou mais), médio (20 a 49) e baixo (menos de 20), parâmetros esses que necessitam revisão periódica, em função de mudanças no perfil epidemiológico. Valores abaixo de 10 por mil são encontrados em vários países, mas devese considerar que taxas reduzidas podem estar encobrindo más condições de vida em segmentos sociais específicos. (REDE Interagencial de Informação para a Saúde, 2008, p. 108)

Número de óbitos de residentes com menos de um ano de idade

Número de nascidos vivos de mães residentes

(1)

A Taxa de Mortalidade Materna (TMM) também conhecida como Razão de Mortalidade Materna e de Coeficiente de Mortalidade Materna, é conceituada como o Número de óbitos maternos, por 100 mil nascidos vivos de mães residentes em determinado espaço geográfico, no ano considerado. O conceito de morte materna utilizado é o estabelecido pela Organização Mundial de Saúde (OMS). Segundo a REDE, interpreta-se o indicador para:

- Estima a freqüência de óbitos femininos, ocorridos até 42 dias após o término da gravidez, atribuídos a causas ligadas à gravidez, ao parto e ao puerpério, em relação ao total de nascidos 
vivos. O número de nascidos vivos é adotado como uma aproximação do total de mulheres grávidas.

- Reflete a qualidade da atenção à saúde da mulher. Taxas elevadas de mortalidade maternal estão associadas à insatisfatória prestação de serviços de saúde a esse grupo, desde o planejamento familiar e a assistência pré-natal, até a assistência ao parto e ao puerpério. (REDE Interagencial de Informação para a Saúde, 2008, p. 120)

No . de óbitos de mães residentes, por causas e condições consideradas de morte materna Número de nascidos vivos de mães residentes

Assim como a TMI, a TMM também é outro indicador relevante para representar a saúde da população. Não tão utilizado como a TMI em estudos empíricos, mas a sua relevância advém da sua sensibilidade em captar as condições do atendimento das consultas pré-natal, que afetam a saúde materna e também a saúde infantil. Alguns estudos utilizam o indicador e argumentam sobre a sua importância como indicador de saúde. (Laurenti, Jorge, \& Gotlieb, 2004; 2008 e Ismail, 2010).

Assim, a principal razão da escolha desse indicador para representar também a saúde neste estudo, foi a sua validade na literatura, em razão do uso em estudos empíricos, e também devido a política de saúde em Minas Gerais, na área de redução da mortalidade infantil e materna no Programa denominado Viva Vida. (Marques, Gonçalves, \& Santos, 2013).

Outros indicadores utilizados neste estudo foram os do Pacto pela Vida foi constituído por um conjunto de compromissos, expressos em objetivos e metas, derivados da análise da situação de saúde do País e das propriedades definidas pelos governos federal, estaduais e municipais. Uma ação prioritária no campo da saúde, deveria ser executada com foco em resultados. Assim as prioridades e os objetivos do Pacto pela Vida em 2006, eram:

SAÚDE DO IDOSO: Implantar a Política Nacional de Saúde da Pessoa Idosa, buscando a atenção integral.

CÂNCER DE COLO DE ÚTERO E DE MAMA: Contribuir para a reduçãp da mortalidade por câncer de colo do útero e de mama.

MORTALIDADE INFANTIL E MATERNA: Reduzir a mortalidade materna, infantil neonatal, infantil por doença diarréica e por pneumonias.

DOENÇAS EMERGENTES E ENDEMIAS, COM ÊNFASE NA DENGUE, HANSENÍASE, TUBERCULOSE, MALÁRIA E INFLUENZA: Fortalecer a capacidade de resposta do sistema de saúde às doenças emergentes e endemias.

PROMOÇÃO DA SAÚDE: Elaborar e implantar a Política Nacional de Promoção da Saúde, com ênfase na adoção de hábitos saudáveis por parte da população brasileira, de forma a internalizar a responsabilidade individual da prática de atividade física regular, alimentação saudável e combate ao tabagismo.

ATENÇÃO BÁSICA À SAÚDE: Consolidar e qualificar a estratégia da Saúde da Família como modelo de atenção básica à saúde e como centro ordenador das redes de atenção à saúde do SUS. (Brasil - Ministério da Saúde, 2006b) 
De 2006 até hoje as prioridades e os objetivos mudaram. Ocorreram mudanças em 2011, 2012, 2013 e 2014, sempre evidenciadas por meio das Notas Técnicas emitidas ano a ano. A última Nota Técnica, ainda vigente, apresenta em torno de 67 Indicadores de Saúde Municipais e também Regionais do rol de Diretrizes, Objetivos, Metas e Indicadores 20132015 - 3 $3^{\mathrm{a}}$. Edição, estabelecidos conforme a Resolução nº 05 da CIT (Brasil - Ministério da Saúde, 2013). Nesta, algumas diretrizes e alguns objetivos atuais são:

Diretriz 1 - Garantir acesso da população a serviços de qualidade, com equidade e em tempo adequado ao atendimento das necessidades de saúde, mediante aprimorando (sic) a política de atenção básica e a atenção especializada.

Objetivo 1.1 - Utilização de mecanismos que propiciem a ampliação do acesso a atenção básica.

Objetivo 1.1 - Garantir acesso da população a serviços de qualidade, com equidade e em tempo adequado ao atendimento das necessidades de saúde, mediante aprimoramento da política da atenção especializada.

Diretriz 2 - Aprimoramento da Rede de Atenção às Urgências, com expansão e adequação de Unidades de Pronto Atendimento (UPA), de Serviços de Atendimento Móvel de Urgência (SAMU), de prontos-socorrs e centrais de regulação, articulada às outras redes de atenção.

Diretriz 3 - Promoção da atenção integral à saúde da mulher e da criança e implementação da "Rede Cegonha", com ênfase nas áreas e populações de maior vulnerabilidade.

Objetivo 3.1 - Fortalecer e ampliar as ações de Prevenção, detecção precoce e tratamento opoturno do Câncer de Mama e do Colo de Útero.

Objetivo 3.2 - Organizar a Rede de Atenção à Saúde Materna e Infantil para garantir acesso, acolhimento e resolutividade.

Diretriz 4 - Fortalecimento da rede de saúde mental, com ênfase no enfrentamento da dependência de crack, álcool e outras drogas. 
agregado, mas que ainda hoje se encontra no sítio do DATASUS. Jannuzzi (2005) alerta sobre um dos maiores gargalos se refere à descontinuidade das pesquisas e atrasos nas publicações.

O IDSUS contempla 24 indicadores, sendo que 20 estão no rol de indicadores que coletamos no sítio do DATASUS, porém muitos deles estão incompletos, principalmente por falta de alimentação do Banco de Dados do DATASUS por parte dos Municípios. Assim selecionamos 12 indicadores do rol de Diretrizes, objetivos, metas e indicadores de 20132015, sendo eles os indicadores:

- $\mathrm{CEAB}$ - Cobertura equipes atenção básica: Cobertura populacional estimada pelas equipes de Atenção Básica;

- ICSAB - \% Int. cond. sensív. at. básica: Proporção de internações por condições sensíveis à atenção básica;

- CESB - Cobertura equipes saúde bucal: Cobertura populacional estimada pelas equipes básicas de saúde bucal;

- PAMC - Proc. amb. média compl/100hab: Razão de procedimentos ambulatoriais de média complexidade e populaçãoo residente;

- RIMC - Int. média complex. p/100 hab: Razão de internações clínico-cirúrgicas de média complexidade e população residente;

- PAAC - Proc. amb. alta compl./100hab: Razão de procedimentos ambulatoriais de alta complexidade e população residente;

- RIAC - Int. alta complex.p/1000 hab: Razão de internações clínico-cirúrgicas de alta complexidade e populaçãoo residente;

- RECCU - Razão exames citopat. colo útero: Razão de exames citopatológicos do colo do útero em mulheres de 25 a 64 anos e a população da mesma faixa etária;

- RMR - Razão mamografias realizadas: Razão de exames de mamografia de rastreamento realizados em mulheres de 50 a 69 anos e população da mesma faixa etária;

- PPN - \% Partos normais: Proporção de parto normal;

- NVCPN - \% NV c/7+ consultas pré-natal: Proporção de nascidos vivos de mães com 7 ou mais consultas de pré-natal; 
- POCD - \% Obitos com causa definida: Proporção de registro de óbitos com causa básica definida. ${ }^{2}$

Portanto, este é o rol de indicadores municipais que analisaremos.

\subsubsection{Estudos Anteriores - Eficiência do Gasto em Saúde}

O objetivo de pesquisas que abordam a eficiência do gasto em saúde é analisar o nível de eficiência sobre os resultados de saúde, normalmente traduzidos na forma de indicadores ou variáveis que podem influenciar o desempenho do setor saúde ou sistemas de saúde. Assim como nas pesquisas sobre descentralização, há muitos estudos no exterior e no Brasil que buscam mensurar a eficiência do gasto em saúde, demonstrando uma preocupação constante, devido ao aumento considerável dos gastos em saúde no mundo.

No Brasil, há vários estudos na saúde pública com abordagens regionalizadas, como a pesquisa de Espírito Santo, Fernando e Bezerra (2012) que analisaram a despesa pública municipal com saúde no Estado de Pernambuco no período de 2000 a 2007, em que estabeleceram uma correlação com o Índice de Desenvolvimento Humano Municipal (IDHM) e verificaram a existência de disparidades na distribuição de recursos públicos para saúde, em detrimento das políticas voltadas ao combate dessas disparidades. A qualidade de gastos públicos pode ser compreendida por eficiência dos recursos empregados pelo governo em determinado setor.

A mensuração da eficiência das ações e serviços executados pelo gestor público tem sido relevante para dar à administração subsídios para a adequação das políticas à realidade dinâmica de cada comunidade, e também para informar à população acerca dos recursos e dos resultados alcançados. Para a aferição do desempenho e eficiência da gestão da saúde pública a metodologia mais recorrente, nos estudos tem sido a Data Envelopment Analysis ou Análise Envoltória de Dados (DEA). Lobo e Lins (2011).

A medida de eficiência em DEA é realizada pela comparação de um conjunto de unidades, denominadas Decision Making Units - (DMU's), as quais consomem inputs (recursos) para produzir outputs (produtos). A técnica estatística não paramétrica DEA

\footnotetext{
${ }^{2}$ Este indicador não está contemplado no rol de indicadores do IDSUS; porém por tratar-se de um indicador sobre mortalidade, decidiu-se mantê-lo sob análise.
} 
constrói uma fronteira de produção empírica e o nível de eficiência, depende da distância da unidade à fronteira. A unidade presente na fronteira somente será eficiente se não for possível a redução ou o aumento simultâneo de nenhum input ou de output (Lobo \& Lins, 2011).

A DEA é muito utilizada em trabalhos no Brasil como: Marinho (2003) nos serviços ambulatoriais e hospitalares nos municípios cariocas; Varela (2008) que mensurou as variações de desempenho dos municípios paulistas, quanto à eficiência técnica na aplicação de recursos na atenção básica considerando como inputs a despesa liquidada na saúde e como outputs os números de procedimentos e a cobertura de programas específicos da atenção básica como o PSF; Ferreira e Pitta (2008) que estudaram os recursos do SUS na produção ambulatorial dos municípios paulistas; Fonseca e Ferreira (2009) que investigaram os níveis de eficiência da utilização de recursos públicos da saúde das 66 microrregiões do Estado de Minas Gerais, tendo o BCC como modelo da DEA, com orientação para produto, sendo os inputs o número de estabelecimentos da saúde, equipamentos e profissionais e os outputs o número de famílias acompanhadas pelo Programa Saúde da Família e Programa Agente Comunitário de Saúde e a produção ambulatorial e o trabalho de Queiroz et al. (2013) que estudaram os recursos destinados à saúde pública nos municípios potiguares.

Em seguida abordamos alguns estudos empíricos no exterior, que foram selecionados por utilizarem técnicas estatísticas como a DEA, na identificação de ganhos em eficiência sobre os resultados de saúde, considerando os gastos com a saúde, são apresentados também em ordem cronológica na última década.

O trabalho de Retzlaff-Roberts, Chang e Rubin (2004) analisaram a eficiência técnica na produção de resultados agregados para a saúde na redução da mortalidade infantil e aumento da expectativa de vida, utilizando dados de saúde da OECD. A aplicação da DEA revelou que alguns países alcançam vantagens de eficiência relativa, incluindo aqueles com bons resultados de saúde (Japão, Suécia, Noruega e Canadá) e aqueles com modestos resultados de saúde (México e Turquia).

O artigo de Afonso e Aubyn (2005), muito citado na literatura, aborda a eficiência nos setores de educação e saúde para uma amostra de países da OECD por meio da aplicação de duas metodologias não paramétricas alternativas: Free Disposable Hull (FDH) e DEA. A despesa pública é de grande importância para que os resultados tenham fortes implicações no que diz respeito a eficiência do setor público. A estimação da fronteira de eficiência concentra-se nas medidas de insumos de quantidade. Esta abordagem é vantajosa uma vez que um país pode ser eficiente do ponto de vista técnico, mas aparece como ineficiente se os 
inputs que ele utiliza, são valores altos. Resultados eficientes em todos os setores e métodos analíticos parecem agrupar-se em torno de um pequeno número de países centrais, ainda que por razões diferentes: Japão, Coréia e Suécia.

A pesquisa de Purohit (2008) analisou o nível de eficiência do sistema de saúde em Bengal (estado indiano de baixa renda). As principais variáveis utilizadas são a expectativa de vida, a taxa de mortalidade infantil, a renda per capita e outros parâmetros relacionados ao desenvolvimento humano e estabelecimentos de saúde. Utilizou um modelo de fronteira estocástica para avaliação e os resultados sugerem que a eficiência global do sistema de saúde pública continua baixo devido às disparidades entre os distritos, devido aos diferenciais na disponibilidade e utilização de insumos, tais como a disponibilidade per capita de hospitais, de leitos e mão de obra, que afetam negativamente a expectativa de vida. A superação dessas disparidades pode ajudar os distritos deficientes a melhorar a expectativa de vida.

O estudo de Ismail (2010) tem como objetivo estimar a eficiência técnica relativa de instituições de saúde do Sudão em nível estadual e desenhar as implicações políticas para o setor da saúde. A DEA orientada para os outputs foi usada para estimar a eficiência técnica das instituições de saúde dos 25 estados do Sudão para o ano de 2007. Os resultados do estudo mostram que 15 estados foram tecnicamente ineficientes A presença de ineficiência indica que os estados tecnicamente ineficientes tiveram excesso de entradas e saídas insuficientes, em comparação com os estados eficientes. O excesso de recursos para a saúde poderia ser transferido para outros estados tecnicamente eficientes com um déficit nesses recursos.

O trabalho de Sinimole (2012) teve por objetivo analisar a eficácia dos sistemas de saúde de 180 países avaliados por meio de DEA. Os países selecionados são membros da OMS. As medidas de eficiência são calculadas em relação a dois grupos de indicadores, o estado de saúde e a cobertura dos serviços de saúde. No grupo de estado de saúde, quatro saídas que representam as taxas de mortalidade e uma entrada que representa a despesa total em saúde, que são usadas na análise. No grupo de cobertura de serviços de saúde, duas saídas representam a cobertura de vacinação e uma entrada que representa a despesa total em saúde, que são utilizadas na análise. Usando dados para o ano de 2008 a partir de dados da OMS, encontraram-se 45 países eficientes.

O objetivo do trabalho de Anton (2013) é avaliar a eficiência técnica de 20 sistemas de saúde da Central and Eastern Europe (CEE) - Europa Oriental Central e Commonwealth of Independent States (CIS) - Comunidade dos Estados Independentes. O autor usou DEA para 
medir a eficiência técnica dos sistemas de saúde, utilizando os últimos dados disponíveis sobre mortalidade infantil e expectativa de vida, como resultados de saúde. Os resultados mostram que a eficiência técnica varia entre estes sistemas de saúde e isso se traduz em potenciais economias de recursos. Mais da metade dos sistemas de saúde na amostra eram tecnicamente ineficientes em 2009 e que 30\% dos sistemas nacionais de saúde eram tecnicamente eficientes.

O artigo de Ferreira, Marques e Nicola (2013) consideram que as crescentes despesas de saúde e seu peso no PIB de Portugal, é de extrema importância para avaliar o desempenho dos prestadores de cuidados de saúde primários, tendo em conta tanto a eficiência, a qualidade e a equidade. Com o objetivo de medir a eficiência dos centros de saúde, a abordagem técnica de fronteira não paramétrica de DEA foi adotada. A qualidade do serviço foi analisada em função da relação entre as queixas e a atividade dos centros de saúde. Observou-se um nível significativo de ineficiência, embora tenha havido uma melhoria geral na eficiência entre 2009 e 2010. Verificou-se que a enfermagem foi o serviço com as pontuações mais baixas. A análise mostrou que não há nenhuma evidência de disparidade relevante entre as diferentes sub-regiões. Com relação às variáveis exógenas o poder de compra, a porcentagem de pacientes com 65 anos ou mais e o tamanho da população afetam a eficiência negativamente. O estudo mostra que uma melhor utilização dos recursos disponíveis e a criação de uma rede de aprendizagem e difusão das melhores práticas contribuirá para melhoria na eficiência dos centros de saúde, mantendo ou até mesmo melhorando a qualidade e equidade.

O quadro 2 sintetiza os objetivos, indicadores, técnicas e principais conclusões das pesquisas descritas, abordando a análise da eficiência no setor saúde, considerando o gasto público, desenvolvidas no exterior.

\begin{tabular}{|l|l|l|l|l|}
\hline $\begin{array}{l}\text { Autoria/Ano } \\
\text { País/Período }\end{array}$ & \multicolumn{1}{|c|}{ Objetivos } & \multicolumn{1}{|c|}{$\begin{array}{c}\text { Dados / } \\
\text { Indicadores }\end{array}$} & $\begin{array}{l}\text { Métodos / } \\
\text { Técnicas }\end{array}$ & \multicolumn{1}{|c|}{ Resultados } \\
\hline $\begin{array}{l}\text { (Retzlaff- } \\
\text { Roberts et al., } \\
(2004)\end{array}$ & $\begin{array}{l}\text { Analisar a eficiência } \\
\text { técnica na produção } \\
\text { de resultados de } \\
\text { saúde em países da } \\
\text { OECD. }\end{array}$ & $\begin{array}{l}\text { TMI, } \\
\text { Expectativa de vida. }\end{array}$ & DEA. & $\begin{array}{l}\text { A aplicação da DEA revelou que alguns } \\
\text { países alcançam vantagens de eficiência } \\
\text { relativa, incluindo aqueles com bons } \\
\text { resultados de saúde (Japão, Suécia, } \\
\text { Noruega e Canadá) e aqueles com modestos } \\
\text { resultados de saúde (México e Turquia). }\end{array}$ \\
\hline $\begin{array}{l}\text { Afonso e } \\
\text { Aubyn (2005) }\end{array}$ & $\begin{array}{l}\text { Analisar a eficiência } \\
\text { nos setores de } \\
\text { educação e saúde } \\
\text { em países da } \\
\text { OECD. }\end{array}$ & $\begin{array}{l}\text { Despesa pública na } \\
\text { educação, } \\
\text { Despesa pública na } \\
\text { saúde, } \\
\text { PIB. }\end{array}$ & $\begin{array}{l}\text { DEA, } \\
\text { FDH. } \\
\text { métodos analíticos parecem agrupar-se em } \\
\text { torno de um pequeno número de países } \\
\text { centrais, ainda que por razões diferentes: } \\
\text { Japão, Coréia e Suécia. }\end{array}$ \\
\hline $\begin{array}{l}\text { Purohit (2008) } \\
\text { India / } \\
\text { Bengal, } \\
\text { 1999-2003 }\end{array}$ & $\begin{array}{l}\text { Analisar o nível de } \\
\text { eficiência do } \\
\text { Sistema de Saúde }\end{array}$ & $\begin{array}{l}\text { Expectativa de vida, } \\
\text { Renda per capita, } \\
\text { No. de leitos, } \\
\text { No. de hospitais. }\end{array}$ & $\begin{array}{l}\text { DEA e } \\
\text { Stochastic } \\
\text { Frontier } \\
\text { Analysis } \\
\text { (SFA). }\end{array}$ & $\begin{array}{l}\text { A eficiência global do sistema de saúde } \\
\text { pública continua baixa devido às } \\
\text { disparidades entre os distritos e aos } \\
\text { diferenciais na disponibilidade e utilização } \\
\text { de insumos, como hospitais, leitos e mão de }\end{array}$ \\
\hline
\end{tabular}




\begin{tabular}{|c|c|c|c|c|}
\hline & & & & $\begin{array}{l}\text { obra, que afetam negativamente a } \\
\text { expectativa de vida. }\end{array}$ \\
\hline Ismail (2010) & $\begin{array}{l}\text { Estimar a eficiência } \\
\text { técnica relativa de } \\
\text { instituições de } \\
\text { saúde nos estados } \\
\text { do Sudão. }\end{array}$ & $\begin{array}{l}\text { Acesso aos serviços } \\
\text { de saúde, Crianças } \\
\text { imunizadas, TMI, } \\
\text { Expectativa de vida, } \\
\text { Taxa mortalidade } \\
\text { materna. }\end{array}$ & DEA. & $\begin{array}{l}\text { Os resultados mostram que } 15 \text { estados eram } \\
\text { tecnicamente ineficientes. A presença de } \\
\text { ineficiência indica que os estados } \\
\text { tecnicamente ineficientes tiveram excesso } \\
\text { de entradas e saídas insuficientes, em } \\
\text { comparação com os estados eficientes. }\end{array}$ \\
\hline $\begin{array}{l}\text { Sinimole } \\
(2012)\end{array}$ & $\begin{array}{l}\text { Analisar a eficácia } \\
\text { dos sistemas de } \\
\text { saúde de } 180 \text { países } \\
\text { da OMS. }\end{array}$ & $\begin{array}{l}\text { TMI, Despesa total } \\
\text { em saúde, Cobertura } \\
\text { de vacinação. }\end{array}$ & DEA. & $\begin{array}{l}\text { Usando dados para o ano de } 2008 \text { a partir } \\
\text { de dados da OMS, de } 180 \text { países, } \\
\text { encontrou-se } 45 \text { países eficientes. }\end{array}$ \\
\hline Anton (2013) & $\begin{array}{l}\text { Avaliar a eficiência } \\
\text { técnica de } 20 \\
\text { sistemas de saúde } \\
\text { da CEE e CIS } \\
\text { (Europa). }\end{array}$ & $\begin{array}{l}\text { TMI, } \\
\text { Expectativa de vida. }\end{array}$ & DEA. & $\begin{array}{l}\text { Os resultados mostram que a eficiência } \\
\text { técnica varia entre estes sistemas de saúde e } \\
\text { isso se traduz em potenciais economias de } \\
\text { recursos. Mais da metade dos sistemas de } \\
\text { saúde na amostra eram tecnicamente } \\
\text { ineficientes em } 2009 \text { e que } 30 \% \text { dos } \\
\text { sistemas nacionais de saúde eram } \\
\text { tecnicamente eficientes. }\end{array}$ \\
\hline $\begin{array}{l}\text { Ferreira, } \\
\text { Marques e } \\
\text { Nicola }(2013)\end{array}$ & $\begin{array}{l}\text { Medir a eficiência } \\
\text { dos centros de saúde } \\
\text { de Portugal. }\end{array}$ & $\begin{array}{l}\text { Despesas de saúde, } \\
\text { PIB. }\end{array}$ & DEA. & $\begin{array}{l}\text { Observou-se um nível significativo de } \\
\text { ineficiência, embora tenha havido uma } \\
\text { melhoria na eficiência entre } 2009 \text { e } 2010 \text {, A } \\
\text { enfermagem foi o serviço com as } \\
\text { pontuações mais baixas. } \\
\text { Não há nenhuma evidência de disparidade } \\
\text { relevante entre as diferentes sub-regiões. }\end{array}$ \\
\hline
\end{tabular}

Quadro 2 - Síntese de estudos empíricos sobre eficiência no exterior

Os artigos apresentados abordam a análise da eficiência no setor saúde no exterior e percebe-se que a metodologia DEA é a mais utilizada para mensurar a eficiência. Quanto aos indicadores, os mais utilizados para representar a eficiência são os da saúde, como a TMI e expectativa de vida. A despesa de saúde que representa o gasto público aparece como relevante na mensuração da eficiência.

Há dispersão nos resultados quanto à mensuração da eficiência dos gastos públicos, mais pela heterogeneidade dos estudos, que abordam a eficiência global em sistemas de saúde e instituições em países e estados, assim como os trabalhos sobre descentralização. Há estudos que abordam de maneira detalhada instituições de saúde estaduais ou centros de saúde regionais, com foco nos serviços médicos e acesso aos serviços de saúde.

Nestes estudos ainda percebe-se a falta de uma abordagem mais detalhada, com uma explanação detalhada da mensuração utilizada, possivelmente pela dificuldade de escolha de indicadores que possam realmente mensurar a eficiência no setor saúde, como um fator limitante. Na pesquisa de estudos anteriores no exterior, não encontrou-se trabalhos que se assemelhe com o objetivo de analisar a relação entre a eficiência das regiões de saúde e a melhoria da condições de saúde, mensurada por meio de indicadores. 


\section{TRAJETÓRIA METODOLÓGICA}

\subsection{Classificação da pesquisa}

A abordagem metodológica do estudo será construída por meio de uma abordagem empírico-analítica, considerando que a coleta, o tratamento e a análise dos dados serão realizados com o emprego de métodos quantitativos, especificamente a técnica não paramétrica Data Envelopment Analysis (DEA). A pesquisa caracteriza-se como explicativa por descrever as características estabelecendo as relações entre as variáveis: gastos públicos com a saúde, indicadores de resultados das Regiões de Saúde e municípios que as compõe. A população objeto do estudo corresponde aos 853 municípios de Minas Gerais, distribuídos nas 77 Regiões de Saúde do estado.

Para a consecução dos objetivos propostos neste estudo adotou-se como estratégia de pesquisa, a documental. (Martins \& Theóphilo, 2009) esclarecem que na estratégia de pesquisa documental, o estudo parte de informações obtidas em vários tipos de documento.

Com base nas etapas do trabalho:

- Inicialmente foi desenvolvida uma pesquisa bibliográfica para a construção da plataforma teórica referente à problemática do estudo sobre a eficiência do gasto público, considerando a descentralização e a regionalização na saúde, para esclarecer a questão do estudo e discussão das teorias relacionadas.

- Na segunda etapa foram coletados os dados referente aos indicadores na área da saúde. A obrigatoriedade desses indicadores advém do Pacto pela Saúde em 2006, que passou por adequações em períodos subsequentes à 2006. Considerando que o período da pesquisa se refere de 2010 à 2014, coletamos os indicadores conforme as alterações relativo aos mesmos períodos, portanto de acordo com as Notas Técnicas e orientações acerca: dos Indicadores de Monitoramento e Avaliação do Pacto pela Saúde 2010/2011; dos Indicadores da Pactuação de Diretrizes, Objetivos e Metas 2012 (Indicadores de transição do Pacto pela Saúde e Contrato Organizativo da Ação Pública de Saúde (COAP) 2012); e principalmente dos Indicadores Municipais e também Regionais do rol de Diretrizes, Objetivos, Metas e Indicadores 2013-2015 - 3 ${ }^{\text {a }}$ Edição, estabelecidos na Resolução nº. 05 da CIT (Brasil - MS, 2013). 
- Coletamos os dados referente aos indicadores já citados dos municípios e também das Regiões de Saúde (RS) de Minas Gerais no sítio do DATASUS. Em seguida coletamos os dados referente aos Relatórios Anuais de Gestão (RAG) dos 853 municípios mineiros nos períodos disponíveis de 2011 à 2014, no sítio do SARGSUS. Coletamos outros indicadores que poderão compor o banco de dados do estudo, como IDH, índice FIRJAN, etc.

- Na terceira etapa, ocorreu o tratamento de dados coletados, cáculo da taxa de mortalidade infantil municipal, considerando que a fonte de dados (DATASUS) não disponibiliza esses indicadores para municípios com menos de $100 \mathrm{mil}$ habitantes, calculo da taxa de mortalidade materna municipal e regional, também não disponibilizada no sítio do DATASUS.

- Na quarta etapa, a eficiência do gasto público foi mensurada com a utilização da técnica estatística não paramétrica DEA, utilizando os modelos clássicos do DEA (CCR e BCC) com orientação a outputs, no período de 2010 à 2014. Foi escolhido o período de cinco anos, retroagindo a partir de 2014, uma vez que este é o último ano com disponibilidade de dados sobre mortalidade no sítio do DATASUS, dado necessário para o cálculo das taxas de mortalidade infantil e materna. Primeiro calculamos os scores de eficiência do gasto público com a utilização dos modelos DEA CCR e BCC, para as 13 Regiões Ampliadas de Saúde ou macrorregiões para os anos de 2010 à 2014. Em seguida calcularmos as eficiências total, técnica e de escala do gasto público com a utilização da técnica estatística não paramétrica DEA, das Regiões de Saúde ou microrregiões, utilizando o modelos CCR e BCC com orientação a output, para os anos do período de 2010 à 2014.

- Na quinta etapa, com o objetivo de analisar os fatores que contribuíram para o desempenho dos municípios mineiros, realizou-se uma avaliação quantitativa da evolução dos indicadores de saúde da atenção básica, por meio de estatísticas descritivas no período de 2010 à 2014, para analisar a contribuição dos municípios mineiros, identificando quais cumpriram suas metas, contribuindo assim nos resultados de eficiência das RS mineiras.

\subsection{Definições: objeto, população e período da pesquisa}


O objeto deste estudo é o estado de Minas Gerais. Desta forma, a população desta pesquisa é formada pelos 853 municípios mineiros, contemplados nas 77 Regiões de Saúde, também conhecidas como Microrregiões, que compõem as 13 Regiões Ampliadas de Saúde, também conhecidas como Macrorregiões.

O período analisado é de 2010 à 2014, cujo processo de seleção levou em consideração a disponibilidade dos dados necessários na composição do cálculo das variáveis: Taxa de mortalidade infantil e Taxa de mortalidade materna. Portanto, a definição do período teve como determinante a existência desses dados que compõem o cálculo das taxas de mortalidade citadas.

Assim no estudo, as unidades de análise são todos os municípios do estado de Minas Gerais, que compõem as 77 (setenta e sete) Regiões de Saúde mineiras, discriminados na tabela 3:

Tabela 3 - Relação das Regiões de Saúde e variação percentual da população de Minas Gerais

\begin{tabular}{|c|c|c|c|c|c|}
\hline \multirow{2}{*}{$\begin{array}{c}\text { Regiões } \\
\text { Ampliadas }\end{array}$} & \multirow{2}{*}{$\begin{array}{l}N^{0} . \\
\text { RS }\end{array}$} & \multirow{2}{*}{ Regiões de Saúde (RS) } & \multicolumn{3}{|c|}{ População em } \\
\hline & & & 2010 & 2014 & $\Delta \%$ \\
\hline \multirow{10}{*}{ Centro } & 01 & Belo Horizonte / Nova Lima / Caeté & 3.185 .567 & 3.358 .067 & $5,42 \%$ \\
\hline & 02 & Betim & 624.062 & 681.860 & $9,26 \%$ \\
\hline & 03 & Contagem & 788.210 & 844.678 & $7,16 \%$ \\
\hline & 04 & Curvelo & 174.714 & 183.638 & $5,11 \%$ \\
\hline & 05 & Guanhães & 113.607 & 117.198 & $3,16 \%$ \\
\hline & 06 & Itabira & 218.442 & 231.571 & $6,01 \%$ \\
\hline & 07 & João Monlevade & 132.648 & 138.797 & $4,64 \%$ \\
\hline & 08 & Ouro Preto & 169.949 & 181.136 & $6,58 \%$ \\
\hline & 09 & Sete Lagoas & 410.587 & 436.612 & $6,34 \%$ \\
\hline & 10 & Vespasiano & 279.500 & 306.612 & $9,70 \%$ \\
\hline \multirow{3}{*}{ Centro Sul } & 11 & Barbacena & 225.183 & 236.393 & $4,98 \%$ \\
\hline & 12 & Conselheiro Lafaiete / Congonhas & 288.371 & 305.174 & $5,83 \%$ \\
\hline & 13 & São João Del Rei & 227.178 & 238.444 & $4,96 \%$ \\
\hline \multirow{2}{*}{ Jequitinhonha } & 14 & Diamantina & 166.513 & 172.567 & $3,64 \%$ \\
\hline & 15 & Minas Novas / Turmalina / Capelinha & 118.517 & 124.303 & $4,88 \%$ \\
\hline \multirow{7}{*}{ Leste } & 16 & Caratinga & 192.172 & 201.608 & $4,91 \%$ \\
\hline & 17 & Coronel Fabriciano / Timóteo & 217.790 & 228.964 & $5,13 \%$ \\
\hline & 18 & Governador Valadares & 410.066 & 428.882 & $4,59 \%$ \\
\hline & 19 & Ipatinga & 374.405 & 398.038 & $6,31 \%$ \\
\hline & 20 & Mantena & 68.145 & 70.657 & $3,69 \%$ \\
\hline & 21 & Resplendor & 87.994 & 90.773 & $3,16 \%$ \\
\hline & 22 & Santa Maria Suaçuí / S. J. Evangelista & 101.991 & 104.173 & $2,14 \%$ \\
\hline \multirow{3}{*}{ Leste do Sul } & 23 & Manhuaçu & 323.342 & 340.735 & $5,38 \%$ \\
\hline & 24 & Ponte Nova & 212.256 & 217.343 & $2,40 \%$ \\
\hline & 25 & Viçosa & 130.215 & 136.886 & $5,12 \%$ \\
\hline \multirow{6}{*}{ Nordeste } & 26 & Águas Formosas & 58.036 & 60.173 & $3,68 \%$ \\
\hline & 27 & Almenara & 175.002 & 182.523 & $4,30 \%$ \\
\hline & 28 & Araçuaí & 88.413 & 91.183 & $3,13 \%$ \\
\hline & 29 & Itaobim & 80.733 & 82.851 & $2,62 \%$ \\
\hline & 30 & Nanuque & 69.315 & 70.686 & $1,98 \%$ \\
\hline & 31 & Padre Paraíso & 59.698 & 62.527 & $4,74 \%$ \\
\hline
\end{tabular}




\begin{tabular}{|c|c|c|c|c|c|}
\hline & 32 & Pedra Azul & 51.404 & 53.796 & $4,65 \%$ \\
\hline & 33 & Teófilo Otoni/Malacacheta/Itambacuri & 316.409 & 328.207 & $3,73 \%$ \\
\hline \multirow{3}{*}{ Noroeste } & 34 & João Pinheiro & 68.117 & 72.608 & $6,59 \%$ \\
\hline & 35 & Patos de Minas & 332.507 & 350.796 & $5,50 \%$ \\
\hline & 36 & Unaí & 252.330 & 267.676 & $6,08 \%$ \\
\hline \multirow{9}{*}{ Norte } & 37 & Brasília Minas / São Francisco & 234.588 & 246.040 & $4,88 \%$ \\
\hline & 38 & Coração de Jesus & 46.979 & 48.427 & $3,08 \%$ \\
\hline & 39 & Francisco Sá & 70.965 & 74.215 & $4,58 \%$ \\
\hline & 40 & Janaúba / Monte Azul & 265.812 & 277.722 & $4,48 \%$ \\
\hline & 41 & Januária & 110.272 & 115.549 & $4,79 \%$ \\
\hline & 42 & Manga & 57.647 & 58.836 & $2,06 \%$ \\
\hline & 43 & Montes Claros / Bocaiúva & 454.682 & 487.819 & $7,29 \%$ \\
\hline & 44 & Pirapora & 138.356 & 145.391 & $5,08 \%$ \\
\hline & 45 & Salinas / Taiobeiras & 197.999 & 207.131 & $4,61 \%$ \\
\hline \multirow{6}{*}{ Oeste } & 46 & Bom Despacho & 100.858 & 106.121 & $5,22 \%$ \\
\hline & 47 & Divinópolis / Santo Antônio Monte & 429.544 & 460.847 & $7,29 \%$ \\
\hline & 48 & Formiga & 126.639 & 131.907 & $4,16 \%$ \\
\hline & 49 & Itaúna & 114.169 & 121.117 & $6,09 \%$ \\
\hline & 50 & Pará de Minas & 208.105 & 231.278 & $11,14 \%$ \\
\hline & 51 & Santo Antônio Amparo / Campo Belo & 194.295 & 203.674 & $4,83 \%$ \\
\hline \multirow{8}{*}{ Sudeste } & 52 & Além Paraíba & 55.791 & 57.840 & $3,67 \%$ \\
\hline & 53 & Carangola & 123.872 & 129.008 & $4,15 \%$ \\
\hline & 54 & Juiz Fora/L.Duarte/Bom Jardim Minas & 637.712 & 676.250 & $6,04 \%$ \\
\hline & 55 & Leopoldina / Cataguases & 173.848 & 182.150 & $4,78 \%$ \\
\hline & 56 & Muriaé & 163.996 & 172.460 & $5,16 \%$ \\
\hline & 57 & Santos Dumont & 50.465 & 51.852 & $2,75 \%$ \\
\hline & 58 & São João Nepomuceno / Bicas & 69.213 & 72.551 & $4,82 \%$ \\
\hline & 59 & Ubá & 291.775 & 309.322 & $6,01 \%$ \\
\hline \multirow{12}{*}{ Sul } & 60 & Alfenas / Machado & 305.376 & 320.458 & $4,94 \%$ \\
\hline & 61 & Guaxupé & 154.619 & 161.354 & $4,36 \%$ \\
\hline & 62 & Itajubá & 196.039 & 204.767 & $4,45 \%$ \\
\hline & 63 & Lavras & 169.756 & 180.091 & $6,09 \%$ \\
\hline & 64 & Passos / Piumhi & 273.649 & 288.434 & $5,40 \%$ \\
\hline & 65 & Poços de Caldas & 215.747 & 229.205 & $6,24 \%$ \\
\hline & 66 & Pouso Alegre & 495.945 & 531.188 & $7,11 \%$ \\
\hline & 67 & São Lourenço & 250.451 & 262.077 & $4,64 \%$ \\
\hline & 68 & São Sebastião do Paraíso & 119.965 & 125.477 & $4,59 \%$ \\
\hline & 69 & Três Corações & 123.868 & 130.935 & $5,71 \%$ \\
\hline & 70 & Três Pontas & 120.384 & 125.544 & $4,29 \%$ \\
\hline & 71 & Varginha & 183.803 & 195.579 & $6,41 \%$ \\
\hline \multirow{3}{*}{ Triâng. do Norte } & 72 & Ituiutaba & 184.303 & 193.506 & $4,99 \%$ \\
\hline & 73 & Patrocínio / Monte Carmelo & 183.217 & 192.805 & $5,23 \%$ \\
\hline & 74 & Uberlândia / Araguari & 811.426 & 874.087 & $7,72 \%$ \\
\hline \multirow{3}{*}{ Triângulo do Sul } & 75 & Araxá & 167.704 & 180.620 & $7,70 \%$ \\
\hline & 76 & Frutal / Iturama & 160.188 & 172.945 & $7,96 \%$ \\
\hline & 77 & Uberaba & 369.920 & 399.383 & $7,96 \%$ \\
\hline \multicolumn{3}{|c|}{ Total da População do estado } & 19.597.330 & 20.734.097 & $5,80 \%$ \\
\hline \multirow{4}{*}{$\begin{array}{l}\text { Estatística } \\
\text { Descritiva }\end{array}$} & & Média & 254.511 & 269.274 & \\
\hline & & Desvio Padrão & 373.548 & 395.204 & \\
\hline & & Mínimo & 46.979 & 48.427 & \\
\hline & & Máximo & 3.185.567 & 3.358.067 & \\
\hline
\end{tabular}

Fonte: Dados da pesquisa

\subsection{Descrição da coleta de dados}


Para atender ao objetivo geral do estudo e mensurar a eficiência do gasto público, coletamos no sítio do Departamento de Informática do SUS (DATASUS), os indicadores de saúde, municipais e regionais do rol de indicadores para pactuação nacional, vinculados às diretrizes do Plano Nacional de Saúde conforme consta na Resolução 05 de 19 de junho de 2013 da CIT (Brasil - MS, 2013); no período de 2010 à 2014, para seleção futura das variáveis que serão utilizadas na análise.

Coletamos no Sistema de Apoio à Construção do Relatório de Gestão (SARGSUS), os Relatórios Anuais de Gestão (RAG) dos 853 municípios mineiros, no período disponível de 2011 à 2014.

No sítio do DATASUS, coletamos em estatísticas vitais, a quantidade de nascimentos e a quantidade de óbitos infantis e maternos, no período de 2010 até o último período disponível de 2014, necessários para compor o cálculo da Taxa de Mortalidade Infantil (TMI) e da Taxa de Mortalidade Materna (TMM).

Os dados referentes aos gastos públicos realizados nas ações de saúde, foram obtidos na rubrica contábil "Despesa liquidada" na função "saúde", que representa os gastos públicos na área da saúde executados, coletados no Sistema de Informações sobre Orçamentos Públicos em Saúde (SIOPS), no período de 2010 à 2014.

Para compreender a opção por essa variável Despesa Liquidada, é preciso estar claro que a "liquidação é uma fase ou estágio da despesa, na qual a administração pública reconhece o direito adquirido do fornecedor do serviço e/ou produto de receber o pagamento, desde que tenham sido prestados ou entregue, e atendam a finalidade pública" (Rosa, 2011).

\subsection{Data Envelopment Analysis (DEA)}

A Análise Envoltória de Dados do termo inglês Data Envelopment Analysis (DEA), usado inicialmente por Charnes, Cooper e Rhodes, em 1978, é muito empregada na avaliação de ações governamentais. Com a DEA é possível estimar uma razão de eficiência técnica por meio de programação linear. Ou seja, da relação entre os inputs (insumos, recursos) e os outputs ou outcomes (produtos, resultados) extrai-se a razão da eficiência para cada Unidade Tomadora de Decisão (DMU, do termo inglês Decision Making Unit). Salienta-se que os 
inputs e os outputs são iguais para todas as unidades, o que varia é a quantidade consumida e produzida (Mello et al, 2005; Varela e Pacheco, 2012; Lobo e Lins, 2011).

A DEA representa uma técnica de apoio ao cálculo da eficiência organizacional por meio da razão entre outputs e inputs. Assim, busca apresentar o melhor desempenho da organização sob análise, recorrendo as técnicas de estimação de fronteira, identificando as DMUs ineficientes daquelas que estão operando na fronteira de eficiência (Asandului, Roman \& Fatulescu, 2014; Mariano, 2008).

A DEA surgiu com Charnes et al. (1978) com a publicação do artigo Measuring Efficiency of Decision Making Units. O artigo traz uma extensão das argumentações de Farrel (1957) no artigo The Measurement of Productive Efficiency, que serviu de inspiração para o primeiro modelo DEA, no qual se desenvolveu um método para avaliar a produtividade combinando múltiplos insumos e um produto, com a finalidade de se obter um único indicador de eficiência relativa. A DEA define um conjunto de observações que possuem os melhores desempenhos como fronteira de possibilidade de produção, e tendo-o por parâmetro, classifica como ineficientes, as observações com valores abaixo desta fronteira (Santos, 2008).

Portanto, a DEA é um método estatístico não paramétrico, que calcula a eficiência comparada das DMUs. O aumento da aceitação do modelo se deve principalmente pela sua objetividade. As variáveis utilizadas para o cálculo da eficiência relativa das DMUs são divididas em inputs e outputs, elas são ponderadas por pesos, fixados livremente ou de forma restrita por meio de programação linear, buscando a maximização da eficiência de cada DMU em relação ao conjunto. Considerando que as melhores DMUs representam a fronteira de eficiência com o uso de inputs e outputs, há a possibilidade de definir os escores de eficiência ou a distância das DMUs ineficientes em relação à fronteira de eficiência. A técnica apoia-se na definição de benchmarks e metas para cada DMU ineficiente, para que a eficiência possa ser maximizada (Mariano, 2008).

Quanto aos modelos clássicos de DEA têm-se tanto o de Retornos Constantes de Escala, do termo inglês Constant Returns to Scale (CRS) ou CCR (dos autores: Charnes, Cooper e Rhodes); quanto o de Retornos Variáveis de Escala do termo inglês Variable Returns to Scale (VRS) ou BCC (dos autores: Banker, Charnes e Cooper). Podem ser classificados em Retornos Crescentes de Escala (Increasing Returns to Scale - IRS) e Retornos Decrescentes de Escala (Decreasing Returns to Scale - DRS). Assim, em um cenário de recursos reduzidos, buscam-se retornos crescentes de escala e, em um cenário com 
muitos recursos, buscam-se retornos decrescentes de escala.

Os modelos CCR e BCC também são conhecidos como modelos dual, devido a sua aplicação direcionada às metas e benchmarks. A Figura 1 apresenta as duas fronteiras: CRS e VRS. Na primeira, apenas a unidade B é eficiente. Na segunda, as unidades A, B e C são eficientes. A unidade D é ineficiente em ambos os modelos, e para alcançar a eficiência deveria aumentar de forma equânime e proporcional, seus produtos para atingir a fronteira, em uma orientação aos outputs, ou reduzir de forma equânime e proporcional seus insumos para atingir a fronteira, em uma orientação ao input. No primeiro caso, D teria como benchmarks as unidades B e C; já no segundo caso, seus benchmarks seriam as unidades B e A.

Figura 1 - Fronteiras do CRS e VRS

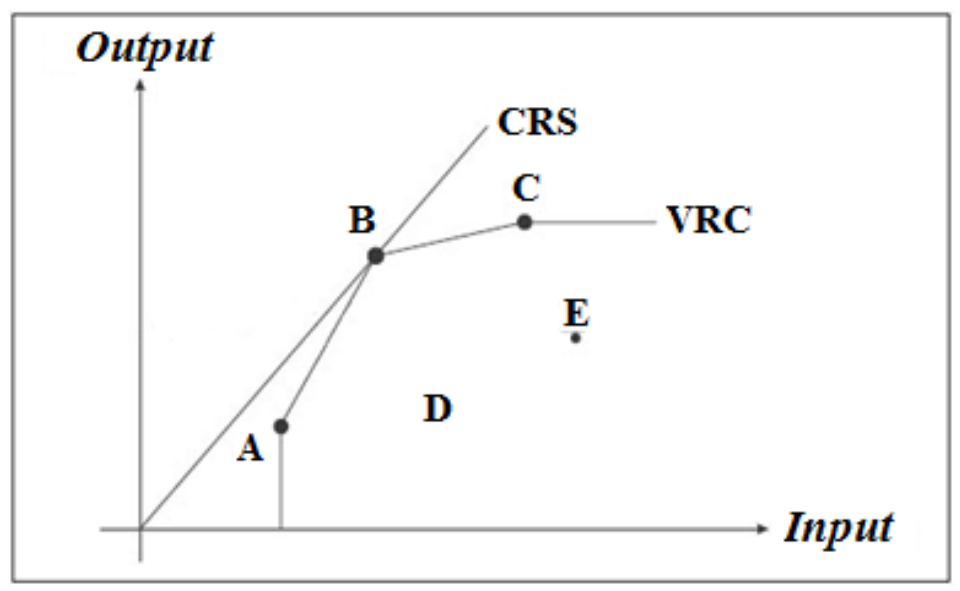

Fonte: Lobo e Lins (2011)

No primeiro modelo, a variação proporcional de produtos esperada está relacionada com a alteração dos recursos em todos os níveis de escala, ou seja, os outputs aumentam ou reduzem proporcionalmente aos aumentos ou reduções dos inputs (Lobo \& Lins, 2011). No segundo modelo, para os valores definidos de recursos despendidos, a variação dos produtos não assume uma proporcionalidade entre os inputs e outputs e sim o axioma da convexidade (Mello et al., 2005). As variações nos outputs e nos inputs não são influenciadas, um em relação ao outro. Refere-se a uma eficiência puramente técnica, por meio da minimização das entradas ou maximização das saídas.

Quanto aos retornos de escala, de acordo com Mariano, Almeida \& Rebelatto (2006), existem 3 (três) tipos de retorno de escala: crescente, constante e decrescente: 
- No retorno crescente, o aumento no número de inputs ocasiona um aumento desproporcionalmente maior no número de outputs, o que ocorre quando uma DMU está operando abaixo da sua capacidade ótima.

- No retorno constante, o aumento do número de inputs ocasiona um aumento proporcional nos outputs, quando uma DMU está operando na sua capacidade ótima.

- No retorno decrescente, o aumento do número de inputs ocasiona um aumento desproporcionalmente menor no número de outputs, se uma DMU está operando na acima da sua capacidade ótima. O retorno variável a escala significa que as DMUs podem apresentar qualquer um dos três tipos de retorno a escala. (p. 5-6)

Os modelos clássicos do DEA calculam diferentes tipos de eficiência. Quando aplicamos o modelo CCR, mensuramos a eficiência global ou total, desde que a combinação adequada de inputs e outputs esteja definida. Uma DMU é considerada eficiente quanto mais próxima estiver da fronteira de eficiência. Isto permite a diferenciação entre as DMUs eficientes e ineficientes.

A eficiência técnica está relacionada ao processo de produção, e mensurada pelo método BCC. Será eficiente a unidade produtiva com um determinado volume de insumos, que consiga atingir o máximo de produtos possíveis, ou seja, não há desperdícios de recursos no processo produtivo, sendo a eficiência técnica a relação da produção observada com uma produção potencial.

Segundo Herrero e Pascoe (2002), a eficiência técnica é apenas um componente da eficiência total, porém, também é pré-requisito para a eficiência econômica. A eficiência nesta percepção é compreendida como uma combinação ótima de entrada para um determinado nível de saída (orientação inputs), ou uma saída ótima para determinadas entradas (orientação outputs).

A eficiência total de uma DMU ocorre por meio da divisão entre a sua produtividade e a maior produtividade dentre as DMUs em análise, enquanto que a eficiência técnica, ocorre a comparação de uma DMU com todas aquelas que operem em escala semelhante a sua. Portanto, considerarando que a eficiência técnica é um componente da eficiência total, o outro componente é a eficiência de escala, definida como sendo a eficiência relacionada ao fato da DMU estar operando acima ou abaixo de sua escala considerada ótima. Assim, após calcularmos a eficiência total e a eficiência técnica (modelos CCR e BCC), pode-se calcular também a eficiência de escala, por meio da razão: 
Onde:

Eficiência total $=$ eficiência calculada pelo método CCR;

Eficiência técnica $=$ eficiência calculada pelo método BCC.

Os modelos clássicos da DEA apresentam duas orientações: para o inputs e para o outputs. Na orientação aos inputs busca-se a maximização dos outputs ou saídas, uma vez que são mantidos os inputs. Por outro lado, na orientação aos outputs, estes são mantidos constantes e busca-se a minimização dos inputs ou insumos (Mariano, 2008).

Considera-se eficiente a DMU que, em termos comparativos, tiver maior produção para volumes fixos de insumos e/ou utilizar menos recursos para gerar um volume fixo de produtos. Nesta pesquisa adotou-se a orientação aos outputs porque se utiliza como variável de entrada os recursos públicos (quando executados, se transformam em gastos, com a nomenclatura de despesa liquidada) que além da dificuldade de se obter um aumento desse recurso, devido a questões orçamentárias e políticas, pouco se alteram no curso dos anos, em termos reais, considerando a escassez de recursos financeiros e a amplitude das necessidades sociais. Também justifica a opção, a necessidade de minimizar os recursos empregados nos serviços de saúde, mantendo-se os outputs em constante evolução, para atender as exigências crescentes da sociedade.

$\mathrm{Na}$ literatura, o modelo VRS é indicado como sendo uma escolha interessante quando se quer comparar unidades de portes muito diferentes entre si. Lobo e Lins (2011, p. 95) destacam que para "garantir a homogeneidade das unidades de saúde a serem comparadas, é fundamental que estas sejam ajustadas por porte e complexidade para que a comparação seja válida e dotada de confiabilidade". Considerando estes preceitos pretende-se considerar nesta pesquisa o modelo VRS ou BCC.

Na seleção de variáveis para compor o modelo da DEA levou-se em consideração a observação de Varela e Pacheco (2012) referente às restrições da DEA quanto à medida das variáveis, no sentido de não se misturar índices com as medidas de volume, sob o risco de provocar distorções nos escores de eficiência.

\subsubsection{Seleção das variáveis}

A seleção das variáveis é uma importante etapa na análise da eficiência. De acordo 
com Bowlin (1998, p. 19), "A escolha de inputs e outputs corretos é importante para a interpretação, utilização e aceitação dos resultados da Análise da DEA". Apresenta quatro diretrizes a seguir na identifição de variáveis de entrada e saída apropriadas. Em primeiro lugar lembrar da questão da positividade da DEA. Deve-se ter uma base para acreditar que existem relações entre entradas e saídas, de tal forma que um aumento em uma entrada pode razoavelmente aumentar uma ou mais das saídas. Todas as medidas de inputs e outputs devem estar disponíveis em valores positivos em cada período, para cada DMU.

Outra consideração é se as variáveis são baseadas em dados disponíveis ou em novas medidas desenvolvidas. É desejável manter-se atualizado e próximo dos tipos de medidas de insumos e produtos utilizados para a avaliação do desempenho. Em terceiro lugar, as entradas e saídas devem ser abrangentes. Ou seja, devem medir completamente as atividades da organização sob avaliação e ser operacionalmente significativas no sentido de que elas devem ser usadas comumente e, portanto, familiar aos envolvidos na avaliação e no controle dessas atividades. Finalmente, os valores das variáveis devem ser controlados de modo que não possam ser facilmente manipulados ou negligentemente relatados sem alguma chance significativa de detecção e correção. Os resultados da DEA e a interpretação destes resultados podem ser significativamente afetados pela falta de dados ou por dados mal relatados.

Para (Golany \& Roll, 1989) a escolha das variáveis deve estar sempre relacionada ao objetivo que foi estabelecido para a análise. Caso seja necessário, as variáveis podem ser reduzidas em três etapas:

a) seleção inicial;

b) análise por modelos quantitativos; e

c) análise de sensibilidade.

A seleção inicial ou seleção criterial segundo Casa Nova (2002, p. 228), "envolve a análise subjetiva das variáveis", ou mesmo eliminar as variáveis que não estão relacionadas com o objetivo da análise. A análise por modelos quantitativos pode "utilizar de regressões estatísticas e a análise de correlação”, para avaliar se há evidência e eliminar redundância ou fatores. Já a análise de sensibilidade utiliza dos resultados da DEA, buscando verificar o impacto que a inclusão ou exclusão de uma variável traz para a eficiência das DMUs.

Nesta pesquisa, as variáveis selecionadas para compor o modelo de eficiência técnica são: 


\begin{tabular}{|c|c|c|c|}
\hline Tipo & Variável & Descrição & Fonte \\
\hline Input 1 & Despliq & Total da despesa liquidada com a função saúde & SIOPS/DATASUS \\
\hline Output 1 & TMI & Taxa de mortalidade infantil & DATASUS \\
\hline Output 2 & TMM & Taxa de mortalidade materna & DATASUS \\
\hline
\end{tabular}

Quadro 3 - Input e Outputs do modelo de eficiência das Regiões de Saúde mineiras

Para cada uma das 77 Regiões de Saúde foi estimada uma função de produção composta por um input e dois outputs. As variáveis consideradas como outputs, nesse modelo tem a condição de indicador como um produto final ou um resultado final representando o setor saúde, no sentido de um indicador de qualidade da saúde, assim as variáveis assemelham-se a outcomes. Destaca-se que todas as variáveis utilizadas, principalmente os outputs, têm relação com a função saúde de forma ampliada, ou seja, em todos os níveis de atenção, desde a atenção básica à saúde, à média e alta complexidade; considerando o interesse do estudo nesses três níveis de atenção. Portanto a escolha dessas variáveis se baseou na utilização ampla das mesmas em estudos empíricos.

\subsubsection{Detecção de outliers}

Observações atípicas ou outliers segundo Hair Jr., Anderson, Tatham e Black (2005),

\footnotetext{
são observações com uma combinação única de características identificáveis como sendo notavelmente diferentes das outras observações. As observações atípicas não podem ser categoricamente caracterizadas como benéficas ou problemáticas, mas devem ser vistas no contexto da análise e avaliadas pelos tipos de informação que possam fornecer. (p.71)
}

As observações atípicas podem ser benéficas e um indicativo de características de uma população, ou problemáticas e não representam uma população e são contrárias ao objetivo da análise, e no caso podem distorcer os testes estatísticos. Podem decorrer de erros na entrada de dados, do resultado de um evento extraordinário, de observações extraordinárias para as quais o pesquisador não tem explicação e de observações que estão no intervalo usual de valores para cada variável, mas são únicas em sua combinação de valores entre as variáveis. (Hair Jr. et al., 2005, p. 71) 
A análise da eficiência calculada pelo DEA, pode ser sensível a presença de outliers nos dados. Portanto a sua existência deve ser examinada, o tratamento definido e se necessário, excluído. Ainda segundo Hair Jr. et al., (2005, p. 73) quando os outliers forem identificados e classificados, o pesquisador deve decidir sobre a sua retenção ou eliminação. Nesse aspecto, sob a ótica dos autores essas observações atípicas “devem ser mantidas, a menos que exista prova demonstrável de que estão verdadeiramente fora do normal e que não são representativas de quaisquer observações na população."

Segundo Sylvain Weber (2010) a identificação de outliers em dados multivariados é computacionalmente intensiva. $\mathrm{O}$ autor recomenda o uso do comando bacon, que permite a identificação de outliers, mesmo em grandes conjuntos de dados para milhares de observações. Sob a sua visão, o comando blocked adaptive computationlly efficient outlier nominators (bacon) constitui uma alternativa atraente e vantajosa em relação ao comando hadimvo, apresentado por Hadi (1992) e Hadi (1994) como um comando disponível no Stata para a detecção de outliers. Comparado com hadimvo, bacon parece identificar mais rapidamente um conjunto de observações como outliers.

Neste estudo decidimos pelo uso do comando bacon, aplicando a técnica a todas as variáveis para os períodos de 2010, 2011, 2012, 2013 e 2014, correspondendo a 77 observações para cada variável, por ano; e também para o conjunto de dados referente ao período de cinco anos, correspondendo a 385 observações para cada variável no período quinquenal. Na tabela 4 apresentamos a estatística descritiva do conjunto de dados em valores originais relativo ao período quinquenal de 2010 à 2014 .

Tabela 4 - Estatística descritiva das variáveis no período quinquenal de 2010 à 2014

\begin{tabular}{|l|l|r|r|r|r|}
\hline \multicolumn{1}{|c|}{ Variable } & Obs & \multicolumn{1}{c|}{ Mean } & \multicolumn{1}{c|}{ Std. Dev. } & \multicolumn{1}{c|}{ Min } & \multicolumn{1}{c|}{ Max } \\
\hline DespLiq & 385 & 364.29 & 110.19 & 121.68 & 845.34 \\
\hline TMI & 385 & 13.76 & 4.08 & 4.97 & 35.50 \\
\hline TMM & 385 & 45.26 & 53.32 & 0 & 310.88 \\
\hline
\end{tabular}

Fonte: Resultados da pesquisa

Tabela 5 - Resultados bacon outliers das variáveis de 2010 à 2014

\begin{tabular}{ccccc}
\hline Resultados quinquenal de $\mathbf{2 0 1 0}$ à $\mathbf{2 0 1 4}$ & \multicolumn{2}{c}{ Resultado anual: de 2010 até $\mathbf{2 0 1 4}$} \\
\hline Total number of observations: & 385 & Total number of observations: & 77 \\
BACON outliers $(\mathrm{p}=0.05):$ & 0 & BACON outliers $(\mathrm{p}=0.05):$ & 0 \\
Non-outliers remaining: & 385 & Non-outliers remaining: & 77 \\
\hline Fonte: Resultados da pesquisa & &
\end{tabular}

Fonte: Resultados da pesquisa 
$\mathrm{Na}$ tabela 5, apresentamos os resultados da técnica bacon aplicada a todas as variáveis em seus valores originais. Verifica-se na exposição dos dados, que os resultados quinquenal de todas as variáveis (conjunto) correspondendo aos cinco anos de 2010 à 2014, nenhuma das 385 observações foram consideradas atípicas ou outliers. O mesmo resultado se repetiu para todos os anos individualmente, ou seja, nenhuma das 77 Regiões de Saúde no ano de 2010, foi considerada atípica ou outlier, sendo que o resultado se repetiu para os anos de 2011, 2012, 2013 e 2014. Portanto, neste estudo não eliminamos nenhuma variável da análise. Trabalhou-se com as 77 Regiões de Saúde do estado de Minas Gerais, para cada ano estudado: de 2010 à 2014. 


\section{APRESENTAÇÃO E ANÁLISE DE DADOS}

Neste capítulo apresentamos a análise das variáveis utilizadas no estudo. Foram utilizadas técnicas de avaliação quantitativas para a organização, caracterização e interpretação dos dados numéricos, principalmente a estatística descritiva. Destaca-se que tanto para a análise dos gastos públicos e dos indicadores, quanto para na sequência a mensuração da eficiência técnica, foram adotados modelos matemático e estatístico, utilizando-se como suporte para efetuar as análises os softwares Excel e o Stata 13.0.

\subsection{Análise da variável despesa liquidada na função saúde: input na DEA}

Há uma exigência legal que obriga a administração pública a informar, em relatórios e demonstrações periódicas, as despesas por função e subfunção. Portanto, passou a ser possível a análise da atuação das despesas de forma pormenorizada. Neste estudo coletamos os dados pelo total da despesa na função saúde, para todos os municípios mineiros.

Considerando que o nosso interesse são os três níveis de atenção à saúde (atenção primária, média e alta complexidade), agrupamos os valores da Despesa liquidada na função saúde para todas as Regiões de Saúde (RS), que agregam como responsabilidade os três níveis de atenção. Portanto selecionamos na Despesa liquidada, os valores referentes a rubrica Atenção básica (nível atenção primária) e a Assistência Hospitalar e Ambulatorial dos municípios (média e alta complexidade), agrupados por Região de Saúde (RS).

A opção pela "despesa liquidada" como variável de entrada (input) se justifica porque nessa fase a despesa é reconhecida efetivamente, tendo, inclusive, os serviços ou produtos já entregues aos usuários. Na literatura citada de trabalhos que utilizaram a análise da eficiência pela técnica DEA na área da saúde, em sua maioria utilizaram a Despesa liquidada como variável de entrada (inputs).

Os dados financeiros referente as despesas liquidadas são por um período de cinco anos (de 2010 à 2014), optamos por fazer a correção dos valores financeiros, e analisar se ocorreram variações significativas no período. Assim os dados foram corrigidos, tendo por base o ano de 2014 (dezembro/2014), utilizando como indicador o Índice Geral de Preços Disponibilidade Interna (IGP-DI), disponibilizado pela Fundacão Getúlio Vargas, conforme 
Tabela 6, para que a análise da evolução dos gastos não sofresse a interferência da variação do poder de compra da moeda no período.

\begin{tabular}{ccc} 
Tabela 6 - Índice Geral de Preços - Disponibilidade Interna (IGP-DI) - 2010 à 2014 \\
\hline Ano & IGP-DI & $\begin{array}{c}\text { IGP-DI } \\
\text { Ano-base 2014 }\end{array}$ \\
\hline Dezembro/2010 & $1.171,6588$ & 1,2434 \\
Dezembro/2011 & $1.230,3887$ & 1,1840 \\
Dezembro/2012 & $1.330,1986$ & 1,0952 \\
Dezembro/2013 & $1.403,7288$ & 1,0378 \\
Dezembro/2014 & $1.456,7897$ & 1,0000 \\
\hline Fonte: Fundação Getúlio Vargas (2016)
\end{tabular}

$\mathrm{Na}$ Tabela 7, verifica-se que na maioria das RS houve variação positiva da despesa liquidada per capita, entre o ano de 2010 e 2014. As RS que apresentaram variações negativas, foram: Betim, Viçosa, Manga e Poços de Caldas. Isto significa que em valores ajustados, trazidos a valor presente, considerando os efeitos da inflação no período, o valor da despesa liquidada nestas RS reduziram no período, entre o ano de 2010 e 2014.

Destaca-se que nas Regiões Ampliadas de Saúde: Noroeste, Triângulo do Norte e Triângulo do Sul, nenhuma das Regiões de Saúde (RS) que as compõem tiveram valores de despesa liquidada abaixo da média per capita anual, no entanto, em Jequitinhonha ocorreu o contrário, ou seja, nenhuma das RS alcançou a média per capita anual, no período. Em todas as outras Regiões Ampliadas de Saúde, constam algumas RS com valores abaixo da média per capita anual, em todos os anos. Pelas medidas do mínimo e máximo observa-se que há uma dispersão dos valores gastos nas RS, o que é confirmado pelos altos valores de desvio padrão. 
Tabela 7 - Despesa Liquidada per capita das Regiões de Saúde de Minas Gerais em valores em R\$ de dezembro de 2014, com uso do IGP-I

\begin{tabular}{|c|c|c|c|c|c|c|c|c|}
\hline \multirow[b]{2}{*}{$\begin{array}{c}\text { Região } \\
\text { Ampliada }\end{array}$} & \multirow[b]{2}{*}{$\begin{array}{l}N^{0} . \\
\text { RS }\end{array}$} & \multirow[b]{2}{*}{ Região de Saúde } & \multicolumn{6}{|c|}{ Despesa Liquidada per capita em reais } \\
\hline & & & 2010 & 2011 & 2012 & 2013 & 2014 & $\begin{array}{c}\Delta \% \\
(2010- \\
2014)\end{array}$ \\
\hline \multirow{10}{*}{ Centro } & 01 & Belo Horizonte & 470,02 & 462,79 & 526,73 & 574,61 & 636,59 & $35,4 \%$ \\
\hline & 02 & Betim & 412,61 & 432,53 & 429,77 & 324,60 & 395,64 & $-4,1 \%$ \\
\hline & 03 & Contagem & 218,22 & 250,28 & 270,86 & 258,15 & 296,25 & $35,8 \%$ \\
\hline & 04 & Curvelo & 365,33 & 337,29 & 418,11 & 425,42 & 475,33 & $30,1 \%$ \\
\hline & 05 & Guanhães & 306,23 & 322,17 & 326,68 & 326,77 & 376,61 & $23,0 \%$ \\
\hline & 06 & Itabira & 424,15 & 506,28 & 593,72 & 673,19 & 845,34 & $99,3 \%$ \\
\hline & 07 & João Monlevade & 438,03 & 439,47 & 486,02 & 502,45 & 589,43 & $34,6 \%$ \\
\hline & 08 & Ouro Preto & 309,71 & 356,84 & 480,88 & 533,46 & 526,69 & $70,1 \%$ \\
\hline & 09 & Sete Lagoas & 423,01 & 431,81 & 550,37 & 474,58 & 576,43 & $36,3 \%$ \\
\hline & 10 & Vespasiano & 289,03 & 343,32 & 414,47 & 429,83 & 487,12 & $68,5 \%$ \\
\hline \multirow{3}{*}{ Centro Sul } & 11 & Barbacena & 305,69 & 549,31 & 547,57 & 462,15 & 587,33 & $92,1 \%$ \\
\hline & 12 & Cons. Lafaiete & 408,70 & 464,89 & 455,61 & 405,32 & 490,39 & $20,0 \%$ \\
\hline & 13 & S. João Del Rei & 345,64 & 381,35 & 403,06 & 394,82 & 440,58 & $27,5 \%$ \\
\hline \multirow{2}{*}{ Jequitinhonha } & 14 & Diamantina & 256,01 & 267,29 & 309,95 & 339,14 & 379,57 & $48,3 \%$ \\
\hline & 15 & Minas Novas & 307,00 & 314,73 & 318,28 & 319,27 & 344,69 & $12,3 \%$ \\
\hline \multirow{7}{*}{ Leste } & 16 & Caratinga & 377,95 & 397,46 & 412,99 & 415,06 & 483,70 & $28,0 \%$ \\
\hline & 17 & Cel. Fabriciano & 303,46 & 306,45 & 330,27 & 281,73 & 325,08 & $7,1 \%$ \\
\hline & 18 & Gov. Valadares & 253,36 & 279,83 & 322,94 & 307,42 & 348,40 & $37,5 \%$ \\
\hline & 19 & Ipatinga & 421,04 & 416,18 & 405,74 & 415,80 & 488,54 & $16,0 \%$ \\
\hline & 20 & Mantena & 307,19 & 325,24 & 334,21 & 341,88 & 432,50 & $40,8 \%$ \\
\hline & 21 & Resplendor & 268,34 & 317,66 & 390,62 & 403,16 & 411,60 & $53,4 \%$ \\
\hline & 22 & S.Maria Suaçui & 269,72 & 291,94 & 313,01 & 287,98 & 328,46 & $21,8 \%$ \\
\hline \multirow{3}{*}{ Leste do Sul } & 23 & Manhuaçu & 362,73 & 365,36 & 375,31 & 356,72 & 407,46 & $12,3 \%$ \\
\hline & 24 & Ponte Nova & 468,85 & 470,15 & 520,26 & 524,61 & 603,20 & $28,7 \%$ \\
\hline & 25 & Viçosa & 348,34 & 332,20 & 370,08 & 205,69 & 238,93 & $-31,4 \%$ \\
\hline \multirow{8}{*}{ Nordeste } & 26 & Águas Formosas & 272,68 & 300,36 & 271,30 & 293,79 & 328,27 & $20,4 \%$ \\
\hline & 27 & Almenara & 285,41 & 274,85 & 312,72 & 319,82 & 362,05 & $26,9 \%$ \\
\hline & 28 & Araçuaí & 263,51 & 269,95 & 287,20 & 270,25 & 398,99 & $51,4 \%$ \\
\hline & 29 & Itaobim & 266,66 & 300,09 & 319,79 & 316,35 & 331,33 & $24,3 \%$ \\
\hline & 30 & Nanuque & 257,78 & 243,05 & 267,15 & 242,39 & 280,90 & $9,0 \%$ \\
\hline & 31 & Padre Paraíso & 300,01 & 298,33 & 246,99 & 298,53 & 317,04 & $5,7 \%$ \\
\hline & 32 & Pedra Azul & 288,84 & 284,71 & 268,33 & 278,15 & 336,28 & $16,4 \%$ \\
\hline & 33 & Teófilo Otoni & 376,70 & 399,24 & 457,08 & 434,60 & 525,50 & $39,5 \%$ \\
\hline \multirow{3}{*}{ Noroeste } & 34 & João Pinheiro & 463,63 & 455,82 & 445,21 & 426,32 & 489,69 & $5,6 \%$ \\
\hline & 35 & Patos de Minas & 434,87 & 471,51 & 492,76 & 477,25 & 544,93 & $25,3 \%$ \\
\hline & 36 & Unaí & 377,40 & 404,33 & 427,76 & 429,19 & 478,03 & $26,7 \%$ \\
\hline \multirow{9}{*}{ Norte } & 37 & Brasília Minas & 366,40 & 382,01 & 390,90 & 373,90 & 423,06 & $15,5 \%$ \\
\hline & 38 & Coração de Jesus & 415,10 & 397,24 & 424,01 & 389,05 & 463,40 & $11,6 \%$ \\
\hline & 39 & Francisco Sá & 377,15 & 379,62 & 433,23 & 427,15 & 477,94 & $26,7 \%$ \\
\hline & 40 & Janaúba & 297,04 & 314,01 & 368,39 & 339,03 & 420,40 & $41,5 \%$ \\
\hline & 41 & Januária & 317,14 & 324,45 & 342,33 & 322,53 & 372,06 & $17,3 \%$ \\
\hline & 42 & Manga & 310,57 & 322,01 & 332,66 & 267,74 & 306,56 & $-1,3 \%$ \\
\hline & 43 & Montes Claros & 542,38 & 545,64 & 598,39 & 540,69 & 578,59 & $6,7 \%$ \\
\hline & 44 & Pirapora & 314,36 & 341,29 & 401,41 & 378,07 & 448,18 & $42,6 \%$ \\
\hline & 45 & Salinas & 364,25 & 388,38 & 417,27 & 395,77 & 430,90 & $18,3 \%$ \\
\hline \multirow{4}{*}{ Oeste } & 46 & Bom Despacho & 279,06 & 275,79 & 308,70 & 300,00 & 330,91 & $18,6 \%$ \\
\hline & 47 & Divinópolis & 415,31 & 463,70 & 472,59 & 436,16 & 494,87 & $19,2 \%$ \\
\hline & 48 & Formiga & 333,53 & 330,71 & 353,96 & 379,14 & 432,30 & $29,6 \%$ \\
\hline & 49 & Itaúna & 415,30 & 448,94 & 486,72 & 478,25 & 572,97 & $38,0 \%$ \\
\hline
\end{tabular}




\begin{tabular}{|c|c|c|c|c|c|c|c|c|}
\hline & 50 & Pará de Minas & 263,29 & 285,12 & 315,92 & 316,47 & 384,41 & $46,0 \%$ \\
\hline & 51 & S. Ant. Amparo & 344,47 & 380,74 & 418,05 & 418,97 & 512,07 & $48,7 \%$ \\
\hline \multirow{8}{*}{ Sudeste } & 52 & Além Paraíba & 396,18 & 400,02 & 412,56 & 415,05 & 462,18 & $16,7 \%$ \\
\hline & 53 & Carangola & 318,90 & 322,45 & 419,17 & 396,57 & 498,61 & $56,4 \%$ \\
\hline & 54 & Juiz de Fora & 529,89 & 571,05 & 604,91 & 552,45 & 680,70 & $28,5 \%$ \\
\hline & 55 & Leopoldina & 341,30 & 378,23 & 390,45 & 385,14 & 418,96 & $22,8 \%$ \\
\hline & 56 & Muriaé & 258,11 & 282,35 & 286,38 & 284,33 & 339,44 & $31,5 \%$ \\
\hline & 57 & Santos Dumont & 151,30 & 165,30 & 179,22 & 151,13 & 249,37 & $64,8 \%$ \\
\hline & 58 & S. João Nepom. & 267,33 & 321,72 & 380,40 & 367,75 & 415,00 & $55,2 \%$ \\
\hline & 59 & Ubá & 281,38 & 265,88 & 272,00 & 282,62 & 333,63 & $18,6 \%$ \\
\hline \multirow{12}{*}{ Sul } & 60 & Alfenas & 400,64 & 424,45 & 472,61 & 483,67 & 513,95 & $28,3 \%$ \\
\hline & 61 & Guaxupé & 293,01 & 309,89 & 339,68 & 340,03 & 368,00 & $25,6 \%$ \\
\hline & 62 & Itajubá & 283,26 & 302,02 & 329,01 & 330,22 & 364,21 & $28,6 \%$ \\
\hline & 63 & Lavras & 492,04 & 515,83 & 546,27 & 507,47 & 562,40 & $14,3 \%$ \\
\hline & 64 & Passos & 428,52 & 426,96 & 449,77 & 477,06 & 542,27 & $26,5 \%$ \\
\hline & 65 & Poços de Caldas & 656,38 & 798,77 & 750,04 & 781,47 & 472,61 & $-28,0 \%$ \\
\hline & 66 & Pouso Alegre & 357,51 & 369,12 & 376,63 & 371,02 & 456,49 & $27,7 \%$ \\
\hline & 67 & São Lourenço & 344,31 & 364,71 & 378,57 & 360,40 & 407,99 & $18,5 \%$ \\
\hline & 68 & S.Seb.Paraiso & 482,61 & 513,94 & 526,74 & 586,36 & 796,53 & $65,0 \%$ \\
\hline & 69 & Três Corações & 294,51 & 340,85 & 351,30 & 386,69 & 329,67 & $11,9 \%$ \\
\hline & 70 & Três Pontas & 388,58 & 430,55 & 439,28 & 471,46 & 500,54 & $28,8 \%$ \\
\hline & 71 & Varginha & 162,37 & 209,91 & 400,74 & 443,12 & 555,02 & $241,8 \%$ \\
\hline \multirow{3}{*}{ Triâng. Norte } & 72 & Ituiutaba & 359,99 & 380,54 & 467,00 & 455,75 & 493,39 & $37,1 \%$ \\
\hline & 73 & Patrocínio & 410,24 & 433,66 & 464,99 & 494,77 & 546,84 & $33,3 \%$ \\
\hline & 74 & Uberlândia & 505,45 & 579,25 & 609,61 & 599,11 & 552,02 & $9,2 \%$ \\
\hline \multirow{3}{*}{ Triâng.do Sul } & 75 & Araxá & 436,62 & 451,80 & 453,53 & 464,89 & 456,56 & $4,6 \%$ \\
\hline & 76 & Frutal & 505,82 & 525,69 & 542,83 & 522,67 & 590,44 & $16,7 \%$ \\
\hline & 77 & Uberaba & 420,10 & 467,63 & 488,75 & 477,27 & 558,30 & $32,9 \%$ \\
\hline \multirow{4}{*}{$\begin{array}{l}\text { Estatística } \\
\text { Descritiva }\end{array}$} & & Média & 355,45 & 379,19 & 409,10 & 401,58 & 454,84 & \\
\hline & & Desvio Padrão & 88,94 & 99,98 & 100,61 & 106,86 & 113,81 & \\
\hline & & Mínimo & 151,30 & 165,30 & 179,22 & 151,13 & 238,93 & \\
\hline & & Máximo & 656,38 & 798,77 & 750,04 & 781,47 & 845,34 & \\
\hline
\end{tabular}

Fonte: Dados da pesquisa coletados no sítio da DATASUS

Observando as variações percentuais em nível horizontal nas RS no período dos cinco anos, a maior evolução percentual do gasto per capita entre 2010 e 2014, foram em Varginha em torno de 242\%, seguida por Itabira, Barbacena, Ouro Preto, Vespasiano, São Sebastião do Paraíso e Santos Dumont. Todas essas RS tiveram acréscimo acima de $60 \%$ de ganho real no período de 5 anos, considerando os valores corrigidos. Portanto, ocorreu um aumento real dos gastos nessas RS, independente se os valores são menores ou não com relação às outras RS.

\subsection{Análise das Variáveis TMI e TMM: outputs na DEA}

Considerando que na análise da eficiência pelo DEA utilizamos como outputs a TMI e a TMM, apresentamos na Tabela 8 por RS a evolução e variação do indicador Taxa de 
Mortalidade Infantil (TMI) de 2010 à 2014, coletado no sítio do DATASUS. Destaca-se que a TMI é um dos indicadores mais utilizados em estudos empíricos, como já citado.

Observando na Tabela 8, os dados das RS de Minas Gerais verifica-se nos valores da TMI absoluta, que há variações significativas entre as RS. Observando a estatística descritiva no período de cinco anos, a menor TMI atingida foi de 4,97 (em 2014), enquanto a maior TMI foi de 35,50 em (2012). A RS de Ituiutaba obteve as menores TMI em dois anos (2011 e 2014), enquanto a RS de Pedra Azul obteve as maiores TMI em dois anos consecutivos (2012 e 2013).

$\mathrm{Na}$ análise horizontal das variações percentuais calculada sobre a diferença da TMI entre o ano de 2010 e o de 2014, não considerando as variações ao longo do período (ano a ano) entre as RS, observa-se a maior variabilidade positiva da TMI na RS de Mantena na Região Ampliada Leste, enquanto a RS de Lavras da Região Ampliada Sul, obteve a maior variabilidade negativa do indicador.

A TMI é um indicador com a tendência de quanto menor, melhor. Assim comparando as RS, a de Mantena obteve a maior redução na TMI, que passou de 16,84 para 6,98 no período de 2010 à 2014, enquanto a RS de Lavras obteve o maior acréscimo na TMI no mesmo período, que passou de 7,82 para 14,27. São casos a se observar pela discrepância das taxas, pois tanto Mantena que obteve valores altos e homogêneos de TMI de 2010 a 2013, baixou drasticamente em 2014, enquanto Lavras onde ocorreu o inverso, obteve uma taxa baixa em 2010 com um acréscimo significante em 2011, se mantendo estável nos períodos subseqüentes, com baixa variabilidade. 
Tabela 8 - Taxa de Mortalidade Infantil (TMI) nas RS de Minas Gerais

\begin{tabular}{|c|c|c|c|c|c|c|c|c|}
\hline \multirow{2}{*}{$\begin{array}{c}\text { Região } \\
\text { Ampliada }\end{array}$} & \multirow{2}{*}{$\begin{array}{l}N^{0} . \\
\text { RS }\end{array}$} & \multirow[b]{2}{*}{ Região de Saúde } & \multicolumn{6}{|c|}{ Taxa de Mortalidade Infantil - TMI } \\
\hline & & & 2010 & 2011 & 2012 & 2013 & 2014 & $\begin{array}{c}\Delta \% \\
(2010-2014)\end{array}$ \\
\hline \multirow{10}{*}{ Centro } & 01 & Belo Horizonte & 11,69 & 10,25 & 10,85 & 10,31 & 9,92 & $15,1 \%$ \\
\hline & 02 & Betim & 10,70 & 10,32 & 10,86 & 12,67 & 11,23 & $-5,0 \%$ \\
\hline & 03 & Contagem & 12,34 & 11,36 & 8,62 & 10,62 & 9,95 & $19,4 \%$ \\
\hline & 04 & Curvelo & 13,68 & 13,86 & 15,21 & 13,72 & 11,74 & $14,2 \%$ \\
\hline & 05 & Guanhães & 18,40 & 14,29 & 16,03 & 18,75 & 17,51 & $4,8 \%$ \\
\hline & 06 & Itabira & 13,34 & 15,74 & 11,36 & 10,38 & 10,78 & $19,2 \%$ \\
\hline & 07 & João Monlevade & 15,08 & 12,55 & 16,31 & 10,01 & 16,83 & $-11,6 \%$ \\
\hline & 08 & Ouro Preto & 12,17 & 13,38 & 10,92 & 6,02 & 10,95 & $10,0 \%$ \\
\hline & 09 & Sete Lagoas & 13,26 & 14,59 & 17,24 & 12,67 & 10,19 & $23,2 \%$ \\
\hline & 10 & Vespasiano & 13,12 & 9,15 & 10,28 & 12,01 & 9,64 & $26,5 \%$ \\
\hline \multirow{3}{*}{ Centro Sul } & 11 & Barbacena & 12,67 & 23,01 & 14,53 & 14,37 & 11,26 & $11,1 \%$ \\
\hline & 12 & Cons. Lafaiete & 14,26 & 13,09 & 13,45 & 13,80 & 10,80 & $24,3 \%$ \\
\hline & 13 & S. João Del Rei & 15,52 & 10,98 & 14,31 & 13,78 & 11,59 & $25,3 \%$ \\
\hline \multirow{2}{*}{ Jequitinhonha } & 14 & Diamantina & 13,11 & 15,96 & 18,96 & 20,19 & 11,42 & $12,9 \%$ \\
\hline & 15 & Minas Novas & 20,08 & 21,88 & 9,73 & 15,60 & 12,91 & $35,7 \%$ \\
\hline \multirow{7}{*}{ Leste } & 16 & Caratinga & 15,32 & 20,50 & 16,01 & 14,98 & 14,67 & $4,2 \%$ \\
\hline & 17 & Cel. Fabriciano & 16,39 & 15,60 & 12,82 & 12,69 & 10,52 & $35,8 \%$ \\
\hline & 18 & Gov. Valadares & 12,56 & 11,81 & 13,53 & 12,75 & 15,04 & $-19,7 \%$ \\
\hline & 19 & Ipatinga & 11,94 & 11,06 & 8,79 & 7,53 & 9,73 & $18,5 \%$ \\
\hline & 20 & Mantena & 16,84 & 12,87 & 17,48 & 15,67 & 6,98 & $58,6 \%$ \\
\hline & 21 & Resplendor & 14,53 & 15,26 & 17,41 & 22,91 & 9,83 & $32,3 \%$ \\
\hline & 22 & S.Maria Suaçui & 9,08 & 16,47 & 18,59 & 20,55 & 10,52 & $-15,9 \%$ \\
\hline \multirow{3}{*}{ Leste do Sul } & 23 & Manhuaçu & 14,66 & 17,04 & 14,84 & 13,30 & 12,26 & $16,4 \%$ \\
\hline & 24 & Ponte Nova & 14,32 & 10,30 & 20,21 & 12,16 & 11,42 & $20,3 \%$ \\
\hline & 25 & Viçosa & 23,77 & 16,62 & 6,92 & 7,13 & 11,07 & $53,4 \%$ \\
\hline \multirow{8}{*}{ Nordeste } & 26 & Águas Formosas & 26,26 & 16,81 & 18,23 & 22,59 & 24,53 & $6,6 \%$ \\
\hline & 27 & Almenara & 16,70 & 22,13 & 17,45 & 19,86 & 17,63 & $-5,6 \%$ \\
\hline & 28 & Araçuaí & 11,01 & 19,68 & 19,06 & 7,70 & 15,31 & $-39,1 \%$ \\
\hline & 29 & Itaobim & 19,41 & 17,26 & 17,93 & 7,25 & 16,51 & $14,9 \%$ \\
\hline & 30 & Nanuque & 11,89 & 14,27 & 13,33 & 10,55 & 14,40 & $-21,1 \%$ \\
\hline & 31 & Padre Paraíso & 15,94 & 17,91 & 17,54 & 13,67 & 23,17 & $-45,4 \%$ \\
\hline & 32 & Pedra Azul & 19,54 & 20,12 & 35,50 & 23,64 & 14,60 & $25,3 \%$ \\
\hline & 33 & Teófilo Otoni & 19,91 & 19,83 & 20,67 & 18,66 & 15,63 & $21,5 \%$ \\
\hline \multirow{3}{*}{ Noroeste } & 34 & João Pinheiro & 12,30 & 12,76 & 10,56 & 15,99 & 13,07 & $-6,3 \%$ \\
\hline & 35 & Patos de Minas & 14,15 & 12,97 & 12,63 & 13,36 & 10,23 & $27,7 \%$ \\
\hline & 36 & Unaí & 11,31 & 11,17 & 15,29 & 14,28 & 10,44 & $7,7 \%$ \\
\hline \multirow{9}{*}{ Norte } & 37 & Brasília Minas & 16,10 & 17,81 & 15,35 & 16,61 & 14,55 & $9,6 \%$ \\
\hline & 38 & Coração de Jesus & 23,03 & 15,90 & 21,70 & 20,08 & 11,83 & $48,6 \%$ \\
\hline & 39 & Francisco Sá & 7,48 & 18,09 & 22,99 & 20,04 & 11,02 & $-47,3 \%$ \\
\hline & 40 & Janaúba & 10,35 & 10,14 & 10,84 & 15,97 & 12,22 & $-18,1 \%$ \\
\hline & 41 & Januária & 15,11 & 10,89 & 14,50 & 14,37 & 18,71 & $-23,8 \%$ \\
\hline & 42 & Manga & 20,45 & 18,95 & 14,77 & 14,02 & 13,05 & $36,2 \%$ \\
\hline & 43 & Montes Claros & 11,58 & 12,15 & 12,13 & 13,16 & 10,49 & $9,4 \%$ \\
\hline & 44 & Pirapora & 20,38 & 13,53 & 14,79 & 18,71 & 12,64 & $38,0 \%$ \\
\hline & 45 & Salinas & 13,40 & 18,78 & 12,19 & 10,78 & 11,97 & $10,7 \%$ \\
\hline \multirow{6}{*}{ Oeste } & 46 & Bom Despacho & 17,75 & 18,21 & 11,47 & 9,96 & 14,43 & $18,7 \%$ \\
\hline & 47 & Divinópolis & 13,10 & 14,26 & 12,34 & 7,85 & 8,25 & $37,0 \%$ \\
\hline & 48 & Formiga & 10,75 & 8,94 & 13,67 & 11,55 & 13,25 & $-23,3 \%$ \\
\hline & 49 & Itaúna & 12,25 & 15,33 & 8,41 & 14,12 & 9,68 & $21,0 \%$ \\
\hline & 50 & Pará de Minas & 13,03 & 15,01 & 15,61 & 12,98 & 9,40 & $27,9 \%$ \\
\hline & 51 & S. Ant. Amparo & 10,40 & 16,20 & 8,81 & 9,44 & 8,95 & $13,9 \%$ \\
\hline \multirow{2}{*}{ Sudeste } & 52 & Além Paraíba & 21,13 & 16,90 & 29,54 & 13,64 & 10,91 & $48,4 \%$ \\
\hline & 53 & Carangola & 15,84 & 21,97 & 21,42 & 12,35 & 8,87 & $44,0 \%$ \\
\hline
\end{tabular}




\begin{tabular}{|c|c|c|c|c|c|c|c|c|}
\hline & 54 & Juiz de Fora & 18,06 & 13,23 & 14,34 & 13,44 & 14,14 & $21,7 \%$ \\
\hline & 55 & Leopoldina & 11,95 & 16,54 & 14,84 & 13,43 & 12,36 & $-3,4 \%$ \\
\hline & 56 & Muriaé & 16,61 & 13,05 & 13,65 & 13,69 & 8,65 & $47,9 \%$ \\
\hline & 57 & Santos Dumont & 20,24 & 8,98 & 23,68 & 11,17 & 26,06 & $-28,8 \%$ \\
\hline & 58 & S. João Nepom. & 17,79 & 18,78 & 17,35 & 19,71 & 16,25 & $8,7 \%$ \\
\hline & 59 & Ubá & 14,11 & 10,99 & 13,95 & 11,99 & 14,85 & $-5,2 \%$ \\
\hline \multirow{12}{*}{ Sul } & 60 & Alfenas & 10,87 & 11,71 & 14,46 & 13,69 & 10,17 & $6,4 \%$ \\
\hline & 61 & Guaxupé & 8,43 & 12,00 & 12,63 & 15,86 & 6,70 & $20,5 \%$ \\
\hline & 62 & Itajubá & 18,15 & 14,51 & 9,98 & 10,33 & 9,86 & $45,7 \%$ \\
\hline & 63 & Lavras & 7,82 & 15,52 & 17,75 & 11,85 & 14,27 & $-82,5 \%$ \\
\hline & 64 & Passos & 10,90 & 14,88 & 10,12 & 9,41 & 12,86 & $-18,0 \%$ \\
\hline & 65 & Poços de Caldas & 7,76 & 8,29 & 8,80 & 12,63 & 8,54 & $-10,1 \%$ \\
\hline & 66 & Pouso Alegre & 12,33 & 13,11 & 12,18 & 9,84 & 12,12 & $1,7 \%$ \\
\hline & 67 & São Lourenço & 7,37 & 11,78 & 11,76 & 10,47 & 10,97 & $-48,8 \%$ \\
\hline & 68 & S.Seb.Paraiso & 16,34 & 12,75 & 13,17 & 9,82 & 13,12 & $19,7 \%$ \\
\hline & 69 & Três Corações & 16,09 & 19,28 & 14,78 & 13,81 & 15,68 & $2,55 \%$ \\
\hline & 70 & Três Pontas & 13,36 & 12,15 & 7,51 & 13,13 & 14,17 & $-6,1 \%$ \\
\hline & 71 & Varginha & 7,06 & 9,17 & 9,99 & 9,21 & 6,79 & $3,8 \%$ \\
\hline \multirow{3}{*}{ Triâng. Norte } & 72 & Ituiutaba & 10,28 & 8,08 & 11,86 & 9,79 & 4,97 & $51,7 \%$ \\
\hline & 73 & Patrocínio & 12,99 & 9,24 & 13,00 & 8,92 & 9,80 & $24,6 \%$ \\
\hline & 74 & Uberlândia & 11,23 & 10,50 & 9,94 & 9,06 & 9,45 & $15,9 \%$ \\
\hline \multirow{3}{*}{ Triâng.do Sul } & 75 & Araxá & 11,30 & 17,75 & 10,65 & 16,30 & 13,26 & $-17,3 \%$ \\
\hline & 76 & Frutal & 11,62 & 10,61 & 11,44 & 10,98 & 12,55 & $-8,0 \%$ \\
\hline & 77 & Uberaba & 9,66 & 13,63 & 10,57 & 12,11 & 9,97 & $-3,2 \%$ \\
\hline \multirow{4}{*}{$\begin{array}{l}\text { Estatística } \\
\text { Descritiva }\end{array}$} & & Média & 14,18 & 14,45 & 14,45 & 13,36 & 12,36 & \\
\hline & & Desvio Padrão & 4,01 & 3,66 & 4,77 & 3,90 & 3,66 & \\
\hline & & Mínimo & 7,06 & 8,08 & 6,92 & 6,02 & 4,97 & \\
\hline & & Máximo & 26,26 & 23,01 & 35,50 & 23,64 & 26,06 & \\
\hline
\end{tabular}

Fonte: Dados da pesquisa coletados no sítio da DATASUS

Destaca-se que 24 das 77 RS (com os percentuais negativos), obtiveram aumento na TMI no período entre 2010 à 2014. Esperava-se a redução da TMI, porém ocorreram acréscimos das taxas conforme demonstras as variações percentuais negativas. Por outro lado, 53 RS obtiveram redução nas suas TMI, com a variabilidade percentual positiva.

Observa-se que a Região Ampliada de Saúde Triângulo do Sul, aumentou de forma gradativa as suas TMI ao longo do período, o que é um impacto negativo para a RS. No entanto, a Região Ampliada de Saúde do Triângulo do Norte obteve redução gradativa de suas TMI no mesmo período, o que contribui para a qualidade da saúde na região, seguidas pelas regiões ampliadas Centro Sul, Jequitinhonha e Leste do Sul. Em todas as outras Regiões Ampliadas de Saúde, constam RS que obtiveram aumento ou redução das TMI. Ou seja, de certa maneira, algumas RS contribuíram com o resultado da Região Ampliada de Saúde positivamente (redução da TMI), enquanto outras contribuíram negativamente (aumento da TMI). O mesmo possivelmente ocorreu com os municípios perante às suas Regiões de Saúde.

Os estudos de Macinko, Guanais e Souza (2006), Aquino, Oliveira e Barreto (2009) e Rocha e Soares (2010), encontraram resultados positivos, quando associaram o impacto da 
implantação ou cobertura da atenção básica - Programa Saúde da Família (PSF) ou Estratégia de Saúde da Família (ESF) - com reduções na mortalidade infantil. Assim os resultados de outros indicadores de saúde podem interferir na variação da TMI, além dos aspectos como o nível educacional da mãe, saneamento básico, nível de renda, etc.

A descentralização na área da saúde é outro fator que influenciou a mortalidade infantil no Brasil e no mundo, como discutidos nos estudos de Habibi et al., (2003); Cantarero \& Pascual, (2008); Uchimura \& Jütting, (2009); Jiménez-Rubio, (2011a); Jiménez-Rubio et al., (2011); Jiménez-Rubio, (2011b); Gadelha, (2011); Fritscher \& Zamora, (2012); Soto \& Lorant, (2012) e Samadi et al., (2013).

Na tabela 9, apresentamos as Taxa de Mortalidade Materna (TMM) no período de 2010 à 2014 para as RS de Minas Gerais, calculadas conforme a fórmula apresentada. Observando na Tabela 9 os dados das RS de Minas Gerais, verifica-se nos valores da TMM absoluta, que há variações significativas entre as RS, de valores 0 (zero) ao valor máximo de 310,88 em 2013, no período dos cinco anos. Destaca-se que as RS de Mantena, Itaobim, Padre Paraíso, Manga e Poços de Caldas, atingiram as maiores TMM no período entre 2010 à 2014. 
Tabela 9 - Taxa de Mortalidade Materna (TMM) nas RS de Minas Gerais

\begin{tabular}{|c|c|c|c|c|c|c|c|c|}
\hline \multirow{2}{*}{$\begin{array}{c}\text { Região } \\
\text { Ampliada }\end{array}$} & \multirow{2}{*}{$\begin{array}{l}\mathrm{N}^{\circ} \text {. } \\
\mathrm{RS}\end{array}$} & \multirow[b]{2}{*}{ Região de Saúde } & \multicolumn{6}{|c|}{ Taxa de Mortalidade Materna - TMM } \\
\hline & & & 2010 & 2011 & 2012 & 2013 & 2014 & $\begin{array}{c}\Delta \% \\
(2010-2014)\end{array}$ \\
\hline \multirow{10}{*}{ Centro } & 01 & Belo Horizonte & 67,83 & 32,33 & 40,50 & 47,90 & 29,24 & $56,9 \%$ \\
\hline & 02 & Betim & 21,83 & 20,84 & 31,33 & 49,90 & 47,57 & $-117,9 \%$ \\
\hline & 03 & Contagem & 62,14 & 26,21 & 42,27 & 41,81 & 74,03 & $-19,1 \%$ \\
\hline & 04 & Curvelo & 47,17 & 0 & 0 & 94,65 & 43,50 & $7,8 \%$ \\
\hline & 05 & Guanhães & 70,77 & 129,87 & 0 & 208,33 & 202,02 & $-185,5 \%$ \\
\hline & 06 & Itabira & 0 & 34,22 & 0 & 32,44 & 30,80 & - \\
\hline & 07 & João Monlevade & 0 & 125,55 & 0 & 58,89 & 60,10 & - \\
\hline & 08 & Ouro Preto & 0 & 0 & 39,00 & 40,16 & 0 & - \\
\hline & 09 & Sete Lagoas & 39,00 & 59,16 & 0 & 0 & 18,54 & $52,5 \%$ \\
\hline & 10 & Vespasiano & 0 & 74,17 & 23,91 & 0 & 107,11 & - \\
\hline \multirow{3}{*}{ Centro Sul } & 11 & Barbacena & 76,80 & 39,67 & 0 & 79,81 & 80,45 & $-4,8 \%$ \\
\hline & 12 & Cons. Lafaiete & 27,43 & 25,66 & 0 & 27,59 & 25,71 & $6,3 \%$ \\
\hline & 13 & S. João Del Rei & 73,88 & 0 & 0 & 0 & 0 & - \\
\hline \multirow{2}{*}{ Jequitinhonha } & 14 & Diamantina & 131,06 & 88,69 & 90,29 & 137,68 & 43,92 & $66,5 \%$ \\
\hline & 15 & Minas Novas & 59,07 & 128,70 & 0 & 0 & 0 & - \\
\hline \multirow{7}{*}{ Leste } & 16 & Caratinga & 0 & 78,83 & 80,06 & 124,79 & 38,60 & - \\
\hline & 17 & Cel. Fabriciano & 38,11 & 0 & 0 & 105,78 & 70,15 & $-84,1 \%$ \\
\hline & 18 & Gov. Valadares & 70,73 & 50,60 & 35,61 & 36,42 & 17,09 & $75,8 \%$ \\
\hline & 19 & Ipatinga & 38,53 & 18,44 & 0 & 0 & 74,84 & $-94,2 \%$ \\
\hline & 20 & Mantena & 210,53 & 116,96 & 0 & 0 & 116,28 & $44,8 \%$ \\
\hline & 21 & Resplendor & 0 & 0 & 87,03 & 91,66 & 178,73 & - \\
\hline & 22 & S.Maria Suaçui & 0 & 0 & 77,46 & 89,37 & 87,64 & - \\
\hline \multirow{3}{*}{ Leste do Sul } & 23 & Manhuaçu & 21,24 & 42,08 & 42,40 & 0 & 41,55 & $-95,6 \%$ \\
\hline & 24 & Ponte Nova & 0 & 42,90 & 41,24 & 45,05 & 42,28 & - \\
\hline & 25 & Viçosa & 0 & 0 & 62,93 & 64,85 & 0 & - \\
\hline \multirow{8}{*}{ Nordeste } & 26 & Águas Formosas & 0 & 120,05 & 0 & 237,81 & 116,82 & - \\
\hline & 27 & Almenara & 87,91 & 0 & 0 & 148,96 & 0 & - \\
\hline & 28 & Araçuaí & 100,10 & 89,45 & 0 & 110,01 & 0 & - \\
\hline & 29 & Itaobim & 102,15 & 90,83 & 105,49 & 310,88 & 103,20 & $-1,0 \%$ \\
\hline & 30 & Nanuque & 0 & 0 & 0 & 117,23 & 110,74 & - \\
\hline & 31 & Padre Paraíso & 106,27 & 0 & 233,92 & 113,90 & 0 & - \\
\hline & 32 & Pedra Azul & 0 & 0 & 0 & 0 & 291,97 & - \\
\hline & 33 & Teófilo Otoni & 89,51 & 127,96 & 46,97 & 0 & 22,98 & $74,3 \%$ \\
\hline \multirow{3}{*}{ Noroeste } & 34 & João Pinheiro & 0 & 0 & 0 & 213,22 & 100,50 & - \\
\hline & 35 & Patos de Minas & 25,27 & 49,88 & 25,26 & 0 & 23,80 & $5,8 \%$ \\
\hline & 36 & Unaí & 59,52 & 30,20 & 0 & 0 & 53,52 & $10,1 \%$ \\
\hline \multirow{9}{*}{ Norte } & 37 & Brasília Minas & 28,25 & 0 & 0 & 127,80 & 30,96 & $-9,6 \%$ \\
\hline & 38 & Coração de Jesus & 0 & 0 & 0 & 200,80 & 0 & - \\
\hline & 39 & Francisco Sá & 0 & 0 & 114,94 & 0 & 122,40 & - \\
\hline & 40 & Janaúba & 25,87 & 25,36 & 111,20 & 81,21 & 76,39 & $-195,3 \%$ \\
\hline & 41 & Januária & 60,42 & 0 & 0 & 0 & 60,35 & $0,1 \%$ \\
\hline & 42 & Manga & 107,64 & 105,26 & 105,49 & 107,87 & 301,20 & $-179,8 \%$ \\
\hline & 43 & Montes Claros & 28,95 & 43,40 & 84,65 & 115,66 & 39,84 & $-37,6 \%$ \\
\hline & 44 & Pirapora & 50,94 & 0 & 52,83 & 103,95 & 97,23 & $-90,9 \%$ \\
\hline & 45 & Salinas & 70,55 & 73,66 & 78,65 & 79,84 & 37,40 & $47,0 \%$ \\
\hline \multirow{6}{*}{ Oeste } & 46 & Bom Despacho & 0 & 0 & 81,90 & 0 & 0 & - \\
\hline & 47 & Divinópolis & 18,99 & 38,02 & 18,70 & 0 & 0 & - \\
\hline & 48 & Formiga & $\mathbf{0}$ & $\mathbf{0}$ & $\mathbf{0}$ & $\mathbf{0}$ & $\mathbf{0}$ & - \\
\hline & 49 & Itaúna & 0 & 0 & 0 & 67,25 & 138,22 & - \\
\hline & 50 & Pará de Minas & 70,45 & 33,36 & 99,63 & 0 & 31,34 & $55,5 \%$ \\
\hline & 51 & S. Ant. Amparo & 0 & 47,64 & 0 & 47,21 & 0 & - \\
\hline \multirow{2}{*}{ Sudeste } & 52 & Além Paraíba & 140,85 & 140,85 & 0 & 0 & 136,43 & $3,1 \%$ \\
\hline & 53 & Carangola & 58,65 & 0 & 0 & 0 & 0 & - \\
\hline
\end{tabular}




\begin{tabular}{|c|c|c|c|c|c|c|c|c|}
\hline & 54 & Juiz de Fora & 94,35 & 38,55 & 37,40 & 39,15 & 50,06 & $46,9 \%$ \\
\hline & 55 & Leopoldina & 0 & 0 & 98,91 & 53,73 & 51,52 & - \\
\hline & 56 & Muriaé & 51,89 & 0 & 0 & 50,71 & 0 & \\
\hline & 57 & Santos Dumont & 0 & 0 & 182,15 & 0 & 0 & - \\
\hline & 58 & S. João Nepom. & 0 & 117,37 & 0 & 0 & 0 & . \\
\hline & 59 & Ubá & 29,39 & 0 & 0 & 57,11 & 28,56 & $2,8 \%$ \\
\hline \multirow{12}{*}{ Sul } & 60 & Alfenas & 108,70 & 27,87 & 80,34 & 0 & 27,48 & $74,7 \%$ \\
\hline & 61 & Guaxupé & 0 & 54,56 & 0 & 54,67 & 0 & - \\
\hline & 62 & Itajubá & 82,51 & 0 & 0 & 0 & 0 & - \\
\hline & 63 & Lavras & 0 & 0 & 0 & 87,8 & 41,98 & - \\
\hline & 64 & Passos & 32,06 & 29,75 & 0 & 30,34 & 0 & . \\
\hline & 65 & Poços de Caldas & 110,86 & 150,66 & 36,68 & 76,54 & 111,36 & $-0,45 \%$ \\
\hline & 66 & Pouso Alegre & 17,37 & 16,59 & 48,72 & 16,13 & 15,74 & $9,4 \%$ \\
\hline & 67 & São Lourenço & 33,50 & 0 & 0 & 104,71 & 35,40 & $-5,7 \%$ \\
\hline & 68 & S.Seb.Paraiso & 65,36 & 0 & 0 & 0 & 0 & . \\
\hline & 69 & Três Corações & 0 & 0 & 59,10 & 125,55 & 0 & - \\
\hline & 70 & Três Pontas & 0 & 63,94 & 125,16 & 0 & 64,39 & . \\
\hline & 71 & Varginha & 0 & 0 & 0 & 41,86 & 39,97 & . \\
\hline \multirow{3}{*}{ Triâng. Norte } & 72 & Ituiutaba & 44,68 & 0 & 0 & 0 & 45,15 & $-1,1 \%$ \\
\hline & 73 & Patrocínio & 41,89 & 0 & 41,93 & 0 & 40,82 & $2,6 \%$ \\
\hline & 74 & Uberlândia & 45,66 & 35,90 & 8,80 & 34,53 & 49,74 & $-8,9 \%$ \\
\hline \multirow{3}{*}{ Triâng.do Sul } & 75 & Araxá & 49,14 & 93,41 & 88,73 & 90,58 & 85,54 & $-74,1 \%$ \\
\hline & 76 & Frutal & 0 & 101,06 & 0 & 49,93 & 46,49 & \\
\hline & 77 & Uberaba & 41,11 & 80,19 & 39,13 & 57,67 & 36,93 & $10,2 \%$ \\
\hline \multirow{4}{*}{$\begin{array}{l}\text { Estatística } \\
\text { Descritiva }\end{array}$} & & Media & 40,74 & 38,45 & 35,07 & 58,85 & 53,20 & \\
\hline & & Desvio Padrao & 43,04 & 44,71 & 47,59 & 64,75 & 60,27 & \\
\hline & & Mínimo & 0,00 & $\mathbf{0 , 0 0}$ & $\mathbf{0 , 0 0}$ & $\mathbf{0 , 0 0}$ & $\mathbf{0 , 0 0}$ & \\
\hline & & Máximo & 210,53 & 150,66 & 233,92 & 310,88 & 301,20 & \\
\hline
\end{tabular}

Fonte: Dados da pesquisa coletados no sítio da DATASUS

$\mathrm{Na}$ análise horizontal as variações percentuais (calculadas somente sobre as RS com valores de TMM em 2010 e 2014), considerando como variação a diferença entre o ano de 2010 e 2014, desprezando as variações ao longo do período (ano a ano), observa-se a maior variabilidade negativa da TMM em 18 RS, sendo que a RS de Janaúba na Região Ampliada de Montes Claros obteve a maior variabilidade negativa do indicador $(-195,3 \%)$.

Observando a Tabela 9 percebe-se muitas RS com valores "zeros" de TMM. Os valores zero, segundo informações obtidas em visita à Diretoria Regional de Saúde da Região de Saúde Ampliada de Montes Claros, em fevereiro de 2016, os valores realmente são zero, significa ausência de morte materna naquele ano para aquela RS, portanto, não são dados missing, ou ausência de alimentação no Banco de Dados da DATASUS (o que pode ocorrer às vezes, com os indicadores de saúde), pois segundo a mesma Diretoria Regional de Saúde, a mortalidade materna vem caindo gradativamente nos últimos anos e que este fato é também enfatizado pela OMS.

A TMM também é um indicador com a tendência de quanto menor, melhor. Assim comparando as RS, onde calculou-se a variação percentual, a de Governador Valadares 
obteve a maior redução na TMM, que passou de 70,73 para 17,09 no período de 2010 à 2014, enquanto a RS de Janaúba obteve o maior acréscimo na TMM no mesmo período, que passou de 25,87 a 76,39. Destaca-se que os cálculos das variações percentuais das TMM argumentadas, foram somente para as RS que tinham valor de TMM acima de zero nos anos de 2010 e de 2014. Para as RS onde o valor é zero em 2010 ou em 2014, ficou inviável o cálculo dessa variação, pois com a mesma pretendeu-se dar ênfase à variação no período quinquenal.

Ressalta-se que 16 das $77 \mathrm{RS}$, constam as TMM em todos os anos do período. Somente a RS de Formiga, não consta TMM em nenhum dos anos do período. Percebe-se que dessas 16 RS, a maioria têm um quantitativo populacional alto, acima de 100.000 habitantes, o que justifica ter uma TMM na RS. Mas, merece destaque as RS de Itaobim (RA Nordeste) e Manga (RA Norte), onde o quantitativo populacional era abaixo de 83.000 habitantes.

Observando os dados, considerando as Regiões Ampliadas de Saúde, percebe-se que em quase todas as Regiões Ampliadas constam pelo menos uma RS com indicador de TMM nos anos analisados de forma intervalar. As Regiões Ampliadas de Jequitinhonha e Norte são as regiões com o maior quantitativo de RS com valores de TMM em todos os anos. Nas Regiões Ampliadas Centro Sul, Leste do Sul, Noroeste e Oeste observamos que em todas as RS que as compõem, constam valores zero em pelo menos um dos anos analisados.

Quanto à estatística descritiva, percebe-se no quadro geral que a TMM têm uma grande discrepância nos valores do indicador, muito heterogênea, demonstrada inclusive pelo desvio padrão alto em todos os anos do período analisado. 


\section{ANÁLISE E DISCUSSÃO DOS RESULTADOS}

Neste capítulo apresentamos a análise e discussão dos resultados do cálculo da eficiência do gasto público por meio da técnica da Analise Envoltória de Dados (DEA) nos anos de 2010 à 2014. Utilizamos o software Frontier Analyst 4, e para o cálculo dos scores de eficiência total, técnica e de escala de cada Região de Saúde. Os softwares são ferramentas capazes de fazer a mensuração do desempenho para determinar a eficiência das Regiões de Saúde.

\subsection{Análise da eficiência por meio da técnica DEA}

Quando se propôs analisar a eficiência técnica dos gastos públicos com a saúde, as perguntas que indiretamente procurou-se responder foram: dado um nível de insumos utilizados por uma região de saúde, as saídas revelam eficiência dos gastos? Em termos comparativos é possível a maximização das saídas?

A eficiência técnica de uma unidade é verificada quando esta maximiza sua produção por cada insumo utilizado. Segundo Casa Nova (2002),

\footnotetext{
É importante ressaltar que os modelos DEA são invariantes à escala, podendo incluir indicadores de diferentes medidas de mensuração. Os indicadores devem, no entanto, manter valores positivos e apenas alguns modelos permitem o ajuste para transformar as variáveis negativas em positivas, sem alteração dos escores de eficiência. (p. 167)
}

Neste aspecto de transformar variáveis, ressalta-se que devido ao fato das TMI e TMM serem outputs com características de "quanto menor, melhor", as mesmas foram utilizadas na análise de forma invertida, ou seja, numa razão de um sobre as mesmas (1 / TMI) e (1 / TMM). A mudança foi inserida nas configurações de variáveis do software Frontier Analyst 4. Como a variável TMM para algumas RS, tinham o valor 0 (zero), as mesmas foram substituídas por valores decimais de 0,01 . O software também conta com esta facilidade de substituir automaticamente os zeros por valores decimais, que não alteram a classificação, mas torna a solução possível.

A substituição de valores para superar a limitação da positividade do modelo DEA, apoiando-se no efeito da chamada translation invariance, é preconizada por alguns autores 
(Ali \& Seiford, 1990; Pastor, 1996 e Cook \& Seiford, 2009), que ressaltam que o modelo não deve ser afetado por uma conversão ou transformação de valores, de negativos em positivos, por exemplo.

Quanto à relação entre as variáveis, é esperado uma correlação positiva entre o insumo utilizado e os produtos alcançados, para a estimação da fronteira de eficiência. Neste aspecto, foram feitas as análises de correlação entre o input e os outputs utilizados no modelo DEA, nos seus valores originais, respectivamente nos anos de 2010 à 2014.

Nota-se nas Tabelas de 10 a 14 que o output TMI apresentou correlação positiva baixa com o input Despesa Liquidada em todos os anos, enquanto o output TMM apresentou correlação negativa fraca, em todos os anos. Isso indica que as variáveis possuem baixa relação associativa com o input. E no caso do output TMM essa relação é inversa, por ser negativa. Observou-se que as variáveis de saída também apresentaram baixa correlação positiva entre si para o ano de 2010, sendo que nos anos de 2011 a 2014, a correlacão foi negativa e fraca.

Tabela 10 - Análise de correlação entre input e outputs do modelo DEA em 2010

\begin{tabular}{lrrr}
\hline \multicolumn{4}{c}{$\mathbf{2 0 1 0}$} \\
\hline \multicolumn{5}{c}{ Despliq } & TMI & TMM \\
\hline Despliq & 1 & & \\
TMI & 0,208534483 & 1 & \\
TMM & $-0,126675538$ & 0,094227945 & 1 \\
\hline Fonte: Resultados da pesquisa & &
\end{tabular}

Fonte: Resultados da pesquisa

Tabela 11 - Análise de correlação entre input e outputs do modelo DEA em 2011

\begin{tabular}{lrrr}
\hline \multicolumn{4}{c}{$\mathbf{2 0 1 1}$} \\
\hline \multicolumn{5}{c}{ Despliq } & TMI & TMM \\
\hline Despliq & 1 & & \\
TMI & 0,192134864 & 1 & \\
TMM & $-0,337371622$ & $-0,003630157$ & 1 \\
\hline
\end{tabular}

Fonte: Resultados da pesquisa

Tabela 12 - Análise de correlação entre input e outputs do modelo DEA em 2012

\begin{tabular}{lrrr}
\hline \multicolumn{5}{c}{$\mathbf{2 0 1 2}$} & TMM \\
\hline Despliq & TMI & \\
TMI & 1 & 1 & \\
TMM & 0,265152504 & 1 & 1 \\
\hline Fonte: Resultados da pesquisa & $-0,087886133$ & $-0,106201388$ &
\end{tabular}

Fonte: Resultados da pesquisa 
Tabela 13 - Análise de correlação entre input e outputs do modelo DEA em 2013

\begin{tabular}{|c|c|c|c|c|}
\hline \multicolumn{5}{|c|}{2013} \\
\hline & Despliq & $T M I$ & $T M M$ & \\
\hline Despliq & 1 & & & \\
\hline TMI & 0,149598896 & 1 & & \\
\hline TMM & $-0,040077779$ & $-0,020293363$ & & 1 \\
\hline
\end{tabular}

Fonte: Resultados da pesquisa

Tabela 14 - Análise de correlação entre input e outputs do modelo DEA em 2014

\begin{tabular}{lrrr}
\hline \multicolumn{5}{c}{$\mathbf{2 0 1 4}$} & \\
\hline \multicolumn{5}{c}{ Despliq } & TMI & TMM \\
\hline Despliq & 1 & 1 & \\
TMI & 0,229345454 & & \\
TMM & $-0,202648389$ & $-0,076870523$ & 1 \\
\hline
\end{tabular}

Fonte: Resultados da pesquisa

Observa-se que a TMM é o output menos dependente, pela sua relação com o input e também com a TMI. Mesmo que a TMM contenha em termos de valores, muita divergência em relação à TMI, há indícios de redundância na relação entre essas duas variáveis: Taxa de mortalidade infantil e taxa de mortalidade materna, considerando que o denominador da razão é o mesmo: Número de nascidos vivos. Apesar da presença de redundâncias, decidiu-se manter as variáveis na análise, pois se considerou que todas constituem importantes bases informacionais. E também porque trabalhou-se com um número pequeno de variáveis.

\subsection{Eficiência total e técnica por meio da DEA nas Regiões Ampliadas de Saúde}

Inicialmente, agregamos os dados regionais coletados de outputs e inputs nas 13 Regiões Ampliadas de Saúde, para estimamos a fronteira da eficiência total e técnica por meio da DEA. Utilizamos das regras preliminares na aplicação do modelo de CCR e em seguida aplicamos o modelo BCC, para consolidar as DMUs eficientes; ambos com orientação aos outputs, .

Aplicou-se o modelo de eficiência total pelo método CRS/CCR, orientado para os outputs com retornos constantes de escala. O CCR por considerar o retorno de escala constante, validou as Regiões Ampliadas de Saúde eficientes por seu rigor na eficiência total do modelo. Na Tabela 15 apresentamos os resultados pelo método CCR: 
Tabela 15 - Resultados da DEA pelo método CRS/CCR com orientação aos outputs

\begin{tabular}{|c|c|c|c|c|c|c|}
\hline \multirow[b]{2}{*}{$\mathbf{N}^{0}$} & \multirow[b]{2}{*}{ Região Ampliada de Saúde } & \multicolumn{5}{|c|}{ Scores de Eficiência } \\
\hline & & $\begin{array}{c}2010 \\
\%\end{array}$ & $\begin{array}{c}2011 \\
\%\end{array}$ & $\begin{array}{c}2012 \\
\%\end{array}$ & $\begin{array}{c}2013 \\
\%\end{array}$ & $\begin{array}{c}2014 \\
\%\end{array}$ \\
\hline 01 & Centro (Belo Horizonte) & 86,3 & 100,0 & 89,5 & 77,2 & 76,2 \\
\hline 02 & Centro Sul (Barbacena) & 84,0 & 100,0 & 100,0 & 70,2 & 77,8 \\
\hline 03 & Jequitinhona (Diamantina) & 95,8 & 87,6 & 100,0 & 67,9 & 100,0 \\
\hline 04 & Leste (Governador Valadares) & 98,5 & 100,0 & 100,0 & 91,4 & 90,0 \\
\hline 05 & Leste do Sul (Ponte Nova & 100,0 & 84,1 & 76,0 & 91,2 & 85,1 \\
\hline 06 & Nordeste (Teófilo Otoni) & 75,6 & 74,6 & 69,5 & 71,8 & 63,0 \\
\hline 07 & Noroeste (Patos de Minas) & 81,5 & 85,6 & 77,4 & 64,5 & 80,3 \\
\hline 08 & Norte (Montes Claros) & 79,6 & 91,1 & 78,2 & 66,4 & 75,3 \\
\hline 09 & Oeste (Divinópolis) & 100,0 & 99,9 & 95,4 & 100,0 & 100,0 \\
\hline 10 & Sudeste (Juiz de Fora) & 66,4 & 100,0 & 68,4 & 73,9 & 64,8 \\
\hline 11 & Sul (Alfenas/Pouso Alegre) & 100,0 & 96,9 & 90,3 & 80,0 & 81,2 \\
\hline 12 & Triângulo do Norte (Uberlândia) & 80,2 & 89,1 & 79,8 & 80,1 & 90,7 \\
\hline 13 & Triângulo do Sul (Uberaba) & 92,5 & 69,5 & 89,5 & 65,9 & 71,5 \\
\hline
\end{tabular}

Fonte: Resultados da pesquisa

Analisando os scores de eficiência total, percebe-se que em todos os anos há Regiões Ampliadas de Saúde eficientes (100\%) e ineficientes (abaixo de 100\%). O menor score obtido foi de $63 \%$ no ano de 2014 , considerando que os dados são agregados para as 13 Regiões Ampliadas de Saúde.

Portanto, foram 3 regões ampliadas de saúde eficientes em 2010 e 4 regiões ampliadas de saúde eficientes em 2011. Em 2012, também foram eficientes 3 regiões ampliadas de saúde; somente uma região ampliada de saúde eficiente em 2013 e 2 regiões ampliadas de saúde eficientes em 2014.

Observa-se na Tabela 15, que nenhuma das Regiões Ampliadas de Saúde foram eficientes em todos os anos. Entretanto, destaca-se que as Regiões Ampliadas de Saúde Nordeste, Noroeste, Norte, Triângulo do Norte e Triângulo do Sul, foram ineficientes em todos os anos do período analisado.

Em seguida aplicou-se a DEA pelo método BCC. Na Tabela 16, apresentamos os resultados da DEA pelo método BCC com orientação aos outputs, no período de cinco anos. Verifica-se que, com os dados agregados obteve-se Regiões Ampliadas de Saúde eficientes e também ineficientes em todos os anos do período analisado.

As Regiões Ampliadas de Saúde com eficiência técnica em todos os anos, foram: Jequitinhonha e Oeste. Enquanto as ineficientes foram as Regiões Nordeste, Noroeste e Norte. Destaca-se que essas Regiões ineficientes em todos os anos, também ja o foram pelo método 
CCR, na eficiência total.

As fronteiras de eficiência estimadas pela DEA, considerando o método BCC com orientação aos outputs, apresentadas na tabela 16, foram compostas por 6 Regiões Ampliadas de Saúde no ano de 2010, correspondendo a 46\% das Regiões Ampliadas, sendo que as Regiões Ampliadas Sul, Triângulo do Sul, Leste, Jequitinhonha e Oeste, servirão de base para o cálculo da eficiência das demais Regiões Ampliadas de Saúde. Em 2011 a fronteira de eficiência foi composta por 8 Regiões Ampliadas, correspondendo ao maior percentual no período, de 61\% das Regiões Ampliadas. Foram referência da eficiência as Regiões Ampliadas Leste, Sul, Triângulo do Norte, Jequitinhonha, Centro e Sudeste.

Em 2012 foram 6 Regiões Ampliadas que atingiram a fronteira de eficiência, correspondendo ao percentual de $46 \%$. Servirão de base para o cálculo da eficiência das demais Regiões Ampliadas de Saúde, as Regiões Ampliadas Centro Sul, Oeste, Triângulo do Sul, Jequitinhonha e Leste. Em 2013 foram eficientes 4 Regiões Ampliadas, correspondendo a 31\%, sendo que as mesmas Regiões Oeste, Triângulo do Norte, Leste e Jequitinhonha foram referência para o cálculo da eficiência das demais Regiões Ampliadas de Saúde. Por último em 2014, somente as Regiões Ampliadas de Saúde Jequitinhonha, Oeste e Triângulo do Norte foram eficientes, correspondendo a 23\% das Regiões, sendo as mesmas referência para o cálculo da eficiência das demais Regiões Ampliadas de Saúde.

Tabela 16 - Resultados da DEA pelo método VRS/BCC com orientação aos outputs

\begin{tabular}{|c|c|c|c|c|c|c|}
\hline \multirow[b]{2}{*}{$\mathbf{N}^{0}$} & \multirow[b]{2}{*}{ Região Ampliada de Saúde } & \multicolumn{5}{|c|}{ Scores de Eficiência Técnica } \\
\hline & & $\begin{array}{c}2010 \\
\% \\
\end{array}$ & $\begin{array}{c}2011 \\
\% \\
\end{array}$ & $\begin{array}{c}2012 \\
\% \\
\end{array}$ & $\begin{array}{c}2013 \\
\% \\
\end{array}$ & $\begin{array}{c}2014 \\
\% \\
\end{array}$ \\
\hline 01 & Centro (Belo Horizonte) & 89,4 & 100,0 & 98,7 & 88,1 & 86,6 \\
\hline 02 & Centro Sul (Barbacena) & 84,6 & 100,0 & 100,0 & 72,7 & 83,4 \\
\hline 03 & Jequitinhona (Diamantina) & 100,0 & 100,0 & 100,0 & 100,0 & 100,0 \\
\hline 04 & Leste (Governador Valadares) & 100,0 & 100,0 & 100,0 & 100,0 & 91,1 \\
\hline 05 & Leste do Sul (Ponte Nova & 100,0 & 86,1 & 80,4 & 94,2 & 86,8 \\
\hline 06 & Nordeste (Teófilo Otoni) & 77,6 & 78,3 & 69,6 & 87,1 & 63,8 \\
\hline 07 & Noroeste (Patos de Minas) & 85,8 & 89,1 & 84,4 & 70,4 & 86,4 \\
\hline 08 & Norte (Montes Claros) & 81,9 & 93,3 & 84,7 & 68,4 & 77,6 \\
\hline 09 & Oeste (Divinópolis) & 100,0 & 100,0 & 100,0 & 100,0 & 100,0 \\
\hline 10 & Sudeste (Juiz de Fora) & 67,0 & 100,0 & 73,7 & 76,4 & 70,1 \\
\hline 11 & Sul (Alfenas/Pouso Alegre) & 100,0 & 100,0 & 97,4 & 87,2 & 85,0 \\
\hline 12 & Triângulo do Norte (Uberlândia) & 92,2 & 100,0 & 100,0 & 100,0 & 100,0 \\
\hline 13 & Triângulo do Sul (Uberaba) & 100,0 & 75,0 & 100,0 & 75,2 & 79,7 \\
\hline
\end{tabular}




\subsection{Resultados da eficiência total e técnica por meio DEA nas Regiões de Saúde}

Neste item discutimos os resultados provenientes da aplicação dos modelos clássicos do DEA de análise de eficiência produtiva. Primeiramente apurou-se a eficiência total por meio da aplicação do método $\mathrm{CRS} / \mathrm{CCR}$, orientado para os outputs com retornos constantes de escala. Em seguida apurou-se a eficiência técnica, aplicando o método VRS/BCC, também orientado para os outputs com retornos variáveis de escala.

O CCR por ter retorno de escala constante, têm um maior rigor no cálculo da eficiência total do modelo, validando as RS eficientes. Poucas foram as RS que apresentaram eficiência total igual a $100 \%$. Conforme apresentado na tabela 17 , considerando a análise anual foram eficientes no ano de 2010 as RS de Santos Dumont e Varginha. Em 2011, somente a RS de Santos Dumont foi eficiente. Em 2012, foram eficientes as RS de Contagem, Minas Novas e Nanuque. Em 2013 foram eficientes as RS de Viçosa e Santos Dumont. E em 2014 foram eficientes as RS de Viçosa, Guaxupé e Ituiutaba.

Todos as outras Regiões de Saúde, obtiveram scores de eficiência total abaixo de $100 \%$, e foram consideradas ineficientes pelo método CCR. Todas essas RS consideradas eficientes pelo método CCR, também serão eficientes nos mesmos períodos pelo método $\mathrm{BCC}$, considerando que a eficiência pelo método BCC por retornos variáveis de escala, é uma eficiência técnica e sempre maior que a eficiência pelo método $\mathrm{CCR}$, devido as RS estarem mais próximas da fronteira de eficiência.

Todas essas RS citadas, que foram eficientes no modelo CCR, nos seus respectivos períodos têm retornos constantes de escala, o que significa dizer que operavam em suas escalas ótimas de produção. Sendo assim, como as mesmas também são eficientes no modelo $\mathrm{BCC}$, ou seja com eficiência técnica, portanto atuaram sem desperdícios de recursos. Assim as mesmas tinham o tamanho ideal para serem produtivas e ao mesmo tempo estavam gerenciando a sua produção bem tecnicamente e sem desperdícios.

Observou-se que a média da eficiência total anual nos anos de 2010 à 2014 foi muito baixa nos anos de 2010, 2011 e 2013. A média anual foi de 33,5\%, 38,1\% e 35,7\%, respectivamente. No ano de 2012 obteve-se a maior média anual de 59,\%, reduzindo para $52,9 \%$ em 2014. De maneira geral as RS não trabalharam bem as suas escalas de produção. 
Tabela 17 - Resultados da DEA pelo método CRS/CCR com orientação aos outputs das Regiões de Saúde

\begin{tabular}{|c|c|c|c|c|c|c|c|}
\hline \multirow[b]{2}{*}{$\begin{array}{c}\text { Região } \\
\text { Ampliada }\end{array}$} & \multirow[b]{2}{*}{$\begin{array}{l}N^{o} . \\
\text { RS }\end{array}$} & \multirow[b]{2}{*}{ Região de Saúde } & \multicolumn{5}{|c|}{ Eficiência Total (\%) } \\
\hline & & & $\begin{array}{c}2010 \\
\% \\
\end{array}$ & $\begin{array}{c}2011 \\
\% \\
\end{array}$ & $\begin{array}{c}2012 \\
\% \\
\end{array}$ & $\begin{array}{c}2013 \\
\% \\
\end{array}$ & $\begin{array}{c}2014 \\
\% \\
\end{array}$ \\
\hline \multirow{10}{*}{ Centro } & 01 & Belo Horizonte & 20,9 & 31,3 & 40,9 & 24,8 & 38,8 \\
\hline & 02 & Betim & 26,0 & 33,3 & 50,0 & 35,7 & 55,2 \\
\hline & 03 & Contagem & 42,6 & 52,2 & 100,0 & 53,5 & 83,2 \\
\hline & 04 & Curvelo & 22,9 & 49,0 & 63,9 & 25,1 & 43,9 \\
\hline & 05 & Guanhães & 20,3 & 32,2 & 81,8 & 23,9 & 37,2 \\
\hline & 06 & Itabira & 36,4 & 18,6 & 49,0 & 21,0 & 26,9 \\
\hline & 07 & João Monlevade & 35,0 & 26,9 & 55,0 & 29,2 & 24,7 \\
\hline & 08 & Ouro Preto & 50,1 & 46,3 & 44,5 & 45,7 & 45,8 \\
\hline & 09 & Sete Lagoas & 20,4 & 23,6 & 48,5 & 31,8 & 41,7 \\
\hline & 10 & Vespasiano & 53,5 & 47,3 & 54,8 & 35,2 & 52,2 \\
\hline \multirow{3}{*}{ Centro Sul } & 11 & Barbacena & 29,6 & 11,7 & 48,8 & 22,1 & 37,1 \\
\hline & 12 & Cons. Lafaiete & 19,7 & 24,4 & 58,6 & 26,2 & 46,3 \\
\hline & 13 & S. João Del Rei & 21,4 & 43,3 & 66,3 & 38,3 & 54,2 \\
\hline \multirow{2}{*}{ Jequitinhonha } & 14 & Diamantina & 34,2 & 34,8 & 39,7 & 21,4 & 56,6 \\
\hline & 15 & Minas Novas & 18,6 & 21,6 & 100,0 & 47,3 & 69,3 \\
\hline \multirow{7}{*}{ Leste } & 16 & Caratinga & 40,5 & 18,2 & 35,3 & 23,6 & 34,6 \\
\hline & 17 & Cel. Fabriciano & 23,0 & 53,9 & 82,6 & 41,0 & 71,7 \\
\hline & 18 & Gov. Valadares & 36,0 & 44,9 & 53,4 & 37,4 & 46,8 \\
\hline & 19 & Ipatinga & 22,8 & 32,2 & 84,8 & 51,6 & 51,6 \\
\hline & 20 & Mantena & 22,2 & 35,5 & 79,9 & 44,2 & 81,2 \\
\hline & 21 & Resplendor & 57,3 & 52,0 & 34,3 & 15,9 & 60,6 \\
\hline & 22 & S.Maria Suaçui & 58,8 & 56,6 & 40,1 & 24,8 & 71,0 \\
\hline \multirow{3}{*}{ Leste do Sul } & 23 & Manhuaçu & 21,6 & 23,8 & 41,9 & 42,4 & 49,1 \\
\hline & 24 & Ponte Nova & 32,8 & 30,7 & 22,2 & 23,0 & 35,6 \\
\hline & 25 & Viçosa & 43,4 & 49,8 & 91,2 & 100,0 & 100,0 \\
\hline \multirow{8}{*}{ Nordeste } & 26 & Águas Formosas & 55,5 & 29,4 & 98,5 & 22,1 & 30,5 \\
\hline & 27 & Almenara & 24,0 & 60,1 & 85,4 & 23,1 & 66,0 \\
\hline & 28 & Araçuaí & 39,5 & 27,9 & 93,0 & 70,5 & 59,9 \\
\hline & 29 & Itaobim & 22,1 & 28,7 & 40,7 & 63,9 & 44,8 \\
\hline & 30 & Nanuque & 60,3 & 68,0 & 100,0 & 57,3 & 60,6 \\
\hline & 31 & Padre Paraíso & 24,0 & 55,4 & 53,9 & 35,9 & 75,4 \\
\hline & 32 & Pedra Azul & 52,5 & 58,1 & 99,6 & 54,3 & 49,9 \\
\hline & 33 & Teófilo Otoni & 15,3 & 18,7 & 24,7 & 34,8 & 29,9 \\
\hline \multirow{3}{*}{ Noroeste } & 34 & João Pinheiro & 33,5 & 36,3 & 68,1 & 21,5 & 38,3 \\
\hline & 35 & Patos de Minas & 18,6 & 24,3 & 37,5 & 31,7 & 44,0 \\
\hline & 36 & Unaí & 26,9 & 32,9 & 62,5 & 35,2 & 49,1 \\
\hline \multirow{9}{*}{ Norte } & 37 & Brasília Minas & 19,4 & 43,3 & 68,3 & 23,6 & 39,8 \\
\hline & 38 & Coração de Jesus & 36,4 & 41,6 & 63,0 & 18,8 & 51,6 \\
\hline & 39 & Francisco Sá & 42,8 & 43,5 & 23,4 & 35,4 & 46,6 \\
\hline & 40 & Janaúba & 37,3 & 46,6 & 58,5 & 27,1 & 47,7 \\
\hline & 41 & Januária & 23,9 & 50,9 & 78,0 & 46,9 & 35,2 \\
\hline & 42 & Manga & 18,0 & 24,3 & 47,5 & 39,1 & 61,3 \\
\hline & 43 & Montes Claros & 18,3 & 22,4 & 32,2 & 20,6 & 40,4 \\
\hline & 44 & Pirapora & 17,9 & 48,4 & 39,3 & 20,7 & 43,3 \\
\hline & 45 & Salinas & 23,5 & 20,4 & 45,9 & 34,4 & 47,5 \\
\hline \multirow{6}{*}{ Oeste } & 46 & Bom Despacho & 54,5 & 59,9 & 65,9 & 55,7 & 72,2 \\
\hline & 47 & Divinópolis & 21,1 & 22,4 & 40,0 & 47,4 & 61,9 \\
\hline & 48 & Formiga & 46,9 & 50,2 & 75,5 & 39,9 & 55,3 \\
\hline & 49 & Itaúna & 37,4 & 36,8 & 73,1 & 21,7 & 44,2 \\
\hline & 50 & Pará de Minas & 33,4 & 34,7 & 47,3 & 47,8 & 67,9 \\
\hline & 51 & S. Ant. Amparo & 45,5 & 24,1 & 82,1 & 37,1 & 55,8 \\
\hline \multirow{2}{*}{ Sudeste } & 52 & Além Paraíba & 13,7 & 22,0 & 64,8 & 36,4 & 48,6 \\
\hline & 53 & Carangola & 22,7 & 51,3 & 63,7 & 38,1 & 57,8 \\
\hline
\end{tabular}




\begin{tabular}{|c|c|c|c|c|c|c|c|}
\hline & 54 & Juiz de Fora & 12,0 & 19,6 & 26,7 & 19,8 & 25,5 \\
\hline & 55 & Leopoldina & 45,5 & 43,7 & 40,3 & 28,4 & 47,4 \\
\hline & 56 & Muriaé & 26,7 & 58,5 & 93,3 & 37,7 & 86,7 \\
\hline & 57 & Santos Dumont & 100,0 & 100,0 & 55,0 & 100,0 & 95,8 \\
\hline & 58 & S. João Nepom. & 56,9 & 24,6 & 70,2 & 41,1 & 57,6 \\
\hline & 59 & Ubá & 28,9 & 62,2 & 98,2 & 43,3 & 49,5 \\
\hline \multirow{12}{*}{ Sul } & 60 & Alfenas & 26,3 & 29,9 & 34,2 & 31,2 & 46,9 \\
\hline & 61 & Guaxupé & 54,5 & 39,9 & 80,9 & 27,2 & 100,0 \\
\hline & 62 & Itajubá & 22,3 & 54,7 & 95,3 & 49,0 & 72,3 \\
\hline & 63 & Lavras & 32,7 & 32,0 & 48,9 & 24,4 & 30,6 \\
\hline & 64 & Passos & 24,5 & 23,4 & 69,1 & 32,7 & 44,1 \\
\hline & 65 & Poços de Caldas & 22,5 & 22,4 & 35,4 & 14,9 & 60,8 \\
\hline & 66 & Pouso Alegre & 26,0 & 30,7 & 50,9 & 40,2 & 44,3 \\
\hline & 67 & São Lourenço & 45,2 & 45,3 & 75,4 & 38,9 & 54,8 \\
\hline & 68 & S.Seb.Paraiso & 14,5 & 32,2 & 51,0 & 28,9 & 30,0 \\
\hline & 69 & Três Corações & 51,9 & 48,5 & 45,0 & 27,5 & 72,5 \\
\hline & 70 & Três Pontas & 39,7 & 28,4 & 70,8 & 32,1 & 34,6 \\
\hline & 71 & Varginha & 100,0 & 78,7 & 78,2 & 35,9 & 65,1 \\
\hline \multirow{3}{*}{ Triâng. Norte } & 72 & Ituiutaba & 31,0 & 48,3 & 60,9 & 37,2 & 100,0 \\
\hline & 73 & Patrocínio & 21,5 & 38,1 & 38,6 & 37,2 & 45,8 \\
\hline & 74 & Uberlândia & 20,2 & 24,4 & 38,5 & 27,0 & 47,0 \\
\hline \multirow{3}{*}{ Triâng.do Sul } & 75 & Araxá & 23,2 & 18,5 & 48,3 & 19,4 & 40,5 \\
\hline & 76 & Frutal & 30,8 & 26,6 & 53,4 & 25,6 & 33,1 \\
\hline & 77 & Uberaba & 28,2 & 23,3 & 45,2 & 25,4 & 44,1 \\
\hline \multirow{4}{*}{$\begin{array}{l}\text { Estatística } \\
\text { Descritiva }\end{array}$} & & Média & 33,5 & 38,1 & 59,8 & 35,7 & 52,9 \\
\hline & & Desvio Padrão & 16,6 & 15,7 & 21,1 & 15,5 & 17,5 \\
\hline & & Mínimo & 12,0 & 11,7 & 22,2 & 14,9 & 24,7 \\
\hline & & Máximo & 100,0 & 100,0 & 100,0 & 100,0 & 100,0 \\
\hline
\end{tabular}

Fonte: Dados da pesquisa

Em continuidade ao estudo calculamos a eficiência técnica pelo método de Retornos Variáveis de Escala VRC/BCC, orientado para os outputs. Na Tabela 18, apresentamos os resultados das RS eficientes, em todos os anos analisados. As RS com um score de eficiência menor que $100 \%$ foram consideradas ineficientes, pois apresentaram escores abaixo da fronteira de eficiência. Destaca-se, que apenas 3 Regiões de Saúde: Viçosa, Formiga e Santos Dumont, foram considerados eficientes pelo método BCC em todos os anos analisados. Portanto as mesmas serviram como benchmarks ou refêrencia no calculo da eficiência técnica das outras RS.

As fronteiras de eficiência estimadas pela DEA foram compostas por $28 \mathrm{RS}$ no ano de 2010, correspondendo a 36\% das RS, sendo que as RS de Santos Dumont e Varginha, servirão de referiencia para o cálculo da eficiência das demais RS. Em 2011 a fronteira de eficiência foi composta por $33 \mathrm{RS}$, correspondendo a 43\% das RS, tendo como base as RS de Santos Dumont e Ituiutaba. Em 2012, 42 RS atingiram a fronteira de eficiência, correspondendo ao maior percentual anual de 55\% no período dos cinco anos. Aumentou também as RS como referência da eficiência, são elas as RS de Contagem, Sete Lagoas, 
Minas Novas, Ipatinga, Viçosa, Nanuque, Itaúna e Santos Dumont.

Em 2013, o número de RS eficientes reduziu para 29, reduzindo o valor percentual para $38 \%$, tendo como base as RS de Ouro Preto, Sete Lagoas, Ipatinga, Viçosa e Santos Dumont. Em 2014, reduziu para 22 RS eficientes, representando 29\% das RS. As RS que serviram como base para o cálculo da eficiência das demais RS, foram: Viçosa, Guaxupé e Ituiutaba. Percebe-se que o ano de 2010 e o de 2014, foram os anos com os menores números de RS eficientes. Percebeu-se que o método considerou os menores inputs como eficientes, para uma combinação dos outputs.

A maioria da Regiões de Saúde obtiveram eficiência técnica em pelo menos um dos anos analisados, pelo método BCC. Neste aspecto os resultados deste estudo assemelham-se aos resultados obtidos por pesquisa similar desenvolvida por Varela e Pacheco (2012) na Região Metropolitana de São Paulo, porém com os municípios nas regiões de saúde, em um ano e com outras variáveis. Naquele, as autoras identificaram pelo menos um município eficiente em cada região de saúde.

Entretanto Regiões de Saúde consideradas de grande porte como Belo Horizonte, Betim, Governador Valadares, Montes Claros, Juiz de Fora, Pouso Alegre, Uberlândia e Uberaba, com um quantitativo populacional em torno ou acima de 400.000 habitantes, não alcançaram a fronteira da eficiência em nenhum dos anos analisados, seguidas de outras regiões de menor porte: Diamantina, Itaobim, Janaúba, Manga, Salinas, Poços de Caldas e Araxá, que também não foram eficientes em nenhum dos anos, considerando o método BCC.

Pode-se depreender que essas RS foram ineficientes devido aos retornos de escala, por serem de grande ou pequeno porte, no caso, considerando o tamanho de suas populações, variações exógenas, não controláveis. Quando ocorrem essas diferenças de porte, entre regiões ou municípios pequenos e grandes, entre empresas pequenas, médias e grandes, etc., é previsto que os mesmos sejam ineficientes, por não estarem atuando em uma escala adequada. Em uma análise do detalhe, utilizando de outros modelos na DEA, pode-se determinar se os retornos de escala são crescentes, constantes ou decrescentes.

Ressaltamos que as RS de Itaobim e Manga tinham um porte populacional pequeno, abaixo de 83.000 habitantes em 2014. As RS de grande porte citadas apresentam os maiores insumos (inputs), no caso os gastos públicos. Além do que contam com uma maior população sob a sua responsabilidade para prestar serviços. Quanto às RS de Itaobim e Manga, as mesmas apresentaram altas TMM, como já citado. 
Tabela 18 - Resultados da DEA pelo método VRS/BCC com orientação aos outputs das Regiões de Saúde

\begin{tabular}{|c|c|c|c|c|c|c|c|}
\hline \multirow{2}{*}{$\begin{array}{c}\text { Região } \\
\text { Ampliada }\end{array}$} & \multirow{2}{*}{$\begin{array}{l}N^{\circ} . \\
\text { RS }\end{array}$} & \multirow[b]{2}{*}{ Região de Saúde } & \multicolumn{5}{|c|}{ Eficiência Técnica } \\
\hline & & & $\begin{array}{c}2010 \\
\% \\
\end{array}$ & $\begin{array}{c}2011 \\
\% \\
\end{array}$ & $\begin{array}{c}2012 \\
\% \\
\end{array}$ & $\begin{array}{c}2013 \\
\% \\
\end{array}$ & $\begin{array}{c}2014 \\
\% \\
\end{array}$ \\
\hline \multirow{10}{*}{ Centro } & 01 & Belo Horizonte & 60,4 & 78,8 & 63,8 & 58,4 & 50,1 \\
\hline & 02 & Betim & 66,0 & 78,3 & 63,7 & 52,7 & 55,4 \\
\hline & 03 & Contagem & 57,2 & 75,7 & 100,0 & 65,2 & 86,3 \\
\hline & 04 & Curvelo & 51,6 & 100,0 & 100,0 & 46,3 & 44,0 \\
\hline & 05 & Guanhães & 38,4 & 58,1 & 100,0 & 35,6 & 37,4 \\
\hline & 06 & Itabira & 100,0 & 51,3 & 100,0 & 58,0 & 46,1 \\
\hline & 07 & João Monlevade & 100,0 & 64,4 & 100,0 & 61,0 & 29,5 \\
\hline & 08 & Ouro Preto & 100,0 & 100,0 & 63,4 & 100,0 & 100,0 \\
\hline & 09 & Sete Lagoas & 53,2 & 55,4 & 100,0 & 100,0 & 48,8 \\
\hline & 10 & Vespasiano & 100,0 & 89,9 & 67,3 & 100,0 & 52,2 \\
\hline \multirow{3}{*}{ Centro Sul } & 11 & Barbacena & 55,7 & 35,1 & 100,0 & 43,4 & 44,1 \\
\hline & 12 & Cons. Lafaiete & 49,5 & 61,7 & 100,0 & 46,5 & 46,3 \\
\hline & 13 & S. João Del Rei & 45,5 & 100,0 & 100,0 & 100,0 & 100,0 \\
\hline \multirow{2}{*}{ Jequitinhonha } & 14 & Diamantina & 53,9 & 53,4 & 41,5 & 32,8 & 56,8 \\
\hline & 15 & Minas Novas & 35,2 & 38,1 & 100,0 & 100,0 & 100,0 \\
\hline \multirow{7}{*}{ Leste } & 16 & Caratinga & 100,0 & 39,4 & 43,2 & 42,6 & 34,6 \\
\hline & 17 & Cel. Fabriciano & 43,1 & 100,0 & 100,0 & 53,9 & 73,3 \\
\hline & 18 & Gov. Valadares & 56,2 & 71,8 & 56,4 & 52,9 & 47,4 \\
\hline & 19 & Ipatinga & 59,1 & 73,1 & 100,0 & 100,0 & 51,6 \\
\hline & 20 & Mantena & 41,9 & 64,4 & 100,0 & 100,0 & 81,4 \\
\hline & 21 & Resplendor & 100,0 & 100,0 & 39,7 & 28,0 & 60,8 \\
\hline & 22 & S.Maria Suaçui & 100,0 & 100,0 & 42,0 & 33,2 & 72,4 \\
\hline \multirow{3}{*}{ Leste do Sul } & 23 & Manhuaçu & 48,2 & 47,8 & 46,6 & 100,0 & 49,3 \\
\hline & 24 & Ponte Nova & 100,0 & 78,4 & 34,2 & 49,7 & 43,5 \\
\hline & 25 & Viçosa & 100,0 & 100,0 & 100,0 & 100,0 & 100,0 \\
\hline \multirow{8}{*}{ Nordeste } & 26 & Águas Formosas & 100,0 & 49,9 & 100,0 & 30,1 & 31,1 \\
\hline & 27 & Almenara & 42,3 & 100,0 & 100,0 & 33,7 & 100,0 \\
\hline & 28 & Araçuaí & 64,1 & 43,3 & 100,0 & 89,4 & 100,0 \\
\hline & 29 & Itaobim & 36,4 & 48,6 & 42,9 & 92,6 & 45,7 \\
\hline & 30 & Nanuque & 100,0 & 100,0 & 100,0 & 66,2 & 63,4 \\
\hline & 31 & Padre Paraíso & 44,3 & 100,0 & 58,9 & 49,6 & 100,0 \\
\hline & 32 & Pedra Azul & 100,0 & 100,0 & 100,0 & 100,0 & 50,8 \\
\hline & 33 & Teófilo Otoni & 35,5 & 40,7 & 33,5 & 100,0 & 31,8 \\
\hline \multirow{3}{*}{ Noroeste } & 34 & João Pinheiro & 100,0 & 100,0 & 100,0 & 39,7 & 38,3 \\
\hline & 35 & Patos de Minas & 49,9 & 62,3 & 54,8 & 100,0 & 48,6 \\
\hline & 36 & Unaí & 62,4 & 72,3 & 100,0 & 100,0 & 49,2 \\
\hline \multirow{9}{*}{ Norte } & 37 & Brasília Minas & 43,9 & 100,0 & 100,0 & 39,2 & 39,9 \\
\hline & 38 & Coração de Jesus & 100,0 & 100,0 & 100,0 & 32,2 & 100,0 \\
\hline & 39 & Francisco Sá & 100,0 & 100,0 & 30,1 & 100,0 & 46,6 \\
\hline & 40 & Janaúba & 68,2 & 82,2 & 64,1 & 41,5 & 47,9 \\
\hline & 41 & Januária & 46,7 & 100,0 & 100,0 & 100,0 & 35,4 \\
\hline & 42 & Manga & 34,5 & 43,8 & 50,6 & 49,1 & 63,2 \\
\hline & 43 & Montes Claros & 61,0 & 66,5 & 57,0 & 45,7 & 47,4 \\
\hline & 44 & Pirapora & 34,6 & 100,0 & 46,8 & 34,7 & 43,4 \\
\hline & 45 & Salinas & 52,7 & 43,0 & 56,8 & 59,8 & 47,7 \\
\hline \multirow{6}{*}{ Oeste } & 46 & Bom Despacho & 100,0 & 100,0 & 68,7 & 100,0 & 100,0 \\
\hline & 47 & Divinópolis & 53,9 & 56,7 & 56,1 & 100,0 & 100,0 \\
\hline & 48 & Formiga & 100,0 & 100,0 & 100,0 & 100,0 & 100,0 \\
\hline & 49 & Itaúna & 100,0 & 100,0 & 100,0 & 43,8 & 51,3 \\
\hline & 50 & Pará de Minas & 54,2 & 56,3 & 49,7 & 100,0 & 68,2 \\
\hline & 51 & S. Ant. Amparo & 100,0 & 49,9 & 100,0 & 67,4 & 100,0 \\
\hline Sudeste & 52 & Além Paraíba & 33,4 & 47,8 & 100,0 & 100,0 & 48,7 \\
\hline
\end{tabular}




\begin{tabular}{|c|c|c|c|c|c|c|c|}
\hline & 53 & Carangola & 44,6 & 100,0 & 100,0 & 100,0 & 100,0 \\
\hline & 54 & Juiz de Fora & 39,1 & 61,1 & 48,3 & 44,8 & 35,2 \\
\hline & 55 & Leopoldina & 100,0 & 100,0 & 46,6 & 48,2 & 47,5 \\
\hline & 56 & Muriaé & 42,5 & 100,0 & 100,0 & 49,9 & 100,0 \\
\hline & 57 & Santos Dumont & 100,0 & 100,0 & 100,0 & 100,0 & 100,0 \\
\hline & 58 & S. João Nepom. & 100,0 & 44,2 & 100,0 & 100,0 & 100,0 \\
\hline & 59 & Ubá & 50,0 & 100,0 & 100,0 & 57,0 & 50,4 \\
\hline \multirow{12}{*}{ Sul } & 60 & Alfenas & 64,9 & 69,0 & 47,9 & 100,0 & 48,9 \\
\hline & 61 & Guaxupé & 100,0 & 69,6 & 100,0 & 41,8 & 100,0 \\
\hline & 62 & Itajubá & 38,9 & 100,0 & 100,0 & 100,0 & 100,0 \\
\hline & 63 & Lavras & 100,0 & 100,0 & 100,0 & 51,4 & 34,8 \\
\hline & 64 & Passos & 64,8 & 54,3 & 100,0 & 65,7 & 100,0 \\
\hline & 65 & Poços de Caldas & 91,0 & 97,5 & 78,6 & 47,7 & 60,8 \\
\hline & 66 & Pouso Alegre & 57,3 & 62,0 & 56,8 & 66,3 & 44,4 \\
\hline & 67 & São Lourenço & 95,8 & 100,0 & 100,0 & 62,6 & 55,0 \\
\hline & 68 & S.Seb.Paraiso & 43,2 & 100,0 & 100,0 & 100,0 & 100,0 \\
\hline & 69 & Três Corações & 100,0 & 100,0 & 48,6 & 46,9 & 100,0 \\
\hline & 70 & Três Pontas & 100,0 & 66,5 & 92,1 & 100,0 & 35,1 \\
\hline & 71 & Varginha & 100,0 & 100,0 & 100,0 & 68,3 & 73,2 \\
\hline \multirow{3}{*}{ Triâng. Norte } & 72 & Ituiutaba & 68,7 & 100,0 & 100,0 & 100,0 & 100,0 \\
\hline & 73 & Patrocínio & 54,3 & 100,0 & 53,2 & 100,0 & 50,7 \\
\hline & 74 & Uberlândia & 62,9 & 77,0 & 69,6 & 66,4 & 52,6 \\
\hline \multirow{3}{*}{ Triâng.do Sul } & 75 & Araxá & 62,5 & 45,5 & 65,0 & 38,2 & 40,6 \\
\hline & 76 & Frutal & 100,0 & 76,2 & 100,0 & 55,1 & 39,6 \\
\hline & 77 & Uberaba & 73,1 & 59,3 & 65,5 & 51,1 & 49,9 \\
\hline \multirow{4}{*}{$\begin{array}{l}\text { Estatística } \\
\text { Descritiva }\end{array}$} & & Média & 70,0 & 77,4 & 79,3 & 69,3 & 64,0 \\
\hline & & Desvio Padrão & 25,2 & 22,6 & 24,5 & 26,4 & 25,1 \\
\hline & & Mínimo & 33,4 & 35,1 & 30,1 & 28,0 & 29,5 \\
\hline & & Máximo & 100,0 & 100,0 & 100,0 & 100,0 & 100,0 \\
\hline
\end{tabular}

Fonte: Dados da pesquisa

O estudo de Ázara (2016), que avaliou o nível de eficiência do gasto público dos municípios da microrregião de Varginha/MG, com outras variáveis como o PIB e um indicador agregado, concluiu que os gastos dos municípios não estão sendo direcionados para a obtenção dos melhores resultados, ou seja, não estão sendo aplicados de maneira eficiente.

O estudo de Fonseca \& Ferreira (2009), que avaliou as 66 RS mineiras em 2009, com outros inputs e outputs de produção pelo DEA, concluíram que o desempenho em um ano das RS foi considerado bom, com scores acima da média estadual (em torno de 78\%, porém apontam disparidades regionais na gestão dos recursos, devido aos altos desvios-padrões obtidos. Mesmo que o estudo tenha trabalho também com as RS mineiras, porém foi para um único ano, com todas as variáveis diferentes das que utilizamos. Mesmo assim, o estudo já detectou discrepâncias regionais na gestão dos recursos, assim como neste estudo.

Outros estudos avaliaram a gestão dos gastos públicos pela técnica DEA em Minas Gerais: Martino Júnior (2011); Cabral \& Ferreira (2014); Lemos \& Moares Jr., (2015).

Como resultados gráficos, a DEA apresenta uma avaliação geral das metas de 
melhoria das RS ineficientes. É possível identificar onde as RS devem investir, considerando os acréscimos proporcionais no escore de eficiência, bem como a possibilidade de acréscimos não proporcionais, o que se chama na DEA de slacks (folgas). Neste estudo, pelo critério de minimizaçãoo do input, quer dizer que as RS estão consumindo recursos de forma inadequada para a quantidade de outputs produzidos. Assim nas figuras 2 a 6, apresentam o percentual geral que as RS ineficientes precisam melhorar em cada outputs e inputs, para alcançarem a fronteira da eficiência.

$\mathrm{Na}$ figura 2, verifica-se que a representatividade das metas de melhorias em 2010, das RS ineficientes, que deveriam considerar as ações sobre os indicadores TMM e TMI ou outputs, e sobre o input DespLiq. Sob o ponto de vista geral, no ano de 2010, considerando as RS ineficientes, as mesmas devem reduzir seus outputs ou as suas TMI e TMM em torno de $28,24 \%$ e $39,71 \%$, respectivamente. Por outro lado, estão consumindo muitos recursos para obterem baixos resultados. Assim também há indicação de redução dos inputs ou das despesas liquidadas em torno de $32,05 \%$.

Figura 2 - Representatividade dos potenciais de melhorias dos inputs e outputs em 2010

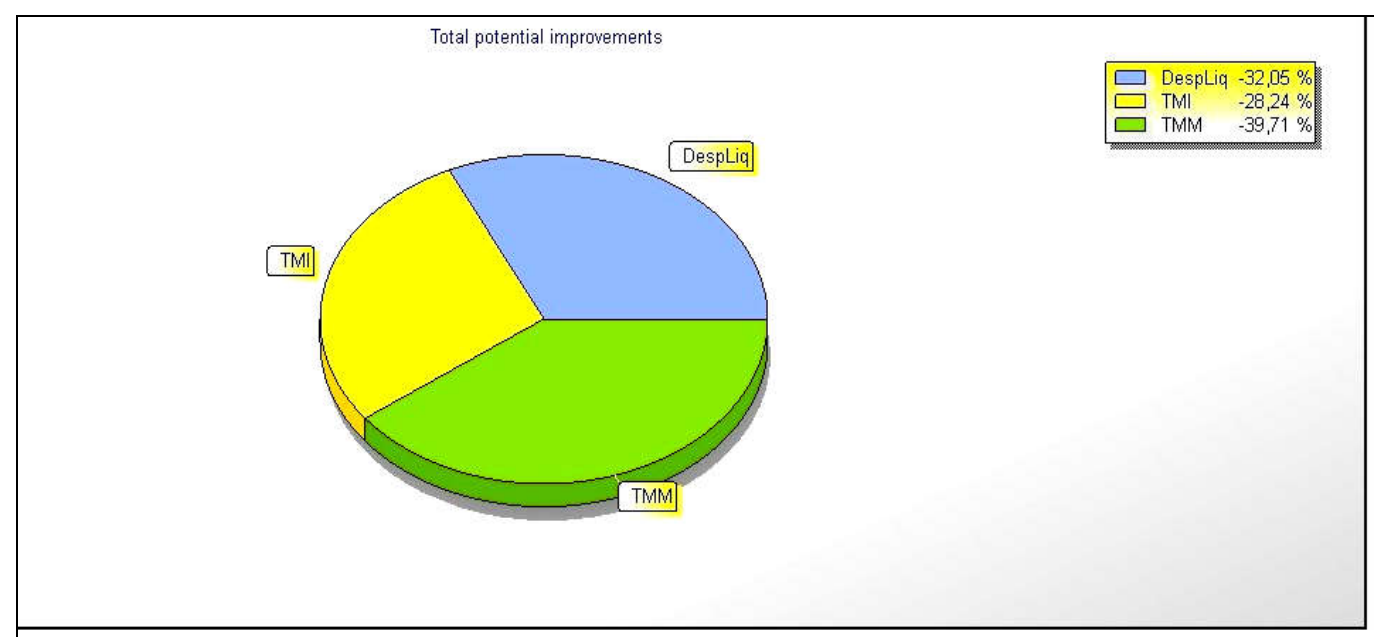

Fonte: Resultados da pesquisa

Na figura 3, verifica-se o mesmo gráfico para 2011 em dimensões e percentuais diferentes, assim como os gráficos das figuras 4, 5 e 6, com os potenciais de melhoria para 2012, 2013 e 2014 das RS ineficientes, que também deveriam considerar as ações sobre os indicadores TMM e TMI ou outputs, e sobre o input DespLiq.

Em 2011, observa-se que as indicações são de uma redução percentual maior para as TMI e TMM, de 30,89\% e de 47,44\%. Percebe-se que há uma variação maior para o output 
TMM.

Figura 3 - Representatividade dos potenciais de melhorias dos inputs e outputs em 2011

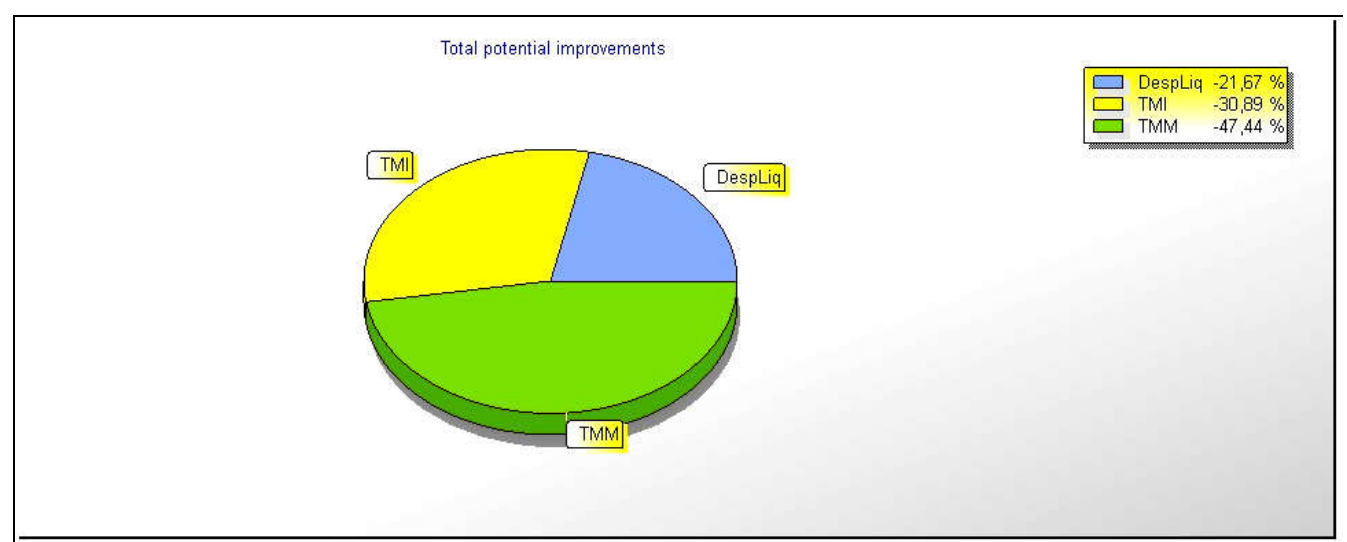

Fonte: Resultados da pesquisa

Em 2012, observa-se que as indicações são de uma redução percentual maior para a TMI de $45,46 \%$.

Figura 4 - Representatividade dos potenciais de melhorias dos inputs e outputs em 2012

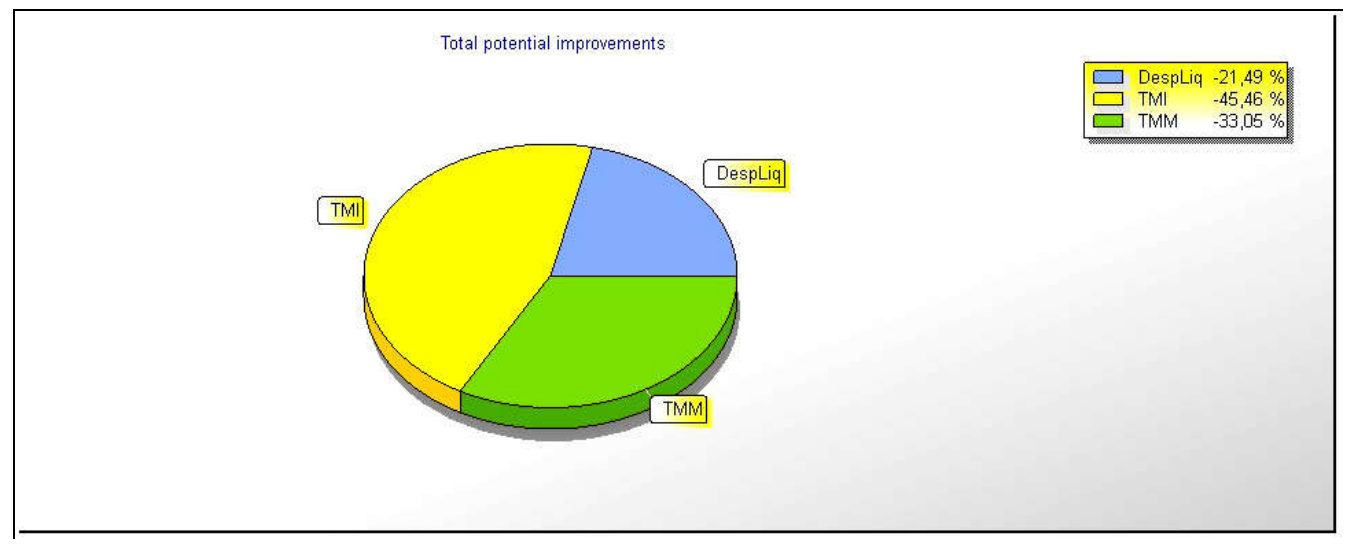

Fonte: Resultados da pesquisa

Em 2013, as indicações de maior redução percentual também são para a TMI, de $43,73 \%$. 
Figura 5 - Representatividade dos potenciais de melhorias dos inputs e outputs em 2013

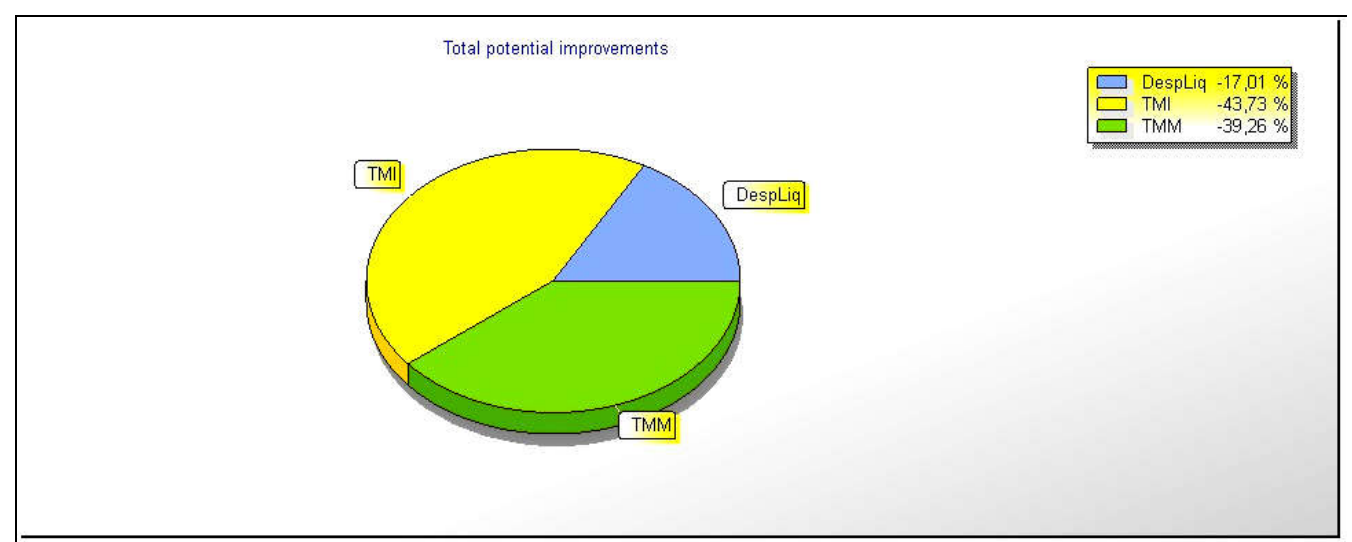

Fonte: Resultados da pesquisa

Em 2014, as indicações de maior redução percentual são para a TMM, de 52,92\%. Observa-se que nos anos analisados há indicação de redução dos inputs (despesas liquidadas), para todos os anos, porém, essa indicação decresceu em termos percentuais do 2010 para 2014, ou seja, as RS utilizaram os seus recursos mais adequadamente em 2014. Por outro lado, ocorreram variações heterogêneas nos outputs de TMI e TMM nos anos analisados.

Figura 6 - Representatividade dos potenciais de melhorias dos inputs e outputs em 2014

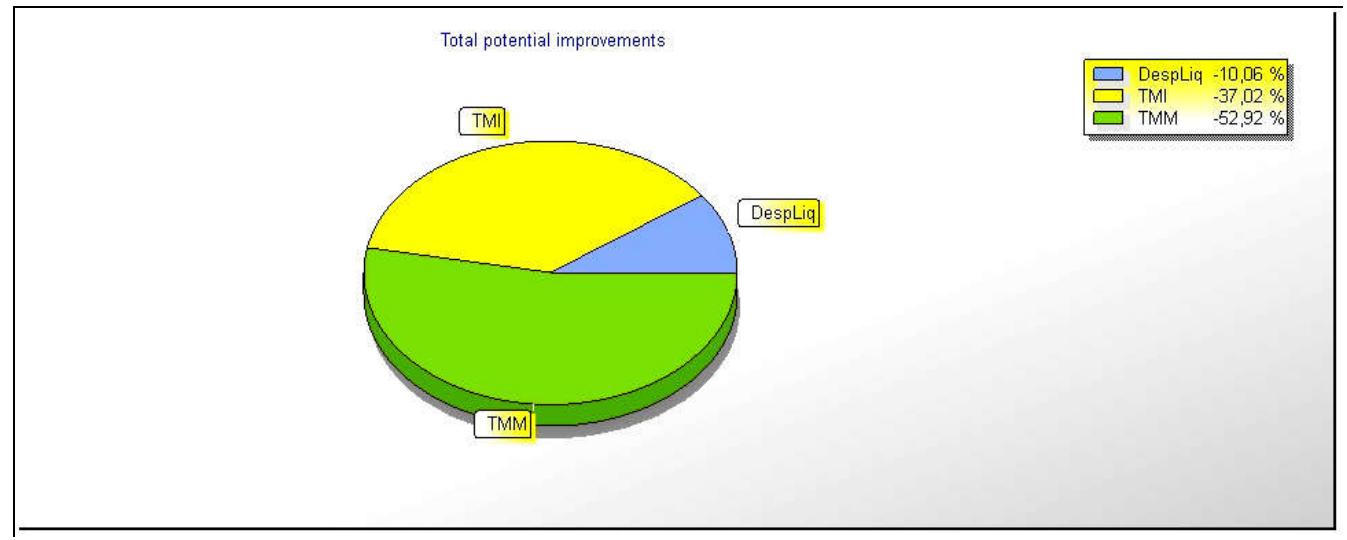

Fonte: Resultados da pesquisa

Nessas regiões há uma necessidade de maiores esclarecimentos, com o objetivo de analisar os fatores que contribuíram para a ineficiência da região de saúde. A DEA oferece outros testes para tentar elucidar essas variações, que não foram realizados neste estudo, devido ao quantitativo de RS. Porém, apresentamos na tabela 19, outra informação importante, a eficiência de escala, que representa a razão entre a eficiência total sobre a efíciência técnica, como já abordado no item 3.4. 
A tabela 19 apresenta o retorno de escala das RS. Isso representa que uma RS pode ser ineficiente tendo como base o seu retorno de escala. As RS podem aumentar a sua eficiência produtiva, simplesmente aumentando a sua escala de produção, sem alterações na eficiência técnica. Porém em casos específicos, aumentar a escala de produção significa obter mais recursos públicos, fato que demanda tempo, orçamento, o que nem sempre é possível a curto prazo. Serve de indicativo de mudanças de políticas públicas.

Por outro lado pode significar que as RS ineficientes tenham que reduzir a suas escalas de produção (o que é inviável para TMI e TMM) ou reduzir parte dos seus recursos obtidos, melhorando assim a alocação dos mesmos.

Tabela 19 - Eficiência de escala das Regiões de Saúde

\begin{tabular}{|c|c|c|c|c|c|c|c|}
\hline \multirow[b]{2}{*}{$\begin{array}{c}\text { Região } \\
\text { Ampliada }\end{array}$} & \multirow[b]{2}{*}{$\begin{array}{l}N^{\circ} . \\
\text { RS }\end{array}$} & \multirow[b]{2}{*}{ Região de Saúde } & \multicolumn{5}{|c|}{ Eficiência de Escala } \\
\hline & & & $\begin{array}{c}2010 \\
\% \\
\end{array}$ & $\begin{array}{c}2011 \\
\% \\
\end{array}$ & $\begin{array}{c}2012 \\
\% \\
\end{array}$ & $\begin{array}{c}2013 \\
\% \\
\end{array}$ & $\begin{array}{c}2014 \\
\% \\
\end{array}$ \\
\hline \multirow{10}{*}{ Centro } & 01 & Belo Horizonte & 34,6 & 39,7 & 64,1 & 42,5 & 77,4 \\
\hline & 02 & Betim & 39,4 & 42,5 & 78,5 & 67,7 & 99,6 \\
\hline & 03 & Contagem & 74,5 & 69,0 & 100,0 & 82,1 & 96,4 \\
\hline & 04 & Curvelo & 44,4 & 49,0 & 63,9 & 54,2 & 99,8 \\
\hline & 05 & Guanhães & 52,9 & 55,4 & 81,8 & 67,1 & 99,5 \\
\hline & 06 & Itabira & 36,4 & 36,3 & 49,0 & 36,2 & 58,4 \\
\hline & 07 & João Monlevade & 35,0 & 41,8 & 55,0 & 47,9 & 83,7 \\
\hline & 08 & Ouro Preto & 50,1 & 46,3 & 70,2 & 45,7 & 45,8 \\
\hline & 09 & Sete Lagoas & 38,3 & 42,6 & 48,5 & 31,8 & 85,5 \\
\hline & 10 & Vespasiano & 53,5 & 52,6 & 81,4 & 35,2 & 100,0 \\
\hline \multirow{3}{*}{ Centro Sul } & 11 & Barbacena & 53,1 & 33,3 & 48,8 & 50,9 & 84,1 \\
\hline & 12 & Cons. Lafaiete & 39,8 & 39,5 & 58,6 & 56,3 & 100,0 \\
\hline & 13 & S. João Del Rei & 47,0 & 43,3 & 66,3 & 38,3 & 54,2 \\
\hline \multirow{2}{*}{ Jequitinhonha } & 14 & Diamantina & 63,5 & 65,2 & 95,7 & 65,2 & 99,6 \\
\hline & 15 & Minas Novas & 52,8 & 56,7 & 100,0 & 47,3 & 69,3 \\
\hline \multirow{7}{*}{ Leste } & 16 & Caratinga & 40,5 & 46,2 & 81,7 & 55,4 & 100,0 \\
\hline & 17 & Cel. Fabriciano & 53,4 & 53,9 & 82,6 & 76,1 & 97,8 \\
\hline & 18 & Gov. Valadares & 64,1 & 62,5 & 94,7 & 70,7 & 98,7 \\
\hline & 19 & Ipatinga & 38,6 & 44,0 & 84,8 & 51,6 & 100,0 \\
\hline & 20 & Mantena & 53,0 & 55,1 & 79,9 & 44,2 & 99,8 \\
\hline & 21 & Resplendor & 57,3 & 52,0 & 86,4 & 56,8 & 99,7 \\
\hline & 22 & S.Maria Suaçui & 58,8 & 56,6 & 95,5 & 74,7 & 98,1 \\
\hline \multirow{3}{*}{ Leste do Sul } & 23 & Manhuaçu & 44,8 & 49,8 & 89,9 & 42,4 & 99,6 \\
\hline & 24 & Ponte Nova & 32,8 & 39,2 & 64,9 & 46,3 & 81,8 \\
\hline & 25 & Viçosa & 43,4 & 49,8 & 91,2 & 100,0 & 100,0 \\
\hline \multirow{8}{*}{ Nordeste } & 26 & Águas Formosas & 55,5 & 58,9 & 98,5 & 73,4 & 98,1 \\
\hline & 27 & Almenara & 56,7 & 60,1 & 85,4 & 68,5 & 66,0 \\
\hline & 28 & Araçuaí & 61,6 & 64,4 & 93,0 & 78,9 & 59,9 \\
\hline & 29 & Itaobim & 60,7 & 59,1 & 94,9 & 69,0 & 98,0 \\
\hline & 30 & Nanuque & 60,3 & 68,0 & 100,0 & 86,6 & 95,6 \\
\hline & 31 & Padre Paraíso & 54,2 & 55,4 & 91,5 & 72,4 & 75,4 \\
\hline & 32 & Pedra Azul & 52,5 & 58,1 & 99,6 & 54,3 & 98,2 \\
\hline & 33 & Teófilo Otoni & 43,1 & 45,9 & 73,7 & 34,8 & 94,0 \\
\hline \multirow{2}{*}{ Noroeste } & 34 & João Pinheiro & 33,5 & 36,3 & 68,1 & 54,2 & 100,0 \\
\hline & 35 & Patos de Minas & 37,3 & 39,0 & 68,4 & 31,7 & 90,5 \\
\hline
\end{tabular}




\begin{tabular}{|c|c|c|c|c|c|c|c|}
\hline & 36 & Unaí & 43,1 & 45,5 & 62,5 & 35,2 & 99,8 \\
\hline \multirow{9}{*}{ Norte } & 37 & Brasília Minas & 44,2 & 43,3 & 68,3 & 60,2 & 99,7 \\
\hline & 38 & Coração de Jesus & 36,4 & 41,6 & 63,0 & 58,4 & 51,6 \\
\hline & 39 & Francisco Sá & 42,8 & 43,5 & 77,7 & 35,4 & 100,0 \\
\hline & 40 & Janaúba & 54,7 & 56,7 & 91,3 & 65,3 & 99,6 \\
\hline & 41 & Januária & 51,2 & 50,9 & 78,0 & 46,9 & 99,4 \\
\hline & 42 & Manga & 52,2 & 55,5 & 93,9 & 79,6 & 97,0 \\
\hline & 43 & Montes Claros & 30,0 & 33,7 & 56,5 & 45,1 & 85,2 \\
\hline & 44 & Pirapora & 51,7 & 48,4 & 84,0 & 59,7 & 99,8 \\
\hline & 45 & Salinas & 44,6 & 47,4 & 80,8 & 57,5 & 99,6 \\
\hline \multirow{6}{*}{ Oeste } & 46 & Bom Despacho & 54,5 & 59,9 & 95,9 & 55,7 & 72,2 \\
\hline & 47 & Divinópolis & 39,1 & 39,5 & 71,3 & 47,4 & 61,9 \\
\hline & 48 & Formiga & 46,9 & 50,2 & 75,5 & 39,9 & 55,3 \\
\hline & 49 & Itaúna & 37,4 & 36,8 & 73,1 & 49,5 & 86,2 \\
\hline & 50 & Pará de Minas & 61,6 & 61,6 & 95,2 & 47,8 & 99,6 \\
\hline & 51 & S. Ant. Amparo & 45,5 & 48,3 & 82,1 & 55,0 & 55,8 \\
\hline \multirow{8}{*}{ Sudeste } & 52 & Além Paraíba & 41,0 & 46,0 & 64,8 & 36,4 & 99,8 \\
\hline & 53 & Carangola & 50,9 & 51,3 & 63,7 & 38,1 & 57,8 \\
\hline & 54 & Juiz de Fora & 30,7 & 32,1 & 55,3 & 44,2 & 72,4 \\
\hline & 55 & Leopoldina & 45,5 & 43,7 & 86,5 & 58,9 & 99,8 \\
\hline & 56 & Muriaé & 62,8 & 58,5 & 93,3 & 75,6 & 86,7 \\
\hline & 57 & Santos Dumont & 100,0 & 100,0 & 55,0 & 100,0 & 95,8 \\
\hline & 58 & S. João Nepom. & 56,9 & 55,7 & 70,2 & 41,1 & 57,6 \\
\hline & 59 & Ubá & 57,8 & 62,2 & 98,2 & 76,0 & 98,2 \\
\hline \multirow{12}{*}{ Sul } & 60 & Alfenas & 40,5 & 43,3 & 71,4 & 31,2 & 95,9 \\
\hline & 61 & Guaxupé & 54,5 & 57,3 & 80,9 & 65,1 & 100,0 \\
\hline & 62 & Itajubá & 57,3 & 54,7 & 95,3 & 49,0 & 72,3 \\
\hline & 63 & Lavras & 32,7 & 32,0 & 48,9 & 47,5 & 87,9 \\
\hline & 64 & Passos & 37,8 & 43,1 & 69,1 & 49,8 & 44,1 \\
\hline & 65 & Poços de Caldas & 24,7 & 23,0 & 45,0 & 31,2 & 100,0 \\
\hline & 66 & Pouso Alegre & 45,4 & 49,5 & 89,6 & 60,6 & 99,8 \\
\hline & 67 & São Lourenço & 47,2 & 45,3 & 75,4 & 62,1 & 99,6 \\
\hline & 68 & S.Seb.Paraiso & 33,6 & 32,2 & 51,0 & 28,9 & 30,0 \\
\hline & 69 & Três Corações & 51,9 & 48,5 & 92,6 & 58,6 & 72,5 \\
\hline & 70 & Três Pontas & 39,7 & 42,7 & 76,9 & 32,1 & 98,6 \\
\hline & 71 & Varginha & 100,0 & 78,7 & 78,2 & 52,6 & 88,9 \\
\hline \multirow{3}{*}{ Triâng. Norte } & 72 & Ituiutaba & 45,1 & 48,3 & 60,9 & 37,2 & 100,0 \\
\hline & 73 & Patrocínio & 39,6 & 38,1 & 72,6 & 37,2 & 90,3 \\
\hline & 74 & Uberlândia & 32,1 & 31,7 & 55,3 & 40,7 & 89,4 \\
\hline \multirow{3}{*}{ Triâng.do Sul } & 75 & Araxá & 37,1 & 40,7 & 74,3 & 50,8 & 99,8 \\
\hline & 76 & Frutal & 30,8 & 34,9 & 53,4 & 46,5 & 83,6 \\
\hline & 77 & Uberaba & 38,6 & 39,3 & 69,0 & 49,7 & 88,4 \\
\hline \multirow{4}{*}{$\begin{array}{l}\text { Estatística } \\
\text { Descritiva }\end{array}$} & & Média & 47,9 & 48,9 & 76,4 & 53,9 & 86,7 \\
\hline & & Desvio Padrão & 13,1 & 11,8 & 15,3 & 15,9 & 17,3 \\
\hline & & Mínimo & 24,7 & 23,0 & 45,0 & 28,9 & 30,0 \\
\hline & & Máximo & 100,0 & 100,0 & 100,0 & 100,0 & 100,0 \\
\hline
\end{tabular}

Fonte: Dados da pesquisa

Observando a estatística descritiva da eficiência de escala das RS, percebe-se que os resultados nos anos analisados são totalmente heterogêneos, porém com a mesma tendência da eficiência total (CCR). 


\subsection{Resultados da análise dos indicadores de saúde municipais}

Uma maneira de se ter conhecimento sobre as condições de saúde de uma população, é avaliá-la por meio de indicadores, e a saúde sempre foi acompanhada por diferentes indicadores, cobrindo os seus múltiplos aspectos, desde antes da obrigatoriedade de indicadores, para cumprir o Pacto pela Saúde em 2006.

Considerando que na estimação da eficiência total pela DEA, as Regiões Ampliadas de Saúde com os piores resultados ressaltadas, ou seja, ineficientes em todos os anos, foram Nordeste, Noroeste, Norte, Triângulo do Norte e Triângulo do Sul. Nessas Regiões Ampliadas de Saúde, compostas por Regiões de Saúde (RS), que foram analisadas pelo método BCC (item 5.3, Tabela 18), apresentaram os seguintes resultados:

- Na Região Ampliada Nordeste: temos como ineficiente em todos os anos a Região de Saúde de Itaobim;

- Na Região Ampliada Noroeste: todas as RS foram eficientes em pelo menos um ano do período analisado;

- Na Região Ampliada Norte: foram ineficientes em todos os anos as Regiões de Saúde de Janaúba, Manga, Montes Claros e Salinas;

- Na Região Ampliada Triângulo do Norte: foi ineficiente em todos os anos a Região de Saúde de Uberlândia;

- Na Região Ampliada Triângulo do Sul: foram ineficientes em todos os anos as Regiões de Saúde de Araxá e Uberaba.

Com base neste painel apresentado, considerando a estimação pelo método BCC, na DEA, optamos por observar no detalhe, analisando os indicadores na área da saúde dos municípios que compõem essas Regiões de Saúde, que foram ineficientes em todos os anos analisados. Assim, justificando o interesse deste trabalho sobre as Regiões de Saúde e os Municípios de Minas Gerais que as compõem, e também a disponibilidade de dados; apresentamos nas Tabelas 20 à 23, a evolução de 12 indicadores de saúde das Regiões de Saúde ineficientes de Itaobim, Janaúba, Manga, Montes Claros, Salinas, Uberlândia, Araxá e Uberaba.

Ressalta-se que devido a Região Ampliada Noroeste, onde todas as RS foram eficientes em pelo menos um ano do período analisado, optamos por não selecionar nenhuma 
RS para ser analisada, mesmo que essa Região Ampliada apresentou-se como ineficiente, na estimação pelo método CCR na análise das 13 Regiões Ampliadas de Saúde.

Selecionamos dentre o rol de Diretrizes, objetivos, metas e indicadores conforme a última Nota Técnica vigente relativo ao período de 2013-2015, doze indicadores mais utilizados na literatura. Outros aspectos considerados na escolha desses indicadores foram:

- Dados faltantes, relativo a alguns indicadores;

- Falta de continuidade do indicador, no período analisado de 2010 à 2014;

- Indicadores informados após a Nota Técnica em 2013;

- Inconsistência dos dados (uma das limitações da pesquisa);

- Relevância do indicador no objetivo deste estudo, etc.

Na seleção dos indicadores, buscou-se aplicar uma técnica estatística para auxiliar na seleção desses indicadores, como a análise fatorial, considerando as suas cargas fatoriais; porém devido às limitações enfrentadas citados acima, e considerando que alguns indicadores têm uma tendência de "quanto menor, melhor", ou o inverso; decidiu-se por uma análise de forma mais qualitativa. Procurou-se selecionar os indicadores que contemplassem os três níveis de atenção: a primária, a média e alta complexidade.

Como já citado, buscou-se apoio na literatura no Índice de Desempenho do Sistema Único de Saúde (IDSUS), instituído em abril de 2011, que contempla 24 indicadores na linha de acesso e efetividade, sendo que destes 24 indicadores, 20 estão contemplados no rol de Diretrizes, objetivos, metas e indicadores de 2013-2015. Ocorreu uma descontinuidade do cálculo desse indicador agregado, mas hoje ainda se encontra no sítio do DATASUS, link: http://idsus.saude.gov.br/apresentacao.html, alguns textos falando sobre o IDSUS.

Como citado, dos 24 indicadores do IDSUS, 20 estão contemplados no rol de indicadores que coletamos no sítio do DATASUS, porém muitos deles estão incompletos, principalmente por falta de alimentação do Banco de Dados do DATASUS por parte dos Municípios. Os 12 indicadores do rol de Diretrizes, objetivos, metas e indicadores de 20132015, selecionados são amplamente utilizados nos trabalhos citados neste, como indicadores de resultado, sendo:

- $\mathrm{CEAB}$ - Cobertura equipes atenção básica: Cobertura populacional estimada pelas equipes de Atenção Básica;

- ICSAB - \% Int. cond. sensív. at. básica: Proporção de internações por condições sensíveis à atenção básica; 
- CESB - Cobertura equipes saúde bucal: Cobertura populacional estimada pelas equipes básicas de saúde bucal;

- PAMC - Proc. amb. média compl/100hab: Razão de procedimentos ambulatoriais de média complexidade e populaçãoo residente;

- RIMC - Int. média complex. p/100 hab: Razão de internações clínico-cirúrgicas de média complexidade e população residente;

- PAAC - Proc. amb. alta compl./100hab: Razão de procedimentos ambulatoriais de alta complexidade e população residente;

- RIAC - Int. alta complex.p/1000 hab: Razão de internações clínico-cirúrgicas de alta complexidade e populaçãoo residente;

- RECCU - Razão exames citopat. colo útero: Razão de exames citopatológicos do colo do útero em mulheres de 25 a 64 anos e a população da mesma faixa etária;

- RMR - Razão mamografias realizadas: Razão de exames de mamografia de rastreamento realizados em mulheres de 50 a 69 anos e população da mesma faixa etária;

- PPN - \% Partos normais: Proporção de parto normal;

- NVCPN - \% NV c/7+ consultas pré-natal: Proporção de nascidos vivos de mães com 7 ou mais consultas de pré-natal;

- POCD - \% Obitos com causa definida: Proporção de registro de óbitos com causa básica definida.

A razão da seleção somente das Regiões de Saúde citadas, se deve ao fato, que a apresentação das tabelas referentes aos 12 indicadores, se torna exaustiva e cansativa em uma análise pormenorizada. As tabelas 20 e 21 apresentam a média municipal, e a variação proporcional no período de cinco anos dos 12 indicadores de saúde citados, para as RS de Itaobim, Uberlândia, Araxá e Uberaba.

Observa-se em uma análise vertical que a evolução dos 6 primeiros indicadores apresentados na tabela 20 estão homogêneos com exceção do indicador Razão de procedimentos ambulatoriais de média complexidade (PAMC), que aumentou excessivamente principalmente para os municípios das RS de Itaobim e Uberlândia. Isso significa que cresceu o atendimento destes procedimentos, aumentou o acesso, o que demanda mais recursos, e o aumento dos gastos sob a responsabilidade desses municípios. 
A Cobertura equipes atenção básica (CEAB) em geral aumentou ou se manteve estável, com exceção para os Municípios de Nova Ponte e Campo Florido. Essa cobertura é relevante para manter o nível de atenção primária assistida, assim como também é importante a Cobertura equipes saúde bucal (CESB) que segue a tendência da CEAB. Os Municípios de Comercinho, Monte Alegre de Minas, Araxá, Pratinha, Santa Juliana e Campo Florido, reduziram as suas coberturas.

O gerenciamento inadequado desses indicadores mencionados, vão refletir no indicador Proporção de internações por condições sensíveis à atenção básica (ICSAB), que reduziu de maneira geral, seguindo a tendência de quanto menor, melhor; com exceção para os municípios de Medina, Indianópolis, Tupaciguara, Sacramento e Veríssimo; o que significa falhas na atenção básica desses municípios.

A razão de internações clínico-cirúrgicas de média complexidade (RIMC) se manteve estável, com reduções significativas em Pedrinópolis e Conquista; enquanto para a Razão de procedimentos ambulatoriais de alta complexidade (PAAC), ocorreram crescimento significativo para os municípios de Comercinho, Monte Formoso e Nova Ponte. O que implica dizer que cresceu o atendimento destes procedimentos, aumentando o acessso, o que demanda mais recursos, portanto aumento dos gastos.

Observa-se que para esses 6 primeiros indicadores apresentados, ficam evidentes as alterações mais significativas para os municípios contemplados nas RS de Itaobim e Uberlândia.

Tabela 20 - Variação \% da evolução dos indicadores de saúde dos municípios das Regiões de Saúde: Itaobim, Uberlândia, Araxá e Uberaba, no período de 2010 à 2014

\begin{tabular}{|c|c|c|c|c|c|c|c|c|c|c|c|c|c|}
\hline \multirow{2}{*}{$\begin{array}{l}\mathbf{R} \\
\mathbf{S}\end{array}$} & \multirow{2}{*}{ Municípios } & \multicolumn{2}{|c|}{ CEAB } & \multicolumn{2}{|c|}{ ICSAB } & \multicolumn{2}{|c|}{ CESB } & \multicolumn{2}{|c|}{ PAMC } & \multicolumn{2}{|c|}{ RIMC } & \multicolumn{2}{|c|}{ PAAC } \\
\hline & & $\mu$ & $\%$ & $\mu$ & $\%$ & $\mu$ & $\%$ & $\mu$ & $\%$ & $\mu$ & $\%$ & $\mu$ & $\%$ \\
\hline \multirow{6}{*}{ 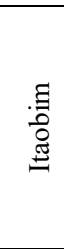 } & Comercinho & 95,5 & 0 & 38,1 & -2 & 90 & -25 & 0,36 & 671 & 3,7 & 66 & 0,9 & 102 \\
\hline & Itaobim & 90,3 & 0 & 33,9 & 15 & 93,2 & 6 & 0,66 & 186 & 4,8 & -14 & 1,5 & 28 \\
\hline & Itinga & 94,9 & 0 & 31,5 & -6 & 78 & 5 & 0,46 & 1600 & 3,6 & 11 & 0,9 & 22 \\
\hline & Medina & 94 & 27 & 42,2 & 24 & 100 & 0 & 0,47 & 700 & 5,3 & 4 & 1,3 & 22 \\
\hline & Monte Formoso & 94,2 & 8 & 24,6 & -38 & 100 & 0 & 1,30 & - & 2,6 & -37 & 0,6 & 282 \\
\hline & Ponto Volantes & 97,4 & 15 & 35,5 & -9 & 100 & 0 & 0,44 & 1625 & 3,6 & -3 & 1,5 & 27 \\
\hline \multirow{9}{*}{ 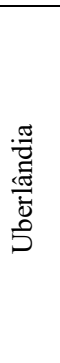 } & Araguari & 56,5 & 46 & 27,8 & 7 & 55,4 & -3 & 0,32 & 195 & 4,1 & -14 & 3,2 & 44 \\
\hline & Araporã & 97,3 & 9 & 23,9 & -15 & 100 & 0 & 0,39 & 673 & 4,2 & 69 & 4,7 & 77 \\
\hline & Cascalho Rico & 100 & 0 & 24,2 & -32 & 100 & 0 & 0,91 & 187 & 2,2 & -24 & 4,5 & 74 \\
\hline & Indianópolis & 100 & 0 & 24,1 & 42 & 86,9 & 6 & 0,70 & 56 & 1,8 & -3 & 4,5 & -6 \\
\hline & M.Alegre Minas & 76,4 & -4 & 20,4 & -5 & 96,6 & -17 & 0,71 & 387 & 3,1 & 30 & 3,1 & 75 \\
\hline & Nova Ponte & 89,7 & -23 & 25,3 & -18 & 100 & 0 & 0,39 & 614 & 2,4 & -21 & 1,6 & 125 \\
\hline & Prata & 83,9 & 78 & 32,0 & -14 & 55,1 & 121 & 0,67 & 154 & 4,5 & -5 & 3,4 & 78 \\
\hline & Tupaciguara & 63,6 & 11 & 37,3 & 35 & 37,2 & -2 & 0,72 & 381 & 4,5 & 24 & 2,3 & 57 \\
\hline & Uberlândia & 40,9 & 56 & 22,0 & 19 & 29,3 & 19 & 2,28 & -2 & 3,7 & 6 & 5,6 & 40 \\
\hline
\end{tabular}




\begin{tabular}{|c|c|c|c|c|c|c|c|c|c|c|c|c|c|}
\hline \multirow{8}{*}{ 菏 } & Araxá & 71,2 & 12 & 38,2 & -1 & 90,5 & -19 & 0,36 & 9 & 3,9 & -10 & 3,9 & 8 \\
\hline & Campos Altos & 92,6 & -1 & 52,2 & -3 & 54,9 & 14 & 0,22 & 38 & 6,0 & 11 & 2,5 & 50 \\
\hline & Ibiá & 80,8 & 17 & 28,2 & -2 & 95,6 & 28 & 0,85 & 316 & 2,8 & 2 & 3,5 & -12 \\
\hline & Pedrinópolis & 93,2 & 15 & 30,6 & -45 & 100 & 0 & 0,43 & -25 & 3,6 & -70 & 3,7 & 12 \\
\hline & Perdizes & 89,4 & 23 & 49,2 & 3 & 100 & 0 & 0,32 & 4 & 7,7 & -4 & 2,5 & 39 \\
\hline & Pratinha & 100 & 0 & 33,1 & -36 & 96,1 & -10 & 0,12 & -6 & 2,7 & 36 & 3,2 & 8 \\
\hline & Santa Juliana & 71,2 & 1 & 35,6 & -21 & 89,1 & -23 & 0,14 & 200 & 3,9 & 32 & 1,8 & 18 \\
\hline & Tapira & 100 & 0 & 43,4 & -18 & 82,9 & 67 & 0,13 & 371 & 3,6 & -3 & 3,3 & -32 \\
\hline \multirow{8}{*}{ 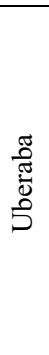 } & Água Comprida & 100 & 0 & 24,0 & -8 & 100 & 0 & 0,27 & 530 & 2,8 & 10 & 4,4 & 38 \\
\hline & Campo Florido & 87,1 & -16 & 21,5 & 4 & 88,4 & -16 & 0,20 & 0 & 2,3 & 5 & 3,8 & 25 \\
\hline & Conceição Alagoas & 98 & 0 & 29,0 & -32 & 100 & 0 & 0,59 & 292 & 3,9 & -2 & 2,9 & -5 \\
\hline & Conquista & 100 & 0 & 30,6 & -17 & 100 & 0 & 0,58 & -42 & 4,1 & -60 & 3,9 & 3 \\
\hline & Delta & 98,3 & 0 & 26,4 & -33 & 100 & 0 & 0,29 & 120 & 2,6 & 15 & 2,6 & 27 \\
\hline & Sacramento & 100 & 0 & 27,4 & 21 & 100 & 0 & 1,46 & 42 & 5,0 & 1 & 3,8 & -5 \\
\hline & Uberaba & 72,9 & -7 & 28,3 & 1 & 73,7 & -6 & 0,87 & -1 & 3,6 & -1 & 7,4 & 39 \\
\hline & Veríssimo & 100 & 0 & 25,8 & 35 & 100 & 0 & 0,35 & -38 & 2,9 & 3 & 4,1 & 4 \\
\hline
\end{tabular}

Fonte: Dados da pesquisa coletados no sítio da DATASUS

Prosseguindo com a análise vertical, na tabela 21 apresentamos a evolução dos outros 6 indicadores para as mesmas RS. Ocorreu aumento significativo da Razão de internações clínico-cirúrgicas de alta complexidade (RIAC), em alguns municípios das RS de Itaobim e Araxá. Isso demanda um crescimento do gasto, em razão das internações serem de alta complexidade.

Percebe-se na tabela 21 que ocorreu uma reduçao nos Exames citopatológicos do colo do útero em mulheres de 25 a 64 anos (RECCU), o que reflete negativamente para o município, pois trata-se de um exame preventivo de câncer de colo de útero, podendo aumentar muitos os custos em médio e longo prazo, devido a uma internação por exemplo. Porém pode ser uma estratégia desses municípios, que com a saturação do RECCU, decidiram gerenciar a demanda para o atendimento de Exames de mamografia (RMR). Este também é um exame preventivo relevante no combate ao câncer na política da Saúde da Mulher. Percebe-se que essa demanda de RMR aumentou significativamente em alguns municípios das RS de Itaobim, Uberlândia e Araxá.

Ainda nessa linha da Saúde da Mulher, a Proporção de parto normal (PPN), reduziu em quase todos os municípios, com exceção de Uberlândia, Tapira, Conquista, Água Comprida e Sacramento. Isto também implica em maior gasto, pois se caiu a taxa de parto normal, possivelmente aumentou a taxa de cirurgias por cesáreas, que demandam um maior custo de procedimento.

Outro indicador relevante na política de Saúde da Criança e da Mulher é a Proporção de nascidos vivos de mães com 7 ou mais consultas de pré-natal (NVCPN). Neste estudo, 
conforme a tabela 21 , as alterações mais significativas ocorreram nos municípios da RS de Itaobim.

O indicador Proporção de registro de óbitos com causa básica definida (POCD), de maneira geral reduziu em todos os municípios apresentados na Tabela 21, o que significa que os municípios não tem o controle da causa básica dos óbitos ocorridos, portanto não terá dados para promover uma mudança na política de saúde, investindo no combate às causas das mortes, como por exemplo, morte por dengue.

Destaca-se que para esses 6 outros indicadores apresentados, também ficam evidentes as alterações mais significativas para os municípios contemplados nas RS de Itaobim e Uberlândia. Assim considerando que essas RS foram ineficientes em todos os anos analisados, observa-se que os municípios dessas RS contribuíram para a ineficiência das mesmas. Em uma escala de importância, ocorreram as maiores discrepâncias nos resultados apresentados pelos municípios das RS de Itaobim, Uberlândia, com médias discrepâncias para a RS de Araxá, e baixas discrepâncias na RS de Uberaba.

Para atender a ótica da gestão e controle dos resultados, coletamos dados disponíveis no sítio do Sistema de Pactuação de Indicadores para o Pacto pela Saúde (SISPACTO), no link http://aplicacao.saude.gov.br/sispacto/faces/login.jsf, referente as metas pactuadas junto à União, ao Estado e às Regiões de Saúde para os períodos de 2010 à 2014. No entanto, as metas previstas para 2010, 2011 (Pacto pela Saúde) e parte de 2012 (transição COAP), continham indicadores diferentes dos indicadores coletados, de acordo com o rol das Diretrizes, objetivos, metas e indicadores de 2013-2015. Devido a essa divergência, analisamos os dados das metas previstas para 2013 e 2014.

Tabela 21 - Variação \% da evolução dos indicadores de saúde dos municípios das Regiões de Saúde: Itaobim, Uberlândia, Araxá e Uberaba, no período de 2010 à 2014

\begin{tabular}{|c|c|c|c|c|c|c|c|c|c|c|c|c|c|}
\hline \multirow{2}{*}{$\begin{array}{l}\text { R } \\
\mathbf{S}\end{array}$} & \multirow{2}{*}{ Municípios } & \multicolumn{2}{|c|}{ RIAC } & \multicolumn{2}{|c|}{ RECCU } & \multicolumn{2}{|c|}{ RMR } & \multicolumn{2}{|c|}{ PPN } & \multicolumn{2}{|c|}{ NVCPN } & \multicolumn{2}{|c|}{ POCD } \\
\hline & & $\mu$ & $\%$ & $\mu$ & $\%$ & $\mu$ & $\%$ & $\mu$ & $\%$ & $\mu$ & $\%$ & $\mu$ & $\%$ \\
\hline \multirow{6}{*}{$\begin{array}{l}\Xi \\
\Xi \\
\Xi \\
\Xi\end{array}$} & Comercinho & 1,0 & 240 & 0,70 & 9 & 0,37 & 200 & 72,2 & -27 & 61,6 & 110 & 66,5 & -24 \\
\hline & Itaobim & 1,4 & 40 & 0,96 & -44 & 0,36 & 88 & 59,3 & -25 & 71,9 & 37 & 70,9 & 6 \\
\hline & Itinga & 1,1 & 93 & 0,73 & -16 & 0,30 & 1500 & 58,1 & -7 & 59,7 & 120 & 68,0 & -24 \\
\hline & Medina & 1,1 & -2 & 0,66 & -35 & 0,26 & 67 & 66,6 & -4 & 53,2 & 89 & 78,8 & -10 \\
\hline & Monte Formoso & 1,1 & 186 & 0,99 & -28 & 0,39 & -69 & 72,0 & -19 & 59,9 & 77 & 85,2 & 0 \\
\hline & Ponto Volantes & 1,1 & 124 & 1,06 & -20 & 0,33 & -35 & 66,0 & -2 & 60,8 & 87 & 73,6 & 31 \\
\hline \multirow{5}{*}{ 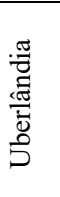 } & Araguari & 2,0 & 16 & 0,67 & -7 & 0,32 & 225 & 25,9 & -21 & 78,7 & 2 & 94,5 & -1 \\
\hline & Araporã & 2,7 & 9 & 1,00 & 0 & 0,07 & - & 13,2 & -65 & 69,8 & 0 & 94,5 & 5 \\
\hline & Cascalho Rico & 4,0 & 14 & 0,76 & 15 & 0,25 & 89 & 16,4 & -62 & 79,2 & 15 & 90,1 & -10 \\
\hline & Indianópolis & 2,2 & -38 & 0,88 & -25 & 0,30 & 119 & 27,8 & -8 & 75,7 & -6 & 90,2 & -9 \\
\hline & M.Alegre Minas & 2,7 & 7 & 0,74 & -42 & 0,18 & 288 & 27,6 & -40 & 85,0 & -10 & 88,2 & 9 \\
\hline
\end{tabular}




\begin{tabular}{|c|c|c|c|c|c|c|c|c|c|c|c|c|c|}
\hline & Nova Ponte & 2,2 & 62 & 0,78 & -25 & 0,17 & - & 26,8 & -16 & 87,0 & 4 & 91,8 & -4 \\
\hline & Prata & 3,3 & 35 & 0,75 & -10 & 0,14 & 550 & 9,0 & -26 & 88,3 & 5 & 92,5 & 2 \\
\hline & Tupaciguara & 1,9 & 18 & 0,64 & 9 & 0,17 & 733 & 18,1 & -15 & 77,6 & -6 & 86,4 & -20 \\
\hline & Uberlândia & 4,7 & -3 & 0,66 & -9 & 0,43 & 15 & 17,9 & 103 & 84,4 & 4 & 96,3 & 3 \\
\hline \multirow{8}{*}{ 荧 } & Araxá & 2,8 & 10 & 0,53 & -71 & 0,29 & 57 & 22,4 & -36 & 71,8 & 3 & 85,2 & 8 \\
\hline & Campos Altos & 2,4 & 30 & 0,71 & -12 & 0,32 & 267 & 42,6 & -10 & 79,4 & 1 & 73,0 & 26 \\
\hline & Ibiá & 3,0 & 72 & 0,83 & -38 & 0,35 & 51 & 31,5 & -14 & 71,4 & -3 & 86,2 & -6 \\
\hline & Pedrinópolis & 4,9 & 116 & 0,83 & 16 & 0,62 & 3214 & 29,9 & 0 & 80,4 & -9 & 89,7 & 17 \\
\hline & Perdizes & 3,2 & 53 & 0,78 & -28 & 0,44 & 626 & 49,3 & -11 & 82,4 & 8 & 83,1 & -3 \\
\hline & Pratinha & 1,8 & 133 & 0,89 & 8 & 0,27 & 247 & 22,3 & -45 & 63,5 & 28 & 80,0 & -1 \\
\hline & Santa Juliana & 3,3 & -31 & 0,34 & 0 & 0,29 & 174 & 32,0 & -13 & 70,5 & -11 & 86,7 & 9 \\
\hline & Tapira & 3,6 & 144 & 0,90 & -49 & 0,35 & 147 & 13,9 & 118 & 67,5 & -18 & 86,9 & -11 \\
\hline \multirow{8}{*}{ 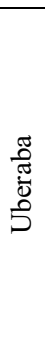 } & Água Comprida & 7,0 & 4 & 0,99 & -10 & 0,21 & 2 & 31,4 & 55 & 59,9 & 65 & 90,0 & -10 \\
\hline & Campo Florido & 3,9 & 42 & 0,51 & -15 & 0,07 & -21 & 46,2 & -24 & 57,1 & 14 & 88,1 & -13 \\
\hline & Conceição Alagoas & 3,7 & -8 & 0,63 & -12 & 0,25 & -67 & 33,3 & -27 & 77,4 & -9 & 89,3 & -4 \\
\hline & Conquista & 3,2 & -40 & 0,58 & -15 & 0,21 & 106 & 41,2 & 58 & 68,5 & -13 & 89,7 & 0 \\
\hline & Delta & 2,5 & 142 & 0,84 & 7 & 0,38 & 190 & 51,2 & 1 & 64,2 & 29 & 90,2 & -6 \\
\hline & Sacramento & 3,5 & -15 & 0,62 & 14 & 0,40 & 115 & 37,7 & 13 & 75,5 & -5 & 89,2 & 4 \\
\hline & Uberaba & 5,3 & 4 & 0,50 & -24 & 0,41 & 16 & 32,0 & -2 & 67,2 & 1 & 93,5 & 1 \\
\hline & Veríssimo & 4,5 & -26 & 0,78 & -66 & 0,13 & -73 & 48,5 & -12 & 60,0 & -25 & 89,2 & 6 \\
\hline
\end{tabular}

Fonte: Dados da pesquisa coletados no sítio da DATASUS

Sob a ótica da gestão, considerando os municípios no atendimento aos objetivos firmados junto à RS, e na análise dos dados coletados no SISPACTO, constatou-se que todos esses municípios dispostos nas tabelas 20 e 21, não atenderam as metas pactuadas em sua totalidade. Todos os municípios inclusive os da RS de Uberaba, com as menores discrepâncias visuais, deixaram de atender a pelo menos dois dos 12 indicadores analisados, com variações negativas acima de 10\%. Essas informações corroboram a nossa fala de que todos os municípios dessas RS, contribuíram com a ineficiência das RS. Portanto, deixaram de atender parte das pactuações ou metas firmadas junto às suas RS.

Um outro aspecto que observamos inerente a gestão dos resultados dos municípios, em relação ao atendimento às metas e objetivos propostos, foi a obrigatoriedade da entrega de um dos instrumentos de planejamento: os Relatórios Anuais de Gestão (RAG), instituído desde a criação do SUS, regulamentado no Pacto pela Saúde, como atribuição do Pacto de Gestão. A partir de 2007 até 2010, os RAGs ainda incipientes, foram entregues por alguns municípios, sem um modelo definido, sem muito rigor.

Somente a partir de 2011, os municípios começaram a entregar efetivamente os RAGs, principalmente após a Lei Complementar nº 141/2012 (Brasil - Ministério da Saúde, 2012a). O RAG é a principal ferramenta de acompanhamento da gestão da saúde nos Municípios, e apresentam os resultados alcançados com a execução da Programação Anual de Saúde, comprovando a aplicação de recursos do SUS, orientando ainda a elaboração de nova 
programação anual e eventuais adequacões que se façam necessárias. Na análise de conteúdo do RAG, percebeu-se a relevância da sua entrega, pois o mesmo configura-se como uma confissão de todas as ações e serviços de saúde executados ou a executar, envolvendo os recursos estruturais, físicos, recursos humanos, financeiros, econômicos, etc., além das orientações futuras.

No levantamento da entrega de RAGs que efetuamos no sítio da SARGSUS, http://datasus.saude.gov.br/informacoes-de-saude/sistemas-de-gestao/sargsus, efetuada até setembro de 2016, constatou-se que dos 853 municípios mineiros:

- Em 2010, somente 38 municípios entregaram os RAGs;

- Em 2011, os relatórios foram entregues por 843 municípios;

- Em 2102, os relatórios foram entregues por 849 municípios;

- Em 2013, os relatórios foram entregues por 824 municípios;

- Em 2014, os relatórios foram entregues por 802 municípios;

- Em 2015, os relatórios foram entregues por 616 municípios.

Neste contexto, verificou-se também se os municípios das RS de Saúde de Itaobim, Uberlândia, Araxá e Uberaba, atenderam à obrigatoriedade da entrega do RAG, como um instrumento de planejamento das ações da saúde, considerando a partir de 2011. Constatou-se que somente os municípios de Prata e de Campos Altos, não entregaram o RAG, relativo ao ano de 2013.

Em continuidade a análise vertical da evolução dos 6 indicadores, apresentados agora na tabela 22, para as RS de Janaúba, Manga, Montes Claros e Salinas; inseridas na Região Ampliada de Saúde Norte, observou-se que o indicador Razão de procedimentos ambulatoriais de média complexidade (PAMC), aumentou expressivamente nos municípios das RS citadas, seguindo a tendência das outras RS analisadas nas tabelas 20 e 21 . Portanto, ocorreu o crescimento do atendimento destes procedimentos, aumentando o acesso, e a demanda de mais recursos, e dos gastos sob a responsabilidade desses municípios.

A Cobertura equipes atenção básica (CEAB) não variou significativamente, se mantendo estável e crescente, com exceção para o Município de Olhos D’Água. A importância desse indicador já foi evidenciada em argumentação anterior. A Cobertura equipes saúde bucal (CESB) seguiu a tendência da anterior, estável e crescente, com destaque para o aumento das coberturas nos Municípios de Juvenília, Manga, Francisco Dumont e Berizal. 
O indicador Proporção de internações por condições sensíveis à atenção básica (ICSAB), reduziu de maneira geral, seguindo a tendência anterior; com exceção para os municípios de Matias Cardoso e Manga; o que pode representar as falhas na atenção básica desses municípios.

A Razão de internações clínico-cirúrgicas de média complexidade (RIMC) se manteve estável, com acréscimos significativos para os municípios das RS de Janaúba e Salinas. Para a Razão de procedimentos ambulatoriais de alta complexidade (PAAC), ocorreram acréscimos relevantes para os municípios de todas as RS. Observa-se que para esses 6 indicadores apresentados, as alterações mais significativas foram realçadas nos municípios inseridos nas $\mathrm{RS}$.

Tabela 22 - Variação \% da evolução dos indicadores de saúde dos municípios das Regiões de Saúde: Janaúba, Manga, Montes Claros e Salinas - Região Ampliada Norte, no período de 2010 à 2014

\begin{tabular}{|c|c|c|c|c|c|c|c|c|c|c|c|c|c|}
\hline \multirow{2}{*}{$\begin{array}{l}\mathbf{R} \\
\mathbf{S}\end{array}$} & \multirow{2}{*}{ Municípios } & \multicolumn{2}{|c|}{ CEAB } & \multicolumn{2}{|c|}{ ICSAB } & \multicolumn{2}{|c|}{ CESB } & \multicolumn{2}{|c|}{ PAMC } & \multicolumn{2}{|c|}{ RIMC } & \multicolumn{2}{|c|}{ PAAC } \\
\hline & & $\mu$ & $\%$ & $\mu$ & $\%$ & $\mu$ & $\%$ & $\mu$ & $\%$ & $\mu$ & $\%$ & $\mu$ & $\%$ \\
\hline \multirow{15}{*}{ 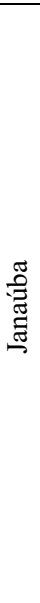 } & Catuti & 84,3 & 0 & 31,0 & -26 & 100 & 0 & 0,77 & 470 & 3,6 & 86 & 2,4 & 93 \\
\hline & Espinosa & 96,8 & 6 & 61,0 & -10 & 73,7 & 27 & 0,37 & 120 & 5,1 & -9 & 2,2 & 33 \\
\hline & Gameleiras & 100 & 0 & 32,2 & -27 & 100 & 0 & 0,56 & 468 & 4,3 & 60 & 2,5 & -2 \\
\hline & Jaíba & 99,3 & 4 & 30,1 & 22 & 86,6 & 5 & 0,32 & 367 & 3,0 & 45 & 1,5 & 43 \\
\hline & Janaúba & 94,8 & 14 & 24,3 & -15 & 99,3 & 4 & 1,25 & -13 & 4,0 & 35 & 2,3 & 37 \\
\hline & Mamonas & 100 & 0 & 33,1 & -35 & 100 & 0 & 0,56 & 268 & 4,9 & 74 & 2,6 & 59 \\
\hline & Matias Cardoso & 100 & 0 & 24,4 & 62 & 96,3 & 23 & 0,51 & 430 & 2,1 & -1 & 1,8 & 93 \\
\hline & Mato Verde & 100 & 0 & 32,1 & -21 & 100 & 0 & 0,53 & 152 & 2,7 & 43 & 2,4 & 47 \\
\hline & Monte Azul & 100 & 0 & 34,3 & -38 & 100 & 0 & 0,51 & 205 & 5,6 & -6 & 2,2 & 93 \\
\hline & Nova Porteirinha & 100 & 0 & 22,6 & -27 & 100 & 0 & 0,40 & 1820 & 3,3 & 64 & 2,2 & 54 \\
\hline & Pai Pedro & 100 & 0 & 39,7 & -1 & 99,3 & 4 & 0,38 & - & 2,9 & -18 & 1,8 & 51 \\
\hline & Porteirinha & 100 & 0 & 40,9 & -19 & 100 & 0 & 0,55 & 310 & 4,9 & 4 & 2,1 & 86 \\
\hline & Riacho Machados & 100 & 0 & 35,6 & 0 & 97,8 & 8 & 0,44 & 305 & 2,8 & 6 & 1,7 & 68 \\
\hline & Serranópolis Minas & 100 & 0 & 38,5 & 8 & 100 & 0 & 0,63 & 365 & 3,8 & 46 & 2,8 & 68 \\
\hline & Verdelândia & 100 & 0 & 26,3 & 27 & 100 & 0 & 0,41 & 177 & 2,9 & 30 & 1,3 & 111 \\
\hline \multirow{5}{*}{ 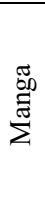 } & Juvenília & 90,5 & 0 & 57,3 & -19 & 80,0 & 111 & 0,18 & - & 3,3 & 14 & 0,9 & 105 \\
\hline & Manga & 93,5 & 19 & 36,5 & 101 & 69,4 & 64 & 0,28 & 146 & 5,0 & -14 & 1,9 & 48 \\
\hline & Miravânia & 100 & 0 & 33,3 & 20 & 71,3 & 67 & 0,15 & 950 & 2,8 & 11 & 1,8 & 39 \\
\hline & Montalvânia & 97,5 & 8 & 58,2 & 4 & 50,2 & 29 & 0,20 & 250 & 6,8 & 11 & 1,2 & 161 \\
\hline & S.João das Missões & 100 & 0 & 30,2 & 28 & 100 & 0 & 0,17 & - & 2,9 & 2 & 1,3 & 482 \\
\hline \multirow{11}{*}{ 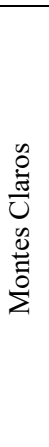 } & Bocaiúva & 88,3 & -6 & 28,6 & -2 & 95,4 & 30 & 0,30 & 8 & 4,6 & 4 & 2,6 & 76 \\
\hline & Claro dos Poções & 100 & 0 & 28,5 & 34 & 100 & 0 & 0,55 & 122 & 3,6 & 7 & 3,0 & 36 \\
\hline & Eng. Navarro & 100 & 0 & 32,9 & -16 & 100 & 0 & 0,74 & 159 & 3,7 & 2 & 3,7 & 44 \\
\hline & Francisco Dumont & 100 & 0 & 26,0 & -26 & 76,6 & 66 & 0,38 & 783 & 3,2 & 23 & 2,2 & 130 \\
\hline & Glaucilândia & 100 & 0 & 28,4 & -26 & 99,5 & 2 & 0,89 & 729 & 2,7 & 38 & 3,5 & 127 \\
\hline & Guaraciama & 100 & 0 & 28,1 & 19 & 100 & 0 & 0,78 & 635 & 4,4 & 50 & 4,4 & 222 \\
\hline & Itacambira & 100 & 0 & 27,6 & 4 & 100 & 0 & 0,18 & 317 & 3,1 & 45 & 1,9 & 255 \\
\hline & Joaquim Felício & 99,5 & 0 & 50,7 & -66 & 100 & 0 & 0,21 & -31 & 3,5 & -41 & 2,0 & 51 \\
\hline & Juramento & 94,6 & 37 & 31,2 & 20 & 100 & 0 & 0,88 & 270 & 3,4 & 0 & 3,7 & 96 \\
\hline & Montes Claros & 79,6 & 47 & 32,7 & 10 & 70,3 & 38 & 1,67 & -13 & 3,9 & 12 & 4,5 & 60 \\
\hline & Olhos-d'Água & 91,9 & -41 & 31,4 & -13 & 84,6 & -1 & 0,27 & 315 & 4,4 & 9 & 2,8 & 273 \\
\hline U & Berizal & 100 & 0 & 30,4 & -48 & 86,6 & 55 & 0,56 & 204 & 3,60 & 45 & 1,5 & 305 \\
\hline
\end{tabular}




\begin{tabular}{lrrrrrrrrrrr|r|} 
Curral de Dentro & 97,9 & 12 & 30,3 & -36 & 100 & 0 & 0,47 & $\mathbf{1 0 3 3}$ & 3,89 & 80 & 1,4 & 104 \\
Fruta de Leite & 100 & 0 & 36,0 & -22 & 100 & 0 & 0,12 & - & 4,74 & 78 & 1,4 & 152 \\
Indaiabira & 100 & 0 & 30,8 & -49 & 100 & 0 & 0,38 & $\mathbf{2 3 8}$ & 3,44 & 12 & 1,3 & 82 \\
Montezuma & 100 & 0 & 28,4 & 12 & 91,7 & 28 & 0,09 & $\mathbf{1 3 0 0}$ & 2,54 & -3 & 1,7 & 77 \\
Ninheira & 100 & 0 & 34,0 & 49 & 100 & 0 & 0,32 & $\mathbf{1 1 6 7}$ & 3,37 & 4 & 1,5 & 34 \\
Novorizonte & 100 & 0 & 30,3 & -33 & 100 & 0 & 0,38 & -46 & 3,66 & 87 & 1,4 & 63 \\
Padre Carvalho & 89,7 & 3 & 33,9 & -33 & 89,6 & 3 & 0,30 & $\mathbf{1 5 6}$ & 4,43 & 103 & 1,1 & 205 \\
Rio Pardo Minas & 100 & 0 & 39,0 & -11 & 100 & 0 & 0,20 & $\mathbf{2 2 5}$ & 5,15 & -3 & 1,6 & 56 \\
Rubelita & 100 & 0 & 32,3 & -35 & 86,1 & 35 & 0,27 & $\mathbf{1 8 0}$ & 3,50 & 67 & 2,0 & 12 \\
Salinas & 91,6 & 28 & 33,0 & -20 & 46,6 & 2 & 0,85 & $\mathbf{3 6 8}$ & 5,24 & 73 & 2,5 & 26 \\
Santa Cruz Salinas & 100 & 0 & 27,5 & -27 & 100 & 0 & 0,67 & $\mathbf{2 1 7}$ & 3,68 & 107 & 2,3 & 188 \\
Sto Antônio Retiro & 100 & 0 & 33,3 & -51 & 100 & 0 & 0,17 & $\mathbf{5 2 5}$ & 3,23 & 3 & 1,5 & 45 \\
São João Paraíso & 100 & 0 & 30,2 & 15 & 100 & 0 & 0,29 & $\mathbf{2 2 3}$ & 4,75 & 4 & 1,9 & 64 \\
Taiobeiras & 100 & 0 & 31,7 & -34 & 99,4 & 0 & 0,52 & -16 & 5,00 & 7 & 2,4 & 89 \\
V. Grande R.Pardo & 100 & 0 & 27,8 & -48 & 100 & 0 & 0,07 & - & 3,13 & 11 & 1,9 & 246 \\
\hline
\end{tabular}

Fonte: Dados da pesquisa coletados no sítio da DATASUS

Na tabela 23 apresentamos a evolução dos outros 6 indicadores para as mesmas RS, pertencentes a Região Ampliada Norte. Ocorreu significativo aumento da Razão de internações clínico-cirúrgicas de alta complexidade (RIAC), em muitos dos municípios de toas as RS. Indica o presságio de crescimento do gasto, devido às internações de alta complexidade.

Para os Exames citopatológicos do colo do útero em mulheres de 25 a 64 anos (RECCU), ocorreram acréscimos e decréscimos em vários municípios em todas as $\mathrm{RS}$, de uma forma menos concentrada, como na análise anterior, como pode-se observar nos municípios com realçe. O município de Mato Verde apresentou um resultado discrepante, possivelmente devido a erro de digitação na alimentação do Banco de Dados do DATASUS. Os municícipios dessas RS também investiram nas ações de Exames de mamografia (RMR), pois ocorreu um aumento significativo para quase todos os municípios das RS.

No quesito Saúde da Mulher, a Proporção de parto normal (PPN), reduziu também em quase todos os municípios, com exceção para Catuti e Pai Pedro. Isto implica em maior gasto, devido ao aumento da taxa de cirurgias por cesáreas, que demandam um maior custo por procedimento. O indicador Proporção de nascidos vivos de mães com 7 ou mais consultas de pré-natal (NVCPN), se manteve estável e crescente, com destaques para os municípios realcados nas RS de Manga, Montes Claros e Salinas.

O indicador Proporção de registro de óbitos com causa básica definida (POCD), de apresentou reduções e acréscimos (realçados) de maneira geral, o que significa reforçar que os municípios não tem o controle da causa básica dos óbitos ocorridos, portanto sem dados para adequar a política de saúde. 
Destaca-se que para esses 6 indicadores apresentados, também ficam evidentes as alterações mais significativas nestes municípios em todas as RS. Assim, esses municípios contribuíram para a ineficiência dessas RS. As maiores discrepâncias estão destacadas com realçe nos municípios.

Tabela 23 - Variação \% da evolução dos indicadores de saúde dos municípios das Regiões de Saúde: Janaúba, Manga, Montes Claros e Salinas - Região Ampliada Norte, no período de 2010 à 2014

\begin{tabular}{|c|c|c|c|c|c|c|c|c|c|c|c|c|c|}
\hline \multirow{2}{*}{$\begin{array}{l}\mathbf{R} \\
\mathbf{S}\end{array}$} & \multirow{2}{*}{ Municípios } & \multicolumn{2}{|c|}{ RIAC } & \multicolumn{2}{|c|}{ RECCU } & \multicolumn{2}{|c|}{ RMR } & \multicolumn{2}{|c|}{ PPN } & \multicolumn{2}{|c|}{ NVCPN } & \multicolumn{2}{|c|}{ POCD } \\
\hline & & $\mu$ & $\%$ & $\mu$ & $\%$ & $\mu$ & $\%$ & $\mu$ & $\%$ & $\mu$ & $\%$ & $\mu$ & $\%$ \\
\hline \multirow{15}{*}{$\begin{array}{l}\text { : } \\
\text { : } \\
\text { : }\end{array}$} & Catuti & 2,3 & 97 & 1,65 & 5 & 0,53 & 348 & 53,8 & 9 & 91,5 & 6 & 79,9 & -1 \\
\hline & Espinosa & 3,7 & 27 & 0,80 & -10 & 0,28 & 500 & 46,8 & -12 & 78,3 & 9 & 79,5 & -1 \\
\hline & Gameleiras & 2,5 & 119 & 1,41 & -10 & 0,60 & 682 & 46,3 & -26 & 90,8 & 19 & 91,1 & 29 \\
\hline & Jaíba & 1,9 & 36 & 0,74 & 17 & 0,30 & 693 & 65,2 & -14 & 59,7 & 35 & 82,8 & 1 \\
\hline & Janaúba & 3,1 & 9 & 0,95 & 106 & 0,31 & 208 & 57,7 & -16 & 75,0 & 9 & 83,2 & 20 \\
\hline & Mamonas & 3,5 & 114 & 0,97 & -17 & 0,49 & 443 & 45,1 & -29 & 87,6 & 0 & 70,8 & -20 \\
\hline & Matias Cardoso & 1,6 & -27 & 1,14 & 2 & 0,46 & 281 & 71,7 & -18 & 73,8 & 49 & 75,9 & 18 \\
\hline & Mato Verde & 2,4 & 43 & 0,73 & 8000 & 0,41 & 316 & 41,2 & -11 & 82,4 & 10 & 85,5 & 3 \\
\hline & Monte Azul & 2,9 & 73 & 0,75 & -30 & 0,32 & 411 & 43,1 & -15 & 88,5 & 2 & 74,0 & 20 \\
\hline & Nova Porteirinha & 2,0 & 176 & 1,09 & 59 & 0,32 & 731 & 65,8 & -13 & 71,1 & 36 & 84,1 & 9 \\
\hline & Pai Pedro & 1,3 & 77 & 1,01 & 48 & 0,38 & 736 & 62,8 & 18 & 71,3 & 45 & 80,3 & 27 \\
\hline & Porteirinha & 3,0 & 121 & 0,83 & 70 & 0,36 & 1210 & 43,5 & -3 & 74,7 & 1 & 79,6 & 15 \\
\hline & Riacho Machados & 2,5 & 19 & 0,63 & 11 & 0,31 & 650 & 58,7 & -21 & 63,4 & 21 & 75,2 & 0 \\
\hline & Serranópolis Min & 2,9 & 165 & 0,89 & 14 & 0,57 & 887 & 57,5 & -29 & 73,0 & 54 & 56,8 & -23 \\
\hline & Verdelândia & 2,2 & 22 & 1,16 & -10 & 0,37 & 1073 & 64,4 & -6 & 66,6 & 44 & 83,7 & -19 \\
\hline \multirow{5}{*}{ 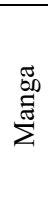 } & Juvenília & 1,0 & 756 & 0,61 & 109 & 0,37 & - & 75,9 & -35 & 50,9 & 143 & 71,9 & 98 \\
\hline & Manga & 2,2 & 24 & 1,00 & 12 & 0,23 & - & 67,9 & -16 & 81,2 & -1 & 90,8 & 8 \\
\hline & Miravânia & 2,2 & -49 & 0,70 & 59 & 0,40 & 3200 & 70,7 & -36 & 56,1 & 141 & 67,3 & 112 \\
\hline & Montalvânia & 1,6 & 163 & 0,04 & 0 & 0,25 & - & 81,0 & -3 & 74,7 & 115 & 71,8 & 38 \\
\hline & São João Missões & 1,8 & 487 & 0,89 & 0 & 0,30 & - & 81,1 & -14 & 60,6 & 53 & 67,4 & 28 \\
\hline \multirow{11}{*}{ 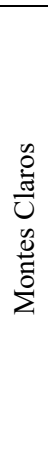 } & Bocaiúva & 3,4 & 22 & 0,63 & 7 & 0,29 & 610 & 59,5 & -3 & 56,7 & 22 & 81,7 & 7 \\
\hline & Claro dos Poções & 4,5 & 97 & 0,99 & 1 & 0,59 & 173 & 64,5 & -1 & 79,6 & 10 & 89,8 & -5 \\
\hline & Eng. Navarro & 4,1 & 22 & 1,13 & 19 & 0,57 & 211 & 69,0 & 0 & 74,8 & 16 & 92,0 & 7 \\
\hline & Francisco Dumont & 2,8 & 144 & 1,21 & 0 & 0,64 & 292 & 65,2 & 0 & 72,0 & 32 & 81,0 & 22 \\
\hline & Glaucilândia & 4,0 & 116 & 0,75 & 128 & 0,53 & 2320 & 69,3 & -2 & 70,9 & 15 & 90,7 & -8 \\
\hline & Guaraciama & 5,0 & 10 & 0,95 & 88 & 0,99 & 193 & 64,2 & -16 & 83,4 & 17 & 86,4 & -8 \\
\hline & Itacambira & 3,9 & -27 & 1,02 & 76 & 0,47 & 435 & 65,3 & -8 & 71,9 & -10 & 81,6 & -12 \\
\hline & Joaquim Felício & 2,1 & 48 & 0,91 & 39 & 0,49 & 244 & 76,7 & -18 & 62,2 & 106 & 83,0 & -8 \\
\hline & Juramento & 3,8 & 165 & 0,77 & 35 & 0,42 & 60 & 65,1 & -18 & 73,4 & 17 & 81,3 & 26 \\
\hline & Montes Claros & 4,6 & 34 & 0,53 & 61 & 0,43 & 49 & 54,7 & -5 & 66,9 & 10 & 87,0 & 0 \\
\hline & Olhos-d'Água & 2,4 & 94 & 0,64 & -5 & 0,62 & 328 & 62,0 & -27 & 54,0 & 82 & 79,5 & 15 \\
\hline \multirow{10}{*}{ 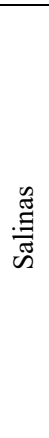 } & Berizal & 2,7 & -21 & 0,97 & 47 & 0,51 & 267 & 53,2 & -31 & 61,2 & 37 & 79,6 & -8 \\
\hline & Curral de Dentro & 1,3 & 244 & 0,63 & 27 & 0,40 & 182 & 60,3 & -22 & 72,7 & 16 & 86,2 & 15 \\
\hline & Fruta de Leite & 2,7 & 74 & 0,67 & -26 & 0,37 & 1933 & 63,2 & -16 & 72,9 & 26 & 83,3 & -11 \\
\hline & Indaiabira & 1,3 & 5 & 0,88 & -34 & 0,43 & 26 & 61,6 & -11 & 82,0 & 20 & 80,3 & -1 \\
\hline & Montezuma & 1,4 & 40 & 1,46 & -5 & 0,44 & -23 & 69,4 & -14 & 94,3 & 0 & 71,5 & 9 \\
\hline & Ninheira & 2,0 & 61 & 1,17 & -30 & 0,37 & -11 & 65,2 & -19 & 88,2 & -4 & 83,2 & -8 \\
\hline & Novorizonte & 1,3 & -17 & 0,73 & -66 & 0,58 & 350 & 57,4 & -33 & 75,4 & 34 & 63,7 & 64 \\
\hline & Padre Carvalho & 2,6 & 219 & 0,25 & -30 & 0,32 & 1517 & 61,8 & -41 & 57,9 & 89 & 87,8 & 12 \\
\hline & Rio Pardo Minas & 2,4 & 42 & 0,81 & 89 & 0,35 & -19 & 55,3 & -13 & 83,3 & 17 & 83,5 & -4 \\
\hline & Rubelita & 2,5 & 12 & 0,57 & -3 & 0,43 & 236 & 62,0 & -23 & 71,7 & 62 & 66,6 & 53 \\
\hline
\end{tabular}




\begin{tabular}{lrrrrrrrrrrrr|r|} 
Salinas & 3,5 & 54 & 0,63 & -37 & 0,28 & $\mathbf{6 3 6}$ & 50,3 & -34 & 72,0 & 29 & 75,2 & 18 \\
Santa Cruz Salinas & 2,1 & 86 & 0,84 & 11 & 0,41 & $\mathbf{5 4 0}$ & 59,7 & -32 & 73,6 & 24 & 73,8 & 85 \\
Sto Antônio Retiro & 2,2 & 13 & 1,15 & 138 & 0,44 & $\mathbf{1 2 3 0}$ & 58,9 & -30 & 87,7 & 17 & 73,3 & 7 \\
São João Paraíso & 2,4 & 50 & 0,88 & 0 & 0,46 & $\mathbf{1 1 6}$ & 62,6 & -23 & 85,8 & 22 & 80,7 & 24 \\
Taiobeiras & 2,8 & 39 & 0,89 & 0 & 0,49 & $\mathbf{9 1}$ & 56,5 & -26 & 80,7 & 15 & 80,2 & 3 \\
V.Grande R.Pardo & 3,5 & 226 & 0,89 & -3 & 0,59 & 43 & 55,3 & -8 & 87,9 & 10 & 84,7 & -3 \\
\hline
\end{tabular}

Fonte: Dados da pesquisa coletados no sítio da DATASUS

Quanto ao atendimento aos objetivos firmados junto à RS, na análise dos dados coletados no SISPACTO, constatou-se que todos os municípios das RS de Janaúba e de Manga dispostos nas tabelas 22 e 23, não atenderam as metas pactuadas em sua totalidade. Na RS de Montes Claros os municípios de Claro dos Poções, Engenheiro Navarro, Guaraciama, Joaquim Felício, Juramento e Montes Claros, atenderam satisfatoriamente a metas pactuadas para estes indicadores analisados. Pode-se dizer que estes municípios não contribuíram para a ineficiência da RS de Montes Claros. Todos os outros municípios que compõem a RS de Montes Claros, não atenderam as metas. Na RS de Salinas, apenas o município de Santa Cruz de Salinas, atendeu aos requisitos dos indicadores, sendo que todos os outros municípios contribuíram para a ineficiência da RS de Salinas. Entendemos que os municípios que deixaram de atender as metas pactuadas, descumprindo o contrato firmado, contribuíram com a ineficiência das RS.

Quanto a a obrigatoriedade da entrega RAG, constatou-se que a maioria do municípios das RS de Janaúba, Manga, Montes Claros e Salinas; entregaram o RAG, e cumpriram com a sua meta de gestão operacional. Alguns municípios em todas as RS, não entregaram os RAG. Não entregaram o RAG relativo a 2013 e 2014 os municípios de Padre Carvalho, Rio Pardo de Minas e Porteirinha. Relativo ao ano de 2014, não entregaram o RAG os municípios de Engenheiro Navarro, Guaraciama, Miravânia e Mato Verde. Relativo ao ano de 2013, somente o município de Janaúba não entregou o RAG.

O levantamento das RS ineficientes por meio da técnica DEA, no período de cinco anos e verificação da seleção de indicadores municipais no mesmo período, permitiu investigar os fatores que contribuíram para a sua ineficiência e comparar essas RS. Considerando os aspectos relacionados à gestão, percebeu-se que os municípios dessas regiões de saúde analisadas com maior detalhe, contribuíram muito para a ineficiência das mesmas, o que em contrapartida refletiu na ineficiência das Regiões Ampliadas de Saúde. 


\section{CONSIDERAÇÕES FINAIS}

O objetivo geral desta pesquisa foi analisar a eficiência da execução dos gastos públicos na função saúde e a melhoria dos indicadores de saúde, nas Regiões de Saúde mineiras no período de 2010 a 2014. A proposta era análise da evolução dos recursos executados destinados ao financiamento da função saúde, que se transformam em gastos públicos e o que se espera de retorno na forma de resultados finais (outcomes), considerando que a melhoria das condições de saúde da população, têm reflexos nos indicadores das regiões de saúde mineiros.

Tanto a evolução do gasto público na saúde quanto o desempenho da gestão regional mensurado por meio da eficiência, são fatores que impactam na formulação ou adequação de diretrizes nas políticas públicas na área da saúde, como exemplo o pacto pela saúde. Primeiro analisamos a evolução do gasto público no período de cinco anos, em seus valores corrigidos. Constatou-se que não há uma homogeneidade nos valores percebidos pelas regiões de saúde mineiras.

Neste sentido, verificamos os níveis de eficiência dos gastos públicos na função saúde nas Regiões de Saúde (RS) de Minas Gerais, em relação ao indicadores de saúde: Taxa de mortalidade infantil e Taxa de mortalidade materna. Aplicando a técnica Data Envelopment Analysis (DEA) calculamos a eficiência total (método CCR) e a eficiência técnica pelo método de Retornos Variáveis de Escala VRC/BCC, ambos orientados para os outputs, em todos os anos de 2010 à 2014.

Inicialmente estimarmos a fronteira da eficiência técnica por meio da DEA das 13 Regiões Ampliadas de Saúde. Isso só foi possível após agregarmos os dados para os mesmos outputs e input. Utilizamos das regras preliminares na aplicação do mesmo modelo de BCC com orientação a outputs, e também aplicamos o modelo CCR para consolidar as DMUs eficientes. Com os dados agregados obteve-se Regiões Ampliadas de Saúde eficientes e também ineficientes em todos os anos do período analisado. As Regiões Ampliadas de Saúde eficientes em todos os anos, foram: Jequitinhonha e Oeste. Enquanto as ineficientes foram as Regiões Nordeste, Noroeste e Norte.

Primeiro cálculamos a eficiência total pelo método $\mathrm{CRS} / \mathrm{CCR}$, orientado para os outputs com retornos constantes de escala. O CCR por considerar o retorno de escala constante, validou as Regiões Ampliadas de Saúde eficientes por seu rigor na eficiência total 
do modelo. Como resultados, nenhuma das Regiões Ampliadas de Saúde foram eficientes em todos os anos. Entretanto, verificou-se que as Regiões Ampliadas de Saúde Nordeste, Noroeste, Norte, Triângulo do Norte e Triângulo do Sul, foram ineficientes em todos os anos do período analisado. Pode-se considerar que este seja os piores resultados observados no estudo. Essa tendência já tinha sido observada na estimação pelo método BCC, onde as Regiões Ampliadas Nordeste, Noroeste e Norte, foram ineficientes em todos os anos.

As fronteiras de eficiência estimadas pela DEA, considerando o método BCC com orientação aos outputs foram compostas por 6 Regiões Ampliadas de Saúde no ano de 2010, sendo que as Regiões Ampliadas Sul, Triângulo do Sul, Leste, Jequitinhonha e Oeste, servirão de base para o cálculo da eficiência das demais Regiões Ampliadas de Saúde. Em 2011 a fronteira de eficiência foi composta por 8 Regiões Ampliadas, correspondendo ao maior percentual no período, de $61 \%$ das Regiões Ampliadas. Foram referência da eficiência as Regiões Ampliadas Leste, Sul, Triângulo do Norte, Jequitinhonha, Centro e Sudeste.

Em 2012 foram 6 Regiões Ampliadas que atingiram a fronteira de eficiência, e servirão de base para o cálculo da eficiência das demais Regiões Ampliadas de Saúde, as Regiões Ampliadas Centro Sul, Oeste, Triângulo do Sul, Jequitinhonha e Leste. Em 2013 foram eficientes 4 Regiões Ampliadas, sendo que as mesmas Regiões Oeste, Triângulo do Norte, Leste e Jequitinhonha foram referência para o cálculo da eficiência das demais Regiões Ampliadas de Saúde. Por último em 2014, somente as Regiões Ampliadas de Saúde Jequitinhonha, Oeste e Triângulo do Norte foram eficientes, correspondendo a 23\% das Regiões, sendo as mesmas referência para o cálculo da eficiência das demais Regiões Ampliadas de Saúde.

Após estimarmos a fronteira da eficiência total e técnica por meio da DEA das 13 Regiões Ampliadas de Saúde, calculamos a eficiência total e técnica das 77 DMUs ou Regiões de Saúde. Utilizamos das mesmas regras preliminares na aplicação dos modelos clássicos da DEA com orientação a outputs.

Em seguida apresentamos os resultados da eficiência total mensurada pelo método CRS/CCR, orientado para os outputs com retornos constantes de escala para as Regiões de Saúde mineiras. O CCR por ter retorno de escala constante, validou as RS eficientes por seu rigor na eficiência total do modelo. A eficiência pelo método BCC por retornos variáveis de escala, é uma eficiência técnica e sempre maior que a eficiência total pelo método CCR. Assim o método por ter retorno constante de escala apresentou poucas regiões de saúde como eficientes. Foram eficientes: no ano de 2010 as RS de Santos Dumont e Varginha; em 2011 a 
RS de Santos Dumont; em 2012 as RS de Contagem, Minas Novas e Nanuque; em 2013, as RS de Viçosa e Santos Dumont; e em 2014 foram eficientes as RS de Viçosa, Guaxupé e Ituiutaba.

Todos as outras Regiões de Saúde, foram consideradas ineficientes em todos os anos pelo método CCR. Todas essas RS consideradas eficientes pelo método CCR, também foram eficientes nos mesmos anos pelo método BCC. As RS que foram eficientes no modelo CCR, têm retornos constantes de escala, o que significa dizer que estavam em suas escalas ótimas. Como as mesmas também são eficientes no modelo BCC, significa dizer que atuaram sem desperdícios de recursos. Assim as mesmas tinham o tamanho ideal para serem produtivas e ao mesmo tempo estavam gerenciando a sua produção bem tecnicamente e portanto, sem desperdícios.

Como resultados as fronteiras de eficiência técnica (método BCC) estimadas pela DEA foram compostas por 28 RS no ano de 2010 e por 33 RS em 2011. Em 2012, 42 RS atingiram a fronteira de eficiência, correspondendo ao maior percentual de $55 \%$ no período dos cinco anos. Em 2013, baixou o número de RS eficientes para 29 e em 2014, reduziu para 22 RS eficientes. Apresentamos as RS que serviram como referência para o cálculo da eficiência das demais RS. Percebeu-se que o ano de 2010 e o de 2014, foram os anos com os menores números de RS eficientes. O método considerou os menores inputs como eficientes, para uma combinação dos outputs.

A maioria das Regiões de Saúde foram eficientes em pelo menos um dos anos analisados, pelo método BCC. As Regiões de Saúde com um score de eficiência técnica menor que $100 \%$ foram consideradas ineficientes, pois apresentaram escores abaixo da fronteira de eficiência. Destaca-se, que apenas 3 Regiões de Saúde: Viçosa, Formiga e Santos Dumont, foram considerados eficientes pelo método BCC em todos os anos analisados.

Outra etapa do estudo foi o cálculo da eficiência de escala das RS. Observando a estatística descritiva da eficiência de escala das RS, percebeu-se que os resultados nos anos analisados foram totalmente heterogêneos, porém com a mesma tendência da eficiência total (CCR).

Considerando a estimação do nível de eficiência pelo método BCC, na DEA, optamos por observar no detalhe, analisando os indicadores na área da saúde dos municípios que compõem essas Regiões de Saúde que foram ineficientes em todos os anos do período analisado. Assim, verificamos a evolução de 12 indicadores de saúde dos municípios das 
Regiões de Saúde de Itaobim, Janaúba, Manga, Montes Claros, Salinas, Uberlândia, Araxá e Uberaba. Analisou-se a evolução dos indicadores municipais apresentados, das RS ineficientes em todos os anos analisados, e constatou-se que a maioria dos municípios dessas RS contribuíram para a ineficiência das mesmas.

Com base nos resultados de eficiência verificados para cada RS, e a análise dos indicadores municipais nas RS ineficientes, verificou-se o cumprimento das metas pactuadas pelas RS junto aos seus municípios, como o atendimento aos objetivos pactuados. O resultado da eficiência de uma RS depende de que cada município cumpra a sua parte nas metas estabelecidas e pode-se observar se os municípios que a compõem, analisando qual deles não atendeu aos objetivos da pactuação junto à RS. Considerando que, cada município compromete-se com a sua RS, o que entregará de resultado em termos de eficiência, e o gestor municipal é o responsável por esse resultado.

Nesse aspecto quanto ao atendimento aos objetivos firmados junto à RS, constatou-se que todos os municípios das RS de Itaobim, Uberlândia, Araxá, Uberaba, Janaúba e Manga não atenderam as metas pactuadas em sua totalidade. $\mathrm{Na}$ RS de Montes Claros os municípios de Claro dos Poções, Engenheiro Navarro, Guaraciama, Joaquim Felício, Juramento e Montes Claros, atenderam satisfatoriamente a metas pactuadas para estes indicadores analisados. Pode-se dizer que estes municípios não contribuíram para a ineficiência da RS de Montes Claros. Todos os outros municípios que compõem a RS de Montes Claros, não atenderam as metas. Na RS de Salinas, apenas o município de Santa Cruz de Salinas, atendeu aos requisitos dos indicadores, sendo que todos os outros municípios contribuíram para a ineficiência da RS de Salinas. Entendemos que os municípios que deixaram de atender as metas pactuadas, descumprindo o contrato firmado, contribuíram com a ineficiência das suas RS.

Quanto a a obrigatoriedade da entrega Relatório Anual de Gestão (RAG), constatou-se que a maioria do municípios de todas as RS, com poucas exceções entregaram o RAG, e cumpriram com a sua meta de gestão.

O levantamento das RS ineficientes por meio da técnica DEA, no período de cinco anos e verificação da seleção de indicadores municipais no mesmo período, permitiu investigar os fatores que contribuíram para a sua ineficiência e comparar essas RS. Considerando os aspectos relacionados à gestão, percebeu-se que os municípios dessas regiões de saúde analisadas com maior detalhe, realmente contribuíram muito para a ineficiência das mesmas, o que em contrapartida refletiu na ineficiência das Regiões Ampliadas de Saúde. 
$\mathrm{Na}$ trajetória deste estudo, verificou-se que muitas são as legislações as quais estão sujeitos os municípios e regiões de saúde do Brasil, com exigências, pactuações, metas, ouvidorias e também punições, caso os mesmos não cumpram conforme as solicitações citadas. Mas, não identificamos nenhuma punição, com exceção de ouvidorias, para os municípios que não cumpriram conforme o seu contrato acordado. É de conhecimento geral que as punições caso ocorram, fazem parte de um processo, que normalmente caem em uma vala comum na linha da política, por se tratar de uma administração municipal.

Assim como na política municipal, mesmo com a Lei de Responsabilidade Fiscal, o processo é longo, passando de uma administração a outra às vezes, o que demanda um período longo para se fazer cumprir, e na saúde, isso fica a cargo da Secretaria Estadual de Saúde do Estado juntamente com as Gerências Regionais de Saúde e Diretorias Regionais de Saúde. 


\section{REFERÊNCIAS}

Abrucio, F. L. (1997). O impacto do modelo gerencial na administração pública - Um breve estudo sobre a experiência internacional recente. Cadernos ENAP, 10, 52. Retrieved from http://www.enap.gov.br/downloads/ec43ea4fAbrciocad 10.pdf

Afonso, A., \& Aubyn, M. St. (2005). Non-parametric Approaches to Education and Health Efficiency in OECD Countries. Journal of Applied Economics, VIII(2), 227-246. Retrieved from http://www.ucema.edu.ar/publicaciones/download/volume8/afonso.pdf

Akin, J., Hutchinson, P., \& Strumpf, K. (2005). Decentralisation and government provision of public goods: The public health sector in Uganda. The Journal of Development Studies, 41(8), 1417-1443. http://doi.org/10.1080/00220380500187075

Albuquerque, M. V. de, \& Viana, A. L. D. (2015). Perspectivas de região e redes na política de saúde brasileira. Saúde Em Debate, 39(N. Especial), 28-38. http://doi.org/10.5935/0103-1104.2015S005390

Alegre, J. G. (2010). Decentralization and the Composition of Public Expenditure in Spain. Regional Studies, 44(8), 1067-1083. http://doi.org/10.1080/00343400903365151

Ali, A. I., \& Seiford, L. M. (1990). Translation invariance in data envelopment analysis. Operations Research Letters, 9, 403-405. http://doi.org/10.1007/978-1-4899-7553-9_8

Anthony, R. G., \& Govindarajan, V. (2008). Sistema de controle gerencial. (McGraw-Hill, Ed.). São Paulo.

Anton, S. G. (2013). Technical Efficiency in the Use of Health Care Resources: A CrossCountry Analysis. In Scientific Annals of the Alexandru Ioan Cuza University of Iasi Economic Sciences (Vol. 60, pp. 31-42). Iasi, Romania: Scientific Annals of the "Alexandru Ioan Cuza" University of Iasi Economic Sciences. http://doi.org/10.2478/aicue-2013-0001

Aquino, R., Oliveira, N. F. de, \& Barreto, M. L. (2009). Impact of the Family Health Program on Infant Mortality in Brazilian Municipalities. American Journal of Public Health, 99(1), 87-93. http://doi.org/10.2105/AJPH.2007.127480

Arretche, M. T. S. (1999). Políticas sociais no Brasil: descentralização em um Estado federativo. RBCS - Revista Brasileira de Ciências Sociais, 14(40), 111-141. http://doi.org/10.1590/S0102-69091999000200009

Arretche, M. T. S. (2001). Federalismo e democracia no Brasil: a visão da ciência política norte-americana. São Paulo Em Perspectiva, 15(4), 23-31. http://doi.org/10.1590/S0102-88392001000400004

Arretche, M. T. S. (2004). Federalismo e políticas sociais no Brasil: problemas de coordenação e autonomia. São Paulo Em Perspectiva, 18(2), 17-26. http://doi.org/10.1590/S0102-88392004000200003

Asandului, L., Roman, M., \& Fatulescu, P. (2014). The efficiency of healthcare systems in Europe: a Data Envelopment Analysis Approach. Procedia Economics and Finance, 10(14), 261-268. http://doi.org/10.1016/S2212-5671(14)00301-3

Atlas do Desenvolvimento Humano no Brasil. (2013). Dados estatísticos de 2010. PNUD, FJP, IPEA. Retrieved from http://www.atlasbrasil.org.br/2013/pt/ranking/

Ázara, L. N. de. (2016). Eficiiencia dos municípios com relação aos gastos públicos na microrregião de Varginha/MG. Universidade Federal de Alfenas.

Baker, G., Gibbons, R., \& Murphy, K. J. (2002). Relational Contracts and the Theory of the Firm. The Quarterly Journal of Economics, 117(1), 39-84.

Benevides, C. do V. (2011). Um estado de bem-estar social no Brasil? Universidade Federal Fluminense - UFF. Universidade Federal Fluminense - UFF. 
Besley, T., \& Coate, S. (2003). Centralized versus decentralized provision of local public goods: a political economy approach. Journal of Public Economics, 87, 2611-2637. http://doi.org/10.1016/S0047-2727(02)00141-X

Bodstein, R. (2002). Atenção básica na agenda da saúde. Ciência \& Saúde Coletiva, 7(3), 401-412. http://doi.org/10.1590/S1413-81232002000300002

Bowlin, W. F. (1998). Measuring Performance: An Introduction to Data Envelopment Analysis (DEA). The Journal of Cost Analysis, 7, 3-27. http://doi.org/10.1080/08823871.1998.10462318

Brasil - Congresso Nacional. (1988). Constituição da República Federativa do Brasil de 05 de Outubro de 1988. Congresso Nacional. Brasília - DF: Senado Federal.

Brasil - Congresso Nacional. (1990a). Lei $\mathrm{n}^{\circ}$. 8.080, de 19 de Setembro de 1990. Ministério Da Saúde. Brasília - DF: Ministério da Saúde. Retrieved from http://www.planalto.gov.br/ccivil_03/Leis/L8080.htm

Brasil - Congresso Nacional. (1990b). Lei $\mathrm{n}^{\circ} .8 .142$ de 28 de dezembro de 1990. Ministério Da Saúde. Brasilia - DF.

Brasil - Conselho Nacional de Secretários de Saúde - CONASS. (2011). Legislação Estruturante do SUS. Brasília - DF: CONASS.

Brasil - Ministério da Saúde. (1996). NOB - SUS 1996 - Norma Operacional Básica do Sistema Único de Saúde - SUS de 06 de novembro de 1996. Ministério Da Saúde. http://doi.org/10.1016/j.neuron.2006.04.006

Brasil - Ministério da Saúde. (2001). Portaria no 95 de 26 de Janeiro de 2001. Norma Operacional da Assistência à Saúde / SUS - NOAS-SUS 01/2001. Ministério Da Saúde, $1-21$.

Brasil - Ministério da Saúde. (2002). Portaria no. 373, de 27 de Fevereiro de 2002. Norma Operacional de Assistência à Saúde / SUS - NOAS-SUS 01/02. Ministério Da Saúde. Brasília - DF: Ministério da Saúde. Retrieved from http://bvsms.saude.gov.br/bvs/saudelegis/gm/2002/prt0373_27_02_2002.html

Brasil - Ministério da Saúde. (2006a). Portaria no 3.085 de $1^{\circ}$. de Dezembro de 2006. Ministério Da Saúde.

Brasil - Ministério da Saúde. (2006b). Portaria no . 399, de 22 de Fevereiro de 2006. Ministério Da Saúde. Brasília - DF: Ministério da Saúde. Retrieved from http://bvsms.saude.gov.br/bvs/saudelegis/gm/2006/prt0399_22_02_2006.html

Brasil - Ministério da Saúde. (2006c). Portaria no. 648, de 28 de Março de 2006. Ministério Da Saúde. Brasília - DF: Ministério da Saúde. Retrieved from http://bvsms.saude.gov.br/bvs/publicacoes/prtGM648_20060328.pdf

Brasil - Ministério da Saúde. (2010). Portaria nº 4.279, de 30 de Dezembro de 2010. Ministério Da Saúde.

Brasil - Ministério da Saúde. (2011). Decreto n ${ }^{\circ}$. 7.508, de 28 de junho de 2011. Ministério Da Saúde, 16. Retrieved from http://www.planalto.gov.br/ccivil_03/_ato20112014/2011/decreto/D7508.htm

Brasil - Ministério da Saúde. (2012a). Lei Complementar nº 141, de 13 de janeiro de 2012. Ministério Da Saúde - Secretaria de Assistência À Saúde. Brasília - DF.

Brasil - Ministério da Saúde. (2012b). Política Nacional de Atenção Básica. Ministério Da Saúde. Brasília - DF: Ministério da Saúde. Retrieved from http://dab.saude.gov.br/portaldab/biblioteca.php?conteudo=publicacoes/pnab

Brasil - Ministério da Saúde. (2012c). Resolução nº. 04, de 19 de Julho de 2012. Comissão Intergestores Tripartite - CIT. Brasília - DF: Diário Oficial da União - Seção 1 20/07/2012. Retrieved from http://www.conselho.saude.pr.gov.br/arquivos/File/Apresentacoes/190_RO/resolucao4_2 00712.pdf 
Brasil - Ministério da Saúde. (2013). Resolução nº. 05, de 19 de junho de 2013. Comissão Intergestores Tripartite - CIT.

Bresser-Pereira, L. C. (2001). Uma nova gestão para um novo Estado: liberal, social e republicano. Revista Do Serviço Público, 52(1), 5-24. Retrieved from http://repositorio.enap.gov.br/handle/1/1827

Buchanan, J. M. (1960). The Theory of Public Finance. Sourthern Economic Association, 26(3), 234-238.

Cabral, K. F. D., \& Ferreira, M. A. M. (2014). Investigação dos níveis de eficiência na alocação dos recursos públicos após o Pacto pela Saúde. RAHIS - Revista de Administração Hospitalar E Inovação Em Saúde, 11(1), 83-98.

Cantarero, D., \& Pascual, M. (2008). Analysing the Impact of Fiscal Decentralization on Health Outcomes: Empirical Evidence from Spain. Applied Economics Letters, 15(2), 109-111. http://doi.org/10.1080/13504850600770913

Casa Nova, S. P. de C. (2002). Utilização da análise por envoltória de dados (DEA) na análise de demonstrações contábeis. Faculdade de Economia, Administração e Contabilidade - Departamento de Contabilidade e Atuária. Universidade de São Paulo FEA/USP.

Cerchiari, A. P. N. (2011). Descentralização e desempenho no setor de saúde: um estudo empírico para os municípios brasileiros. Fundação Getúlio Vargas - FGV. Fundação Getúlio Vargas. Retrieved from http://bibliotecadigital.fgv.br/dspace/handle/10438/8553

Charnes, A., Cooper, W. W., \& Rhodes, E. (1978). Measuring the efficiency of decision making units. European Journal of Operational Research, 2(6), 429-444. http://doi.org/10.1016/0377-2217(78)90138-8

Cook, W. D., \& Seiford, L. M. (2009). Data envelopment analysis (DEA) - Thirty years on. European Journal of Operational Research, 192(1), 17. http://doi.org/10.1016/j.ejor.2008.01.032

Couttolenc, B. F. (2002). A dimensão econômica da saúde. In Icone (Ed.), Saúde, desenvolvimento e globalização: um desafio para os gestores do terceiro milênio. São Paulo.

Eikemo, T. A., \& Bambra, C. (2008). The welfare state: a glossary for public health. Journal of Epidemiology and Community Health, 62(1), 3-6. http://doi.org/10.1136/jech.2007.066787

Eisenhardt, K. M. (1988). Agency - and Institutional -Theory Explanations: The Case of Retail Sales Compensation. The Academy of Management Journal, 31(3), 488-511. Retrieved from http://www.jstor.org/stable/256457 Accessed:

Elazar, D. J. (1987). Exploring Federalism. (The University of Alabama Press, Ed.)The University of Alabama Press. The University of Alabama Press.

Elazar, D. J. (1994). Federalism and the way to peace. (Q. U. Kingston: Institute of Intergovernmental Relations, Ed.)Kingston: Institute of Intergovernmental Relations, Queens University. Kingston: Institute of Intergovernmental Relations, Queens University.

Espírito Santo, A. C. G. do, Fernando, V. C. N., \& Bezerra, A. F. B. (2012). Despesa pública municipal com saúde em Pernambuco, Brasil, de 2000 a 2007. Ciência \& Saúde Coletiva, 17(4), 861-871. http://doi.org/10.1590/S1413-81232012000400009

Falleti, T. G. (2006). Efeitos da decentralização nas relações intergovernamentais: O Brasil em perspectiva comparada. Sociologias, 8(16), 46-85.

Farrel, M. J. (1957). The measurement of productive efficiency. Journal of the Royal Statistical Society - Series A (General), 120(3), 253-290. Retrieved from http://www.jstor.org/stable/2343100

Ferrario, C., \& Zanardi, A. (2011). Fiscal decentralization in the Italian NHS: What happens 
to interregional redistribution? Health Policy, 100(1), 71-80. http://doi.org/10.1016/j.healthpol.2010.08.016

Ferreira, C., Marques, R. C., \& Nicola, P. (2013). On evaluating health centers groups in Lisbon and Tagus Valley: efficiency, equity and quality. BMC Health Services Research, 13(1-17), 529-545. http://doi.org/10.1186/1472-6963-13-529

Ferreira, M. P., \& Pitta, M. T. (2008). Avaliação da eficiência técnica na utilização dos recursos do Sistema Único de Saúde na produção ambulatorial. São Paulo Em Perspectiva, 22(2), 55-71. $\quad$ Retrieved from http://www.seade.gov.br/produtos/spp/v22n02/v22n02_05.pdf

FIRJAN, S. (2016). Índice FIRJAN de Desenvolvimento Municipal - IFDM Geral MG ano base 2013. Sistema FIRJAN. FIRJAN. Retrieved from http://www.firjan.com.br/ifdm/downloads/

Fonseca, P. C., \& Ferreira, M. A. M. (2009). Investigação dos níveis de eficiência na utilização de recursos no Setor de Saúde: uma análise das microrregiões de Minas Gerais. Saúde E Sociedade, 18(2), 199-213. Retrieved from http://www.revistas.usp.br/sausoc/article/view/29592/0

Franzese, C. (2010). Federalismo cooperativo no Brasil: da Constituição de 1988 aos sistemas de politicas públicas. Fundação Getúlio Vargas - FGV. Fundação Getúlio Vargas - FGV. Retrieved from http://bibliotecadigital.fgv.br/dspace/handle/10438/8219

Fritscher, A. M., \& Zamora, R. Z. (2012). An Evaluation of the 1997 Fiscal Decentralization Reform in Mexico: The Case of the Health Sector. (No. April 03, 2012). Banco de México - Research Economics Division. Retrieved from http://www.webmeets.com/files/papers/lacealames/2013/722/Draft_Martinez_Rodriguez_03042012.pdf

Gadelha, S. R. de B. (2011). Analisando o impacto da descentralização fiscal na saúde pública: Evidência empírica para os Municípios Brasileiros (2000-2009). Revista Faz Ciência, 13(18), 121-144. Retrieved from http:/erevista.unioeste.br/index.php/fazciencia/article/viewArticle/7978

Giacomoni, J. (2002). Orçamento público. (Atlas, Ed.) (11a.). São Paulo.

Giambiagi, F., \& Além, A. C. (2011). Finanças públicas: Teoria e prática no Brasil. (Elsevier, Ed.) (4a.). Rio de Janeiro.

Golany, B., \& Roll, Y. (1989). An application procedure for DEA. Omega - The International Journal of Management Science, 17(3), 237-250. http://doi.org/10.1016/03050483(89)90029-7

Guimarães, R. B., \& Ribeiro, E. A. W. (2009). Plano Nacional de Saúde e o Lugar Social em Disputa. Saúde E Sociedade, 18(4), 609-619. Retrieved from www.revistas.usp.br/sausoc/article/download/29487/31347

Habibi, N., Huang, C., Miranda, D., Murillo, V., Ranis, G., Sarkar, M., \& Stewart, F. (2003). Decentralization and Human Development in Argentina. Journal of Human Development, 4(1), 73-101. http://doi.org/10.1080/1464988032000051496

Hadi, A. S. (1992). Identifying Multiple Outliers in Multivariate. Journal of the Royal Statistical Society - Series B (Methodological), 54(3), 761-771.

Hadi, A. S. (1994). A Modification of a Method for the Detection of Outliers in Multivariate Samples. Journal of the Royal Statistical Society. Series B (Methodological), 56(2), 393396. http://doi.org/10.2307/2345910

Hair Jr., J. F., Anderson, R. E., Tatham, R. L., \& Black, W. C. (2005). Análise Multivariada de Dados. (Bookman, Ed.) (5. ed.). Porto Alegre.

Herrero, I., \& Pascoe, S. (2002). Estimation of technical efficiency: a review of some of the stochastic frontier and DEA software. Computers in Higher Education Economics Review, 15(1), 38-43. 
IBGE - Instituto Brasileiro de Geografia e Estatística. (2010). Perfil dos estados. Retrieved January 15, 2015, from www.ibge.gov.br/estadosat/perfil.php

IBGE - Instituto Brasileiro de Geografia e Estatística. (2012). Produto Interno Bruto dos Municipios 2010. Rio de Janeiro.

IBGE - Instituto Brasileiro de Geografia e Estatística. (2016). Produto Interno Bruto dos Municípios 2010-2014. IBGE - Instituto Brasileiro de Geografia e Estatística.

Ismail, M. A. (2010). Technical Efficiency of Sudan's Health Institutions: A State-level Analysis. Sudanese Journal of Public Health, 5(3), 122-129. Retrieved from http://www.sjph.net.sd/files/Vol5N3/Original Article1.pdf

Jannuzzi, P. de M. (2005). Indicadores para diagnóstico, monitoramento e avaliação de Programas Sociais no Brasil. Revista Do Serviço Público, 56(2), 137-160. Retrieved from http://seer.enap.gov.br/index.php/RSP/article/view/222

Javed, Z. H., \& Qaden, S. (2013). Does Fiscal Decentralization Nexus with Life Expectancy? Evidence from Pakistan. British Journal of Economics, Management \& Trade, 3(2), 115-122. http://doi.org/10.9734/BJEMT/2013/2462

Jensen, M. C., \& Meckling, W. H. (1976). Theory of the Firm: Managerial behavior, agency costs and ownership structure. Journal of Financial Economics, 3, 305-360. http://doi.org/http://dx.doi.org/10.1016/0304-405X(76)90026-X

Jensen, M. C., \& Meckling, W. H. (2008). Teoria da firma: comportamento dos administradores, custos de agência e estrutura de propriedade. RAE - Revista de Administração de Empresas, 48(2), 87-125. http://doi.org/10.1016/0304405X(76)90026-X

Jiménez-Rubio, D. (2011a). The impact of decentralization of health services on health outcomes: evidence from Canada. Applied Economics, 43(26), 3907-3917. http://doi.org/10.1080/00036841003742579

Jiménez-Rubio, D. (2011b). The impact of fiscal decentralization on infant mortality rates: Evidence from OECD countries. Social Science \& Medicine, 73(9), 1401-1407. http://doi.org/10.1016/j.socscimed.2011.07.029

Jiménez-Rubio, D., Cantarero-Prieto, D., \& Pascual-Sáez, M. (2011). Is fiscal decentralization good for your health? Evidence from a panel of OECD countries. In X. E. de E. Publica (Ed.), XVIII Encuentro de Economia Publica (pp. 1-28). Málaga. Retrieved from http://dialnet.unirioja.es/servlet/articulo? codigo $=3632176$

Kuschnir, R., \& Chorny, A. H. (2010). Redes de atenção à saúde: contextualizando o debate. Ciência \& Saúde Coletiva, 15(5), 2307-2316.

Laurenti, R., Jorge, M. H. P. D. M., \& Gotlieb, S. L. D. (2004). A mortalidade materna nas capitais brasileiras: algumas características e estimativa de um fator de ajuste. Revista Brasileira de Epidemiologia, 7(4), 449-460. http://doi.org/10.1590/S1415790X2004000400008

Laurenti, R., Jorge, M. H. P. D. M., \& Gotlieb, S. L. D. (2008). Mortes maternas e mortes por causas maternas. Epidemiologia E Serviços de Saúde, 17(4), 283-292. http://doi.org/10.5123/S1679-49742008000400005

Leles, F. A. G., Nicolato, B. de C. S., \& Tavares Júnior, F. A. (2010). As experiências da Secretaria de Estado de Saúde de Minas Gerais com a gestão participativa na elaboração dos instrumentos de gestão do SUS. In CONSAD - III Congresso CONSAD de Gestão Pública (p. 29).

Lélis, J. L. B. (2012). Indicador de resolubilidade como instrumento de avaliação da regionalização da assistência à saúde do SUS/MG. In CONSAD - V Congresso CONSAD de Gestão Pública (pp. 1-20). Brasília - DF.

Lemos, T. B. de O., \& Moares Jr, C. S. (2015). Avaliação da eficiência dos gastos em saúde na Zona da Mata Mineira pelo método da Análise Envoltória de Dados. XVIII SEMEAD, 
Seminários Em Administração, 1-45.

Lobo, M. S. de C., \& Lins, M. P. E. (2011). Avaliação da eficiência dos serviços de saúde por meio da análise envoltória de dados. Caderno de Saúde Coletiva, 19(1), 93-102. Retrieved from http://bases.bireme.br/cgibin/wxislind.exe/iah/online/?IsisScript $=$ iah/iah.xis\&src=google \&base $=$ LILACS\&lang $=$ p \&nextAction $=$ lnk\&exprSearch $=593705 \&$ indexSearch $=$ ID

Machado, R. R., Costa, E., Erdmann, A. L., Albuquerque, G. L. de, \& Ortiga, Â. M. B. (2009). Entendendo o pacto pela saúde na gestão do SUS e refletindo sua implementação. REE - Revista Eletrônica de Enfermagem, 11(1), 181-187.

Macinko, J. A., Guanais, F. C., \& Souza, M. de F. M. de. (2006). Evaluation of the impact of the Family Health Program on infant mortality in Brazil, 1990-2002. Journal of Epidemiology and Community Health, 60(1), 13-19. http://doi.org/10.1136/jech.2005.038323

Mariano, E. B. (2008). Sistematização e comparação de técnicas, modelos e perspectivas não-paramétricas de análise de eficiência produtiva. Universidade de São Paulo - USP.

Mariano, E. B., Almeida, M. R., \& Rebelatto, D. A. N. (2006). Peculiaridades da Análise por Envoltória de Dados. In XII SIMPEP. Bauru - SP.

Marinho, A. (2003). Avaliação da Eficiência Técnica nos Serviços de Saúde nos Municípios do Estado do Rio de Janeiro. RBE - Revista Brasileira de Economia, 57(2), 515-534. http://doi.org/10.1590/S0034-71402003000300002

Marinho, A., Cardoso, S. de S., \& Almeida, V. V. de. (2009). Brasil e OCDE: Avaliação da eficiência em Sistemas de Saúde. (No. 1370). IPEA - Instituto de Pesquisa Econômica Aplicada. Rio de Janeiro - RJ.

Marinho, A., \& Façanha, L. O. (2001). Programas Sociais: Efetividade, eficiência e eficácia como dimensões operacionais da avaliação (No. 787). IPEA - Instituto de Pesquisa Econômica Aplicada. Rio de Janeiro.

Marques, A. M. de F., Gonçalves, M. A., \& Santos, L. M. dos. (2013). Gasto público e políticas públicas: Uma avaliação do desempenho da rede materno-infantil em Minas Gerais. Revista Eletrônica Gestão \& Saúde, 4(4), 1269-1299.

Marques, R. M., \& Mendes, Á. (2002). A política de incentivos do Ministério da Saúde para a atenção básica: uma ameaça à autonomia dos gestores municipais e ao princípio da integralidade? Cadernos de Saúde Pública, 18, S163-S171. http://doi.org/10.1590/S0102-311X2002000700016

Martinelli, N. L., Viana, A. L. D., \& Scatena, J. H. G. (2015). O pacto pela Saúde e o processo de regionalização no estado de Mato Grosso. Saúde Em Debate, 39(Especial), 76-90. http://doi.org/10.5935/0103-1104.2015S005239

Martino Júnior, R. (2011). Gestão administrativa e eficiência dos gastos públicos com saúde: estudo de caso dos municípios da macrorregião Leste Sul - MG. Universidade Federal de Viçosa.

Martins, G. de A., \& Theóphilo, C. R. (2009). Metodologia da investigação para Ciências Sociais Aplicadas. (Atlas, Ed.) (2 $2^{\mathrm{a}}$.). São Paulo - SP.

Mello, J. C. C. B. S. de, Meza, L. A., Gomes, E. G., \& Biondi Neto, L. (2005). Curso de Análise de Envoltória de Dados. In SPBO (Ed.), SBPO - XXXVII Simposio Brasileiro de Pesquisa Operacional (pp. 2520-2547). Gramado - RS: SBPO. Retrieved from http://www.researchgate.net/profile/Joao_Mello/publication/237473886_CURSO_DE_A NLISE_DE_ENVOLTRIA_DE_DADOS-/links/0deec5226afdc4f679000000.pdf

Mendes, Á., Louvison, M. C. P., Ianni, A. M. Z., Leite, M. G., Feuerwerker, L. C. M., Tanaka, O. Y., ... Almeida, C. A. L. (2015). O processo de construção da gestão regional da saúde no estado de São Paulo: subsídios para a análise. Saúde E Sociedade, 24(2), 423-437. http://doi.org/10.1590/S0104-12902015000200003 
Mendes, E. V. (2010). As redes de atenção à saúde. Ciência \& Saúde Coletiva, 15(5), $2297-$ 2305. http://doi.org/10.1590/S1413-81232010000500005

Mendes, M., \& C. Biderman \& P. Arvate. (2004). Federalismo fiscal. In Campus / Elsevier (Ed.), Economia do Setor Público no Brasil (pp. 421-461). Rio de Janeiro.

Musgrave, R. A. (1939). The Voluntary Exchange Theory of Public Economic. The Quarterly Journal of Economics, 53(2), 213-237. http://doi.org/10.1080/17470210500151444

Musgrave, R. A. (1959). The Theory of Public Finance. (McGraw-Hill, Ed.). New York.

Musgrave, R. A., \& Musgrave, P. B. (1980). Finanças públicas - Teoria e prática. (Campus, Ed.). São Paulo.

Noronha, K. V. M. de S., \& Andrade, M. V. (2006). Aspectos teóricos e metodológicos da relação entre o estado de saúde e a desigualdade de renda (No. Texto para discussao n. 291). UFMG / Cedeplar. Belo Horizonte.

Oates, W. E. (1972). Fiscal Federalism. (Harcourt Brace Jovanovich, Ed.). New York.

Oates, W. E. (2005). Toward A Second-Generation Theory of Fiscal Federalism. International Tax and Public Finance, 12(4), 349-373. http://doi.org/10.1007/s10797005-1619-9

Oliveira, A. C. de. (2007). Ensaios sobre atenção pública à saúde em Minas Gerais. UFMG / Cedeplar. Universidade Federal de Minas Gerais - UFMG.

Pastor, J. T. (1996). Translation invariance in data envelopment analysis: A generalization. In Operations Research (Vol. 66, pp. 91-102). http://doi.org/10.1007/BF02187295

Peacock, S., Johansen, D., Chris, C., \& Melvino, M. (2001). Techniques for Measuring Efficiency in Health Services. (No. July). Productivity Commision Staff Working Paper.

Pense SUS - Fiocruz. (2016). SUS: o que é? Retrieved October 20, 2016, from http://pensesus.fiocruz.br/sus

Pinheiro Filho, F. P., \& Sarti, F. M. (2012). Falhas de mercado e redes em políticas públicas: desafios e possibilidades ao Sistema Único de Saúde. Ciência \& Saúde Coletiva, 17(11), 2981-2990.

Portal da Saúde - SUS. (2016). Entenda o SUS. Retrieved October 20, 2016, from http://portalsaude.saude.gov.br/index.php/cidadao/entenda-o-sus

Puccini, P. de T., Cornetta, V. K., Sahyom, T. Z., Fuentes, I. C. P., Botta, L. M. G., \& Puccini, R. F. (2012). Concepção de profissionais de saúde sobre o papel das unidades básicas nas redes de atenção do SUS/Brasil. Ciência \& Saúde Coletiva, 17(11), 29412952. http://doi.org/10.1590/S1413-81232012001100011

Purohit, B. C. (2008). Efficiency of the health care system: A sub-state level analysis for West Bengal (India). Review of Urban and Regional Development Studies, 20(3), 212-225. http://doi.org/10.1111/j.1467-940X.2008.00149.x

Qi, Y. (2007). Fiscal Decentralization and Health Outcomes. School of Economics and Management, 14. Retrieved from https://scholar.google.com.br/scholar?hl=ptBR\&q $=\% 22$ Fiscal+Decentralization + and + Health + Outcomes $\% 22 \& b t n G=\& 1 r=$

Queiroz, M. de F. M. de, Silva, J. L. M. da, Figueiredo, J. de S., \& Vale, F. F. R. do. (2013). Eficiência no Gasto Público com Saúde: Uma análise nos Municípios do Rio Grande do Norte. RENE - Revista Econômica Do Nordeste, 44(3), 761-776. Retrieved from http://www.bnb.gov.br/projwebren/Exec/artigoRenPDF.aspx?cd_artigo_ren=1392

REDE Interagencial de Informação para a Saúde. (2008). Indicadores básicos para a saúde no Brasil: conceitos e aplicações. Organização Pan-Americana Da Saúde. Brasília - DF. Retrieved from http://bases.bireme.br/cgibin/wxislind.exe/iah/online/?IsisScript=iah/iah.xis\&src=google\&base=REPIDISCA\&lan $\mathrm{g}=\mathrm{p} \&$ nextAction $=$ lnk\&exprSearch $=7469$ \&indexSearch $=$ ID

Retzlaff-Roberts, D., Chang, C. F., \& Rubin, R. M. (2004). Technical efficiency in the use of health care resources: A comparison of OECD countries. Health Policy, 69(1), 55-72. 
http://doi.org/10.1016/j.healthpol.2003.12.002

Rocha, R., \& Soares, R. R. (2010). Evaluating the impact of community-based health interventions: Evidence from Brazil's Family Health Program. Health Economics, 19(SUPPL. 1), 126-158. http://doi.org/10.1002/hec.1607

Roncalli, A. G. (2003). O desenvolvimento das políticas públicas de saúde no Brasil e a construção do Sistema Único de Saúde. Odontologia Em Saúde Coletiva, (Cap.2), 2849. http://doi.org/10.5205/reuol.8127-71183-1-SM.0912201536

Rosa, M. B. (2011). Contabilidade do setor público. (Atlas, Ed.). São Paulo - SP.

Samadi, A. H., Keshtkaran, A., Kavosi, Z., \& Vahedi, S. (2013). The Effect of Fiscal Decentralization on Under-five Mortality in Iran: A Panel Data Analysis. International Journal of Health Policy and Management, 1(4), 301-306. http://doi.org/10.15171/ijhpm.2013.60

Samuelson, P. A. (1954). The Pure Theory of Public Expenditure. The Review of Economics and Statistics, 36(4), 387-389. Retrieved from http://www.jstor.org/discover/10.2307/1925895?uid=3737664\&uid=2\&uid=4\&sid=2110 6863827173

Sanchez, O. A. (2005). Os controles internos da administração pública: a e-governança e a construção de controles no Governo do Estado de São Paulo. Universidade de São Paulo - USP.

Santos, L., \& Campos, G. W. de S. (2015). SUS Brasil: a região de saúde como caminho. Saúde E Sociedade, 24(2), 438-446. http://doi.org/10.1590/S0104-12902015000200004

Santos, É. G. F. de A. dos. (2008). Uma avaliação comparativa da eficiência dos gastos públicos com saúde nos municípios brasileiros. Universidade de São Paulo - USP. Universidade de São Paulo - USP. Retrieved from http://www.teses.usp.br/teses/disponiveis/12/12138/tde-13012009-152753/en.php

Saravia, E. (2006). Introdução à teoria da política pública. In ENAP - Fundação Escola Nacional de Administração Pública (Ed.), Políticas Públicas - Coletânea. (Vol. 1, pp. 21-42). Brasília - DF.

Scatena, J. H. G., \& Tanaka, O. Y. (2001). Os instrumentos normalizadores (NOB) no processo de descentralização da saúde. Saúde E Sociedade, 10(2), 47-74. http://doi.org/10.1590/S0104-12902001000200005

Schneider, A., Miranda, A. M., Kujawa, H., Andrade, J., Both, V., \& Brutscher, V. (2007). Pacto pela saúde - possibilidades ou realidade? CEAP - Centro de Educação e Assessoramento Popular. Passo Fundo - RS. Retrieved from http://medcontent.metapress.com/index/A65RM03P4874243N.pdf

SES-MG, Secretaria de Estado de Saúde, M. G. (2014). Adscrição e população dos municípios por macrorregiões e microrregiões de saúde. Belo Horizonte: SES-MG.

Silva, L. M. (2009). Contabilidade governamental. (Atlas, Ed.) (7a.). São Paulo.

Sinimole, K. R. (2012). Evaluation of the efficiency of national health systems of the members of World Health Organization. Leadership in Health Services, 25(2), 139-150. http://doi.org/10.1108/17511871211221055

Soto, V. E., \& Lorant, V. (2012). Infant Mortality Inequities in Colombia: Progress and Challenges After Major Repsonsibility Measures from Local Authorities. Well-Being and Social Policy, 8(1), 23-51. Retrieved from http://wellbeing.ciss.org.mx/pdf/en/2012/vol_8_num_1_2_12_en.pdf

Souza, C. (2006). Políticas Públicas: uma revisão da literatura. Sociologias, 8(16), 20-45. http://doi.org/10.1590/S1517-45222006000200003

Souza, C. (2008). Federalismo: Teorias e Conceitos Revisitados. Revista Brasileira de Informação Bibliográfica Em Ciências Sociais - BIB, 65, 27-48. Retrieved from http://anpocs.org/portal/index.php?option=com_docman\&task $=$ cat_view\&gid=143\&Ite 
$\operatorname{mid}=301$

Tanaka, O. Y., \& Tamaki, E. M. (2012). O papel da avaliação para a tomada de decisão na gestão de serviços de saúde. Ciência \& Saúde Coletiva, 17(4), 821-828. Retrieved from http://www.scielo.br/pdf/csc/v17n4/v17n4a02

Teixeira, H. V., \& Gonçalves, V. B. (2003). Gasto público com a saúde no Brasil: possibilidades e desafios. In A. B. de E. da S. ABrES (Ed.), I Jornada da Economia da Saúde (p. 19). São Leopoldo - RS.

Tiebout, C. M. (1956). A Pure Theory of Local Expenditures. Journal of Political Economy, 64(5), 416-424. Retrieved from http://www.jstor.org/discover/10.2307/1826343?uid=2\&uid=4\&sid=21106137676141

Uchimura, H., \& Jütting, J. P. (2009). Fiscal Decentralization, Chinese Style: Good for Health Outcomes? World Development, 37(12), 1926-1934. http://doi.org/10.1016/j.worlddev.2009.06.007

Varela, P. S. (2008). Financiamento e controladoria dos municípios paulitas no setor saúde: uma avaliação de eficiência. Universidade de São Paulo - USP. Universidade de São Paulo - USP. Retrieved from http://www.teses.usp.br/teses/disponiveis/12/12136/tde19012009-113206/pt-br.php

Varela, P. S., \& Pacheco, R. S. V. M. (2012). Federalismo e Gastos em Saúde: competição e cooperação nos municípios da Região Metropolitana de São Paulo. Revista Contabilidade \& Finanças, 23(59), 116-127. http://doi.org/10.1590/S151970772012000200004

Viana, A. L. D., Bousquat, A., Pereira, A. P. C. de M., Uchimura, L. Y. T., Albuquerque, M. V. de, Mota, P. H. dos S., ... Ferreira, M. P. (2015). Tipologia das regiões de saúde: condicionantes estruturais para a regionalização no Brasil. Saúde E Sociedade, 24(2), 413-422. http://doi.org/10.1590/S0104-12902015000200002

Weber, M. (2009). Economia e sociedade: fundamentos da sociologia compreensiva. (UnB, Ed.)Universidade de Brasília - UnB (4a.). Brasília - DF.

Weber, S. (2010). bacon: An effective way to detect outliers in multivariate data using Stata (and Mata). The Stata Journal, 10(3), 331-338. http://doi.org/The Stata Journal

Weiller, J. A. B. (2014). Desempenho dos gastos municipais com saúde no município de São Bernardo do Campo: um estudo sobre o instrumento "Orçamento por Desempenho." Universidade de São Paulo - USP. Faculdade de Saúde Pública, Universidade de São Paulo. Retrieved from http://www.teses.usp.br/teses/disponiveis/6/6135/tde-05112014131724/en.php

Williamson, O. E. (2002). The Theory of the Firm as Governance Structure: From Choice to Contract. Journal of Economic Perspectives, 16(3), 171-195. http://doi.org/10.1257/089533002760278776

World Health Organization. (2015). World Health statistics 2015. Geneva, Switzerland. Retrieved from http://apps.who.int/iris/bitstream/10665/170250/1/9789240694439_eng.pdf?ua=1\&ua=1

Zucchi, P., Del Nero, C., \& Malik, A. M. (2000). Gastos em saúde: os fatores que agem na demanda e na oferta dos serviços de saúde. Saúde E Sociedade, 9(1-2), 127-150. http://doi.org/10.1590/S0104-12902000000100010 